\author{
UNIVERSIDADE DE SÃO PAULO \\ ESCOLA DE ENGENHARIA DE SÃO CARLOS \\ DEPARTAMENTO DE ENGENHARIA HIDRÁULICA E SANEAMENTO
}

DARIO NARANJO FERNANDEZ

ANÁLISE BIOTERMODINÂMICA DOS PROCESSOS ANAERÓBIOS E FOTOSSINTÉTICOS DE RECUPERAÇÃO DE ENERGIA

VERSÃO CORRIGIDA

São Carlos - SP 



\title{
ANÁLISE BIOTERMODINÂMICA DOS PROCESSOS ANAERÓBIOS E FOTOSSINTÉTICOS DE RECUPERAÇÃO DE ENERGIA
}

\begin{abstract}
Tese apresentada à Escola de Engenharia de São Carlos, da Universidade de São Paulo, como parte dos requisitos para obtenção do título de Doutor em Ciências: Engenharia Hidráulica e Saneamento.
\end{abstract}

Orientador Prof. Tit. Eduardo Cleto Pires

\section{VERSÃO CORRIGIDA}

São Carlos - SP 
AUTORIZO A REPRODUÇÃO TOTAL OU PARCIAL DESTE TRABALHO, POR QUALQUER MEIO CONVENCIONAL OU ELETRÔNICO, PARA FINS DE ESTUDO E PESQUISA, DESDE QUE CITADA A FONTE.

Ficha catalográfica elaborada pela Biblioteca Prof. Dr. Sérgio Rodrigues Fontes da EESC/USP com os dados inseridos pelo(a) autor(a).

Naranjo Fernandez, Dario

N218a Análise biotermodinâmica dos processos anaeróbios e fotossintéticos de recuperação de energia / Dario Naranjo Fernandez; orientador Eduardo Cleto Pires. São Carlos, 2018.

Tese (Doutorado) - Programa de Pós-Graduação em Engenharia Hidráulica e Saneamento e Área de Concentração em Hidráulica e Saneamento -- Escola de Engenharia de São Carlos da Universidade de São Paulo, 2018 .

1. Modelo biotermodinâmico. 2. Recuperação de energia. 3. Digestão anaeróbia. 4. Fotossíntese oxigênica. 5. Fotossíntese anoxigênica. 6. Eficiência energética. I. Título.

Eduardo Graziosi Silva - CRB - 8/8907 


\section{FOLHA DE JULGAMENTO}

Candidato: Engenheiro DARIO NARANJO FERNANDEZ.

Título da tese: "Análise biotermodinâmica dos processos anaeróbios e fotossintéticos de recuperação de energia".

Data da defesa: 12/03/2018.

Comissão Julgadora:

Resultado:

Prof. Titular Eduardo Cleto Pires

(Orientador)

(Escola de Engenharia de São Carlos/EESC)

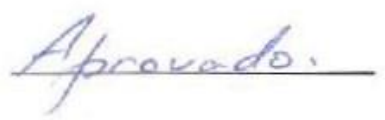

Prof. Titular Marcelo Zaiat

(Escola de Engenharia de São Carlos/EESC)

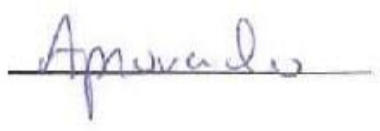

Prof. Associado Eduardo Bessa Azevedo

APRO VADO

(Instituto de Química de São Carlos/IQSC-USP)

Prof. Dr. José Mansur Assaf

(Universidade Federal de São Carlos/UFSCar)

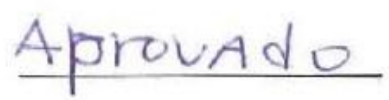

Prof. Dr. Wu Hong Kwong

(Universidade Federal de São Carlos/UFSCar)

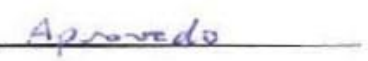

Coordenador do Programa de Pós-Graduação em Engenharia Hidráulica e Saneamento:

Prof. Dr. Eduardo Mario Mendiondo

Presidente da Comissão de Pós-Graduação:

Prof. Associado Luis Fernando Costa Alberto 

A meus pais, irmãos, enteada, sobrinhos e amigos, meu poder redutor. A minha amorosa esposa e nosso filho, minha energia. 



\section{AGRADECIMENTOS}

Ao Prof. Tit. Eduardo Cleto Pires, pela confiança nesta pesquisa e seus resultados e o apoio durante o processo de doutorado; nossa interação contribuiu para meu crescimento pessoal e científico.

À Escola de Engenharia, o Instituo de Química e o Instituto de Física, Campus de São Carlos, da Universidade de São Paulo, e, em geral, aos meus professores, pela sólida formação científica na minha formação como Doutor em Ciências.

Finalmente, à Coordenação de Aperfeiçoamento de Pessoal de Nível Superior (CAPES) do Brasil, pelo fornecimento da bolsa de doutorado CAPEX-PROEX, e à Fundação para o Futuro da Colômbia (Colfuturo) pela concessão da bolsa para o último ano de doutorado. 

"Me gusta andar,

pero no sigo el camino pues lo seguro ya no tiene misterio."

Facundo Cabral

"Es demasiado aburrido seguir y seguir la huella, demasiado largo el camino sin nada que me entretenga." Atahualpa Yupanqui 



\section{RESUMO}

\section{NARANJO FERNANDEZ, D. Análise biotermodinâmica dos processos anaeróbios e}

fotossintéticos de recuperação de energia. 195 p. Tese (Doutorado) - Escola de Engenharia de São Carlos, Universidade de São Paulo, São Carlos, 2018.

A digestão anaeróbia e as fotossínteses oxigênica e anoxigênica são processos usados para a recuperação e produção de energia. Nestes processos, a aplicação de modelos biotermodinâmicos permitiria analisar o comportamento e estimar rendimentos celulares e eficiências energéticas. Porém, realizar cálculos termodinâmicos de maior exatidão para reduzir os erros porcentuais nos processos anaeróbios, e incorporar a energia dos fótons nos balanços dos processos fotossintéticos, dificulta a aplicação dos modelos biotermodinâmicos nestes processos. A partir deste problema, esta pesquisa visa desenvolver um modelo biotermodinâmico dos processos anaeróbios e fotossintéticos de recuperação de energia com produção de metano e hidrogênio. $\mathrm{O}$ modelo está baseado em modelos biotermodinâmicos que usam semi-reações e se incorporam as influências de variáveis físico-químicas (i.e. temperatura e $\mathrm{pH}$ ) em condições diferentes da padrão, assim como aos fótons e sua energia nas semi-reações fotossintéticas. Os resultados permitem estabelecer, por exemplo, que a digestão anaeróbia separada (fermentação e metanogênese) atinge uma eficiência entre 10 e $12 \%$ maior na recuperação de energia que a digestão anaeróbia completa, e que a produção de hidrogênio é mais eficiente com cianobactérias e bactérias anoxigênicas por meio da nitrogenase, que com microalgas por meio da hidrogenase. Assim, a aplicação do modelo biotermodinâmico permitiu avaliar as condições de espontaneidade das reações biológicas e estimar rendimentos e eficiências para a análise dos processos anaeróbios e fotossintéticos de recuperação de energia.

Palavras-chave: Modelo biotermodinâmico, recuperação de energia, digestão anaeróbia, fotossíntese oxigênica, fotossíntese anoxigênica, eficiência energética. 



\begin{abstract}
NARANJO FERNANDEZ, D. Biothermodynamic analysis of the anaerobic and photosynthetic processes of energy recovery. 195 p. Tese (Doutorado) - Escola de Engenharia de São Carlos, Universidade de São Paulo, São Carlos, 2018.

The anaerobic digestion and the oxigenic and anoxigenic photosynthesis are processes for energy production and recovery. For these processes, the application of biothermodynamic models would allow to analyse their dynamic and estimate the cell yields and the energetic efficiencies. However, the application of these models is hindered by the complexity in including both precise thermodynamic calculations in anaerobic processes and the photon energy in balances for photosynthetic processes. Inside this framework, a biothermodynamic model of anaerobic and photosynthetic processes of energy recovery with methane and hydrogen production is developed in this work. The model is based on biothermodynamic models that use half-reactions and incorporate the effect of physicochemical parameters (i.e. temperature and $\mathrm{pH}$ ) different to the standard conditions, together with the photons and their energy on photosynthetic half-reactions. Results indicate that separated anaerobic digestion (fermentation and methanogenesis) reaches efficiencies between 10 to $12 \%$ higher in energy recovery than the complete anaerobic digestion, and the hydrogen production is more efficient on cyanobacteria and anoxigenic bacteria, through nitrogenase, than on microalgae, through hydrogenase. Thus, the use of biothermodynamic model allowed to evaluate the spontaneity conditions of biological reactions and to estimate yields and efficiency for analyse of anaerobic and photosynthetic processes for energy recovery.
\end{abstract}

Keywords: Biothermodynamic model, energy recovery, anaerobic digestion, oxygenic photosynthesis, anoxigenic photosynthesis, energy efficiency. 



\section{LISTA DE ABREVIATURAS E SIGLAS}

ADP: Adenosina difosfato.

AGV: Ácidos graxos voláteis.

ATP: Adenosina trifosfato.

cit: Citocromo.

DHID: Desidrogenase.

Fdox: Ferredoxina oxidada.

$\mathrm{Fd}_{\mathrm{RED}}$ : Ferredoxina reduzida.

FNR: Ferredoxina NAD $(\mathrm{P})^{+}$redutase.

HID: Hidrogenase.

HIDB: Hidrogenase bidirecional.

HIDUP: Hidrogenase de assimilação.

$\mathrm{NAD}^{+}$: Nicotinamida adenina dinucleótido, forma oxidada.

NADH: Nicotinamida adenina dinucleótido, forma reduzida.

$\mathrm{NADP}^{+}$: Nicotinamida adenina dinucleótido fosfato, forma oxidada.

NADPH: Nicotinamida adenina dinucleótido fosfato, forma reduzida.

$\mathrm{NAD}(\mathrm{P})^{+}$: Nicotinamida adenina dinucleótido (fosfato), forma oxidada.

NAD(P)H: Nicotinamida adenina dinucleótido (fosfato), forma reduzida.

NIT: Nitrogenase.

NPQR: NAD(P)H-plastoquinona oxidorredutase.

OPF: Oxidative pentose phosphate pathway (ciclo oxidativo das pentoses-fosfato).

PAR: Photosynthetically active radiation (radiação fotosinteticamente ativa).

PDH: Piruvato desidrogenase.

PFR: Piruvato ferredoxina oxidorredutase.

Pi: Íon fosfato.

PQ: Plastoquinona.

PSI: Fotossistema I.

PSII: Fotossistema II.

P680: Clorofila do fotossistema II, com máxima absorção em $680 \mathrm{~nm}$.

P680*: Forma excitada da clorofila P680.

P700: Clorofila do fotossistema I, com máxima absorção em $700 \mathrm{~nm}$.

P700*: Forma excitada da clorofila P700. 
P840: Bacterioclorofila, com máxima absorção em 840 nm.

P840*: Forma excitada da bacterioclorofila P840.

P870: Bacterioclorofila, com máxima absorção em $870 \mathrm{~nm}$.

P870*: Forma excitada da bacterioclorofila P870.

Q: Quinona.

RPF: Reductive pentose phosphate cycle (ciclo redutivo das pentoses-fosfato ou ciclo de Calvin).

TCA: Tricarboxylic acid cycle (ciclo dos ácidos tricarboxílicos ou ciclo de Krebs). 


\section{LISTA DE SÍMBOLOS}

\section{Componentes químicos}

$\mathrm{CHO}_{2}^{-}$: Íon formiato.

$\mathrm{CH}_{2} \mathrm{O}$ : Glicose (fórmula química condensada).

$\mathrm{CH}_{4}$ : Metano.

$\mathrm{C}_{2} \mathrm{H}_{3} \mathrm{O}_{2}^{-}$: Íon acetato.

$\mathrm{C}_{2} \mathrm{H}_{4} \mathrm{O}_{2}$ : Ácido acético.

$\mathrm{C}_{2} \mathrm{H}_{6} \mathrm{O}$ : Etanol.

$\mathrm{C}_{3} \mathrm{H}_{5} \mathrm{O}_{2}^{-}$: Íon propionato.

$\mathrm{C}_{3} \mathrm{H}_{5} \mathrm{O}_{3}{ }^{-}$: Íon lactato.

$\mathrm{C}_{3} \mathrm{H}_{6} \mathrm{O}_{2}$ : Ácido propiônico.

$\mathrm{C}_{3} \mathrm{H}_{6} \mathrm{O}_{3}$ : Ácido láctico.

$\mathrm{C}_{4} \mathrm{H}_{7} \mathrm{O}_{2}^{-}$: Íon butirato.

$\mathrm{C}_{4} \mathrm{H}_{8} \mathrm{O}_{2}$ : Ácido butírico.

$\mathrm{C}_{5} \mathrm{H}_{7} \mathrm{O}_{2} \mathrm{~N}$ : Fórmula empírica para bactérias (Hoover e Porges, 1952).

$\mathrm{C}_{5} \mathrm{H}_{7} \mathrm{O}_{2} \mathrm{NP}_{0,06} \mathrm{~S}_{0,1}$ : Fórmula empírica para bactérias (Speece, 1996).

$\mathrm{C}_{6} \mathrm{H}_{12} \mathrm{O}_{6}$ : Glicose.

$\mathrm{C}_{16} \mathrm{H}_{32} \mathrm{O}_{2}$ : Ácido palmítico.

$\mathrm{C}_{106} \mathrm{H}_{263} \mathrm{O}_{110} \mathrm{~N}_{16} \mathrm{P}$ : Fórmula empírica para microalgas (Redfield, Ketchum e Richards, 1963).

$\mathrm{C}_{106} \mathrm{H}_{263} \mathrm{O}_{110} \mathrm{~N}_{16} \mathrm{PS}$ : Fórmula empírica para microalgas.

$\mathrm{C}_{23} \mathrm{H}_{38} \mathrm{O}_{17} \mathrm{~N}_{7} \mathrm{P}_{3} \mathrm{~S}$ : Acetilcoenzima A (acetil-CoA).

CO: Monóxido de carbono.

$\mathrm{CO}_{2}$ : Dióxido de carbono.

$\mathrm{CO}_{3}{ }^{2-}$ : Íon carbonato.

$\mathrm{e}^{-}$: Elétrons.

$\mathrm{H}^{+}$: Íon hidrogênio.

$\mathrm{HCO}_{3}^{-}$: Íon bicarbonato.

$\mathrm{HPO}_{4}{ }^{2-}$ : Íon hidrogeno fosfato.

$\mathrm{HS}^{-}$: Íon bissulfeto.

$\mathrm{H}_{2}$ : Hidrogênio molecular.

$\mathrm{H}_{2} \mathrm{O}$ : Água.

$\mathrm{H}_{2} \mathrm{~S}$ : Sulfeto de hidrogênio (gasoso) ou ácido sulfídrico (aquoso). 
$\mathrm{H}_{2} \mathrm{PO}_{4}^{-}$: Íon diidrogenofosfato.

$\mathrm{H}_{3} \mathrm{PO}_{4}$ : Ácido fosfórico.

$\mathrm{NH}_{3}$ : Amoníaco.

$\mathrm{NH}_{4}^{+}$: Íon amônio.

$\mathrm{N}_{2}$ : Nitrogênio molecular.

$\mathrm{O}_{2}$ : Oxigênio molecular.

$\mathrm{PO}_{4}{ }^{3-}$ : Íon fosfato.

$\mathrm{S}^{0}$ : Enxofre elementar.

$\mathrm{S}^{2-}$ : Íon sulfeto.

$\mathrm{SO}_{2}$ : Dióxido de enxofre.

$\mathrm{S}_{2} \mathrm{O}_{3}{ }^{2-}$ : Íon tiossulfato.

\section{Constantes}

$c$ : Velocidade da luz (299792458 $\left.\mathrm{m} \mathrm{s}^{-1}\right)$.

$h$ : Constante de Planck $\left(6,6261 \times 10^{-37} \mathrm{~kJ} \mathrm{~s}\right)$.

$N_{A}$ : Número de Avogadro $\left(6,022 \times 10^{23} \mathrm{~mol}^{-1}\right)$.

$R$ : Constante universal dos gases ideais $\left(8,314 \times 10^{-3} \mathrm{~kJ} \mathrm{~mol}^{-1} \mathrm{~K}^{-1}\right)$.

$T_{S}$ : Temperatura do Sol (5778 K).

\section{Parâmetros físico-químicos}

$\gamma^{\circ}$ : Grau de redução das moléculas orgânicas.

$\Delta H^{\circ}$ : Entalpia padrão por mol de carbono.

$\Delta_{C} H^{\circ}$ : Entalpia padrão de combustão por mol de carbono.

$\Delta_{C} H_{i}^{\circ}$ : Entalpia padrão de combustão por mol do componente $i$.

$\Delta_{f} H^{\circ}$ : Entalpia padrão de formação por mol.

$\Delta_{r} H^{\circ}$ : Entalpia padrão de reação por equivalente de elétrons.

$\Delta G^{\circ}$ : Energia livre padrão por mol de carbono.

$\Delta_{C} G^{\circ}$ : Energia livre padrão de combustão por mol de carbono.

$\Delta_{c} G^{\circ}$ : Energia livre de reação para converter o intermediário e os nutrientes em células, por equivalente de elétrons.

$\Delta_{f} G^{\circ}$ : Energia livre padrão de formação por mol.

$\Delta_{f} G_{C}{ }^{\circ}$ : Energia livre padrão de formação de células por equivalente de elétrons.

$\Delta_{f} G_{P}{ }^{\circ}$ : Energia livre padrão de formação de produtos por equivalente de elétrons.

$\Delta_{f} G_{R}{ }^{\circ}$ : Energia livre padrão de formação de reagentes por equivalente de elétrons. 
$\Delta_{f} G_{S}{ }^{\circ}$ : Energia livre padrão de formação de substratos por equivalente de elétrons.

$\Delta_{r} G^{\circ}$ : Energia livre padrão de reação por equivalente de elétrons.

$\Delta_{a} G^{\circ}$ : Energia livre de semi-reação para aceptor de elétrons, por equivalente de elétrons, com concentrações diferentes da padrão.

$\Delta_{d} G^{\circ}$ : Energia livre de semi-reação para doador de elétrons, por equivalente de elétrons, com concentrações diferentes da padrão.

$\Delta_{i} G^{\circ}$ : Energia livre de reação para formar o intermediário a partir do doador de elétrons, por equivalente de elétrons, com concentrações diferentes da padrão.

$\Delta_{r} G^{\circ}$ : Energia livre de reação, por equivalente de elétrons, com concentrações diferentes da padrão.

$\Delta_{s} G^{\circ}$ : Energia livre de reação de síntese celular, por equivalente de elétrons, com concentrações diferentes da padrão.

$\Delta S^{\circ}$ : Entropia padrão por mol de carbono.

$\varepsilon$ : Eficiência de transferência de energia nos processos metabólicos.

$\eta$ : Eficiência de recuperação de energia na digestão anaeróbia ou eficiência da fotossíntese oxigênica ou anoxigênica.

$\lambda$ : Comprimento de onda.

v: Frequência de onda.

A: Mols de elétrons destinados a produtos respeito aos mols de elétrons destinados a síntese celular $\left(f_{e} / f_{s}\right)$.

$C_{\mathrm{T}}$ Concentração total das espécies em solução.

$e_{a i}$ : Fração do produto reduzido $i$ no total de produtos reduzidos.

$E_{f}$ : Energia por mol de fótons na radiação solar.

$e q_{a i}$ : Equivalentes de elétrons do produto reduzido $i$.

$f_{e}$ : Fração dos elétrons do doador destinados a produtos.

$f_{e}^{\circ}$ : Fração mínima dos elétrons do doador destinados a produtos.

$f_{i}$ : Fração de elétrons transferidos desde o substrato ao produto reduzido $i$.

$f_{s}$ : Fração dos elétrons do doador destinados para síntese celular.

$f_{s}^{\circ}$ Fração máxima dos elétrons do doador destinados para síntese celular.

$G^{\circ}$ : Energia livre padrão por mol de fótons.

$G_{p}{ }^{\circ}$ : Energia livre perdida no processo.

$H^{\circ}$ : Entalpia padrão por mol de fótons.

$K$ : Constante de equilíbrio.

$K_{A}$ : Constante ácida. 
$K_{A 1}$ : Constante ácida da primeira ionização.

$K_{A 2}$ : Constante ácida da segunda ionização.

$K_{A 3}$ : Constante ácida da terceira ionização.

$K_{H}$ : Constante de Henry.

$n$ : Potencia do modelo biotermodinâmico.

$n_{i}$ : Número de mols do componente $i$.

$P$ : Pressão total do sistema.

$p_{i}$ : Pressão parcial do componente $i$.

$\mathrm{pH}$ : Potencial de íons hidrogênio.

$S^{\circ}$ : Entropia padrão por mol de fótons.

$T$ : Temperatura absoluta do sistema.

$T_{1}$ : Temperatura padrão absoluta inicial $(298,15 \mathrm{~K})$.

$T_{2}$ : Temperatura absoluta final.

$v_{i}$ : Sinal (positivo para produtos e negativo para reagentes).

$x_{i}:$ : Fração molar do componente $i$.

$z_{i}$ : Coeficiente estequiométrico de reagentes ou produtos.

[i]: Concentração molar do componente $i$.

\section{Reações}

A: Composto químico em equilíbrio gasoso-aquoso.

$\mathrm{A}^{-}$: Espécie ionizada.

HA: Espécie ácida.

c: Mols de carbono nas moléculas orgânicas.

h: Mols de hidrogênio nas moléculas orgânicas.

n: Mols de nitrogênio nas moléculas orgânicas.

o: Mols de oxigênio nas moléculas orgânicas.

p: Mols de fosforo nas moléculas orgânicas.

s: Mols de enxofre nas moléculas orgânicas.

$R$ : Reação redox global.

$R_{a}$ : Semi-reação do aceptor de elétrons.

$R_{a i}$ : Semi-reação do aceptor de elétrons $i$.

$R_{c}$ : Semi-reação para síntese de células de microorganismos.

$R_{d}$ : Semi-reação do doador de elétrons. 


\section{Subíndices}

(g): Componente em estado gasoso.

(1): Componente em estado líquido.

(aq): Componente em estado aquoso. 



\section{SUMÁRIO}

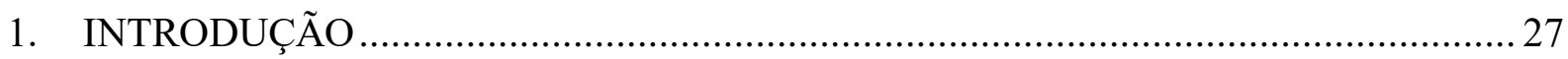

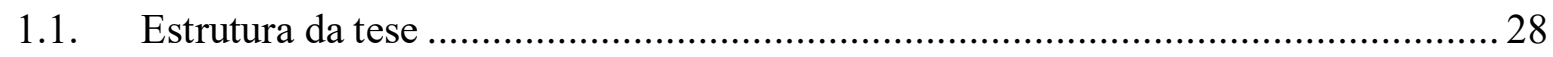

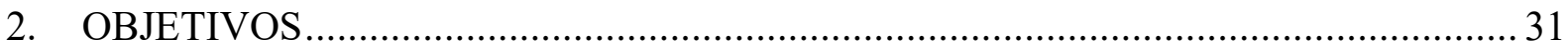

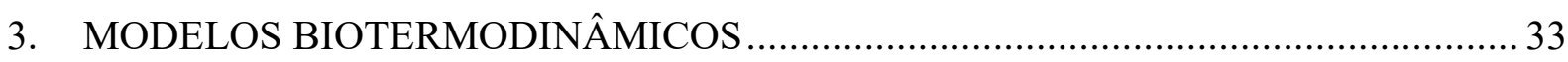

3.1. Desenvolvimento do modelo biotermodinâmico ............................................... 36

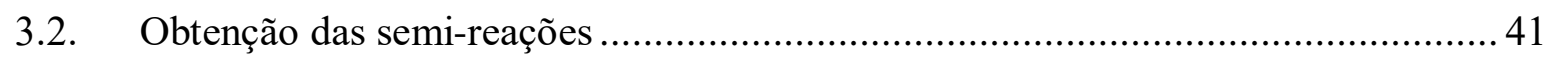

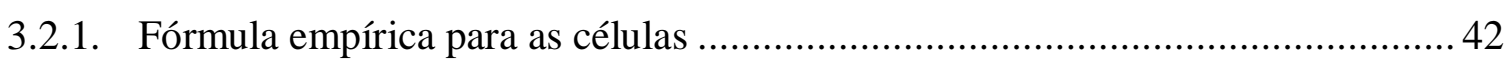

3.2.2. Estequiometrias das semi-reações de redução .............................................. 42

3.2.3. Distribuição de espécies e frações molares ....................................................... 45

3.2.4. Cálculo de propriedades termodinâmicas (condições padrão) ........................... 51

3.3. Cálculo de energia livre (concentrações diferentes da padrão) ............................. 55

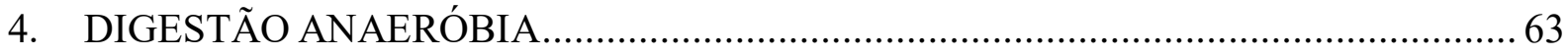

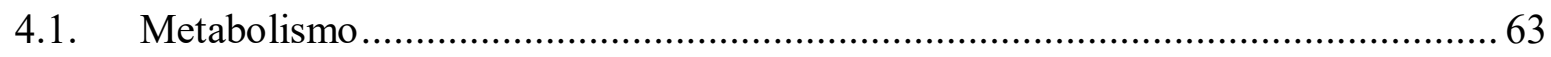

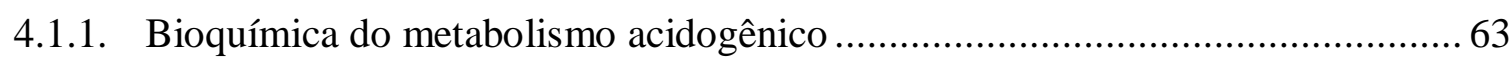

4.1.2. Bioquímica do metabolismo acetogênico .................................................... 68

4.1.3. Bioquímica do metabolismo metanogênico ................................................... 73

4.2. Aplicação do modelo-resultados e discussão.................................................... 75

4.2.1. Comportamento dos processos acidogênicos ................................................... 76

4.2.2. Comportamento dos processos acetogênicos ................................................. 83

4.2.3. Comportamento dos processos metanogênicos ............................................ 90

4.3. Rendimentos molares da digestão anaeróbia completa e separada ....................... 93

4.4. Eficiências energéticas da digestão anaeróbia completa e separada ..................... 100

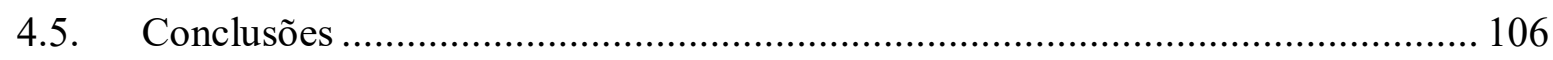

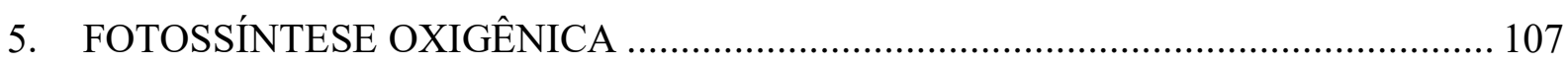

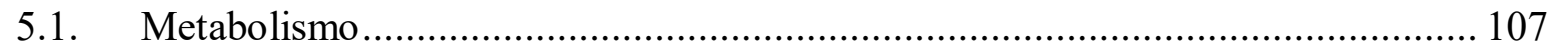

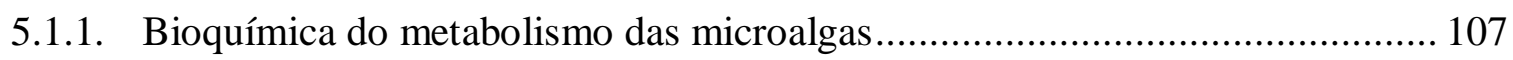

5.1.2. Bioquímica do metabolismo das cianobactérias .......................................... 111

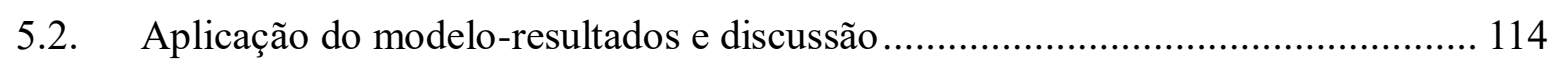

5.2.1. Comportamento da fotossíntese oxigênica com microalgas ........................... 115

5.2.2. Comportamento da fotossíntese oxigênica com cianobactérias ....................... 122

5.3. Rendimentos molares da fotossíntese oxigênica ........................................ 127 
5.4. Eficiências energéticas da fotossíntese oxigênica .......................................... 136

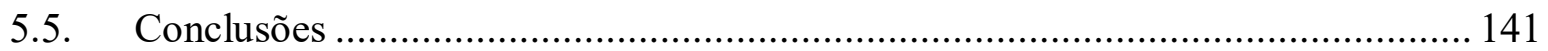

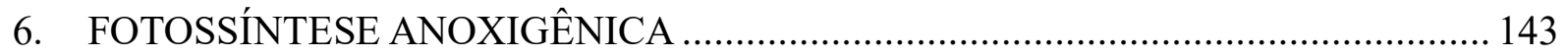

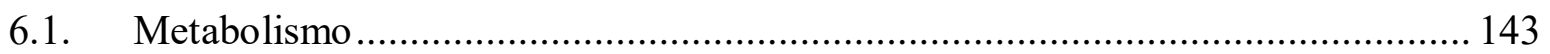

6.1.1. Bioquímica do metabolismo das bactérias verdes sulfurosas .......................... 143

6.1.2. Bioquímica do metabolismo das bactérias púrpuras sulfurosas ....................... 146

6.1.3. Bioquímica do metabolismo das bactérias verdes não sulfurosas ..................... 148

6.1.4. Bioquímica do metabolismo das bactérias púrpuras não sulfurosas .................. 150

6.2. Aplicação do modelo-resultados e discussão ..................................................... 152

6.2.1. Comportamento da fotossíntese anoxigênica com bactérias sulfurosas ............. 153

6.2.2. Comportamento da fotossíntese anoxigênica com bactérias não sulfurosas...... 160

6.3. Rendimentos molares da fotossíntese anoxigênica ........................................ 168

6.4. Eficiências energéticas da fotossíntese anoxigênica .......................................... 176

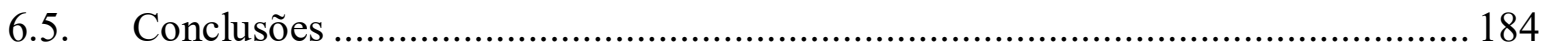

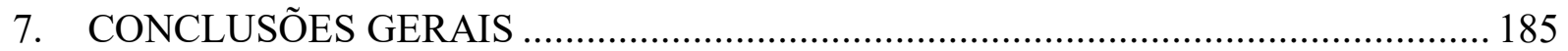

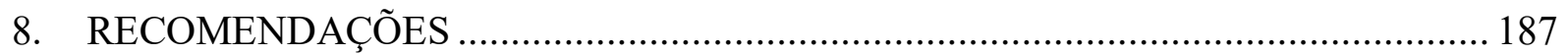

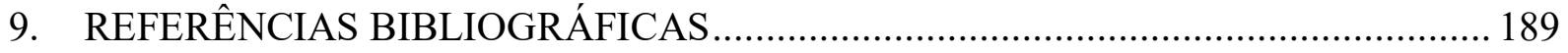




\section{INTRODUÇÃO}

A digestão anaeróbia, um tratamento secundário de águas residuárias, produz um biogás com 60 a $80 \%$ de metano $\left(\mathrm{CH}_{4}\right)$, combustível no qual fica contido o carbono reduzido proveniente da matéria orgânica e que representa uma recuperação energética a partir de um resíduo. Uma alternativa para a recuperação de energia na digestão anaeróbia é separar as duas etapas que a compõem para produzir dois gases a partir do substrato: hidrogênio $\left(\mathrm{H}_{2}\right)$ na primeira etapa de fermentação escura e metano na segunda etapa de metanogênese. Durante a fermentação escura se produz acetato junto com o hidrogênio, que serve como substrato à metanogênese.

Não obstante, o acetato produzido durante a fermentação escura também pode servir como substrato a bactérias anoxigênicas fotoorganotróficas (bactérias púrpuras não sulfurosas) que produzem hidrogênio por fotofermentação com radiação solar próxima do infravermelho. Assim, a fermentação escura pode-se unir com a fotofermentação e produzir hidrogênio nos dois processos a partir do substrato.

Estas alternativas de tratamentos secundários podem-se unir com tratamentos terciários para a remoção de nutrientes com microalgas ou cianobactérias, microorganismos oxigênicos fotolitotróficos que podem produzir hidrogênio por biofotólise direta ou biofotólise indireta por fermentação ou fixação de nitrogênio (cianobactérias) com radiação solar no espectro visível.

Os benefícios podem ir além dos energéticos. Quando um tratamento terciário (e.g. fotossíntese oxigênica com microalgas) se combina com um tratamento secundário anaeróbio (e.g. digestão anaeróbia) se gera uma sinergia entre os dois processos: o tratamento secundário degrada a matéria orgânica dissolvida e produz biogás e um efluente rico em nutrientes e alcalinidade, enquanto o tratamento terciário remove esses nutrientes evitando a eutrofização e fixando carbono bem a partir do dióxido de carbono $\left(\mathrm{CO}_{2}\right)$, um gás de efeito estufa, ou a partir da alcalinidade gerada no tratamento secundário. A biomassa produzida por fotossíntese (microalgas) pode-se remover e conduzir ao tratamento secundário para aumentar a concentração de matéria orgânica dissolvida e gerar mais quantidade de biogás por codigestão, enquanto os lodos estabilizados obtidos (biosólidos) podem-se utilizar na agricultura dada sua elevada concentração de nutrientes.

Embora os processos mencionados visem a recuperação de energia a partir do tratamento de resíduos, existem combinações alternativas de processos anaeróbios- 
fotossintéticos direcionadas à produção de energia e não só na recuperação.

Para a análise tanto dos balanços de massa quanto de energia para estes processos biológicos podem-se aplicar modelos biotermodinâmicos. Estes modelos permitem analisar o comportamento das reações bioquímicas e estimar rendimentos celulares e eficiências energéticas a partir de relações estequiométricas entre substratos e produtos do metabolismo.

A abordagem termodinâmica dos processos biológicos em geral e dos processos de interesse ambiental e industrial em particular, comparada com outras abordagens teóricas, oferece a vantagem de estabelecer os limites (e.g. de $\mathrm{pH}$, temperatura, pressões, etc.) nos que estes processos ocorrem. Assim, conhecendo estes limites, muito trabalho experimental pode ser poupado e predições valiosas podem ser feitas na procura de novos microorganismos para processos biológicos possíveis. Não obstante, algumas condições têm dificultado a aplicação dos modelos biotermodinâmicos em processos anaeróbios e fotossintéticos. Nos processos anaeróbios, dada a energia marginal liberada, a aplicação do modelo exige realizar cálculos termodinâmicos considerando condições diferentes das condições padrão, e incorporando as influências de variáveis físico-químicas (i.e. temperatura e $\mathrm{pH}$ ) para atingir estimativas de maior exatidão e reduzir os erros porcentuais. No caso de processos fotossintéticos, a aplicação do modelo exige incorporar os fótons e sua energia nos balanços de massa e energia. Consequentemente, a modelação biotermodinâmica não tem sido aplicada ainda nestes processos.

A partir deste problema, esta pesquisa visa resolver estas dificuldades e desenvolver um modelo biotermodinâmico dos processos anaeróbios e fotossintéticos de recuperação de energia, com produção de metano e hidrogênio, para analisar seu comportamento do ponto de vista termodinâmico e estabelecer seus rendimentos molares e eficiências energéticas a partir de relações estequiométricas.

\subsection{Estrutura da tese}

Os primeiros capítulos da tese abordam a contextualização desta pesquisa, começando com a presente introdução (Capítulo 1), continuando com a definição de objetivos (Capítulo 2) e terminando com [i] o embasamento teórico dos modelos biotermodinâmicos, [ii] a físicoquímica envolvida na obtenção das semi-reações e [iii] os cálculos das propriedades termodinâmicas (Capítulo 3).

Os seguintes capítulos dedicam-se aos metabolismos de interesse e aos resultados da aplicação do modelo biotermodinámico nesses metabolismos, finalizando com conclusões 
específicas da aplicação do modelo. Assim, o Capítulo 4 apresenta a digestão anaeróbia considerando os metabolismos acidogénico, acetogénico e metanogênico, os resultados da aplicação do modelo em cada metabolismo e os rendimentos molares e eficiências energéticas obtidas na digestão anaeróbia completa e separada (fermentação e metanogênese). O Capítulo 5 apresenta a fotossíntese oxigênica considerando os metabolismos de microalgas e cianobactérias, e o Capítulo 6 apresenta a fotossíntese anoxigênica considerando os metabolismos de bactérias sulfurosas e não sulfurosas. Estes últimos finalizam com os resultados da aplicação do modelo em cada metabolismo e seus rendimentos molares e eficiências energéticas.

Por fim, nos capítulos finais são relatadas conclusões gerais da pesquisa (Capítulo 7), recomendações para futuros estudos sobre o tema (Capítulo 8) e as referências bibliográficas citadas no texto (Capítulo 9). 


\section{OBJETIVOS}

Objetivo geral: Desenvolver um modelo biotermodinâmico dos processos anaeróbios e fotossintéticos de recuperação de energia com ênfase na produção de metano e hidrogênio.

\section{Objetivos específicos}

- Selecionar as reações bioquímicas anaeróbias e fotossintéticas de produção de metano e hidrogênio mediante o estudo dos processos metabólicos para a aplicação do modelo biotermodinámico.

- Desenvolver um modelo biotermodinâmico baseado em modelos estabelecidos, que considere as variações de $\mathrm{pH}$ e temperatura no sistema, para aplicar em processos anaeróbios e fotossintéticos de recuperação de energia.

- Aplicar o modelo biotermodinâmico nos processos anaeróbios e fotossintéticos de produção de metano e hidrogênio para a predição de rendimentos molares e eficiências energéticas e a análise dos comportamentos metabólicos. 


\section{MODELOS BIOTERMODINÂMICOS}

Nos sistemas biológicos, quando o fluxo de energia alcança níveis quase constantes com o tempo, o sistema se aproxima a um estado pseudo-estacionário e se mantém longe do equilíbrio pelo fluxo constante de energia e a ordem resultante. A energia se libera pelo fluxo de elétrons de doadores para aceptores; porém, como os sistemas biológicos são sistemas abertos que intercambiam materiais com o ambiente nos quais ocorrem processos irreversíveis, só uma fração dessa energia pode se transformar em trabalho útil para os processos metabólicos e o remanescente se dissipa (Kleerebezem \& van Loosdrecht, 2010). Assim, o crescimento dos organismos é uma função da energia liberada pela transferência de elétrons e da eficiência dos organismos no aproveitamento dessa energia (McCarty, 1972).

Aplicando estes princípios em sistemas bacterianos, aqueles microorganismos que podem produzir uma transferência mais rápida e podem capturar a energia liberada mais eficientemente tenderão a ser dominantes porque sua velocidade de crescimento será maior (McCarty, 1972).

Modelos biotermodinâmicos, baseados na estequiometría e na termodinâmica do metabolismo, são uteis para realizar balanços de massa em sistemas bacterianos e identificar fatores importantes como: requisitos de nutrientes para o crescimento dos microorganismos, efeito das reações de conversão na alcalinidade e no $\mathrm{pH}$, quantidade de produtos finais gerados, entre outros (Rittmann \& McCarty, 2001; Kleerebezem \& van Loosdrecht, 2010). Os modelos propostos consideram a bioenergética do crescimento microbiano e procuram basicamente estabelecer relações entre a eficiência energética do metabolismo (catabolismo e anabolismo), medida como entalpia ou energia livre, e o rendimento da biomassa, devido ao interesse biotecnológico neste último parâmetro. Ao respeito, Heijnen \& van Dijken (1992) e Liu et al. (2007) apresentam uma revisão de algumas destas propostas.

As propostas biotermodinâmicas iniciais consideram a eficiência da conservação da entalpia para determinar o rendimento usando sua produção durante o crescimento microbiano (Battley, 1960a) ou as mudanças desta propriedade nos processos de crescimento (Minkevich \& Eroshin, 1973; Roels, 1983). Não obstante, as propostas baseadas na entalpia têm uma limitação: a segunda lei da termodinâmica não restringe a possibilidade que o crescimento microbiano consuma entalpia, pelo que as eficiências podem ser maiores à unidade (Heijnen \& van Dijken, 1992). Esta limitação foi superada nas propostas posteriores pelo uso da eficiência da conservação da energia livre, uma vez que, segundo a segunda lei, esta sempre 
deve ser dissipada em processos espontâneos (e.g. metabolismo microbiano, composto pelo catabolismo exergônico e o anabolismo endergônico).

A continuação se apresentam as generalidades das propostas de maior interesse, devido a seu enfoque termodinâmico, que consideram a conservação da energia livre para determinar o rendimento celular.

Battley (1960b) apresentou um estudo teórico da termodinâmica do crescimento microbiano no qual correlacionou o rendimento da biomassa com a eficiência da conservação da energia livre no metabolismo. A eficiência foi determinada com base na energia livre produzida em duas reações redox, uma conservativa correspondente à reação metabólica na qual os substratos são transformados (catabolismo) e a biomassa sintetizada (anabolismo), e uma não conservativa correspondente unicamente ao catabolismo. Nesta última, a energia livre representa a máxima energia que pode ser dissipada no metabolismo.

McCarty (1972) analisou a termodinâmica da síntese biológica e o crescimento baseado em um tratamento termodinâmico do metabolismo no qual correlacionou o rendimento da biomassa com a razão entre os mols de elétrons destinados a produtos (catabolismo) respeito aos mols de elétrons destinados a síntese celular (anabolismo). Para determinar esta razão, usou um balanço de energia para o processo metabólico no qual considerou a energia livre do catabolismo e do anabolismo mais as perdas. $\mathrm{O}$ anabolismo o dividiu em dois passos; primeiro, a transferência de elétrons do doador a um intermediário metabólico (piruvato) e, segundo, a transferência de elétrons do intermediário às células, e considerou a eficiência nestas transferências. A energia livre do primeiro passo foi obtida a partir da reação redox da transformação do doador de elétrons ao intermediário, enquanto a energia livre do segundo passo foi suposta constante para a síntese de células bacterianas. Posteriormente, o modelo foi explicado mais detalhadamente (Rittmann \& McCarty, 2001) e atualizado corrigir os baixos rendimentos celulares preditos em processos aeróbios de degradação de compostos orgânicos mediados por oxigenases e em processos com substratos de um carbono (McCarty, 2007). Nesta última a acetil-CoA foi considerada como intermediário no lugar do piruvato.

Roels (1983) propôs a eficiência energética do metabolismo, medida como energia livre, como parâmetro de correlação com o rendimento da biomassa. A eficiência foi determinada de duas formas: como o quociente entre a energia livre dos reagentes e os produtos ou como o quociente entre a energia livre de combustão conservada na biomassa e a energia livre de combustão disponível nos substratos.

Westerhoff \& van Dam (1987) analisaram a eficiência da transdução da energia livre 
em processos biológicos e sua de correlação com o rendimento da biomassa. A eficiência foi determinada como o quociente da energia livre do anabolismo e a energia livre do catabolismo. A suma das duas reações corresponde à reação conservativa usada por Battley (1960b).

Heijnen \& van Dijken (1992) sugeriram a dissipação da energia livre por mole de biomassa produzida para a descrição termodinâmica do rendimento. Esta energia é igual à energia livre produzida na reação conservativa usada por Battley (1960b), mas de sinal oposta.

von Stockar \& Liu (1999) fizeram um analise termodinâmico do crescimento microbiano e estabeleceram uma correlação entre o rendimento da biomassa e as energias livres do metabolismo, catabolismo e de uma reação hipotética de degradação da biomassa aos mesmos produtos do catabolismo. Aqui, a reação de metabolismo é a mesma reação conservativa de Battley (1960b).

Kleerebezem \& van Loosdrecht (2010) propuseram um método generalizado para o analise do estado termodinâmico de sistemas ambientais baseado em um tratamento termodinâmico do metabolismo, no qual consideraram a influência das concentrações de reagentes e produtos e da temperatura nos resultados de energia livre das reações catabólica e anabólica. O método desenvolvido não precisa de estados de referência predefinidos para nenhum dos reagentes ou produtos das reações metabólicas, aumentando a aplicabilidade do método respeito a métodos anteriores como os de McCarty (1972) e Heijnen \& van Dijken (1992).

Como sumário dos diferentes métodos, todas as propostas biotermodinâmicas de conservação da energia livre para determinar o rendimento celular estabelecem relações entre a energia livre e o metabolismo, mas com dois enfoques diferentes: o enfoque de Battley (1960b) baseado nas entradas e saídas do processo metabólico (Battley, 1960b; Heijnen \& van Dijken, 1992; Roels, 1983; von Stockar \& Liu, 1999; Westerhoff \& van Dam, 1987) e o enfoque de McCarty (1972) baseado em uma descrição mais ampla do metabolismo no qual considera, além das entradas e saídas, os intermediários (Kleerebezem \& van Loosdrecht, 2010; McCarty, 1972). Entre os dois enfoques, os métodos mais usados são os de McCarty (1972) e Heijnen \& van Dijken (1992), acerca dos que Kleerebezem \& van Loosdrecht (2010) e VanBriesen (2002) realizaram comparações.

Nesta pesquisa se selecionou o modelo biotermodinâmico de McCarty (McCarty, 1972; McCarty, 2007; Rittmann \& McCarty, 2001) devido a sua rigorosidade termodinâmica na descrição do metabolismo (Seção 3.1). No modelo se incorporam algumas modificações na 
obtenção das semi-reações (Seção 3.2) e no cálculo das propriedades termodinâmicas (Seção 3.3) com o escopo de aumentar a exatidão na estimação da energia livre dissipada no metabolismo; modificações como:

- Fórmulas empíricas para células de bactérias e microalgas que incluem fósforo e enxofre (Seção 3.2.1).

- Distribuição das espécies de reagentes e produtos como função do $\mathrm{pH}$ e da temperatura para a determinação dos coeficientes estequiométricos (Seções 3.2.2 e 3.2.3).

- Participação de fótons nas semi-reações e determinação das propriedades termodinâmicas para aplicar o modelo em processos fotossintéticos (Seções 3.2.2 e 3.2.4).

- Cálculo de propriedades termodinâmicas de compostos orgânicos sem dados na bibliografia (Seção 3.2.4).

- Concentrações e pressões parciais de ordem biológica de reagentes e produtos e influência da temperatura para as determinações de energia livre (Seção 3.3).

Neste capítulo se apresenta inicialmente o modelo biotermodinâmico a aplicar aos processos anaeróbios e fotossintéticos de recuperação de energia (Seção 3.1) para posteriormente apresentar a obtenção da informação necessária para a aplicação do modelo (Seções 3.2 e 3.3).

\subsection{Desenvolvimento do modelo biotermodinâmico}

A partir das semi-reações de oxidação e redução se obtêm as reações redox e as propriedades termodinâmicas para diferentes processos químicos usando-se a Equação 1.

$$
R=R_{a}-R_{d}
$$

Na qual $R$ representa a reação redox global, $R_{a}$ representa a semi-reação do aceptor de elétrons e $R_{d}$ a semi-reação do doador de elétrons. O sinal positivo significa que a semi-reação é de redução $\left(R_{a}\right)$, enquanto o sinal negativo significa que a semi-reação é de oxidação $\left(R_{d}\right)$.

Não obstante, conhecer a reação redox não brinda informação completa na maioria de processos biológicos, porquanto nela não se considera a produção de células. Para incorporála na reação redox se precisa de um modelo biotermodinâmico como o modelo de McCarty (McCarty, 1972; McCarty, 2007), apresentado em detalhe por Rittmann \& McCarty (2001). Este modelo se baseia na transferência de energia (ATP) e poder redutor $[\mathrm{NAD}(\mathrm{P}) \mathrm{H}]$ dos 
processos catabólicos exergônicos para os processos anabólicos endergônicos por meio de um intermediário metabólico comum (acetil-CoA) (Rittmann \& McCarty 2001) como apresenta a Figura 1.

Catabolismo

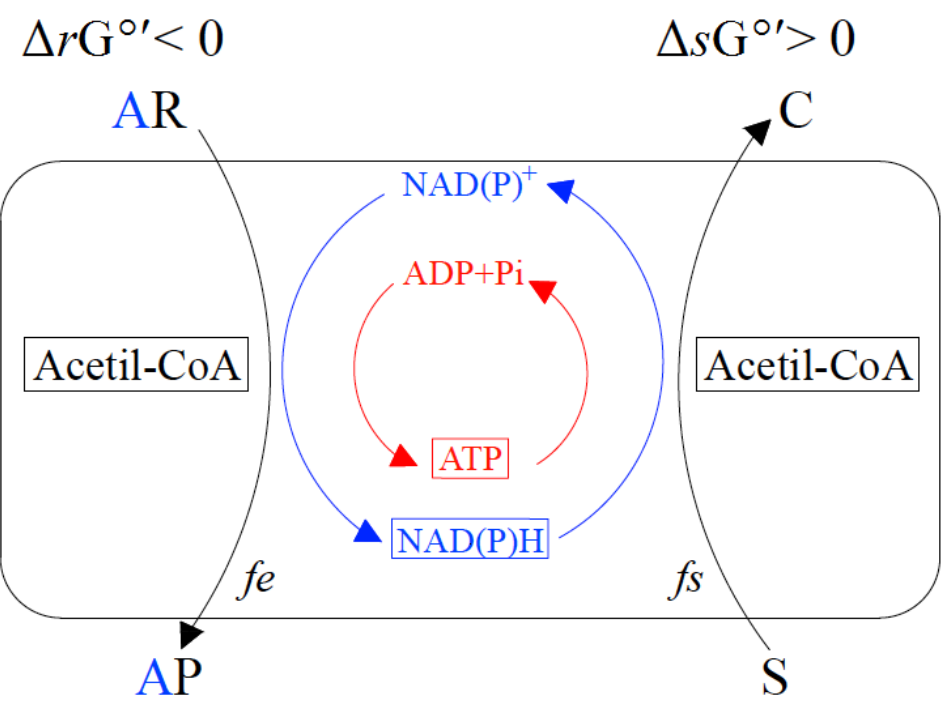

Figura 1. Esquema conceptual do modelo biotermodinâmico.

ATP: Adenosina trifosfato. ADP: Adenosina difosfato. Pi: Íon fosfato. NAD(P)H e NAD $(\mathrm{P})^{+}$: Formas reduzida e oxidada, respetivamente, da nicotinamida adenina dinucleótido (fosfato). $f_{s}$ : Fração dos elétrons do doador destinados para síntese. $f_{e}$ : Fração dos elétrons do doador destinados a produtos. A: Razão entre $f_{e}$ e $f_{s}$. R: Reagentes. P: Produtos. S: Substrato. C: Células.

No modelo, a reação redox para o processo biológico incorpora, além da transferência de elétrons do doador para o aceptor (catabolismo, primeiro termo da Equação 2), a transferência de elétrons do doador para a síntese celular (anabolismo, segundo termo da Equação 2) (Sawyer, McCarty \& Parkin, 2003; Rittmann \& McCarty 2001).

$$
R=f_{e}\left(R_{a}-R_{d}\right)+f_{s}\left(R_{c}-R_{d}\right)
$$

Como $f_{s}+f_{e}=1$, a Equação 2 se transforma na Equação 3:

$$
R=f_{s} R_{c}+f_{e} R_{a}-R_{d}
$$

Nestas equações $R_{c}, R_{a}$ e $R_{d}$ representam as semi-reações para síntese de células de microorganismos, aceptor de elétrons e doador de elétrons, respetivamente. Os valores $f_{s}$ e $f_{e}$ 
são a fração dos elétrons do doador destinados para síntese e produtos, respetivamente (Figura 1), os quais determinam a estequiometria da reação redox global $(R)^{1}$. A razão entre $f_{e}$ e $f_{s}$ representa os mols de elétrons destinados a produtos (catabolismo) respeito aos mols de elétrons destinados a síntese celular (anabolismo) e se simboliza por $A$. A determinação deste parâmetro se realiza por considerações energéticas como apresenta a Equação 7.

Em algumas reações (e.g. fermentações) podem atuar vários aceptores e doadores de elétrons; nelas devem-se conhecer as proporções relativas de cada aceptor nos produtos ou doador nos reagentes para determinar uma única semi-reação de redução $\left(R_{a}\right)$ ou oxidação $\left(R_{d}\right)$, respetivamente. Por exemplo, para vários aceptores de elétrons, para conhecer a semireação de redução se usam as Equações 4 a 6 (Rittmann \& McCarty, 2001).

$$
R_{a}=\sum_{i=1}^{n} e_{a i} R_{a i} \quad[4] \quad e_{a i}=\frac{e q_{a i}}{\sum_{j=1}^{n} e q_{a j}} \quad \text { [5] } \quad \sum_{i=1}^{n} e_{a i}=1
$$

Nas quais $e_{a i}$ é a fração do produto reduzido $i$ no total de produtos reduzidos e $e q_{a i}$ são os equivalentes de elétrons do produto reduzido $i$. A fração $e_{a i}$ multiplica sua semi-reação de redução $\left(R_{a i}\right)$ e todas as semi-reações resultantes se somam para obter a semi-reação de redução global $\left(R_{a}\right)$. Quando atuam vários doadores de elétrons se segue o mesmo procedimento para obter a semi-reação de oxidação $\left(R_{d}\right)$.

Segundo o modelo desenvolvido por McCarty (1972), a energia liberada pela reação redox se transfere em dois passos; primeiro para um transportador de energia como o ADP, e segundo, do transportador para a reação de síntese celular (não se considera a energia para a manutenção celular) como mostra a Figura 1. Para cada transferência uma fração da energia se perde e está relacionada com a eficiência da transferência de energia $(\varepsilon)$. Realizando um balanço de energia livre no sistema indicado na Figura 1 obtêm-se a Equação 7.

$$
A\left(\Delta_{f} G_{R}^{\circ}-\Delta_{f} G_{P}^{\circ}\right)=\left(\Delta_{f} G_{C}^{\circ}-\Delta_{f} G_{S}^{\circ}\right)+G_{p}^{\circ}
$$

Como $\Delta_{f} G_{R}{ }^{\circ}-\Delta_{f} G_{P}{ }^{\circ}=-\Delta_{r} G^{\circ}$ e $\Delta_{f} G_{C}{ }^{\circ}-\Delta_{f} G_{S}{ }^{\circ}=\Delta_{s} G^{\circ}$, então (Equações 8 e 9):

\footnotetext{
1 Uma forma alternativa de analisar os valores de $f_{s}$ e $f_{e}$ é como a intensidade necessária do catabolismo $\left(f_{e}\right)$ para fornecer a energia do anabolismo $\left(f_{s}\right)$.
} 


$$
-A \Delta_{r} G^{\circ \prime}=\Delta_{s} G^{\circ \prime}+G_{p}^{\circ} \quad[8] \quad A \Delta_{r} G^{\circ \prime}=-\Delta_{S} G^{\circ \prime}-G_{p}^{\circ}
$$

Nas quais $A$ é a razão entre $f_{e}$ e $f_{s}, \Delta_{f} G_{R}{ }^{\circ}$ é a energia livre padrão de formação dos reagentes, $\Delta_{f} G_{P}{ }^{\circ}$ é a energia livre padrão de formação dos produtos, $\Delta_{f} G_{C}{ }^{\circ}$ é a energia livre padrão de formação das células, $\Delta_{f} G_{S}{ }^{\circ}$ é a energia livre padrão de formação dos substratos e $G_{p}{ }^{\circ}$ é a energia livre padrão perdida no processo. $\Delta_{r} G^{\circ}$ é a energia livre da reação redox, $\Delta_{S} G^{\circ}$, a energia livre consumida pela reação de síntese celular, ambas com concentrações diferentes das concentrações padrão. $A \Delta_{r} G^{\circ}$, representa a energia livre da reação redox de síntese celular mais as perdas. Todas as energias expressas por equivalente de elétrons. $A \Delta_{r} G^{\circ}$, é formada por dois componentes, o primeiro pela energia efetivamente transferida à síntese celular $\left(\varepsilon A \Delta_{r} G^{\circ}\right.$ ) e o segundo pela energia perdida $\left[(1-\varepsilon) A \Delta_{r} G^{\circ}\right.$ ’ (Equação 10).

$$
A \Delta_{r} G^{\circ \prime}=\varepsilon A \Delta_{r} G^{\circ \prime}+(1-\varepsilon) A \Delta_{r} G^{\circ \prime}
$$

Comparando-se as Equações 9 e 10 se obtém a igualdade da Equação 11 e, isolando $A$, a Equação 12.

$$
\varepsilon A \Delta_{r} G^{\circ \prime}=-\Delta_{s} G^{\circ \prime} \quad[11] \quad A=-\frac{\Delta_{S} G^{\circ \prime}}{\varepsilon \Delta_{r} G^{\circ \prime}}
$$

Segundo o resultado da Equação 12, quando a energia livre da reação redox $\left(\Delta_{r} G^{\circ}\right)$ é alta, $A$ é baixo e $f_{s}$ maior que $f_{e}$, comportamento típico dos processos aeróbios nos quais se produzem muitas bactérias (lodos); enquanto se $\Delta_{r} G^{\circ}$ é baixa, $A$ é alto e $f_{s}$ menor que $f_{e}$, comportamento típico dos processos anaeróbios nos quais se produzem poucas bactérias.

Os componentes na Equação 12 equivalem as Equações 13 e 14.

$$
\Delta_{r} G^{\circ \prime}=\Delta_{a} G^{\circ \prime}-\Delta_{d} G^{\circ \prime}
$$

$$
\Delta_{S} G^{\circ \prime}=\frac{\Delta_{i} G^{\circ \prime}}{\varepsilon^{n}}+\frac{\Delta_{c} G^{\circ}}{\varepsilon}
$$

$\Delta_{r} G^{\circ}$ ' se calcula selecionando as energias livres das semi-reações do aceptor $\left(\Delta_{a} G^{\circ}\right)$ e o doador de elétrons $\left(\Delta_{d} G^{\circ}\right)$.

$\Delta_{S} G^{\circ}$, depende do intermediário metabólico no processo de síntese celular e das fontes de energia (doador de elétrons), nitrogênio e enxofre. Não depende da fonte de fósforo porque ele se toma do ambiente no mesmo estado de oxidação (V) no qual se encontra no material 
celular.

$\Delta_{i} G^{\circ}$ ' é a energia livre da reação redox para formar o intermediário a partir do doador de elétrons, por equivalente de elétrons, com concentrações diferentes da padrão. O principal intermediário metabólico é acetil-CoA (McCarty, 2007; Thauer, Jungermann \& Decker, 1977), portanto $\Delta_{i} G^{\circ}$, se calcula usando a energia livre da semi-reação da acetil-CoA como aceptor de elétrons $\left(\Delta_{a} G^{\circ}\right)$ e a energia livre da semi-reação do doador de elétrons $\left(\Delta_{d} G^{\circ}\right)$. Quando se requer energia para transformar a fonte de carbono no intermediário $\left(\Delta_{i} G^{\circ}>0\right), n$ $=1$; mas quando o processo libera energia $\left(\Delta_{i} G^{\circ},<0\right), n=-1$ (McCarty, 2007).

Posteriormente o intermediário metabólico e as fontes de nitrogênio e enxofre se transformam em material celular. Os microorganismos podem tomar do ambiente o nitrogênio como amônio $\left(\mathrm{NH}_{4}^{+}\right)$, nitrato $\left(\mathrm{NO}_{3}^{-}\right)$, nitrito $\left(\mathrm{NO}_{2}{ }^{-}\right)$ou nitrogênio $\left(\mathrm{N}_{2}\right)$ e o enxofre como sulfeto $\left(\mathrm{H}_{2} \mathrm{~S}, \mathrm{HS}^{-}\right)$, sulfato $\left(\mathrm{HSO}_{4}^{-}, \mathrm{SO}_{4}{ }^{2-}\right)$, enxofre elementar $\left(\mathrm{S}^{0}\right)$ ou sulfito $\left(\mathrm{HSO}_{3}{ }^{-}, \mathrm{SO}_{3}{ }^{2-}\right)$. Não obstante, tomar formas diferentes das reduzidas implica a redução do nitrogênio até amônio (estado de oxidação -III) e do enxofre até sulfeto (estado de oxidação -II) que correspondem aos estados de oxidação desses elementos no material celular, processos que requerem poder redutor (elétrons) e energia química (ATP) o que reduz sua disponibilidade para síntese. $\Delta_{c} G^{\circ}$ é a energia livre de reação por equivalente de elétrons para converter o intermediário e os nutrientes em células e equivale a $19,6 \mathrm{~kJ} \mathrm{e}^{-} \mathrm{eq}^{-1}$, obtida de multiplicar o coeficiente estequiométrico das células (Reação 22, Tabela 3$)^{2}$ e a massa molar (118,18 g mol${ }^{1}$ segundo a Seção 3.2 .1 ) por $3,33 \mathrm{~kJ} \mathrm{~g} \mathrm{cel}^{-1}$, valor estimado por McCarty a partir de valores relatados de moles de ATP requeridos para síntese celular (McCarty, 2007; Rittmann \& McCarty, 2001). Esta estimação pode-se usar para calcular o valor de $\Delta_{c} G^{\circ}$ para processos nos quais as fontes de nitrogênio e enxofre são diferentes das fontes reduzidas ou para fórmulas empíricas para células diferentes da proposta para bactérias (Seção 3.2.1). Nesta pesquisa se consideram fontes reduzidas de nitrogênio (i.e. amônio) e enxofre (i.e. sulfeto) tanto para bactérias quanto para microalgas, mas a fórmula empírica é diferente. Para microalgas, o valor de $3,33 \mathrm{~kJ} \mathrm{~g} \mathrm{cel}^{-1}$ se multiplica pelo coeficiente estequiométrico das células (Reação 23, Tabela 3) e pela massa molar (3585,31 $\mathrm{g} \mathrm{mol}^{-1}$ segundo a Seção 3.2.1) e obtém-se 28,3 kJ e $\mathrm{eq}^{-1}$. Assim, para bactérias $\Delta_{c} G^{\circ}$ equivale a $19,6 \mathrm{~kJ} \mathrm{e}^{-} \mathrm{eq}^{-1}$ e para microalgas a $28,3 \mathrm{~kJ} \mathrm{e}^{-} \mathrm{eq}^{-1}$.

Finalmente, para se obter o valor de $A$ precisasse supor um valor para a eficiência da transferência de energia $(\varepsilon)$. Valores de $\varepsilon$ de 0,55 e 0,70 são típicos sob condições ótimas,

${ }^{2}$ Aqui é preciso citar resultados obtidos posteriormente devido à configuração do capítulo e com o escopo de apresentar o modelo biotermodinâmico completo. 
enquanto um valor de 0,60 se usa comumente (McCarty, 1972; Rittmann \& McCarty, 2001) e é o valor selecionado nesta pesquisa.

Com o resultado de $A\left(f_{e} / f_{s}\right)$ se obtêm os valores de $f_{s}$ e $f_{e}$ (Equações 15 e 16) e a reação química balanceada global $(R)$ para o processo biológico. Como no modelo não se considera a energia de manutenção celular, o valor de $f_{s}$ obtido pelo modelo será o máximo $\left(f_{s}{ }^{\circ}\right)$ e o valor de $f_{e}$ será o mínimo $\left(f_{e}{ }^{\circledR}\right)$ (Rittmann \& McCarty, 2001).

$$
f_{s}^{\circ}=\frac{1}{A+1} \quad[15] \quad f_{e}^{\circ}=1-f_{s}^{\circ}=\frac{A}{A+1}
$$

Neste modelo, nem a energia livre para formar o intermediário a partir do doador de elétrons $\left(\Delta_{i} G^{\circ}\right)$ nem a energia livre para converter o intermediário e os nutrientes em células $\left(\Delta_{c} G^{\circ}\right)$ variam com mudanças no $\mathrm{pH}$, porquanto, por se tratar de processos metabólicos realizados no interior celular (citoplasma), o $\mathrm{pH}$ se supõe próximo do $\mathrm{pH}$ neutro $(7,0)$ independentemente das condições externas. Como consequência, os valores de $f_{s}$ e $f_{e}$ também não variam com as mudanças no $\mathrm{pH}$.

Por outro lado, a temperatura do citoplasma se encontra em equilíbrio térmico com o ambiente, pelo que a temperatura dos processos metabólicos varia. Assim, ao contrário do $\mathrm{pH}$, as variações de temperatura afetam a energia livre para formar o intermediário a partir do doador de elétrons $\left(\Delta_{i} G^{\circ}\right)$ e, portanto, os valores de $f_{s}$ e $f_{e}$. Não obstante, no intervalo considerado nesta pesquisa $\left(10\right.$ a $\left.70{ }^{\circ} \mathrm{C}\right)$, as variações de $f_{s}$ e $f_{e}$ são inferiores a $3 \%$ pelo que não se considera este efeito no modelo.

Para aplicar o modelo biotermodinâmico apresentado precisa-se definir as semireações de produção de células e de doadores e aceptores de elétrons (Seção 3.2) nos processos de digestão anaeróbia e fotossintéticos oxigênicos e anoxigênicos, junto com os valores da energia livre para concentrações diferentes da padrão $\left(\Delta_{r} G^{\circ}\right)$ para cada uma (Seção $3.3)$.

\subsection{Obtenção das semi-reações}

Inicialmente, para plantear as semi-reações de produção de células é preciso considerar a fórmula empírica para as células de bactérias e microalgas. 


\subsubsection{Fórmula empírica para as células}

Os elementos presentes nas células dos microorganismos e, principalmente, sua proporção dependem das características dos microorganismos e dos substratos usados como fonte de energia, carbono e nutrientes, dando origem a uma ampla variedade de fórmulas empíricas. Para bactérias, Hoover \& Porges (1952) propuseram uma fórmula empírica com ampla aceitação $\left(\mathrm{C}_{5} \mathrm{H}_{7} \mathrm{O}_{2} \mathrm{~N}\right)$, base do modelo biotermodinâmico de McCarty (1972). Variações desta fórmula para bactérias têm sido relatadas por Rittmann \& McCarty (2001) e Comeau (2008), algumas das quais consideram o fósforo além do nitrogênio como nutriente. Nesta pesquisa, com o escopo de aumentar a exatidão do modelo, a formula empírica para bactérias selecionada é $\mathrm{C}_{5} \mathrm{H}_{7} \mathrm{O}_{2} \mathrm{NP}_{0,06} \mathrm{~S}_{0,1}$ (Speece, 1996). Para microalgas, fórmulas empíricas como a proposta por Stumm \& Morgan (1996) $\left(\mathrm{C}_{106} \mathrm{H}_{263} \mathrm{O}_{110} \mathrm{~N}_{16} \mathrm{P}\right)$, baseada na relação de Redfield, Ketchum \& Richards (1963), têm sido comumente usadas. Neste caso, baseada na mesma relação e com o escopo de incluir o enxofre para aumentar a exatidão, a fórmula empírica para microalgas selecionada é $\mathrm{C}_{106} \mathrm{H}_{263} \mathrm{O}_{110} \mathrm{~N}_{16} \mathrm{PS}$.

\subsubsection{Estequiometrias das semi-reações de redução}

Posteriormente, para plantear as semi-reações de produção de células e de doadores e aceptores de elétrons é preciso obter os coeficientes estequiométricos de reagentes e produtos. Cabe salientar que nesta pesquisa, com exceção da biomassa, todas as espécies consideradas nas semi-reações estão em solução aquosa ${ }^{3}$.

Para compostos orgânicos como acetil-CoA (intermediário metabólico) e células de bactérias e microalgas, a Reação 1 mostra a semi-reação de redução padrão na qual compostos inorgânicos de carbono, nitrogênio, fosforo e enxofre se transformam em um mol do composto orgânico e água. Nesta reação as fontes de nitrogênio e enxofre estão reduzidas.

${ }^{3}$ Battley (1960a) estimou discrepâncias nos balanços de energia de $48 \%$ para um crescimento anaeróbio e entre 1 a $8 \%$ para um crescimento aeróbio de leveduras quando não se usa o estado termodinâmico correto dos reagentes e produtos do metabolismo. 


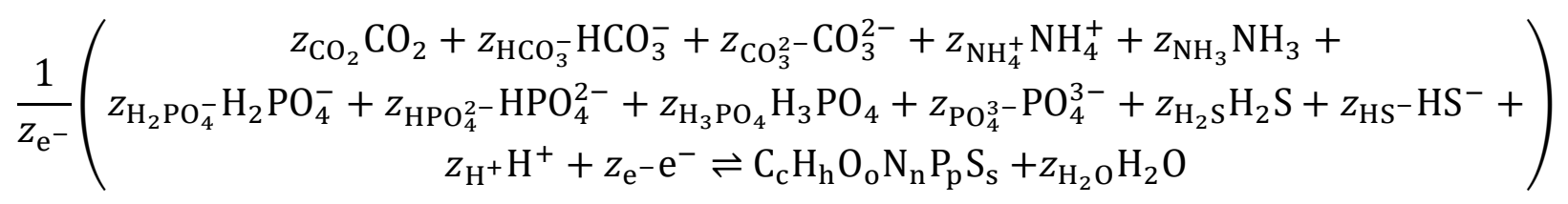

Reação 1

$\mathrm{Na}$ qual c, h, o, n, p e s são os mols de carbono, hidrogênio, oxigênio, nitrogênio, fosforo e enxofre, respetivamente, na molécula orgânica e $z_{i}$ é o coeficiente estequiométrico de reagentes ou produtos que, por balanceamento químico da reação, equivalem a: $z_{\mathrm{CO}_{2}}=$ $\mathrm{c} x_{\mathrm{CO}_{2}}, \quad z_{\mathrm{HCO}_{3}^{-}}=\mathrm{c} x_{\mathrm{HCO}_{3}^{-}}, \quad z_{\mathrm{CO}_{3}^{2-}}=\mathrm{c} x_{\mathrm{CO}_{3}^{2-}}, \quad Z_{\mathrm{NH}_{4}^{+}}=\mathrm{n} x_{\mathrm{NH}_{4}^{+}}, \quad Z_{\mathrm{NH}_{3}}=\mathrm{n} x_{\mathrm{NH}_{3}}, Z_{\mathrm{H}_{2} \mathrm{PO}_{4}^{-}}=$ $\mathrm{p} x_{\mathrm{H}_{2} \mathrm{PO}_{4}^{-}}, z_{\mathrm{HPO}_{4}^{2-}}=\mathrm{p} x_{\mathrm{HPO}_{4}^{2-}}, Z_{\mathrm{H}_{3} \mathrm{PO}_{4}}=\mathrm{p} x_{\mathrm{H}_{3} \mathrm{PO}_{4}}, Z_{\mathrm{PO}_{4}^{3-}}=\mathrm{p} x_{\mathrm{PO}_{4}^{3-}}, Z_{\mathrm{H}_{2} \mathrm{~S}}=\mathrm{s} x_{\mathrm{H}_{2} \mathrm{~S}}, z_{\mathrm{HS}^{-}}=$ $\mathrm{s} x_{\mathrm{HS}^{-}}$. Nestas equivalências, $x_{i}$ é a fração molar do componente $i$ (Seção 3.2.3)

O coeficiente estequiométrico d'água e do íon hidrogênio se obtêm por balanceamento dos átomos de oxigênio e hidrogênio, respetivamente: $z_{\mathrm{H}_{2} \mathrm{O}}=\left(2 z_{\mathrm{CO}_{2}}+3 z_{\mathrm{HCO}_{3}^{-}}+3 z_{\mathrm{CO}_{3}^{2-}}+\right.$ $\left.4 z_{\mathrm{H}_{2} \mathrm{PO}_{4}^{-}}+4 z_{\mathrm{HPO}_{4}^{2-}}+4 z_{\mathrm{H}_{3} \mathrm{PO}_{4}}+4 z_{\mathrm{PO}_{4}^{3-}}\right)-(\mathrm{o}), \quad z_{\mathrm{H}^{+}}=\left(\mathrm{h}+2 z_{\mathrm{H}_{2} \mathrm{O}}\right)-\left(z_{\mathrm{HCO}_{3}^{-}}+4 z_{\mathrm{NH}_{4}^{+}}+\right.$ $\left.3 z_{\mathrm{NH}_{3}}+2 z_{\mathrm{H}_{2} \mathrm{PO}_{4}^{-}}+z_{\mathrm{HPO}_{4}^{2-}}+3 z_{\mathrm{H}_{3} \mathrm{PO}_{4}}+2 z_{\mathrm{H}_{2} \mathrm{~S}}+z_{\mathrm{HS}^{-}}\right)$.

Para os elétrons, seu coeficiente estequiométrico divide as semi-reações para expressar toda a estequiometria por mol de elétrons transferidos e depende do grau de redução $\left(\gamma^{\circ}\right)$ das moléculas orgânicas e do número de carbonos na molécula (c): $z_{\mathrm{e}^{-}}=\mathrm{c} \gamma^{\circ}$.

Para determinar o grau de redução é preciso um estado de referência dos compostos inorgânicos que produzem a molécula orgânica. Neste caso, como apresenta a Reação 1, nos compostos inorgânicos o carbono e o fósforo estão em estados oxidados (i.e. carbono IV e fósforo $\mathrm{V}$ ) e o nitrogênio e o enxofre em estados reduzidos (i.e. nitrogênio -III e enxofre -II). Para oxigênio e hidrogênio o estado de referência é água (i.e. hidrogênio I e oxigênio -II). Assim, se calcula o grau de redução como apresenta a Equação 17:

$$
\gamma^{\circ}=\frac{4 c+h-2 o-3 n+5 p-2 s}{c}
$$

Por outro lado, caso o composto orgânico não contenha nitrogênio, fósforo e enxofre (e.g. glicose, etanol, ácido palmítico e metano), a Reação 1 se simplifica devido a que as distribuições de espécies de nitrogênio, fósforo e enxofre se desconsideram (Reação 2): 


$$
\frac{1}{z_{\mathrm{e}^{-}}}\left(z_{\mathrm{CO}_{2}} \mathrm{CO}_{2}+z_{\mathrm{HCO}_{3}^{-}} \mathrm{HCO}_{3}^{-}+z_{\mathrm{CO}_{3}^{2-}} \mathrm{CO}_{3}^{2-}+z_{\mathrm{H}^{+}} \mathrm{H}^{+}+z_{\mathrm{e}^{-}} \mathrm{e}^{-} \rightleftharpoons \mathrm{C}_{\mathrm{c}} \mathrm{H}_{\mathrm{h}} \mathrm{O}_{\mathrm{o}}+\mathrm{z}_{\mathrm{H}_{2} \mathrm{O}} \mathrm{H}_{2} \mathrm{O}\right)
$$

Reação 2

Os ácidos orgânicos considerados no modelo são monopróticos (e.g. fórmico, acético, propiônico, butírico, láctico e palmítico) e, portanto, a Reação 2 muda para considerar a distribuição das espécies ácida e iónica como apresenta a Reação 3. Uma exceção é o ácido palmítico que não ioniza significativamente, para o que aplica a Reação 2.

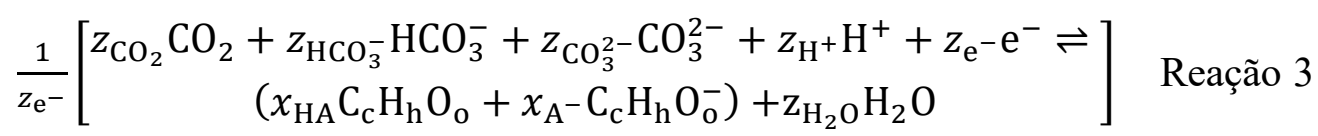

$\mathrm{Na}$ qual HA e $\mathrm{A}^{-}$simbolizam as espécies ácida e ionizada, respetivamente.

As equivalências dos coeficientes estequiométricos da Reação 1 aplicam para as Reações 2 e 3 .

As semi-reações de redução de oxigênio, nitrogênio, enxofre elementar e íon hidrogênio são mais simples de plantear devido a que não contêm compostos orgânicos nos produtos. Estas se apresentam nas Reações 4 a 7.

$$
\begin{aligned}
& \frac{1}{4}\left(\mathrm{O}_{2}+4 \mathrm{H}^{+}+4 \mathrm{e}^{-} \rightleftharpoons 2 \mathrm{H}_{2} \mathrm{O}\right) \\
& \text { Reação } 4 \\
& \frac{1}{6}\left(\mathrm{~N}_{2}+z_{\mathrm{H}^{+}} \mathrm{H}^{+}+6 \mathrm{e}^{-} \rightleftharpoons z_{\mathrm{NH}_{4}^{+}} \mathrm{NH}_{4}^{+}+z_{\mathrm{NH}_{3}} \mathrm{NH}_{3}\right) \quad \text { Reação } 5 \\
& \frac{1}{2}\left(\mathrm{~S}+z_{\mathrm{H}^{+}} \mathrm{H}^{+}+2 \mathrm{e}^{-} \rightleftharpoons z_{\mathrm{H}_{2} \mathrm{~S}} \mathrm{H}_{2} \mathrm{~S}+z_{\mathrm{HS}^{-}} \mathrm{HS}^{-}\right) \quad \text { Reação } 6 \\
& \begin{array}{ll}
\frac{1}{2}\left(2 \mathrm{H}^{+}+2 \mathrm{e}^{-} \rightleftharpoons \mathrm{H}_{2}\right) & \text { Reação } 7
\end{array}
\end{aligned}
$$

$\mathrm{Na}$ Reação 5, por balanceamento químico: $z_{\mathrm{NH}_{4}^{+}}=2 x_{\mathrm{NH}_{4}^{+}}, z_{\mathrm{NH}_{3}}=2 x_{\mathrm{NH}_{3}}, z_{\mathrm{H}^{+}}=$ $4 z_{\mathrm{NH}_{4}^{+}}+3 z_{\mathrm{NH}_{3}}$; enquanto na Reação 6: $z_{\mathrm{H}_{2} \mathrm{~S}}=x_{\mathrm{H}_{2} \mathrm{~S}}, z_{\mathrm{HS}^{-}}=x_{\mathrm{HS}^{-}}, z_{\mathrm{H}^{+}}=2 z_{\mathrm{H}_{2} \mathrm{~S}}+z_{\mathrm{HS}^{-}}$, com $x_{i}$ como a fração molar do componente $i$.

Nas semi-reações fotossintéticas, o número de mols de fótons que participam depende do processo. Nesta pesquisa, baseado nos resultados da fotossíntese oxigênica nos quais para 
o consumo de uma molécula de oxigênio (quatro mols de elétrons) precisam-se oito mols de fótons (Bolton \& Hall, 1991; Dubini \& Gonzalez-Ballester, 2016; Kok, 2011; Scott et al., 2010; Spilling \& Seppälä, 2012), se supõe que a transferência de um mol de elétrons por meio do sistema fotossintético oxigênico ou anoxigênico precisa de dois mols de fótons ${ }^{4}$. Assim, para a fotossíntese oxigênica, na qual o oxigênio é o aceptor de elétrons, com base na Reação 4 se obtém a Reação 8:

$$
\frac{1}{4}\left(\mathrm{O}_{2}+4 \mathrm{H}^{+}+4 \mathrm{e}^{-} \rightleftharpoons 8 \text { fótons }+2 \mathrm{H}_{2} \mathrm{O}\right) \quad \text { Reação } 8
$$

Para a fotossíntese anoxigênica, tanto enxofre elementar quanto ácido acético ou láctico podem ser aceptores de elétrons; portanto, com base nas Reações 3 e 6 se obtêm as Reações 9 e 10:

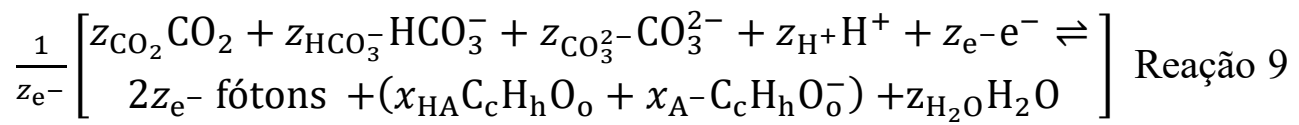

$$
\begin{aligned}
& \frac{1}{2}\left(\mathrm{~S}+z_{\mathrm{H}^{+}} \mathrm{H}^{+}+2 \mathrm{e}^{-} \rightleftharpoons 4 \text { fótons }+z_{\mathrm{H}_{2} \mathrm{~S}} \mathrm{H}_{2} \mathrm{~S}+z_{\mathrm{HS}^{-}} \mathrm{HS}^{-}\right) \quad \text { Reação } 10
\end{aligned}
$$

\subsubsection{Distribuição de espécies e frações molares}

Para determinar as frações molares necessárias para obter os coeficientes estequiométricos das semi-reações, devem-se considerar os equilíbrios ácido-base dos compostos orgânicos e inorgânicos (distribuição de espécies) como uma função do $\mathrm{pH}$.

Os compostos inorgânicos de carbono são produzidos por duas ionizações; na primeira ionização (Reação 11 e Equações 18 e 19):

$$
\mathrm{CO}_{2(\mathrm{aq})}+\mathrm{H}_{2} \mathrm{O}_{(\mathrm{l})} \stackrel{K_{A 1}}{\rightleftharpoons} \mathrm{H}_{(\mathrm{aq})}^{+}+\mathrm{HCO}_{3(\mathrm{aq})}^{-} \quad \text { Reação } 11
$$

${ }^{4}$ Sob esta consideração cabe salientar que os fótons considerados nesta pesquisa são os que efetivamente participam nas reações fotossintéticas e não todos os fótons que atingem as células e que compõem a radiação fotosinteticamente ativa (PAR, por suas siglas em inglês). 


$$
K_{A 1}=\frac{\left[\mathrm{H}^{+}\right]\left[\mathrm{HCO}_{3}^{-}\right]}{\left[\mathrm{CO}_{2}\right]}=4,47 \times 10^{-7}
$$

$$
\left[\mathrm{HCO}_{3}^{-}\right]=\frac{K_{A 1}\left[\mathrm{CO}_{2}\right]}{\left[\mathrm{H}^{+}\right]}
$$

Nas quais $K_{A i}$ é a constante ácida da ionização $i$ e [i] é a concentração molar do componente $i$. As constantes ácidas se obtêm de Haynes, Lide \& Bruno (2015) para $25{ }^{\circ} \mathrm{C}$ (Tabela 1).

Na segunda ionização (Reação 12 e Equações 20 e 21):

$$
\begin{gathered}
\mathrm{HCO}_{3(\mathrm{aq})}^{-} \stackrel{K_{A 2}}{\rightleftharpoons} \mathrm{H}_{(\mathrm{aq})}^{+}+\mathrm{CO}_{3(\mathrm{aq})}^{2-} \\
K_{A 2}=\frac{\left[\mathrm{H}^{+}\right]\left[\mathrm{CO}_{3}^{2-}\right]}{\left[\mathrm{HCO}_{3}^{-}\right]}=4,68 \times 10^{-11} \quad[20] \quad\left[\mathrm{CO}_{3}^{2-}\right]=\frac{K_{A 2}\left[\mathrm{HCO}_{3}^{-}\right]}{\left[\mathrm{H}^{+}\right]}
\end{gathered}
$$

Tabela 1. Valores da constante ácida e da constante de Henry a $25^{\circ} \mathrm{C}$ para diferentes componentes considerados no modelo biotermodinâmico.

\begin{tabular}{ccc}
\hline Composto & Constante ácida & $\begin{array}{c}\text { Constante de Henry } \\
\left(\mathrm{mol} \mathrm{L}^{-1} \mathrm{~atm}^{-1}\right)\end{array}$ \\
\hline Oxigênio $\left(\mathrm{O}_{2}\right)$ & - & $K_{H}=1,3 \times 10^{-3}$ \\
\hline Nitrogênio $\left(\mathrm{N}_{2}\right)$ & - & $K_{H}=6,5 \times 10^{-4}$ \\
\hline Hidrogênio $\left(\mathrm{H}_{2}\right)$ & - & $K_{H}=7,8 \times 10^{-4}$ \\
\hline Metano $\left(\mathrm{CH}_{4}\right)$ & - & $K_{H}=1,4 \times 10^{-3}$ \\
\hline Dióxido de carbono $\left(\mathrm{CO}_{2}\right)$ & $K_{A 1}=4,47 \times 10^{-7}$ & \multirow{2}{*}{$K_{H}=3,4 \times 10^{-2}$} \\
\cline { 2 - 3 } & $K_{A 2}=4,68 \times 10^{-11}$ & $K_{H}=1,0 \times 10^{-1}$ \\
\hline Ácido sulfídrico $\left(\mathrm{H}_{2} \mathrm{~S}\right)$ & $K_{A 1}=8,91 \times 10^{-8}$ & \\
\hline Amoníaco $\left(\mathrm{NH}_{3}\right)$ & $K_{A 2}=1,00 \times 10^{-19}$ & \\
\hline Íon amônia $\left(\mathrm{NH}_{4}{ }^{+}\right)$ & - & $K_{H}=5,8 \times 10^{1}$ \\
\hline Ácido fosfórico $\left(\mathrm{H}_{3} \mathrm{PO}_{4}\right)$ & $K_{A}=5,62 \times 10^{-10}$ & - \\
\cline { 2 - 3 } & $K_{A 1}=6,92 \times 10^{-3}$ & - \\
\hline Ácido fórmico & $K_{A 2}=6,17 \times 10^{-8}$ & - \\
\hline Ácido acético & $K_{A 3}=4,79 \times 10^{-13}$ & - \\
\hline Ácido propiônico & $K_{A}=1,78 \times 10^{-4}$ & - \\
\hline Ácido butírico & $K_{A}=1,75 \times 10^{-5}$ & \\
\hline Ácido láctico & $K_{A}=1,35 \times 10^{-5}$ & - \\
\hline & $K_{A}=1,48 \times 10^{-5}$ & \\
\hline
\end{tabular}

Como a concentração do íon hidrogênio $\left(\mathrm{H}^{+}\right)$é função do $\mathrm{pH}\left(\mathrm{pH}=-\log \left[\mathrm{H}^{+}\right]\right)$, as Equações 19 e 21 podem-se expressar em termos das frações molares e do pH (Equações 22 e 23): 


$$
x_{\mathrm{HCO}_{3}^{-}}=\frac{K_{A 1} x_{\mathrm{CO}_{2}}}{10^{-p H}} \quad[22] \quad x_{\mathrm{CO}_{3}^{2-}}=\frac{K_{A 2} x_{\mathrm{HCO}_{3}^{-}}}{10^{-p H}}
$$

A suma das espécies de carbono inorgânico é igual à unidade (Equação 24):

$$
x_{\mathrm{CO}_{2}}+x_{\mathrm{HCO}_{3}^{-}}+x_{\mathrm{CO}_{3}^{2-}}=1
$$

As Equações 22 a 24 constituem um sistema de três equações e três incógnitas. As Equações 25 a 27 apresentam os resultados:

$$
\begin{gathered}
x_{\mathrm{CO}_{2}}=\frac{1}{\left[1+\frac{K_{A 1}}{10^{-p H}}+\frac{K_{A 1} K_{A 2}}{\left(10^{-p H}\right)^{2}}\right]} \\
x_{\mathrm{HCO}_{3}^{-}}=x_{\mathrm{CO}_{2}} \frac{K_{A 1}}{10^{-p H}} \quad[26] \quad x_{\mathrm{CO}_{3}^{2-}}=x_{\mathrm{CO}_{2}} \frac{K_{A 1} K_{A 2}}{\left(10^{-p H}\right)^{2}}
\end{gathered}
$$

Para os compostos inorgânicos de nitrogênio (Reação 13 e Equações 28 a 30):

$$
\begin{array}{cc}
\mathrm{NH}_{4(\mathrm{aq})}^{+} \stackrel{K_{A}}{\rightleftharpoons} \mathrm{H}_{(\mathrm{aq})}^{+}+\mathrm{NH}_{3(\mathrm{aq})} & \text { Reação } 13 \\
K_{A}=\frac{\left[\mathrm{H}^{+}\right]\left[\mathrm{NH}_{3}\right]}{\left[\mathrm{NH}_{4}^{+}\right]}=5,62 \times 10^{-10} \quad[28] & \\
{\left[\mathrm{NH}_{3}\right]=\frac{K_{A}\left[\mathrm{NH}_{4}^{+}\right]}{\left[\mathrm{H}^{+}\right]}} & {[29] \quad \equiv \quad x_{\mathrm{NH}_{3}}=\frac{K_{A} x_{\mathrm{NH}_{4}^{+}}}{10^{-p H}} \quad[30]}
\end{array}
$$

A suma das espécies de nitrogênio inorgânico é igual à unidade (Equação 31):

$$
x_{\mathrm{NH}_{4}^{+}}+x_{\mathrm{NH}_{3}}=1
$$

As Equações 30 e 31 constituem um sistema de duas equações e duas incógnitas. As Equações 32 e 33 apresentam os resultados: 


$$
x_{\mathrm{NH}_{4}^{+}}=\frac{1}{\left(1+\frac{K_{A}}{10^{-p H}}\right)} \quad[32] \quad x_{\mathrm{NH}_{3}}=x_{\mathrm{NH}_{4}^{+}} \frac{K_{A}}{10^{-p H}} \equiv 1-x_{\mathrm{NH}_{4}^{+}}
$$

Os compostos inorgânicos de fósforo são produzidos por três ionizações; na primeira ionização (Reação 14 e Equações 34 a 36):

$$
\begin{array}{cc}
\mathrm{H}_{3} \mathrm{PO}_{4(\mathrm{aq})} \stackrel{K_{A 1}}{\rightleftharpoons} \mathrm{H}_{(\mathrm{aq})}^{+}+\mathrm{H}_{2} \mathrm{PO}_{4(\mathrm{aq})}^{-} & \text {Reação } 14 \\
K_{A 1}=\frac{\left[\mathrm{H}^{+}\right]\left[\mathrm{H}_{2} \mathrm{PO}_{4}^{-}\right]}{\left[\mathrm{H}_{3} \mathrm{PO}_{4}\right]}=6,92 \times 10^{-3} \\
{\left[\mathrm{H}_{2} \mathrm{PO}_{4}^{-}\right]=\frac{K_{A 1}\left[\mathrm{H}_{3} \mathrm{PO}_{4}\right]}{\left[\mathrm{H}^{+}\right]}} & {[35] \equiv x_{\mathrm{H}_{2} \mathrm{PO}_{4}^{-}}=\frac{K_{A 1} x_{\mathrm{H}_{3} \mathrm{PO}_{4}}}{10^{-p H}}}
\end{array}
$$

Na segunda ionização (Reação 15 e Equações 37 a 39):

$$
\begin{array}{ccc}
\mathrm{H}_{2} \mathrm{PO}_{4(\mathrm{aq})}^{-} \stackrel{K_{A 2}}{\rightleftharpoons} \mathrm{H}_{(\mathrm{aq})}^{+}+\mathrm{HPO}_{4(\mathrm{aq})}^{2-} & \text { Reação } 15 \\
K_{A 2}=\frac{\left[\mathrm{H}^{+}\right]\left[\mathrm{HPO}_{4}^{2-}\right]}{\left[\mathrm{H}_{2} \mathrm{PO}_{4}^{-}\right]}=6,17 \times 10^{-8} & {[37]} \\
{\left[\mathrm{HPO}_{4}^{2-}\right]=\frac{K_{A 2}\left[\mathrm{H}_{2} \mathrm{PO}_{4}^{-}\right]}{\left[\mathrm{H}^{+}\right]}} & {[38] \quad \equiv \quad x_{\mathrm{HPO}_{4}^{2-}}=\frac{K_{A 2} x_{\mathrm{H}_{2} \mathrm{PO}_{4}^{-}}}{10^{-p H}}}
\end{array}
$$

Na terceira ionização (Reação 16 e Equações 40 a 42):

$$
\begin{gathered}
\mathrm{HPO}_{4(\mathrm{aq})}^{2-} \stackrel{K_{A 3}}{\rightleftharpoons} \mathrm{H}_{(\mathrm{aq})}^{+}+\mathrm{PO}_{4(\mathrm{aq})}^{3-} \\
K_{A 3}=\frac{\left[\mathrm{H}^{+}\right]\left[\mathrm{PO}_{4}^{3-}\right]}{\left[\mathrm{HPO}_{4}^{-}\right]}=4,79 \times 10^{-13} \quad[40] \\
{\left[\mathrm{PO}_{4}^{3-}\right]=\frac{K_{A 3}\left[\mathrm{HPO}_{4}^{2-}\right]}{\left[\mathrm{H}^{+}\right]} \quad[41] \equiv x_{\mathrm{PO}_{4}^{3-}}=\frac{K_{A 3} x_{\mathrm{HPO}_{4}^{2-}}}{10^{-p H}}}
\end{gathered}
$$


A suma das espécies de fósforo inorgânico é igual à unidade (Equação 43):

$$
x_{\mathrm{H}_{3} \mathrm{PO}_{4}}+x_{\mathrm{H}_{2} \mathrm{PO}_{4}^{-}}+x_{\mathrm{HPO}_{4}^{2-}}+x_{\mathrm{PO}_{4}^{3-}}=1
$$

As Equações 36, 39, 42 e 43 constituem um sistema de quatro equações e quatro incógnitas. As Equações 44 a 47 apresentam os resultados:

$$
\begin{gathered}
x_{\mathrm{H}_{3} \mathrm{PO}_{4}}=\frac{1}{\left[1+\frac{K_{A 1}}{10^{-p H}}+\frac{K_{A 1} K_{A 2}}{\left(10^{-p H}\right)^{2}}+\frac{K_{A 1} K_{A 2} K_{A 3}}{\left(10^{-p H}\right)^{3}}\right]} \quad[44] \\
x_{\mathrm{H}_{2} \mathrm{PO}_{4}^{-}}=x_{\mathrm{H}_{3} \mathrm{PO}_{4}} \frac{K_{A 1}}{10^{-p H}} \quad[45] \quad x_{\mathrm{HPO}_{4}^{2-}}=x_{\mathrm{H}_{3} \mathrm{PO}_{4}} \frac{K_{A 1} K_{A 2}}{\left(10^{-p H}\right)^{2}} \\
x_{\mathrm{PO}_{4}^{3-}}=x_{\mathrm{H}_{3} \mathrm{PO}_{4}} \frac{K_{A 1} K_{A 2} K_{A 3}}{\left(10^{-p H}\right)^{3}}
\end{gathered}
$$

Os compostos inorgânicos de enxofre são produzidos por duas ionizações; na primeira ionização (Reação 17 e Equações 48 a 50):

$$
\begin{array}{cc}
\mathrm{H}_{2} \mathrm{~S}_{(\mathrm{aq})} \stackrel{K_{A 1}}{\rightleftharpoons} \mathrm{H}_{(\mathrm{aq})}^{+}+\mathrm{HS}_{(\mathrm{aq})}^{-} & \text {Reação } 17 \\
K_{A 1}=\frac{\left[\mathrm{H}^{+}\right]\left[\mathrm{HS}^{-}\right]}{\left[\mathrm{H}_{2} \mathrm{~S}\right]}=8,91 \times 10^{-8} & {[48]} \\
{\left[\mathrm{HS}^{-}\right]=\frac{K_{A 1}\left[\mathrm{H}_{2} \mathrm{~S}\right]}{\left[\mathrm{H}^{+}\right]}} & {[49] \quad \equiv \quad x_{\mathrm{HS}^{-}}=\frac{K_{A 1} x_{\mathrm{H}_{2} \mathrm{~S}}}{10^{-p H}}}
\end{array}
$$

Na segunda ionização (Reação 18 e Equação 51):

$$
\begin{gathered}
\mathrm{HS}_{(\mathrm{aq})}^{-} \stackrel{K_{A 2}}{\rightleftharpoons} \mathrm{H}_{(\mathrm{aq})}^{+}+\mathrm{S}_{(\mathrm{aq})}^{2-} \\
K_{A 2}=\frac{\left[\mathrm{H}^{+}\right]\left[\mathrm{S}^{2-}\right]}{\left[\mathrm{HS}^{-}\right]}=1,00 \times 10^{-19}
\end{gathered}
$$


O pequeno valor de $K_{A 2}$ indica que a concentração do íon sulfeto é muito próxima de zero no intervalo de pH ( 0 a 14$)$ e, portanto, esta segunda ionização é desconsiderada nos cálculos do modelo.

A suma das espécies de enxofre inorgânico é igual à unidade (Equação 52):

$$
x_{\mathrm{H}_{2} \mathrm{~S}}+x_{\mathrm{HS}^{-}}=1
$$

As Equações 50 e 52 constituem um sistema de duas equações e duas incógnitas. As Equações 53 e 54 apresentam os resultados:

$$
x_{\mathrm{H}_{2} \mathrm{~S}}=\frac{1}{\left(1+\frac{K_{A 1}}{10^{-p H}}\right)}
$$

$$
x_{\mathrm{HS}^{-}}=x_{\mathrm{H}_{2} \mathrm{~S}} \frac{K_{A 1}}{10^{-p H}} \equiv 1-x_{\mathrm{H}_{2} \mathrm{~S}}
$$

Por fim, para determinar as frações molares dos ácidos orgânicos monopróticos se precisa de uma única ionização (Reação 19 e Equações 55 a 57):

$$
\begin{gathered}
\mathrm{HA}_{(\mathrm{aq})} \stackrel{K_{A}}{\rightleftharpoons} \mathrm{H}_{(\mathrm{aq})}^{+}+\mathrm{A}_{(\mathrm{aq})}^{-} \\
K_{A}=\frac{\left[\mathrm{H}^{+}\right]\left[\mathrm{A}^{-}\right]}{[\mathrm{HA}]} \quad[55] \\
{\left[\mathrm{A}^{-}\right]=\frac{K_{A}[\mathrm{HA}]}{\left[\mathrm{H}^{+}\right]} \quad[56] \quad \equiv \quad x_{\mathrm{A}^{-}}=\frac{K_{A} x_{\mathrm{HA}}}{10^{-p H}}}
\end{gathered}
$$

A suma das espécies de ácido orgânico é igual à unidade (Equação 58):

$$
x_{\mathrm{HA}}+x_{\mathrm{A}^{-}}=1
$$

As Equações 57 e 58 constituem um sistema de duas equações e duas incógnitas. As Equações 59 e 60 apresentam os resultados:

$$
x_{\mathrm{HA}}=\frac{1}{\left(1+\frac{K_{A}}{10^{-p H}}\right)} \quad[59] \quad x_{\mathrm{A}^{-}}=x_{\mathrm{HA}} \frac{K_{A}}{10^{-p H}} \equiv 1-x_{\mathrm{HA}}
$$


Além de ser função do pH, as frações molares são função da temperatura devido à sua influência nas constantes de equilíbrio $(K)$ segundo a equação de van’t Hoff (Equação 61):

$$
\ln \left[\frac{K\left(T_{2}\right)}{K\left(T_{1}\right)}\right]=-\frac{\Delta_{r} H^{\circ}}{R}\left(\frac{1}{T_{2}}-\frac{1}{T_{1}}\right)
$$

$\mathrm{Na}$ qual $T_{1}$ é a temperatura padrão absoluta inicial $(298,15 \mathrm{~K}), T_{2}$ é a temperatura absoluta final, $R$ é a constante universal dos gases ideais e $\Delta_{r} H^{\circ}$ é a entalpia padrão de reação por equivalente de elétrons. A entalpia de reação se considera constante para o intervalo de variação da temperatura em processos biológicos (von Stockar et al., 1993) e sua determinação se realiza como apresenta a Seção 3.2.4.

\subsubsection{Cálculo de propriedades termodinâmicas (condições padrão)}

Em geral, o cálculo de entalpia padrão e energia livre padrão de reações se realiza com as Equações 62 e 63.

$$
\Delta_{r} H^{\circ}=\sum_{i=1}^{n} v_{i} z_{i} \Delta_{f} H_{i}^{\circ} \quad[62] \quad \Delta_{r} G^{\circ}=\sum_{i=1}^{n} v_{i} z_{i} \Delta_{f} G_{i}^{\circ}
$$

Nas quais $v_{i}$ é o sinal positivo para produtos e negativo para reagentes, $z_{i}$ é o coeficiente estequiométrico de reagentes ou produtos, $\Delta_{r} H^{\circ}$ é a entalpia de reação por equivalente de elétrons, $\Delta_{r} G^{\circ}$ é a energia livre de reação por equivalente de elétrons, $\Delta_{f} H^{\circ}$ é a entalpia de formação por mol e $\Delta_{f} G^{\circ}$ é a energia livre de formação por mol, todas em condições termodinâmicas padrão de temperatura e pressão $\left(25^{\circ} \mathrm{C}^{5}, 1 \mathrm{~atm}\right)$ e concentrações 1 mol L $\mathrm{L}^{-1}$ para todas as espécies em solução a diluição infinita (nesta pesquisa, se desconsideram os efeitos da forca iônica devido a que as soluções se consideram diluídas e, portanto, os coeficientes de atividade são iguais à unidade). As entalpias e energias livres padrão de formação das espécies se obtêm de Battley (2007), Haynes, Lide \& Bruno (2015), Heijnen (2013), Sawyer, McCarty \& Parkin (2003) e Wagman et al. (1982), como se

\footnotetext{
${ }^{5}$ Cabe anotar que o coeficiente estequiométrico $\left(z_{i}\right)$ pode variar com mudanças na temperatura (Seção 3.2.3) e, portanto, gerar variações nos valores de entalpia padrão de reação $\left(\Delta_{r} H^{\circ}\right)$ e energia livre padrão de reação $\left(\Delta_{r} G^{\circ}\right)$.
} 
apresenta na Tabela 2. Para espécies que não possuem dados nessas referencias (i.e. células de bactérias e microalgas ${ }^{6}$, acetil-CoA, propionato e ácido láctico) se usa o método baseado no grau de redução $\left(\gamma^{\circ}\right)$ para o cálculo de energia livre e entalpia padrão de combustão $\left(\Delta_{C} G^{\circ}\right.$ e $\Delta_{C} H^{\circ}$, respetivamente) de moléculas orgânicas proposto por Roels (1983) (von Stockar \& Liu, 1999) (Equações 64 e 65).

$$
-\Delta_{C} G^{\circ}=86,6+94,4 \gamma^{\circ} \quad[64] \quad \Delta_{C} H^{\circ}=-115 \gamma^{\circ}
$$

Nas quais $\Delta_{C} H^{\circ}$ é a entalpia de combustão por mol de carbono e $\Delta_{C} G^{\circ}$ é a energia livre de combustão por mol de carbono.

O grau de redução das moléculas orgânicas na combustão é diferente do grau de redução na síntese (Seção 3.2.2) devido a que muda o estado de referência. Na combustão, os estados de referência dos compostos inorgânicos produzidos são: carbono IV $\left(\mathrm{CO}_{2(\mathrm{~g})}\right)$, nitrogênio $0\left(\mathrm{~N}_{2(\mathrm{~g})}\right)$, fósforo $\mathrm{V}\left(\mathrm{PO}_{4}{ }^{3-}{ }_{(\mathrm{aq})}\right)$, enxofre IV $\left(\mathrm{SO}_{2(\mathrm{~g})}\right)$ e hidrogênio I e oxigênio -II $\left(\mathrm{H}_{2} \mathrm{O}_{(1)}\right)$. Assim, o grau de redução das moléculas orgânicas nas Equações 64 e 65 se determina como apresenta a Equação 66:

$$
\gamma^{\circ}=\frac{4 \mathrm{c}+\mathrm{h}-2 \mathrm{o}+5 \mathrm{p}+4 \mathrm{~s}}{\mathrm{c}}
$$

Para determinar a entalpia e energia livre padrão de formação a partir dos valores de combustão, a Reação 20 mostra a semi-reação de oxidação padrão na qual um mol do composto orgânico e água se transformam em compostos inorgânicos produtos da combustão.

$$
\begin{aligned}
& \frac{1}{Z_{\mathrm{e}^{-}}}\left[\begin{array}{c}
\mathrm{C}_{\mathrm{c}} \mathrm{H}_{\mathrm{h}} \mathrm{O}_{\mathrm{o}} \mathrm{N}_{\mathrm{n}} \mathrm{P}_{\mathrm{p}} \mathrm{S}_{\mathrm{s}}+(2 \mathrm{c}+4 \mathrm{p}+2 \mathrm{~s}-\mathrm{o}) \mathrm{H}_{2} \mathrm{O}_{(\mathrm{l})} \rightleftharpoons \mathrm{cCO}_{2(\mathrm{~g})}+\mathrm{n} / 2 \mathrm{~N}_{2(\mathrm{~g})}+ \\
\mathrm{pPO}_{4}^{3-}+\mathrm{sSO}_{2(\mathrm{~g})}+[2(2 \mathrm{c}+4 \mathrm{p}+2 \mathrm{~s}-\mathrm{o})+\mathrm{h}] \mathrm{H}^{+}+z_{\mathrm{e}^{-}} \mathrm{e}^{-}
\end{array}\right] \\
& \text {Reação } 20
\end{aligned}
$$

$\mathrm{Na}$ qual c, h, o, n, p e s são os mols de carbono, hidrogênio, oxigênio, nitrogênio, fosforo e enxofre, respetivamente, na molécula orgânica e $z_{e}$ - é o coeficiente estequiométrico dos elétrons que equivale, como apresentado anteriormente, $\mathrm{a}: z_{\mathrm{e}^{-}}=\mathrm{c} \gamma^{\circ}$.

\footnotetext{
${ }^{6}$ Ainda as células não sejam substâncias puras, as fórmulas empíricas permitem estimar suas propriedades termodinâmicas baseadas em equações que as relacionam com o grau de redução.
} 
Combinando a semi-reação de oxidação da molécula orgânica (Reação 20) com a semi-reação de redução do oxigênio (Reação 4), se obtém a reação global de combustão à que se aplicam as Equações 67 e 68 adaptadas a partir das Equações 62 e 63 para dar consistência dimensional.

$$
\Delta_{C} H^{\circ} \frac{\mathrm{c}}{z_{\mathrm{e}^{-}}}=\sum_{i=1}^{n} v_{i} z_{i} \Delta_{f} H_{i}^{\circ} \quad \text { [67] } \quad \Delta_{C} G^{\circ} \frac{\mathrm{c}}{z_{\mathrm{e}^{-}}}=\sum_{i=1}^{n} v_{i} z_{i} \Delta_{f} G_{i}^{\circ}
$$

Nas quais $v_{i}$ é o sinal positivo para produtos e negativo para reagentes, $z_{i}$ é o coeficiente estequiométrico de reagentes ou produtos, $z_{e}$ - é o coeficiente estequiométrico dos elétrons na semi-reação de oxidação (Reação 20), c são os mols de carbono na molécula orgânica, $\Delta_{C} H^{\circ}$ é a entalpia de combustão por mol de carbono, $\Delta_{C} G^{\circ}$ é a energia livre de combustão por mol de carbono, $\Delta_{f} H^{\circ}$ é a entalpia de formação por mol e $\Delta_{f} G^{\circ}$ é a energia livre de formação por mol, todas em condições termodinâmicas padrão de temperatura e pressão $\left(25^{\circ} \mathrm{C}, 1 \mathrm{~atm}\right)$ e concentrações $1 \mathrm{~mol} \mathrm{~L}^{-1}$ para todas as espécies em solução.

Com a reação global de combustão e os resultados das Equações 64 e 65, as únicas incógnitas nas Equações 67 e 68 são a entalpia de formação por mol $\left(\Delta_{f} H^{\circ}\right)$ e a energia livre de formação por mol $\left(\Delta_{f} G^{\circ}\right)$ da molécula orgânica. Os resultados se reportam na Tabela 2.

Tabela 2. Valores de propriedades em condições termodinâmicas padrão de temperatura e pressão $\left(25^{\circ} \mathrm{C}, 1 \mathrm{~atm}\right)$ e concentrações $1 \mathrm{~mol} \mathrm{~L}^{-1}$ para todas as espécies.

\begin{tabular}{cccc}
\hline Componente & Estado & $\Delta_{f} H^{\circ}\left(\mathrm{kJ} \mathrm{mol}^{-1}\right)$ & $\Delta_{f} G^{\circ}\left(\mathrm{kJ} \mathrm{mol}^{-1}\right)$ \\
\hline Hidrogênio $\left(\mathrm{H}_{2}\right)$ & $\mathrm{g}$ & 0 & 0 \\
\hline Hidrogênio $\left(\mathrm{H}_{2}\right)$ & $\mathrm{aq}$ & $-4,18$ & 17,57 \\
\hline Oxigênio $\left(\mathrm{O}_{2}\right)$ & $\mathrm{g}$ & 0 & 0 \\
\hline Oxigênio $\left(\mathrm{O}_{2}\right)$ & $\mathrm{aq}$ & $-11,71$ & 16,32 \\
\hline Nitrogênio $\left(\mathrm{N}_{2}\right)$ & $\mathrm{g}$ & 0 & 0 \\
\hline Nitrogênio $\left(\mathrm{N}_{2}\right)$ & $\mathrm{aq}$ & $-10,54$ & 18,07 \\
\hline Dióxido de carbono $\left(\mathrm{CO}_{2}\right)$ & $\mathrm{g}$ & $-393,5$ & $-394,4$ \\
\hline Dióxido de carbono $\left(\mathrm{CO}_{2}\right)$ & $\mathrm{aq}$ & $-412,92$ & $-386,23$ \\
\hline Íon carbonato $\left(\mathrm{CO}_{3}{ }^{2-}\right)$ & $\mathrm{aq}$ & $-677,1$ & $-527,8$ \\
\hline Ín bicarbonato $\left(\mathrm{HCO}_{3}{ }^{-}\right)$ & $\mathrm{aq}$ & $-692,0$ & $-586,8$ \\
\hline Amoníaco $\left(\mathrm{NH}_{3}\right)$ & $\mathrm{g}$ & $-45,9$ & $-16,4$ \\
\hline Amoníaco $\left(\mathrm{NH}_{3}\right)$ & $\mathrm{aq}$ & $-80,83$ & $-26,65$ \\
\hline Íon amônio $\left(\mathrm{NH}_{4}{ }^{+}\right)$ & $\mathrm{aq}$ & $-132,0$ & $-79,3$ \\
\hline Dióxido de enxofre $\left(\mathrm{SO}_{2}\right)$ & $\mathrm{g}$ & $-296,8$ & $-300,1$ \\
\hline Sulfeto de hidrogênio $\left(\mathrm{H}_{2} \mathrm{~S}\right)$ & $\mathrm{g}$ & $-20,6$ & $-33,4$ \\
\hline Ácido sulfídrico $\left(\mathrm{H}_{2} \mathrm{~S}\right)$ & $\mathrm{aq}$ & $-39,30$ & $-27,87$ \\
\hline Íon bissulfeto $\left(\mathrm{HS}^{-}\right)$ & $\mathrm{aq}$ & $-17,6$ & 12,1 \\
\hline
\end{tabular}


Tabela 2. Valores de propriedades em condições termodinâmicas padrão de temperatura e pressão $\left(25^{\circ} \mathrm{C}, 1 \mathrm{~atm}\right)$ e concentrações $1 \mathrm{~mol} \mathrm{~L}^{-1}$ para todas as espécies (continuação).

\begin{tabular}{|c|c|c|c|}
\hline Componente & Estado & $\Delta_{f} H^{\circ}\left(\mathrm{kJ} \mathrm{mol}^{-1}\right)$ & $\Delta_{f} G^{\circ}\left(\mathrm{kJ} \mathrm{mol}^{-1}\right)$ \\
\hline Íon sulfeto $\left(\mathrm{S}^{2-}\right)$ & $\mathrm{aq}$ & 33,1 & 85,8 \\
\hline Enxofre elementar $\left(\mathrm{S}^{0}\right)$ & $\mathrm{s}$ & 0 & 0 \\
\hline Ácido fosfórico $\left(\mathrm{H}_{3} \mathrm{PO}_{4}\right)$ & $\mathrm{aq}$ & $-1288,3$ & $-1142,6$ \\
\hline Íon diidrogenofosfato $\left(\mathrm{H}_{2} \mathrm{PO}_{4}^{-}\right)$ & $\mathrm{aq}$ & $-1296,3$ & $-1130,2$ \\
\hline Íon hidrogenofosfato $\left(\mathrm{HPO}_{4}{ }^{2-}\right)$ & $\mathrm{aq}$ & $-1292,1$ & $-1089,2$ \\
\hline Íon fosfato $\left(\mathrm{PO}_{4}{ }^{3-}\right)$ & $\mathrm{aq}$ & $-1277,4$ & $-1018,7$ \\
\hline Íon hidrogênio $\left(\mathrm{H}^{+}\right)$ & $\mathrm{aq}$ & 0 & 0 \\
\hline Água $\left(\mathrm{H}_{2} \mathrm{O}\right)$ & 1 & $-285,8$ & $-237,1$ \\
\hline Metano $\left(\mathrm{CH}_{4}\right)$ & $\mathrm{g}$ & $-74,6$ & $-50,5$ \\
\hline Metano $\left(\mathrm{CH}_{4}\right)$ & $\mathrm{aq}$ & $-89,04$ & $-34,33$ \\
\hline Ácido fórmico & $\mathrm{aq}$ & -410 & $-356,1$ \\
\hline Formiato $^{-}$ & $\mathrm{aq}$ & $-425,6$ & $-351,0$ \\
\hline Ácido acético & $\mathrm{aq}$ & $-488,4$ & $-399,6$ \\
\hline Acetato $^{-}$ & $\mathrm{aq}$ & $-486,0$ & $-369,3$ \\
\hline Ácido propiônico ${ }^{1}$ & 1 & $-510,7$ & $-390,0$ \\
\hline Propionato $^{-}$ & $\mathrm{aq}$ & $-508,9$ & $-361,0$ \\
\hline Ácido butírico ${ }^{1}$ & 1 & $-533,8$ & $-380,6$ \\
\hline Butirato $^{-}$ & $\mathrm{aq}$ & -535 & $-352,63$ \\
\hline Ácido láctico & $\mathrm{aq}$ & $-657,9$ & $-531,2$ \\
\hline Lactato $^{-}$ & $\mathrm{aq}$ & -687 & $-517,18$ \\
\hline Etanol & $\mathrm{aq}$ & $-287,02$ & $-180,96$ \\
\hline Glicose & $\mathrm{s}$ & $-1274,45$ & $-910,56$ \\
\hline Glicose & $\mathrm{aq}$ & $-1263,07$ & $-914,54$ \\
\hline Ácido palmítico ${ }^{1}$ & 1 & $-838,1$ & $-287,6$ \\
\hline Bactérias-Arqueias & $\mathrm{S}$ & $-322,9$ & $-201,4$ \\
\hline Algas & $\mathrm{s}$ & $-25699,2$ & $-19834,2$ \\
\hline Acetil-CoA & $\mathrm{aq}$ & $-4098,6$ & $-3017,6$ \\
\hline
\end{tabular}

${ }^{1}$ Valores para compostos em estado líquido usados no modelo devido a que a bibliografia não reporta valores para o estado aquoso.

Para aplicar as Equações 62 e 63 para o cálculo da energia livre padrão e entalpia padrão para reações fotossintéticas, deve-se determinar a entalpia padrão molar $\left(H^{\circ}\right)$ e a energia livre padrão molar $\left(G^{\circ}\right)$ para os fótons.

A partir da equação de Planck e considerando um mol de fótons em um sistema com pressão e volume constante se obtém a Equação 69.

$$
E_{f}(\lambda)=\frac{N_{A} h c}{\lambda}=H^{\circ}
$$

$\mathrm{Na}$ qual $E_{f}$ é a energia $(\mathrm{kJ})$ por mol de fótons na radiação solar que efetivamente 
participam nas reações fotossintéticas, $\lambda$ é o comprimento de onda $(\mathrm{m}), N_{A}$ é o número de Avogadro, $h$ é a constante de Planck e $c$ é a velocidade da luz. O comprimento de onda depende da máxima absorção do pigmento fotossintético de cada processo; para fotossíntese oxigênica com microalgas e cianobactérias $\lambda=680 \mathrm{~nm}$, para fotossíntese anoxigênica com bactérias verdes sulfurosas $\lambda=840 \mathrm{~nm}$ e com bactérias púrpuras sulfurosas e não sulfurosas $\lambda$ $=870$ nm (Albarrán-Zavala \& Angulo-Brown, 2007; Madigan et al., 2015).

Com a relação de Boltzmann, se aproxima a entropia padrão por mol de fótons $\left(S^{\circ}\right)$ na radiação solar ao valor na radiação de um corpo negro (Keller, 2013) pela Equação 70.

$$
S^{\circ}=\frac{4}{3} \frac{E_{f}(\lambda)}{T_{S}}=\frac{4}{3} \frac{N_{A} h c}{\lambda T_{S}}
$$

Na qual $T_{S}$ é a temperatura do Sol $(5778 \mathrm{~K})$.

Da definição termodinâmica de energia livre se obtém a energia livre padrão por mol de fótons $\left(G^{\circ}\right)$ na radiação solar com as Equações 69 e 70 (Equação 71).

$$
G^{\circ}=H^{\circ}-T S^{\circ}=\frac{N_{A} h c}{\lambda}-T\left(\frac{4}{3} \frac{N_{A} h c}{\lambda T_{S}}\right)=\frac{N_{A} h c}{\lambda}\left(1-\frac{4}{3} \frac{T}{T_{S}}\right)
$$

Na qual $T_{l}$ é a temperatura padrão absoluta do sistema fotossintético $(298,15 \mathrm{~K})$.

Com este procedimento se obtêm as semi-reações de produção de células e de doadores e aceptores de elétrons nos processos de digestão anaeróbia e fotossintéticos oxigênicos e anoxigênicos, apresentadas posteriormente na Tabela 3.

\subsection{Cálculo de energia livre (concentrações diferentes da padrão)}

Em reações organotróficas aeróbias e fototróficas, as diferenças entre a energia livre padrão $\left(\Delta_{r} G^{\circ}\right)$ e a energia livre de reação para concentrações diferentes da padrão $\left(\Delta_{r} G^{\circ}\right)$ costumam ser percentualmente pequenas dada a elevada liberação de energia contida no substrato, mas usualmente não é o caso em reações organotróficas anaeróbias (nas quais grande parte da energia do substrato fica contida nos produtos) nem em reações litotróficas, nas quais as diferenças porcentuais entre $\Delta_{r} G^{\circ}$ e $\Delta_{r} G^{\circ}$, são significativas (McCarty, 2007; Rittmann \& McCarty, 2001) e $\Delta_{r} G^{\circ}$ está próxima do equilíbrio (Kleerebezem \& van Loosdrecht, 2010). Nestes processos, para o cálculo da energia livre dissipada é importante 
considerar concentrações de ordem milimolar para espécies em solução devido a que são mais ajustadas à realidade dos sistemas biológicos que as concentrações do estado padrão (Battley, 2013). Nesta pesquisa se supõem concentrações dessa ordem para espécies em solução e pressões parciais de $10^{-3}$ atm para gases.

Assim, obtidas as semi-reações para os processos, se precisa dos valores da energia livre da reação para concentrações diferentes da padrão $\left(\Delta_{r} G^{\circ}\right)$ para aplicar o modelo biotermodinâmico. Para seu cálculo se usa a Equação 72:

$$
\Delta_{r} G^{\circ \prime}=\Delta_{r} G^{\circ}+R T \sum_{i=1}^{n} v_{i} z_{i} \ln [i]
$$

$\mathrm{Na}$ qual $\Delta_{r} G^{\circ}$ é a energia livre padrão de reação por equivalente de elétrons, $R$ é a constante universal dos gases ideais, $T$ é a temperatura absoluta do sistema, $v_{i}$ é o sinal positivo para produtos e negativo para reagentes, $z_{i}$ é o coeficiente estequiométrico de reagentes ou produtos e [i] é a concentração molar do componente $i^{7}$.

As concentrações molares dos componentes são valores de entrada no modelo e se determinam segundo o comportamento físico-químico da espécie. No modelo se classificam quatro comportamentos físico-químicos diferentes.

Primeiro, espécies gasosas com equilíbrio gasoso-aquoso, mas que não geram equilíbrio ácido-base [oxigênio $\left(\mathrm{O}_{2}\right)$, nitrogênio $\left(\mathrm{N}_{2}\right)$, hidrogênio $\left(\mathrm{H}_{2}\right)$ e metano $\left(\mathrm{CH}_{4}\right)$ ]. Para estes compostos, a concentração da espécie em solução é obtida da pressão parcial. As pressões parciais de hidrogênio e metano se supõem iguais a $10^{-3} \mathrm{~atm}$, enquanto as pressões parciais de oxigênio e nitrogênio se determinam a partir das frações molares no ar (0,21 e 0,78 respetivamente) e a pressão total suposta de 1 atm (Equações 73 e 74):

$$
p_{\mathrm{O}_{2}}=x_{\mathrm{O}_{2}} P=0,21 \mathrm{~atm}
$$

$$
p_{\mathrm{N}_{2}}=x_{\mathrm{N}_{2}} P=0,78 \mathrm{~atm}
$$

Nas quais $p_{i}$ e $x_{i}$ são a pressão parcial e a fração molar do componente $i$, respetivamente, e $P$ é a pressão total do sistema ( $1 \mathrm{~atm})$.

Com as pressões parciais dos gases se determinam as concentrações das espécies em solução aquosa usando a lei de Henry (Reação 21 e Equações 75 e 76):

\footnotetext{
${ }^{7}$ Para água como solvente a quantidade de matéria é 55,35 mols $\mathrm{L}^{-1}$.
} 


$$
\begin{array}{ccc}
\mathrm{A}_{(\mathrm{g})} \stackrel{K_{H}}{\rightleftharpoons} \mathrm{A}_{(\mathrm{aq})} & \text { Reação } 21 \\
K_{H}=\frac{[A]}{p_{\mathrm{A}}} & {[75] \quad[\mathrm{A}]=K_{H} p_{\mathrm{A}}} & {[76]}
\end{array}
$$

Nas quais A simboliza um composto em equilíbrio gasoso-aquoso, [i] é a concentração molar do componente $i$ e $K_{H}$ é a constante de Henry. O valor da constante de Henry para todos os gases a $25^{\circ} \mathrm{C}$ é obtido de Sander (1999) e se apresentam na Tabela 1.

Segundo, espécies gasosas com equilíbrio gasoso-aquoso que geram equilíbrio ácidobase [dióxido de carbono $\left(\mathrm{CO}_{2}\right)$ e sulfeto de hidrogênio $\left(\mathrm{H}_{2} \mathrm{~S}\right)$ ]. Para estes compostos, as pressões parciais se supõem iguais a $10^{-3}$ atm e a concentração da espécie em solução é obtida da pressão parcial com as Equações 77 e 78:

$$
\left[\mathrm{CO}_{2}\right]=K_{\mathrm{H}} p_{\mathrm{CO}_{2}} \quad[77] \quad\left[\mathrm{H}_{2} \mathrm{~S}\right]=K_{\mathrm{H}} p_{\mathrm{H}_{2} \mathrm{~S}} \quad[78]
$$

As Equações 26, 27 e 54 se modificam para expressá-las em termos das concentrações (Equações 79 a 81):

$$
\begin{gathered}
{\left[\mathrm{HCO}_{3}^{-}\right]=\left[\mathrm{CO}_{2}\right] \frac{K_{A 1}}{10^{-p H}} \quad[79] \quad\left[\mathrm{CO}_{3}^{2-}\right]=\left[\mathrm{CO}_{2}\right] \frac{K_{A 1} K_{A 2}}{\left(10^{-p H}\right)^{2}}} \\
{\left[\mathrm{HS}^{-}\right]=\left[\mathrm{H}_{2} \mathrm{~S}\right] \frac{K_{A 1}}{10^{-p H}}}
\end{gathered}
$$

Substituindo as Equações 77 ou 78 nas Equações 79 a 81 obtêm-se as equações para determinar as concentrações das outras espécies do equilíbrio ácido-base em solução a partir da pressão parcial do gás e do pH (Equações 82 a 84):

$$
\begin{gathered}
{\left[\mathrm{HCO}_{3}^{-}\right]=p_{\mathrm{CO}_{2}} \frac{K_{H} K_{A 1}}{10^{-p H}} \quad[82] \quad\left[\mathrm{CO}_{3}^{2-}\right]=p_{\mathrm{CO}_{2}} \frac{K_{H} K_{A 1} K_{A 2}}{\left(10^{-p H}\right)^{2}}} \\
{\left[\mathrm{HS}^{-}\right]=p_{\mathrm{H}_{2} \mathrm{~S}} \frac{K_{H} K_{A 1}}{10^{-p H}}}
\end{gathered}
$$


Terceiro, espécies aquosas que não geram equilíbrio gasoso-aquoso, mas que geram equilíbrio ácido-base [amoníaco $\left(\mathrm{NH}_{3}\right)^{8}$, ácido fosfórico $\left(\mathrm{H}_{3} \mathrm{PO}_{4}\right)$ e ácidos orgânicos monopróticos]. Para estes compostos, a concentração total das espécies em solução $\left(C_{\mathrm{T}}\right)$ se supõe igual a $10^{-3} \mathrm{M}$; portanto, a concentração de cada espécie se determina pela Equação 85 :

$$
[i]=\mathrm{C}_{T} x_{i}
$$

Nesta equação, as frações molares das espécies foram definidas antes para os diferentes compostos (Seção 3.2.3). Por exemplo, para os ácidos orgânicos monopróticos, substituindo as Equações 59 ou 60 na Equação 85 determinam-se as concentrações das espécies ácida e ionizada (Equações 86 e 87):

$$
\begin{gathered}
{[\mathrm{HA}]=\mathrm{C}_{T} x_{\mathrm{HA}}=\mathrm{C}_{T} \frac{1}{\left(1+\frac{K_{A}}{10^{-p H}}\right)}} \\
{\left[\mathrm{A}^{-}\right]=\mathrm{C}_{T} x_{\mathrm{A}^{-}}=\mathrm{C}_{T} x_{\mathrm{HA}} \frac{K_{A}}{10^{-p H}} \equiv \mathrm{C}_{T}-[\mathrm{HA}]}
\end{gathered}
$$

Quarto, espécies aquosas que não geram equilíbrio gasoso-aquoso nem ácido-base [glicose, ácido palmítico, etanol, enxofre (S), acetil-CoA e células de bactérias e microalgas]. Para estes compostos sua concentração se supõe igual a $10^{-3} \mathrm{M}$.

Cabe observar que, para os três primeiros comportamentos, a concentração molar da espécie é função da temperatura devido à influência dessa variável nas constantes de equilíbrio das reações ácido-base $\left(K_{A}\right)$ e nas constantes de Henry dos processos de solubilização-desolubilização de gases $\left(K_{H}\right)$, como apresenta a Equação 61.

Também a energia livre da reação para concentrações diferentes da padrão $\left(\Delta_{r} G^{\circ}\right)$ é função da temperatura segundo a equação de Gibbs-Helmholtz (Equação 88):

$$
\frac{\Delta_{r} G^{\circ \prime}\left(T_{2}\right)}{T_{2}}-\frac{\Delta_{r} G^{\circ \prime}\left(T_{1}\right)}{T_{1}}=\Delta_{r} H^{\circ}\left(\frac{1}{T_{2}}-\frac{1}{T_{1}}\right)
$$

\footnotetext{
${ }^{8} \mathrm{O}$ amoníaco não se considera como espécie gasosa no modelo dada sua elevada constante de Henry (Tabela 1).
} 
$\mathrm{Na}$ qual $T_{1}$ é a temperatura padrão absoluta inicial $(298,15 \mathrm{~K}), T_{2}$ é a temperatura absoluta final e $\Delta_{r} H^{\circ}$ é a entalpia padrão de reação por equivalente de elétrons (Seção 3.2.4).

As reações e equações apresentadas neste procedimento são levadas a Excel 2013 (Microsoft Corporation) para obter os valores de energia livre da reação apresentadas na Tabela 3, para concentrações diferentes da padrão $\left(\Delta_{r} G^{\circ}\right)$, e aplicar o modelo biotermodinâmico (Seção 3.1) para os processos de digestão anaeróbia (Capítulo 4) e fotossintéticos oxigênicos (Capítulo 5) e anoxigênicos (Capítulo 6) de recuperação de energia. Os resultados obtidos serão válidos desde a termodinâmica, independentemente de considerações cinéticas ou biológicas. 
Tabela 3. Semi-reações de redução para os processos de digestão anaeróbia e fotossintéticos oxigênicos e anoxigênicos $\left(25^{\circ} \mathrm{C}, 1 \mathrm{~atm}\right)$.

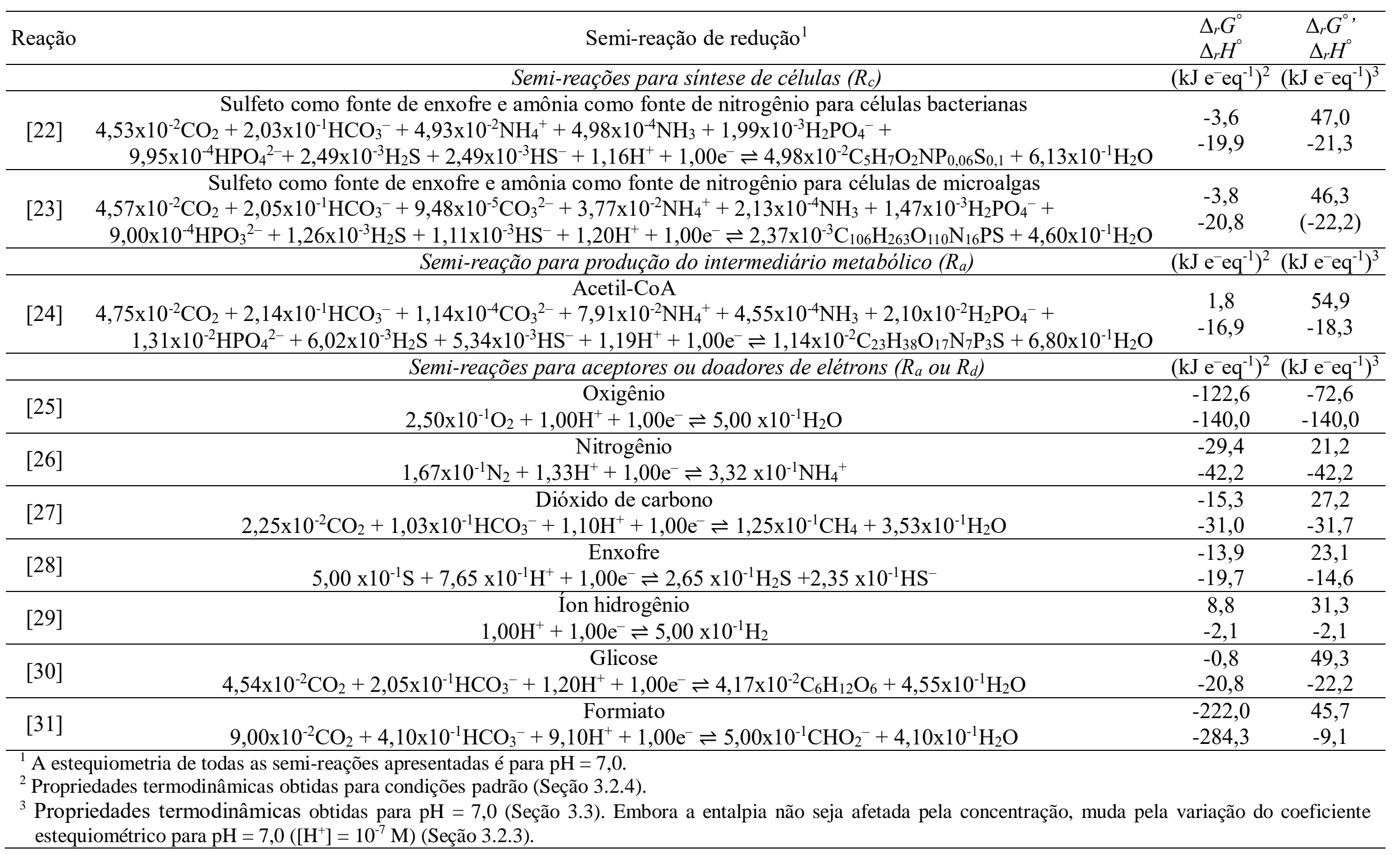


Tabela 3. Semi-reações de redução para os processos de digestão anaeróbia e fotossintéticos oxigênicos e anoxigênicos ( $25^{\circ} \mathrm{C}, 1$ atm) (continuação).

\begin{tabular}{|c|c|c|c|}
\hline Reação & Semi-reação de redução ${ }^{1}$ & $\begin{array}{l}\Delta_{r} G^{\circ} \\
\Delta_{r} H^{\circ}\end{array}$ & $\begin{array}{c}\Delta_{r} G^{\circ} \\
\Delta_{r} H^{\circ}\end{array}$ \\
\hline & Semi-reações para aceptores ou doadores de elétrons $\left(R_{a}\right.$ ou $\left.R_{d}\right)$ & $\left(\mathrm{kJ} \mathrm{e}^{-} \mathrm{eq}^{-1}\right)^{2}$ & $\left(\mathrm{~kJ} \mathrm{e}^{-} \mathrm{eq}^{-1}\right)^{3}$ \\
\hline \multirow[b]{2}{*}[32]{} & Acetato & $-71,9$ & 34,4 \\
\hline & $4,50 \times 10^{-2} \mathrm{CO}_{2}+2,05 \times 10^{-1} \mathrm{HCO}_{3}^{-}+1,09 \mathrm{H}^{+}+1,00 \mathrm{e}^{-} \rightleftharpoons 1,24 \times 10^{-1} \mathrm{C}_{2} \mathrm{H}_{3} \mathrm{O}_{2}{ }^{-}+1,25 \times 10^{-3} \mathrm{C}_{2} \mathrm{H}_{4} \mathrm{O}_{2}+4,58 \times 10^{-1} \mathrm{H}_{2} \mathrm{O}$ & $-100,7$ & $-31,1$ \\
\hline \multirow{2}{*}{ [33] } & Propionato & $-46,7$ & 34,9 \\
\hline & $3,93 \times 10^{-2} \mathrm{CO}_{2}+1,75 \times 10^{-1} \mathrm{HCO}_{3}^{-}+1,11 \mathrm{H}^{+}+1,00 \mathrm{e}^{-} \rightleftharpoons 7,07 \times 10^{-2} \mathrm{C}_{3} \mathrm{H}_{5} \mathrm{O}_{2}^{-}+7,14 \times 10^{-4} \mathrm{C}_{3} \mathrm{H}_{6} \mathrm{O}_{2}+4,62 \times 10^{-1} \mathrm{H}_{2} \mathrm{O}$ & $-70,5$ & $-31,1$ \\
\hline \multirow{2}{*}{ [34] } & Butirato & $-36,6$ & 35,1 \\
\hline & $3,65 \times 10^{-2} \mathrm{CO}_{2}+1,64 \times 10^{-1} \mathrm{HCO}_{3}{ }^{-}+1,12 \mathrm{H}^{+}+1,00 \mathrm{e}^{-} \rightleftharpoons 4,95 \times 10^{-2} \mathrm{C}_{4} \mathrm{H}_{7} \mathrm{O}_{2}{ }^{-}+5,00 \times 10^{-4} \mathrm{C}_{4} \mathrm{H}_{8} \mathrm{O}_{2}+4,65 \times 10^{-1} \mathrm{H}_{2} \mathrm{O}$ & $-58,4$ & $-31,3$ \\
\hline \multirow{2}{*}[35]{} & $\begin{array}{ll} & \text { Lactato } \\
\end{array}$ & $-66,3$ & 40,2 \\
\hline & $4,58 \times 10^{-2} \mathrm{CO}_{2}+2,04 \times 10^{-1} \mathrm{HCO}_{3}^{-}+1,12 \mathrm{H}^{+}+1,00 \mathrm{e}^{-} \rightleftharpoons 8,33 \times 10^{-2} \mathrm{C}_{3} \mathrm{H}_{5} \mathrm{O}_{3}{ }^{-}+4,54 \times 10^{-1} \mathrm{H}_{2} \mathrm{O}$ & $-94,5$ & $-26,8$ \\
\hline \multirow{2}{*}{ [36] } & Etanol & $-10,0$ & 36,6 \\
\hline & $3,00 \times 10^{-2} \mathrm{CO}_{2}+1,37 \times 10^{-1} \mathrm{HCO}_{3}^{-}+1,14 \mathrm{H}^{+}+1,00 \mathrm{e}^{-} \rightleftharpoons 8,33 \times 10^{-2} \mathrm{C}_{2} \mathrm{H}_{6} \mathrm{O}+3,87 \times 10^{-1} \mathrm{H}_{2} \mathrm{O}$ & $-26,5$ & $-27,5$ \\
\hline \multirow{2}{*}[37]{} & Ácido palmítico & $-13,3$ & 35,5 \\
\hline & $3,16 \times 10^{-2} \mathrm{CO}_{2}+1,42 \times 10^{-1} \mathrm{HCO}_{3}{ }^{-}+1,09 \times 10^{-4} \mathrm{CO}_{3}{ }^{2-}+1,14 \mathrm{H}^{+}+1,00 \mathrm{e}^{-} \rightleftharpoons 1,09 \times 10^{-2} \mathrm{C}_{16} \mathrm{H}_{32} \mathrm{O}_{2}+4,68 \times 10^{-1} \mathrm{H}_{2} \mathrm{O}$ & $-30,5$ & $-31,5$ \\
\hline \multirow{3}{*}{ [38] } & Semi-reações para doador de elétrons em processos fotossintéticos $\left(R_{d}\right)$ & $\left(\mathrm{kJ} \mathrm{e}^{-} \mathrm{eq}^{-1}\right)^{2}$ & $\left(\mathrm{~kJ} \mathrm{e}^{-} \mathrm{eq}^{-1}\right)^{3}$ \\
\hline & Oxigênio $(\lambda=680 \mathrm{~nm})$ & 205,0 & 255,0 \\
\hline & $2,50 \times 10^{-1} \mathrm{O}_{2}+1,00 \mathrm{H}^{+}+1,00 \mathrm{e}^{-} \rightleftharpoons 2,00$ fótons $+5,00 \times 10^{-1} \mathrm{H}_{2} \mathrm{O}$ & 211,9 & 211,9 \\
\hline \multirow[b]{2}{*}{ [39] } & Enxofre $(\lambda=840 \mathrm{~nm})$ & 251,3 & 288,3 \\
\hline & $5,00 \times 10^{-1} \mathrm{~S}+7,65 \times 10^{-1} \mathrm{H}^{+}+1,00 \mathrm{e}^{-} \rightleftharpoons 2,00$ fótons $+2,65 \times 10^{-1} \mathrm{H}_{2} \mathrm{~S}+2,35 \times 10^{-1} \mathrm{HS}^{-}$ & 265,2 & 270,3 \\
\hline \multirow[b]{2}{*}[40]{} & Enxofre $(\lambda=870 \mathrm{~nm})$ & 242,1 & 279,2 \\
\hline & $5,00 \times 10^{-1} \mathrm{~S}+7,65 \times 10^{-1} \mathrm{H}^{+}+1,00 \mathrm{e}^{-} \rightleftharpoons 2,00$ fótons $+2,65 \times 10^{-1} \mathrm{H}_{2} \mathrm{~S}+2,35 \times 10^{-1} \mathrm{HS}^{-}$ & 255,3 & 260,4 \\
\hline \multirow[b]{2}{*}{ [41] } & Acetato $(\lambda=870 \mathrm{~nm})$ & 184,1 & 290,5 \\
\hline & $\begin{array}{r}4,50 \times 10^{-2} \mathrm{CO}_{2}+2,05 \times 10^{-1} \mathrm{HCO}_{3}^{-}+1,09 \mathrm{H}^{+}+1,00 \mathrm{e}^{-} \rightleftharpoons \\
2,00 \text { fótons }+1,24 \times 10^{-1} \mathrm{C}_{2} \mathrm{H}_{3} \mathrm{O}_{2}^{-}+1,25 \times 10^{-3} \mathrm{C}_{2} \mathrm{H}_{4} \mathrm{O}_{2}+4,58 \times 10^{-1} \mathrm{H}_{2} \mathrm{O}\end{array}$ & $\begin{array}{l}104,1 \\
174,3\end{array}$ & 243,9 \\
\hline \multirow[b]{2}{*}{ [42] } & Lactato $(\lambda=870 \mathrm{~nm})$ & 189,8 & 296,3 \\
\hline & $4,58 \times 10^{-2} \mathrm{CO}_{2}+2,04 \times 10^{-1} \mathrm{HCO}_{3}^{-}+1,12 \mathrm{H}^{+}+1,00 \mathrm{e}^{-} \rightleftharpoons 2,00$ fótons $+8,33 \times 10^{-2} \mathrm{C}_{3} \mathrm{H}_{5} \mathrm{O}_{3}^{-}+4,54 \times 10^{-1} \mathrm{H}_{2} \mathrm{O}$ & 180,5 & 248,2 \\
\hline \multicolumn{4}{|c|}{$\begin{array}{l}{ }_{1}^{1} \text { A estequiometria de todas as semi-reações apresentadas é para } \mathrm{pH}=7,0 . \\
2 \text { Propriedades termodinâmicas obtidas para condições padrão (Seção 3.2.4). } \\
{ }^{3} \text { Propriedades termodinâmicas obtidas para } \mathrm{pH}=7,0(\text { Seção 3.3). Embora a entalpia não seja afetada pela concentração, muda pela variação do coeficiente } \\
\text { estequiométrico para } \mathrm{pH}=7,0\left(\left[\mathrm{H}^{+}\right]=10^{-7} \mathrm{M}\right)(\text { Seção 3.2.3). }\end{array}$} \\
\hline
\end{tabular}




\section{DIGESTÃO ANAERÓBIA}

\subsection{Metabolismo}

A digestão anaeróbia é um processo de transformação da matéria orgânica de duas etapas, realizado por diferentes populações de microorganismos com funções especializadas (Bitton, 2005; Chernicharo, 2007). Na primeira etapa, um grupo de bactérias anaeróbias facultativas e anaeróbias estritas convertem, por hidrolise e fermentação, os compostos orgânicos complexos em materiais orgânicos simples, principalmente ácidos graxos voláteis $(\mathrm{AGV})$, e em dióxido de carbono $\left(\mathrm{CO}_{2}, \mathrm{HCO}_{3}{ }^{-}, \mathrm{CO}_{3}{ }^{2-}\right)$ e hidrogênio $\left(\mathrm{H}_{2}\right)$ (Chernicharo, 2007), produzindo energia química (ATP) essencialmente por fosforilação a nível de substrato (Madigan et al., 2015). Na segunda etapa, arqueias metanogênicas estritamente anaeróbias convertem os ácidos graxos e o hidrogênio em dióxido de carbono e metano $\left(\mathrm{CH}_{4}\right)$ produzindo energia química (ATP) por fosforilação oxidativa. Entre os dois grupos de microorganismos se estabelece uma relação sintrófica (Bitton, 2005): as arqueias metanogênicas dependem dos ácidos graxos produzidos pelas bactérias fermentativas e estas últimas dependem do consumo do hidrogênio das arqueias para diminuir sua pressão parcial permitindo que o metabolismo continue termodinamicamente viável (Chernicharo, 2007).

As duas etapas da digestão anaeróbia podem-se subdividir em três processos metabólicos diferenciados com a participação de diferentes grupos de microorganismos (Chernicharo, 2007) como se descreve a continuação.

\subsubsection{Bioquímica do metabolismo acidogênico}

Incialmente, os compostos orgânicos complexos (carboidratos, lipídeos e proteínas) se hidrolisam por exoenzimas em compostos orgânicos simples (monossacarídeos, ácidos graxos, glicerol e aminoácidos) que podem penetrar a membrana celular das bactérias fermentativas (Bitton, 2005; Chernicharo, 2007). Esses substratos fermentáveis se catabolizam em um metabolismo quimioorganotrófico produzindo substâncias reduzidas para atingir o balanço redox (Madigan et al., 2015) por meio de uma primeira fermentação denominada acidogênese. Os produtos excretados pelas células são ácidos orgânicos (acético, láctico, butírico, propiônico, fórmico, entre outros), álcoois (etanol, butanol, metanol, glicerol, isopropanol, propanol), cetonas (acetona), dióxido de carbono $\left(\mathrm{CO}_{2}, \mathrm{HCO}_{3}{ }^{-}, \mathrm{CO}_{3}{ }^{2-}\right)$, 
hidrogênio $\left(\mathrm{H}_{2}\right)$, amoníaco $\left(\mathrm{NH}_{3}, \mathrm{NH}_{4}^{+}\right)$, sulfeto $\left(\mathrm{H}_{2} \mathrm{~S}, \mathrm{HS}^{-}\right)$e novas células bacterianas (Bitton, 2005; Chernicharo, 2007). A acidogênese se realiza por um grupo amplo e diverso de bactérias anaeróbias facultativas e anaeróbias estritas usualmente pertencentes ao gênero Clostridium (Chernicharo, 2007), mas que abrange outros gêneros como Acetobacterium, Lactobacillus, Leuconostoc, Propionibacterium e Streptococcus (Madigan et al., 2015),

Os processos acidogênicos mais comuns envolvem a produção de butirato, lactato, propionato, acetato e etanol a partir da glicose.

O butirato é o principal produto da fermentação em algumas espécies do gênero Clostridium (Madigan et al., 2015). Inicialmente a glicose é convertida em piruvato pela glicólise, na qual se geram poder redutor (NADH) e energia química (ATP) por fosforilação a nível de substrato. Posteriormente, o piruvato é transformado em acetil-CoA e dióxido de carbono como subproduto na descarboxilação oxidativa. Nesta reação redox, pela conversão de cada piruvato, se produzem dois elétrons que passam à ferredoxina diretamente ou indiretamente por meio do NADH, e produzem hidrogênio $\left(\mathrm{H}_{2}\right)$ por meio de uma hidrogenase bidirecional (Valdez-Vazquez \& Poggi-Varaldo, 2009) que catalisa a Reação 43:

$$
2 \mathrm{H}^{+}+2 \mathrm{Fd}_{\mathrm{RED}} \rightleftharpoons \mathrm{H}_{2}+2 \mathrm{Fd}_{\mathrm{OX}} \quad \text { Reação } 43
$$

Dentre todos os produtores de hidrogênio, as hidrogenases são um grupo generalizado de enzimas oxidorreductases que produzem hidrogênio $\left(\mathrm{H}_{2}\right)$ como um mecanismo de eliminação do excesso de elétrons no metabolismo (Boichenko, Greenbaum \& Seibert, 2004). As hidrogenases presentes em bactérias anaeróbias e arqueias são inibidas pela presença de oxigênio $\left(\mathrm{O}_{2}\right)$ ou por elevadas concentrações de hidrogênio $\left(\mathrm{H}_{2}\right)$ (Dasgupta et al., 2010; Valdez-Vazquez \& Poggi-Varaldo, 2009).

Como esta, fermentação, algumas outras produzem hidrogênio $\left(\mathrm{H}_{2}\right)$ para facilitar o balanço redox do processo metabólico (Madigan et al., 2015). Por fim, a acetil-CoA é transformada em butirato com a geração de energia química adicional pela fosforilação a nível de substrato e consumindo o poder redutor produzido na glicólise. A fermentação de glicose a butirato é apresentada na Figura 2.

Espécies do gênero Streptococcus e alguns Lactobacillus produzem lactato como único produto da fermentação (fermentação homoláctica), enquanto espécies do gênero Leuconostoc e alguns Lactobacillus produzem lactato e outros produtos, principalmente etanol (fermentação heteroláctica) (Madigan et al., 2015). Na fermentação homoláctica, inicialmente a glicose é convertida em piruvato pela glicólise e se produzem energia química 
(ATP), por fosforilação a nível de substrato, e poder redutor (NADH); este último é consumido posteriormente durante a transformação do piruvato em lactato. $\mathrm{Na}$ fermentação heteroláctica, inicialmente a glicose é transformada em pentose fosfato e dióxido de carbono, com produção de poder redutor $(\mathrm{NADH})$ e consumo de energia química (ATP). A partir da pentose fosfato se produzem acetilfosfato e triose fosfato. A triose fosfato forma posteriormente piruvato com geração de poder redutor (NADH) e energia química (ATP) por fosforilação a nível de substrato. Finalmente, o piruvato é convertido em lactato com o consumo do poder redutor produzido na reação anterior. Nestas reações, a redução do acetilfosfato a etanol usa o poder redutor produzido na formação da pentose fosfato para atingir o balanço redox (Madigan et al., 2015). Ambos os processos se apresentam na Figura 3.

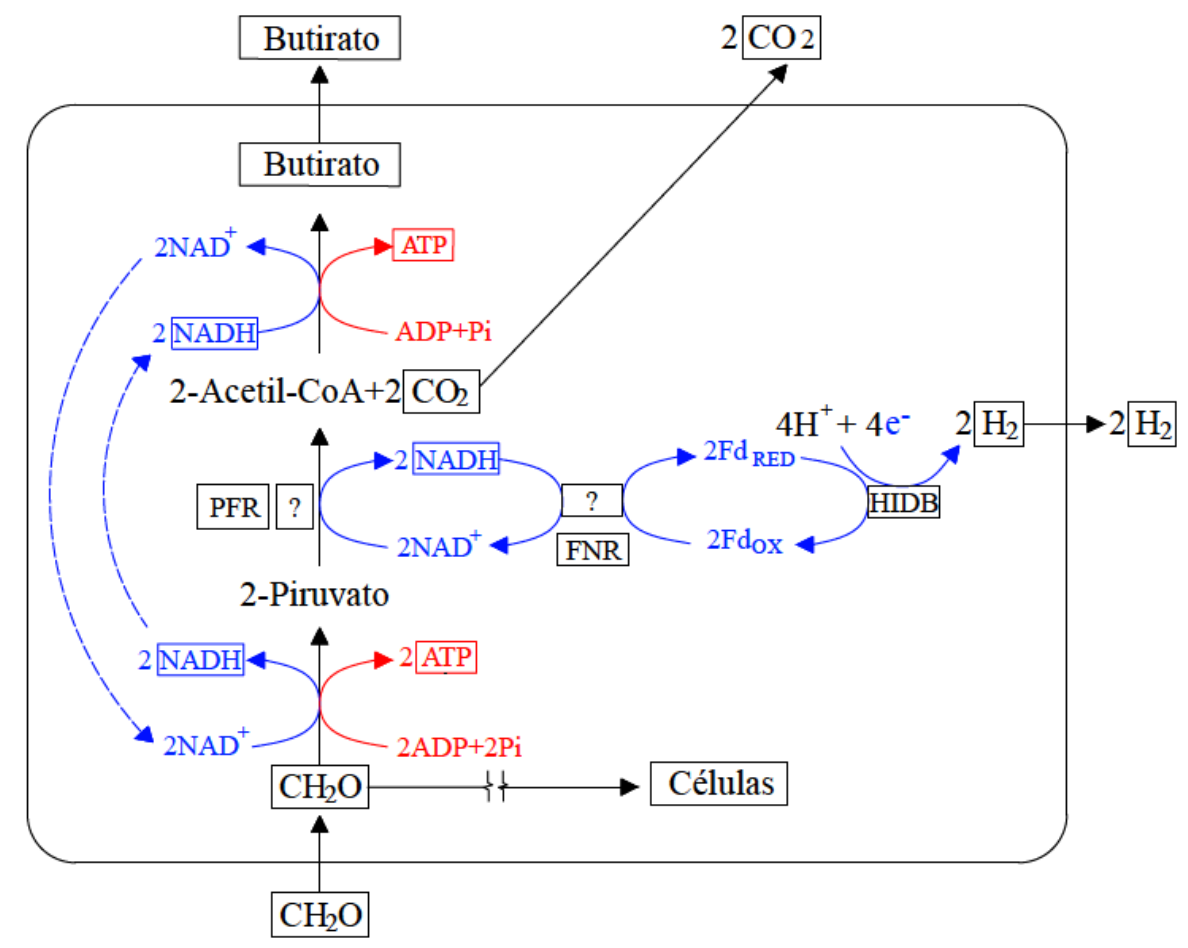

Figura 2. Fermentação de glicose para produção de butirato.

Se a enzima PFR atua no processo, a transferência de elétrons pode ser direta à ferredoxina. Se essa transferência se realiza por meio do NADH, a enzima FNR ou uma similar deve estar presente na transferência de elétrons do NADH à ferredoxina. A figura detalha o processo catabólico. No processo anabólico de, por exemplo, a formação de novas células, se produz um intermediário energético como acetil-CoA. NADH e $\mathrm{NAD}^{+}$: Forma reduzida e oxidada, respetivamente, da nicotinamida adenina dinucleótido. $\mathrm{Fd}_{\mathrm{RED}}$ e Fdox: Forma reduzida e oxidada, respetivamente, da ferredoxina. PFR: Piruvato ferredoxina oxidorredutase. FNR: Ferredoxina NAD(P) ${ }^{+}$redutase. HIDB: Hidrogenase bidirecional. 

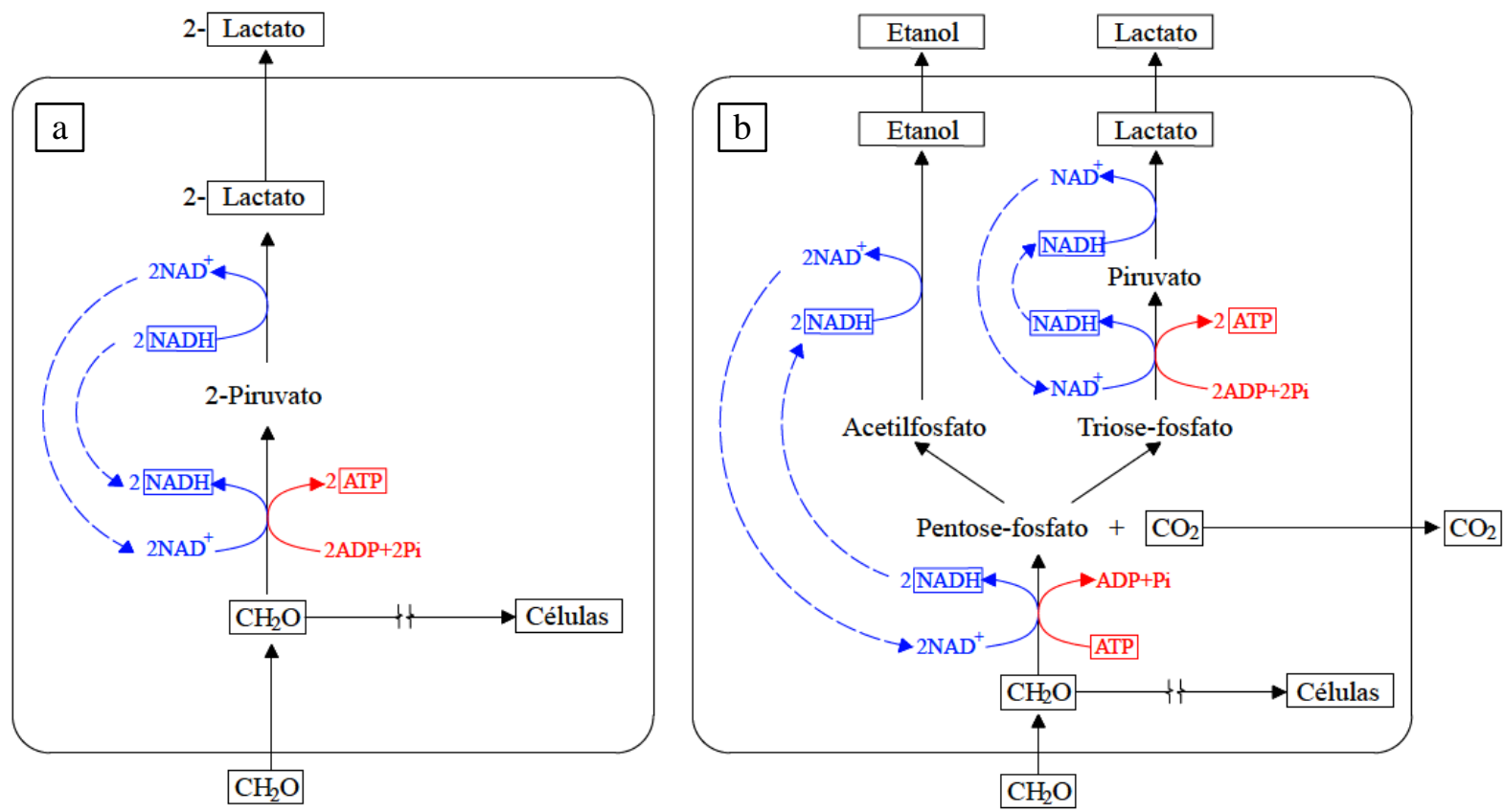

Figura 3. Fermentação de glicose para produção de lactato.

a) Fermentação homoláctica com duas moléculas de lactato a partir de uma molécula de glicose. b) Fermentação heteroláctica com uma molécula de lactato e uma de etanol a partir de uma molécula de glicose. A figura detalha o processo catabólico. No processo anabólico de, por exemplo, a formação de novas células, se produz um intermediário energético como acetil-CoA.

Por outro lado, para complementar os processos acidogênicos mais comuns a partir de glicose, alguns gêneros como Acetobacterium produzem acetato com glicose como substrato. A glicose, como em outros metabolismos, é convertida em piruvato pela glicólise, na qual se geram poder redutor (NADH) e energia química (ATP) por fosforilação a nível de substrato. Posteriormente o piruvato é transformado em acetil-CoA e dióxido de carbono como subproduto na descarboxilação oxidativa, e, por fim a acetil-CoA é transformada em acetato. Nestas últimas transformações se geram poder redutor e energia química adicionais; a última, pela fosforilação a nível de substrato. Para atingir o balanço redox, o poder redutor gerado no processo global pode-se usar por uma hidrogenase bidirecional para produzir hidrogênio $\left(\mathrm{H}_{2}\right)$ por meio da ferredoxina (Reação 43). A produção de acetato a partir da glicose é apresentada na Figura 4.

Finalmente, espécies do gênero Propionibacterium e alguns Clostridium produzem propionato como principal produto da fermentação de glicose (fermentação primária) ou, essencialmente, de lactato (fermentação secundária) (Madigan et al., 2015). Quando a glicose é o substrato, primeiro é catabolizado pela glicólise até piruvato; mesmo produto inicial quando o substrato é o lactato (Madigan et al., 2015). O piruvato posteriormente é 
transformado em dióxido de carbono e acetil-CoA (descarboxilação oxidativa) ou propionilCoA, que finalmente se convertem em acetato e propionato, respetivamente. Na produção de acetato se produz poder redutor (NADH) e energia química (ATP) por fosforilação a nível de substrato, enquanto na transformação em propionato é consumido o poder redutor gerado nas transformações anteriores, atingindo o balanço redox, e é produzida energia química, mas, neste caso, por fosforilação oxidativa a partir da força próton-motriz. Poder redutor para produzir propionato pode também se obter pela oxidação de hidrogênio $\left(\mathrm{H}_{2}\right)$ por meio de uma hidrogenase bidirecional (Valdez-Vazquez \& Poggi-Varaldo, 2009), por meio da ferredoxina, pela reação inversa da Reação 43. Estes processos fermentativos de produção de propionato são apresentados na Figura 5.

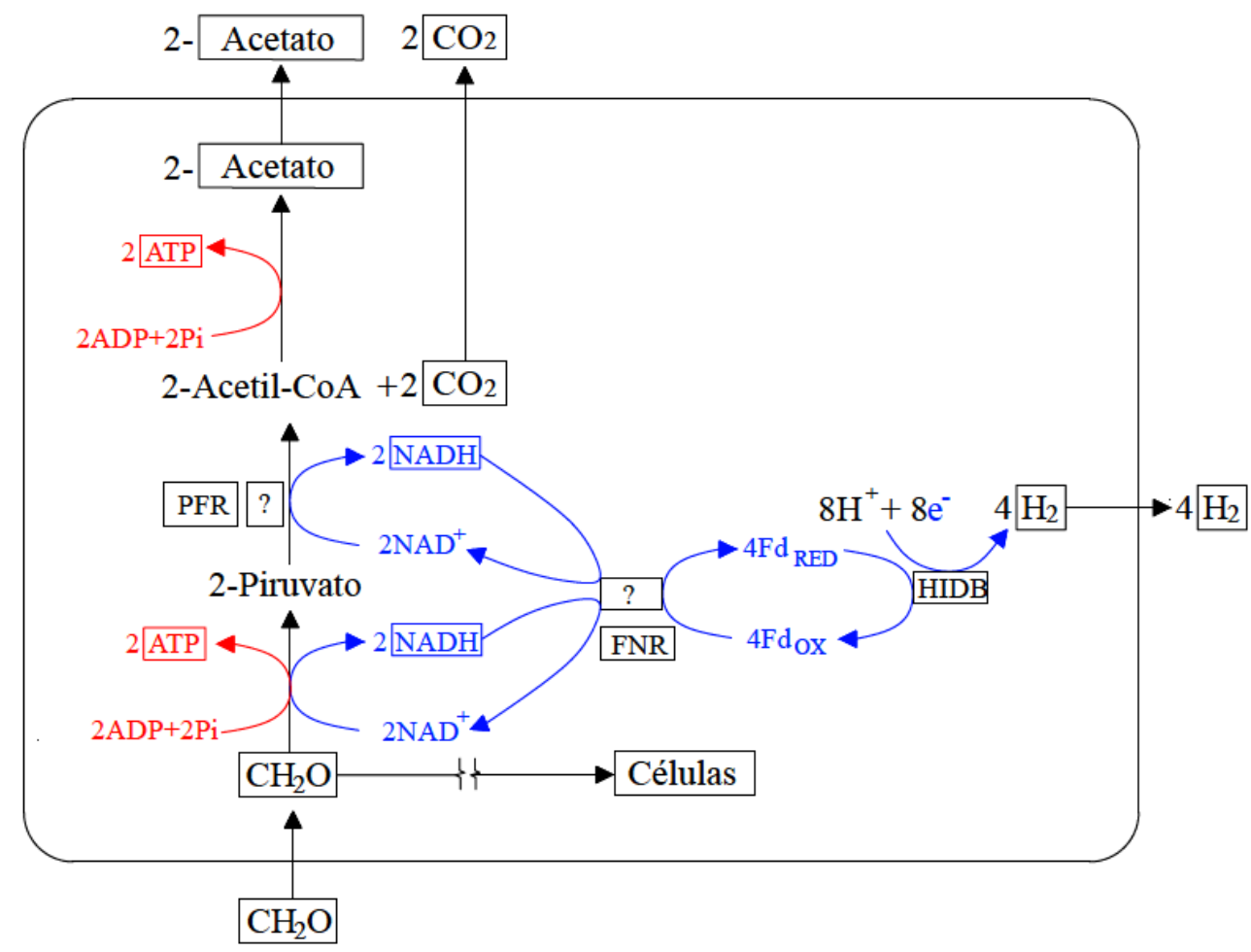

Figura 4. Fermentação de glicose para produção de acetato (fermentação homoacética).

São produzidas duas moléculas de acetato e quatro de hidrogênio por molécula de glicose. Este rendimento é o máximo teórico, mas por processos catabólicos desconsiderando os processos anabólicos. Se a enzima PFR atua no processo, a transferência de elétrons pode ser direta à ferredoxina. Se essa transferência se realiza por meio do NADH, a enzima FNR ou uma similar deve estar presente na transferência de elétrons do NADH à ferredoxina. A figura detalha o processo catabólico. No processo anabólico de, por exemplo, a formação de novas células, se produz um intermediário energético como acetil-CoA. PFR: Piruvato ferredoxina oxidorredutase. FNR: Ferredoxina $\mathrm{NAD}(\mathrm{P})^{+}$redutase. HIDB: Hidrogenase bidirecional. 

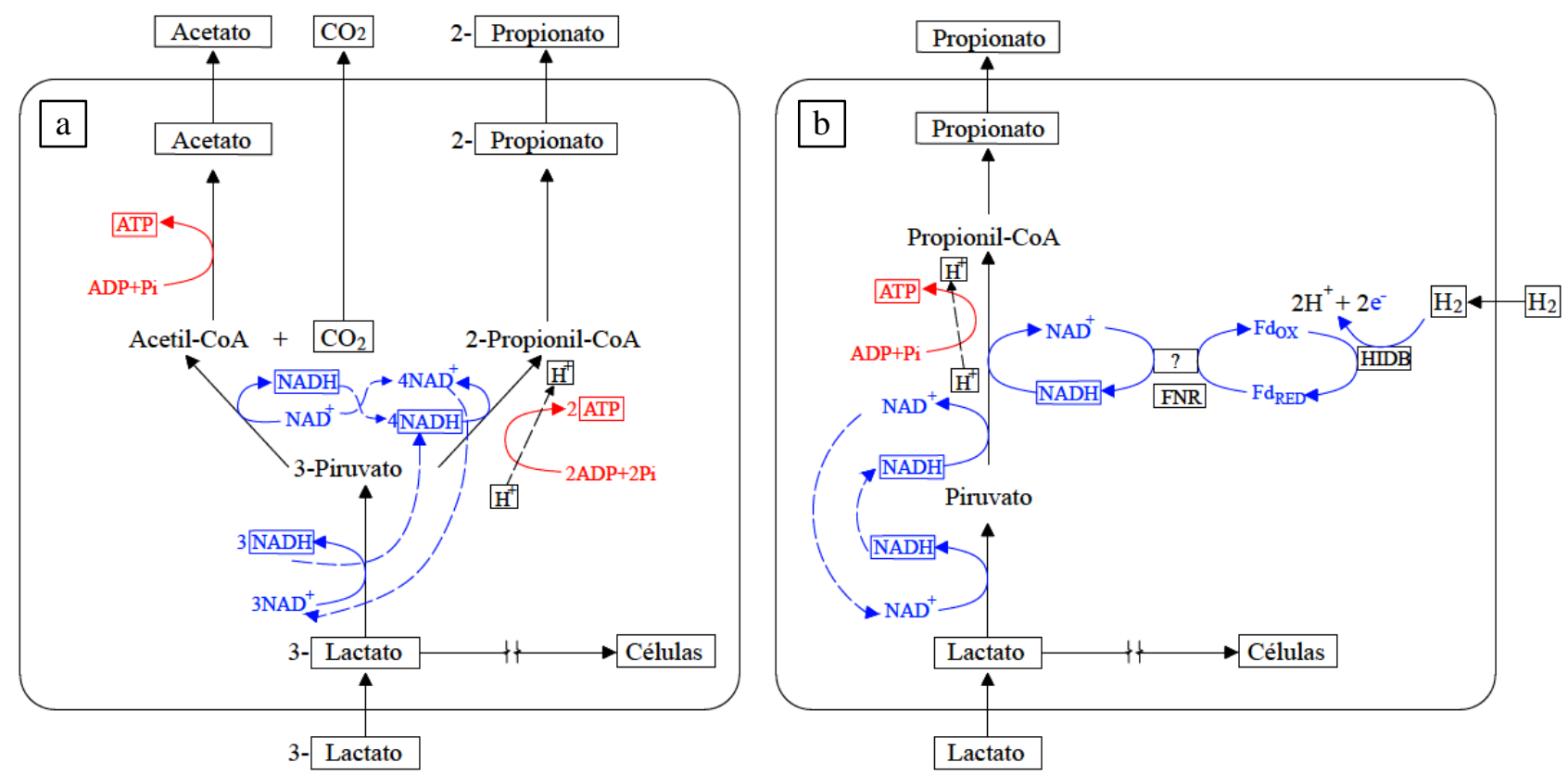

Figura 5. Fermentação de lactato para produção de propionato.

a) Fermentação "heteropropiónica" com duas moléculas de propionato e uma de acetato a partir de três moléculas de lactato. b) Fermentação "homopropiónica" com uma molécula de propionato a partir de uma molécula de lactato com consumo de hidrogênio pela HIDB para fornecer o poder redutor. A figura detalha o processo catabólico. No processo anabólico de, por exemplo, a formação de novas células, se produz um intermediário energético como acetil-CoA. Na transformação de piruvato em propionil-CoA, a figura expressa a produção de energia química (ATP) pela fosforilação oxidativa a partir da força próton-motriz. FNR: Ferredoxina $\mathrm{NAD}(\mathrm{P})^{+}$redutase. HIDB: Hidrogenase bidirecional.

\subsubsection{Bioquímica do metabolismo acetogênico}

Produtos da acidogênese como ácido acético, dióxido de carbono $\left(\mathrm{CO}_{2}, \mathrm{HCO}_{3}{ }^{-}, \mathrm{CO}_{3}{ }^{2-}\right.$ ) e hidrogênio $\left(\mathrm{H}_{2}\right)$ continuam diretamente à metanogênese, último passo na digestão anaeróbia; mas os compostos orgânicos intermediários (ácidos orgânicos e álcoois) não podem ser metabolizados pelas arqueias metanogênicas e devem ser transformados em uma fermentação secundária por bactérias sintróficas (Bitton, 2005; Chernicharo, 2007; Madigan et al., 2015). Na ausência de aceptores de elétrons diferentes do hidrogênio, as bactérias sintróficas são incapazes de transformar os intermediários isoladamente; elas dependem do consumo de hidrogênio por parte das arqueias metanogênicas com as quais se estabelece uma transferência de hidrogênio interespécies (Madigan et al., 2015). A fermentação secundária, denominada acetogênese, produz os substratos da metanogênese pela ação de bactérias anaeróbias de gêneros como Syntrophobacter, Syntrophomonas, Pelotomaculum e Syntrophus 
(Bitton, 2005; Madigan et al., 2015; Mara, 2003), em um metabolismo quimiorganotrófico.

Alguns dos processos acetogênicos mais comuns são a transformação de lactato, propionato, butirato e etanol em ácido acético e hidrogênio (Madigan et al., 2015). Na conversão de lactato em acetato, o lactato é transformado inicialmente em piruvato com geração poder redutor $(\mathrm{NADH})$ e, posteriormente, o piruvato é transformado em acetil-CoA na descarboxilação oxidativa com geração de poder redutor adicional. O poder redutor produz hidrogênio por meio de uma hidrogenase (Reação 43) com a ferredoxina como intermediário direto ou indireto, como explicado em processos anteriores. Finalmente, a acetil-CoA é transformada em acetato com geração de energia química (ATP) por fosforilação a nível de substrato, como se apresenta na Figura 6.

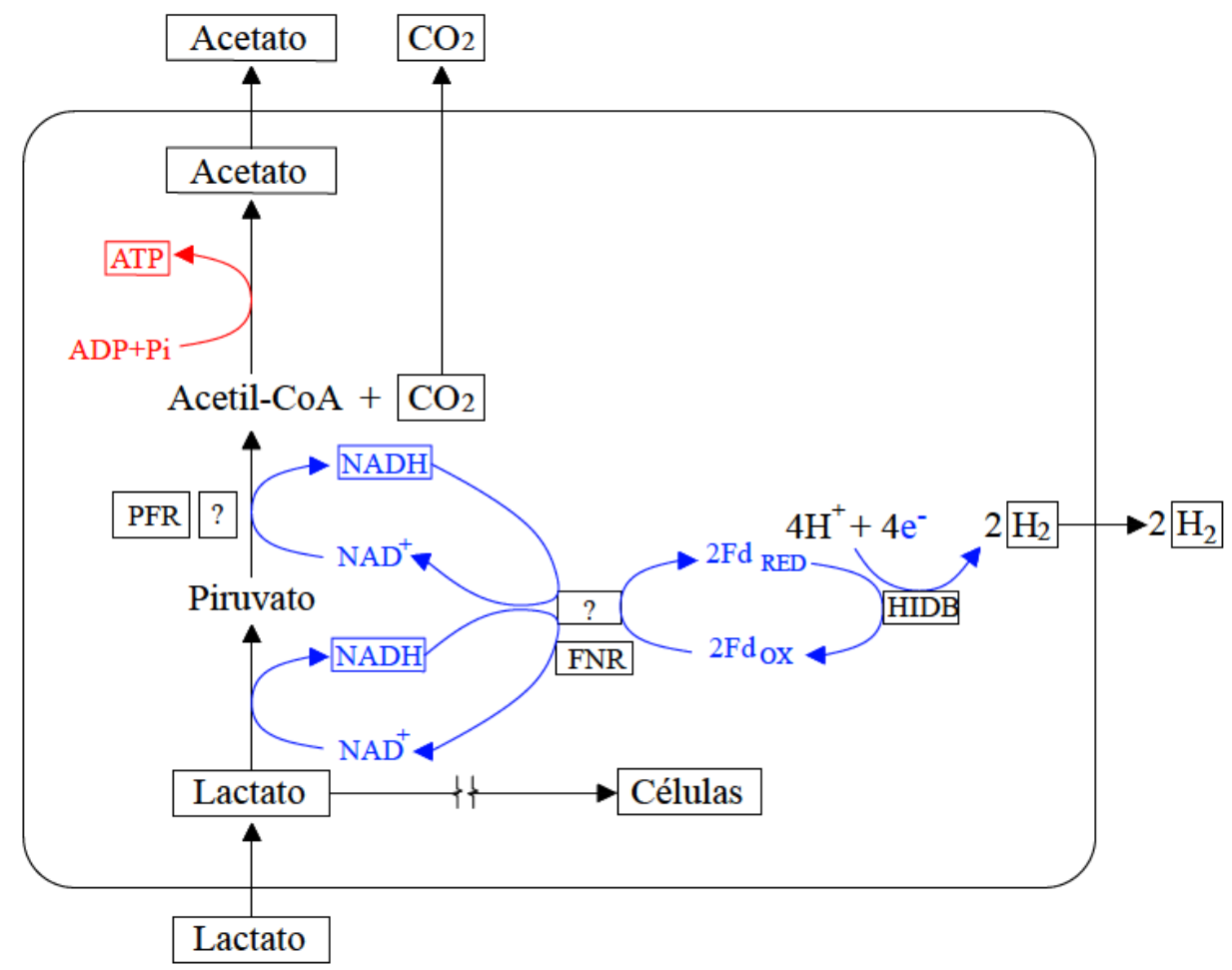

Figura 6. Fermentação de lactato para produção de acetato.

Se a enzima PFR atua no processo, a transferência de elétrons pode ser direta à ferredoxina. Se essa transferência se realiza por meio do NADH, a enzima FNR ou uma similar deve estar presente na transferência de elétrons do NADH à ferredoxina. A figura detalha o processo catabólico. No processo anabólico de, por exemplo, a formação de novas células, se produz um intermediário energético como acetil-CoA. PFR: Piruvato ferredoxina oxidorredutase. FNR: Ferredoxina NAD $(\mathrm{P})^{+}$redutase. HIDB: Hidrogenase bidirecional.

Por outro lado, na transformação sintrófica de propionato em acetato, o propionato 
inicialmente é convertido em propionil-CoA e este intermediário passa posteriormente a piruvato com consumo de energia química (ATP) e a geração de poder redutor (NADH). O piruvato é transformado em acetil-CoA na descarboxilação oxidativa com a geração de poder redutor adicional e, por fim, a acetil-CoA produz acetato com geração de energia química por fosforilação a nível de substrato. O poder redutor produz hidrogênio por meio de uma hidrogenase (Reação 43), usando a ferredoxina como intermediário direto no processo de transporte de elétrons, na presença de enzimas adequadas, ou como intermediário indireto usando além NADH. Este processo é apresentado na Figura 7.

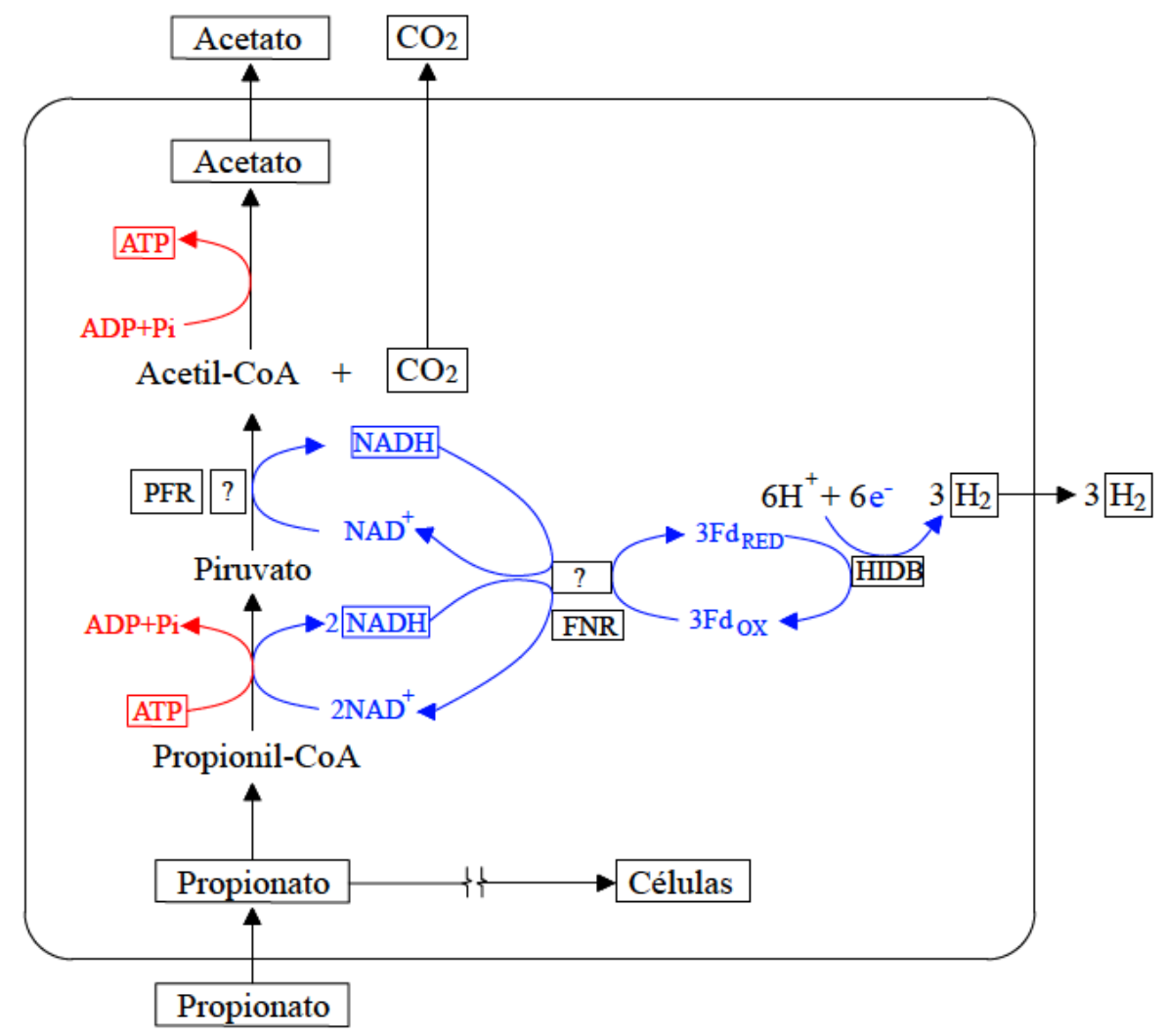

Figura 7. Fermentação de propionato para produção de acetato.

Se a enzima PFR atua no processo, a transferência de elétrons pode ser direta à ferredoxina. Se essa transferência se realiza por meio do NADH, a enzima FNR ou uma similar deve estar presente na transferência de elétrons do NADH à ferredoxina. A figura detalha o processo catabólico. No processo anabólico de, por exemplo, a formação de novas células, se produz um intermediário energético como acetil-CoA. PFR: Piruvato ferredoxina oxidorredutase. FNR: Ferredoxina NAD $(\mathrm{P})^{+}$redutase. HIDB: Hidrogenase bidirecional.

Para a conversão de butirato em acetato, inicialmente o butirato é convertido em acetil-CoA com consumo de energia química (ATP) e geração de poder redutor (NADH); este 
último produz hidrogênio por meio de uma hidrogenase (Reação 43) com a ferredoxina como intermediário indireto. Finalmente, a acetil-CoA se transforma em acetato com geração de energia química por fosforilação a nível de substrato, como se apresenta na Figura 8.

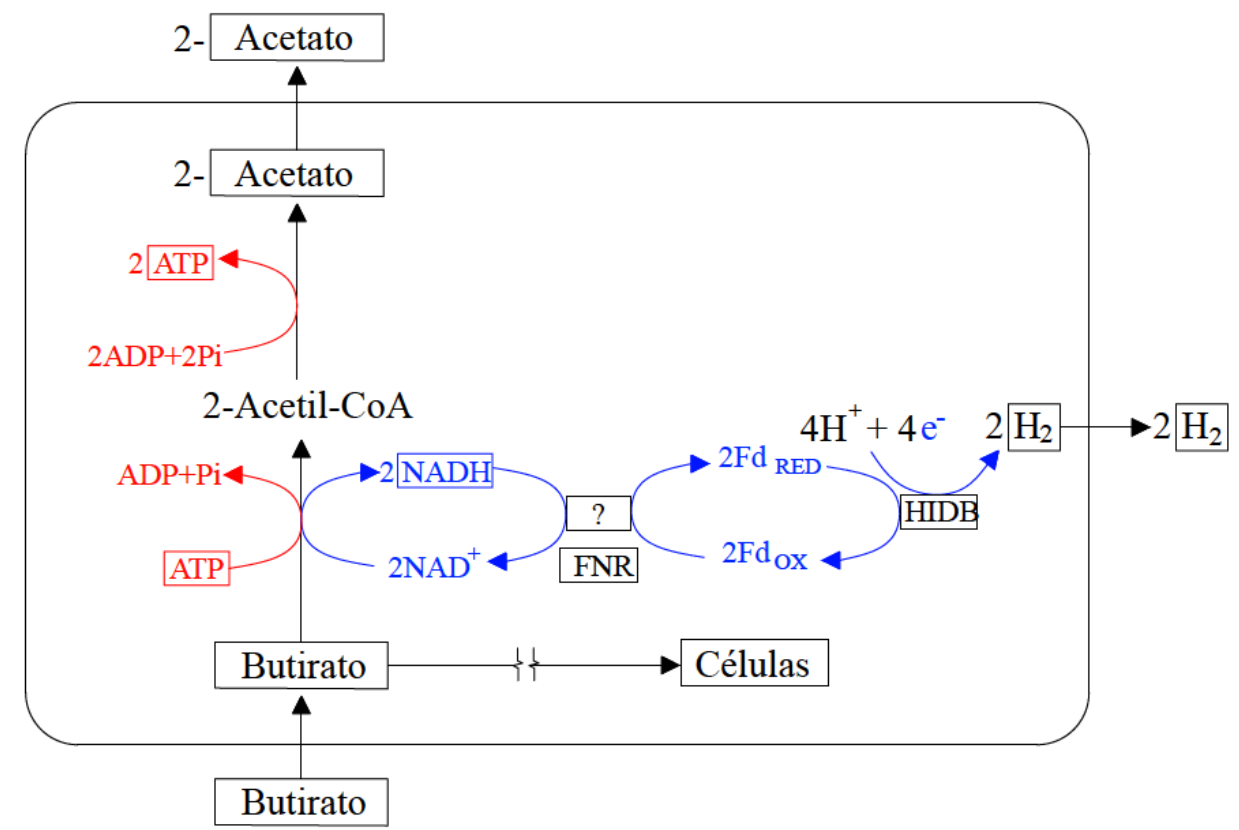

Figura 8. Fermentação de butirato para produção de acetato.

Se a enzima PFR atua no processo, a transferência de elétrons pode ser direta à ferredoxina. Se essa transferência se realiza por meio do NADH, a enzima FNR ou uma similar deve estar presente na transferência de elétrons do NADH à ferredoxina. A figura detalha o processo catabólico. No processo anabólico de, por exemplo, a formação de novas células, se produz um intermediário energético como acetil-CoA. FNR: Ferredoxina NAD $(\mathrm{P})^{+}$redutase. HIDB: Hidrogenase bidirecional.

Entre os processos acetogênicos quimioorganotróficos, o último processo comum é a transformação de etanol em acetato. Neste processo, o etanol é convertido inicialmente em acetil-CoA com geração de poder redutor $(\mathrm{NADH})$ que produz hidrogênio por meio de uma hidrogenase (Reação 43) com ferredoxina como intermediário indireto. Finalmente, a acetilCoA é transformada em acetato com a produção de energia química (ATP) por fosforilação a nível de substrato como se apresenta na Figura 9.

Uma exceção aos processos com metabolismo quimioorganotróficos da acetogênese é a homoacetogênese, metabolismo quimiolitotrófico no qual as bactérias homoacetogênicas [e.g. algumas espécies de Clostridium (Thauer, Jungermann \& Decker, 1977)] tomam o dióxido de carbono $\left(\mathrm{CO}_{2}, \mathrm{HCO}_{3}{ }^{-}, \mathrm{CO}_{3}{ }^{2-}\right)$ e produzem acetato usando o hidrogênio $\left(\mathrm{H}_{2}\right)$ como doador de elétrons (Müller, 2003). Neste processo, inicialmente duas moléculas de dióxido de 
carbono se assimilam por duas vias paralelas; uma é reduzida ao grupo metil do acetato, com o consumo de energia química (ATP), e a outra é reduzida ao grupo carbonila do acetato por meio de uma desidrogenase (Madigan et al., 2015). Posteriormente, os dois grupos são unidos pela desidrogenase para formar acetil-CoA, processo no qual é produzida uma força sódiomotriz que gera a síntese de energia química. Por fim, a acetil-CoA é transformada em acetato, produzindo energia química adicional pela fosforilação a nível de substrato, ou podese usar para processos anabólicos de produção de novas células bacterianas. Esta via autotrófica de fixação de carbono inorgânico por meio da acetil-CoA, apresentada na Figura 10, não é cíclica (Madigan et al., 2015; Sirevåg, 1995), ao contrário das outras vias autotróficas de fixação analisadas mais adiante (fotossíntese oxigênica e anoxigênica, Seções 5.1 e 6.1 , respetivamente).

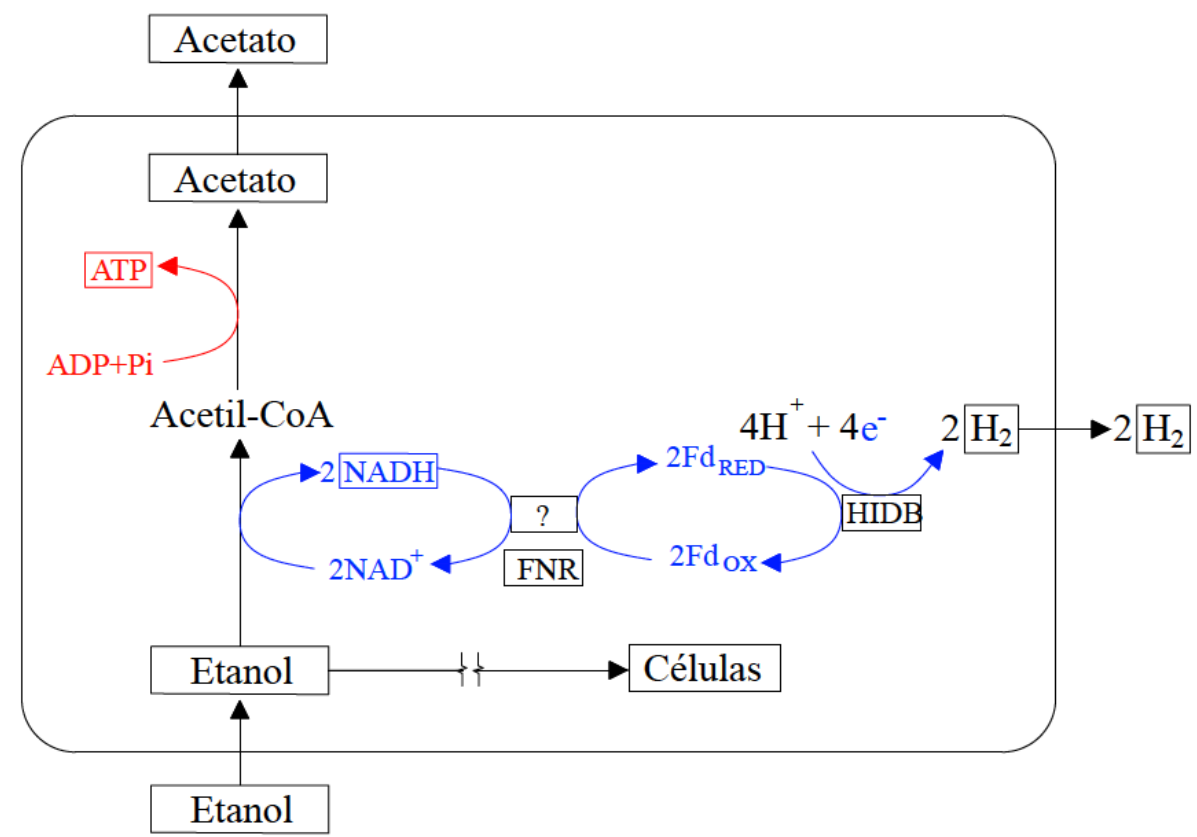

Figura 9. Fermentação de etanol para produção de acetato.

Se a enzima PFR atua no processo, a transferência de elétrons pode ser direta à ferredoxina. Se essa transferência se realiza por meio do NADH, a enzima FNR ou uma similar deve estar presente na transferência de elétrons do NADH à ferredoxina. A figura detalha o processo catabólico. No processo anabólico de, por exemplo, a formação de novas células, se produz um intermediário energético como acetil-CoA. FNR: Ferredoxina NAD $(\mathrm{P})^{+}$redutase. HIDB: Hidrogenase bidirecional.

A homoacetogênese "inversa", metabolismo quimioorganotrófico para a produção de hidrogênio a partir de acetato, tem sido relatada (Zinder, 1994; Zinder \& Koch, 1984), inclusive para bactérias do gênero Clostridium (Schnurer, Schink \& Svensson, 1996). Ainda, 
Schnurer, Schink \& Svensson (1997) demostraram a natureza reversível do sistema enzimático no catabolismo em Clostridium ultunense que pode catalisar as reações de homoacetogênese direta e inversa. Contudo, ainda não é claro como é realizado o metabolismo da homoacetogênese "inversa".

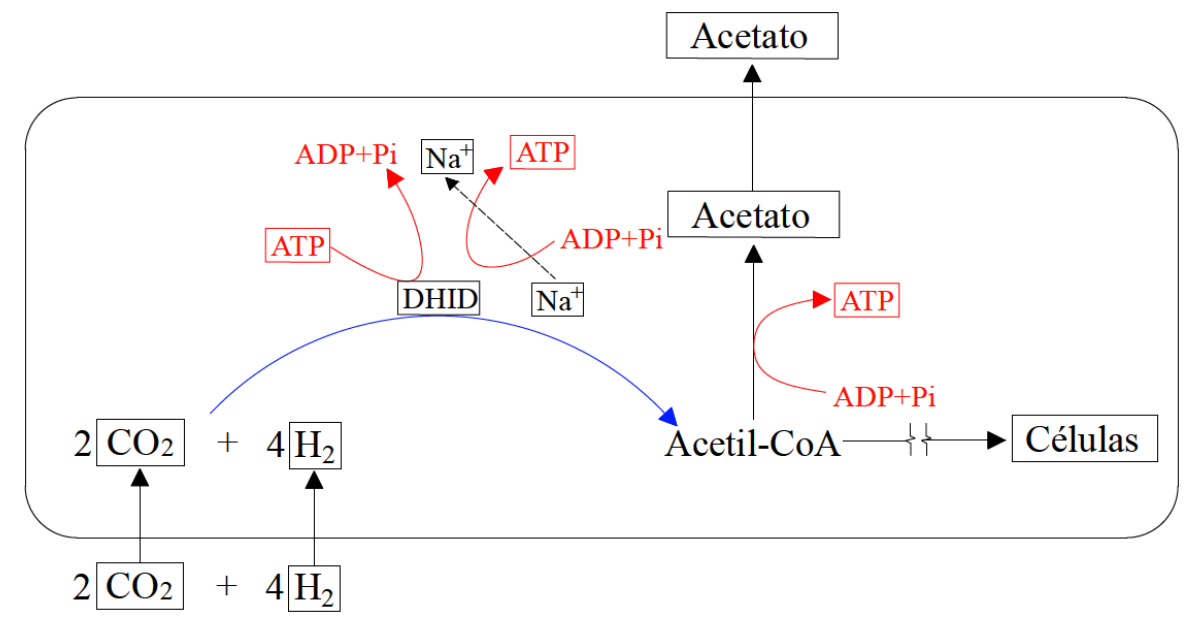

Figura 10. Acetogênese hidrogeniotrófica (homoacetogênese).

A figura detalha o processo catabólico. O intermediário energético acetil-CoA é fundamental para o processo anabólico de, por exemplo, formação de novas células. Na formação de acetil-CoA, a figura expressa a produção de energia química (ATP) pela fosforilação oxidativa a partir da força sódiomotriz. DHID: Desidrogenase.

\subsubsection{Bioquímica do metabolismo metanogênico}

A metanogênese, a fase final da digestão anaeróbia, se realiza pelas arqueias metanogênicas; microorganismos estritamente anaeróbios (Bitton, 2005; Madigan et al., 2015) de lento crescimento (Mara, 2003), fundamentais para o consumo do hidrogênio produzido nos processos anteriores de acidogênese e acetogênese, mantendo muito baixa a pressão parcial deste gás. Estes microorganismos usam um número limitado de substratos: ácido acético, dióxido de carbono $\left(\mathrm{CO}_{2}, \mathrm{HCO}_{3}{ }^{-}, \mathrm{CO}_{3}{ }^{2-}\right)$, hidrogênio $\left(\mathrm{H}_{2}\right)$, ácido fórmico, ácido pirúvico, metanol, metilaminas, metilsulfetos e monóxido de carbono $(\mathrm{CO})$, e produzem metano $\left(\mathrm{CH}_{4}\right)$ e dióxido de carbono (Bitton, 2005; Chernicharo, 2007; Madigan et al., 2015). As arqueias metanogênicas estão divididas em dois grupos dependendo dos substratos metabolizados: as acetoclásticas que usam ácido acético ou metanol e produzem metano e dióxido de carbono (metabolismo quimioorganotrófico), e as hidrogeniotróficas que usam dióxido de carbono e hidrogênio e produzem metano (metabolismo quimiolitotrófico) (Bitton, 
2005; Chernicharo, 2007).

Poucas espécies de arqueias metanogênicas são acetoclásticas, porém são as espécies metanogênicas que prevalecem na digestão anaeróbia (Chernicharo, 2007; Madigan et al., 2015). Dentre as arqueias metanogênicas acetoclásticas os gêneros mais comuns são Methanosarcina, Methanosaeta e Methanothrix; as Methanosarcina se consideram o gênero mais versátil das metanogênicas, porquanto, além do acetato, podem usar hidrogênio e metilaminas como substrato, enquanto as Methanosaeta são acetoclásticas exclusivas (Chernicharo, 2007). Na metanogênese acetoclástica, o acetato é inicialmente ativado em acetil-CoA com consumo de energia química (ATP), e, posteriormente, a acetil-CoA é transformada por duas vias: uma produz dióxido de carbono a partir do grupo carbonila e a outra produz metano a partir do grupo metila com metil-CoA como intermediário (Jin, 2012; Madigan et al., 2015). Nesta última conversão gera-se uma força próton-motriz que produz energia química (ATP) por meio da fosforilação oxidativa (Madigan et al., 2015), como se apresenta na Figura 11.

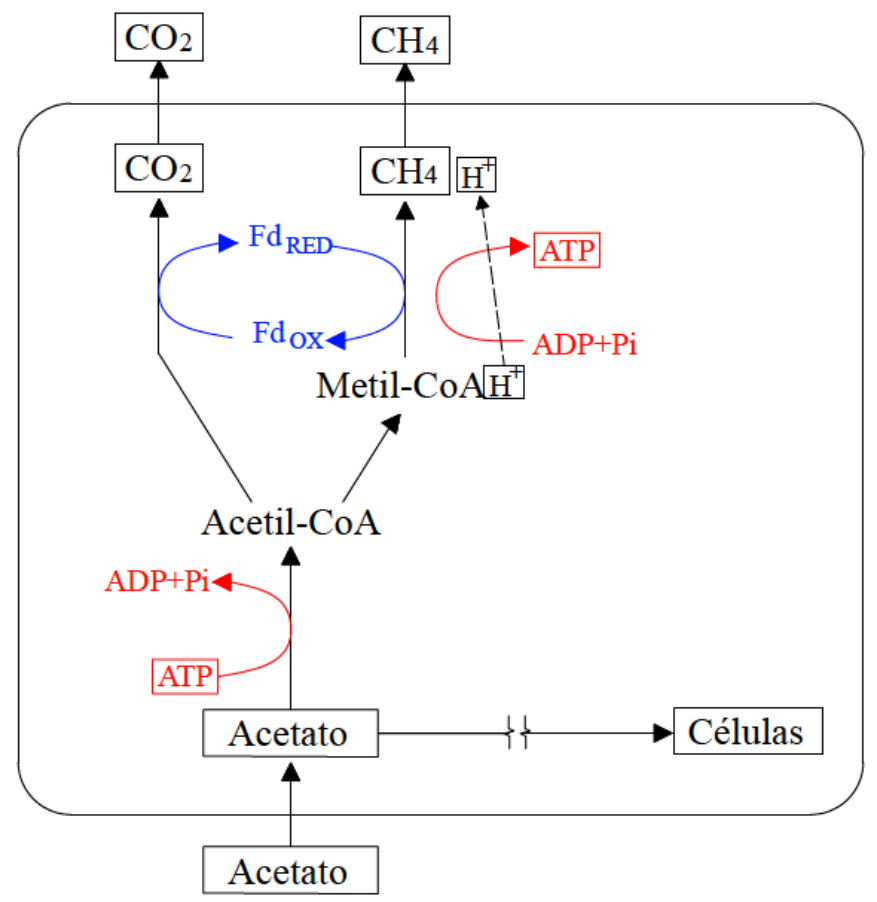

Figura 11. Metanogênese acetotrófica (metanogênese acetoclástica).

A figura detalha o processo catabólico. No processo anabólico de, por exemplo, a formação de novas células, se produz um intermediário energético como acetil-CoA. Na produção de metano, a figura expressa a produção de energia química (ATP) pela fosforilação oxidativa a partir da força prótonmotriz. 
Por outro lado, a maioria das arqueias metanogênicas são hidrogeniotróficas e usam o hidrogênio como doador de elétrons (Jin, 2012) em um metabolismo quimiolitotrófico; os gêneros mais comuns são Methanobacterium, Methanospirillum e Methanobrevibacter (Chernicharo, 2007). A metanogênese hidrogeniotrófica está composta por reações sequenciais nas quais se produzem intermediários ligados a diferentes coenzimas e se usam diferentes vias na transferência de elétrons do hidrogênio a metil-CoM, intermediário final do processo (Jin, 2012). Uma via, por exemplo, usa a hidrogenase para oxidar hidrogênio e transferir os elétrons para reduzir dióxido de carbono a metano por meio da ferredoxina (Dasgupta et al., 2010); processo que gera uma força próton (sódio)-motriz que produz energia química (ATP) por meio da fosforilação oxidativa (Jin, 2012), como se apresenta na Figura 12. Esta hidrogenase das arqueias metanogênicas não está envolvida na produção de hidrogênio (Dasgupta et al., 2010) e catalisa uma reação como a inversa da Reação 43.

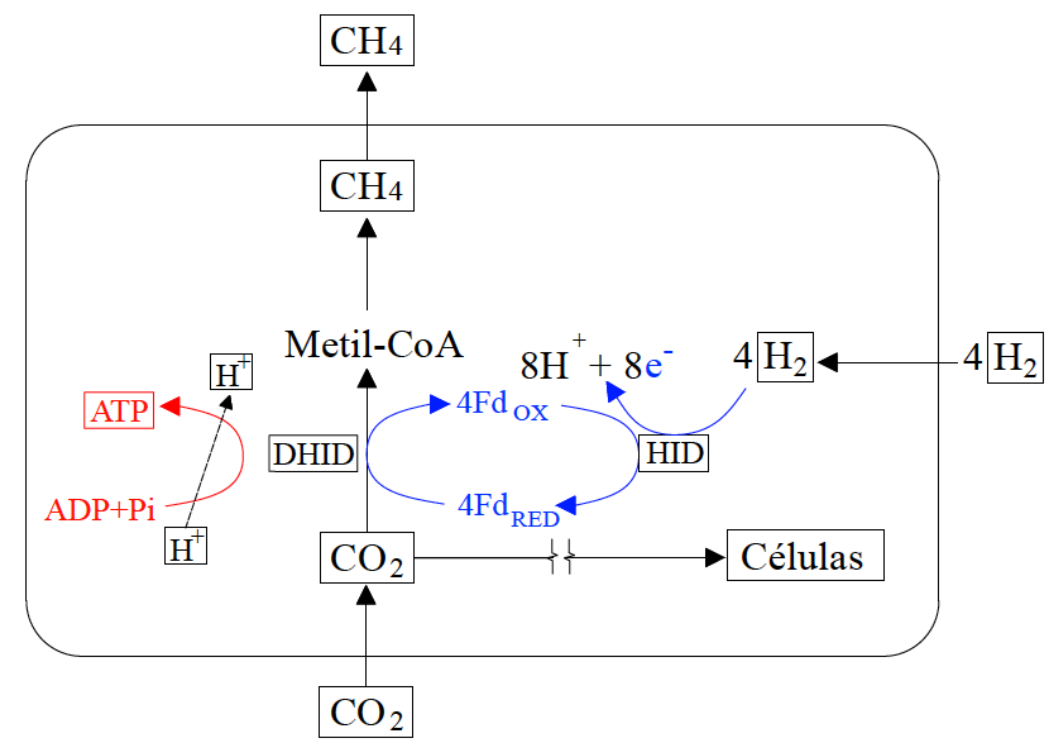

Figura 12. Uma via da metanogênese hidrogeniotrófica.

A figura detalha o processo catabólico. No processo anabólico de, por exemplo, a formação de novas células, se produz um intermediário energético como acetil-CoA. Na produção do intermediário energético metil-CoA, a figura expressa a produção de energia química (ATP) pela fosforilação oxidativa a partir da força próton-motriz. DHID: Desidrogenase. HID: Hidrogenase.

\subsection{Aplicação do modelo-resultados e discussão}

Ao aplicar o modelo biotermodinâmico aos metabolismos dos processos fermentativos (acidogênico e acetogênico) e metanogênicos que compõem a digestão anaeróbia discutidos, 
para condições diferentes da padrão, se obtêm as biorreações apresentadas nas Seções 4.2.1 a 4.2.3, baseadas nas semi-reações da Tabela 3. Para todas as figuras apresentadas nessas seções, e em geral no trabalho, o quadro representa o intervalo biológico típico de pH no qual são realizados os processos e, portanto, onde os resultados do modelo fazem maior sentido.

Neste ponto cabe salientar que um dos resultados do modelo biotermodinâmico é estabelecer a estequiometria das reações para os processos biológicos analisados. Essa estequiometria pode-se usar como base para a construção de modelos cinéticos ou para analisar as interações entre as condições químicas e as respostas biológicas (e.g. inibições). Assim, por exemplo, na medida em que o $\mathrm{pH}$ diminui (e.g. para valores menores de 5,0), uma resposta biológica pode dar preferência às vias de consumo de acidez (como as fermentações de lactato ou a homoacetogênese) sobre as vias que a produzem (como as fermentações de glicose), embora as últimas dissipem mais energia livre e, portanto, tenham maiores conversões; obviamente, sempre que ambas sejam termodinamicamente viáveis. Não obstante, este tipo de análise escapa ao escopo desta pesquisa que se centra no comportamento termodinâmico e nas eficiências dos diferentes processos de recuperação de energia e é discutido a seguir.

\subsubsection{Comportamento dos processos acidogênicos}

Os resultados da aplicação do modelo biotermodinâmico aos metabolismos acidogénicos discutidos na Seção 4.1.1 se apresentam nas Tabelas 4 a 9 (Reações 44 a 49), nas quais se inclui a estequiometria da reação para diferentes $\mathrm{pH}$ (temperatura de $30{ }^{\circ} \mathrm{C}$ ), e nas Figuras 13 a 18, com o comportamento da energia livre dissipada como função do $\mathrm{pH}$ e pressão parcial de hidrogênio (temperatura constante de $30{ }^{\circ} \mathrm{C}$ ) e do $\mathrm{pH}$ e temperatura (pressão parcial de hidrogênio constante de $1,00 \times 10^{-3} \mathrm{~atm}$ ).

Todas as fermentações da glicose consideradas (Reações 44 a 47) são processos espontâneos nos intervalos de $\mathrm{pH}$ (0 a 14), pressões parciais de hidrogênio $\left(1,00 \times 10^{-5}\right.$ a 1,00 atm) e temperatura $\left(10\right.$ a $\left.70{ }^{\circ} \mathrm{C}\right)$ avaliados; portanto, acontecem naturalmente na digestão anaeróbia sempre que presentes os microorganismos para cada metabolismo.

A energia livre dissipada das fermentações da glicose a butirato (Figura 13a) e acetato (Figura 16a) aumenta significativamente para $\mathrm{pH}$ inferiores a $6,0\left(\mathrm{a} 30^{\circ} \mathrm{C}\right)$, e para todo o intervalo de $\mathrm{pH}$ a fermentação a acetato dissipa mais energia livre que a fermentação a butirato, mas são muito parecidas no intervalo de $\mathrm{pH}$ entre 6,0 e 8,0. O aumento da energia 
Tabela 4. Biorreação do modelo biotermodinâmico e estequiometria $\left(\mathrm{T}=30{ }^{\circ} \mathrm{C}\right) \mathrm{da}$ fermentação de glicose para produção de butirato.

\begin{tabular}{|c|c|c|c|}
\hline \multicolumn{2}{|r|}{$\mathrm{R}=f s 22+f e^{\circ}(1 / 629+5 / 634)-30$} & $f_{s}^{0}$ & $\begin{array}{c}\Delta_{r} G^{\circ} \\
\Delta_{r} H^{\circ} \\
\left(\mathrm{kJ} \mathrm{e}^{-} \mathrm{eq}^{-1}\right)\end{array}$ \\
\hline 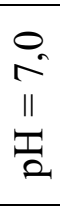 & $\begin{array}{l}4,17 \times 10^{-2} \mathrm{C}_{6} \mathrm{H}_{12} \mathrm{O}_{6}+8,90 \times 10^{-3} \mathrm{NH}_{4}^{+}+8,99 \times 10^{-5} \mathrm{NH}_{3}+3,60 \times 10^{-4} \mathrm{H}_{2} \mathrm{PO}_{4}^{-} \\
+1,80 \times 10^{-4} \mathrm{HPO}_{4}{ }^{2-}+4,50 \times 10^{-4} \mathrm{H}_{2} \mathrm{~S}+4,50 \times 10^{-4} \mathrm{HS}^{-}+2,70 \times 10^{-2} \mathrm{H}_{2} \mathrm{O} \rightleftharpoons \\
8,99 \times 10^{-3} \mathrm{C}_{5} \mathrm{H}_{7} \mathrm{O}_{2} \mathrm{NP}_{0,06} \mathrm{~S}_{0,1}+3,38 \times 10^{-2} \mathrm{C}_{4} \mathrm{H}_{7} \mathrm{O}_{2}^{-}+3,41 \times 10^{-4} \mathrm{C}_{4} \mathrm{H}_{8} \mathrm{O}_{2}+ \\
6,83 \times 10^{-2} \mathrm{H}_{2}+1,19 \times 10^{-2} \mathrm{CO}_{2}+5,66 \times 10^{-2} \mathrm{HCO}_{3}+9,67 \times 10^{-2} \mathrm{H}^{+}\end{array}$ & 0,18 & $\begin{array}{l}-12,7 \\
-3,3\end{array}$ \\
\hline 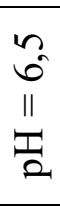 & $\begin{array}{l}4,17 \times 10^{-2} \mathrm{C}_{6} \mathrm{H}_{12} \mathrm{O}_{6}+8,91 \times 10^{-3} \mathrm{NH}_{4}^{+}+4,45 \times 10^{-4} \mathrm{H}_{2} \mathrm{PO}_{4}^{-}+8,91 \times 10^{-} \\
{ }^{5} \mathrm{HPO}_{4}{ }^{2-}+7,13 \times 10^{-4} \mathrm{H}_{2} \mathrm{~S}+1,78 \times 10^{-4} \mathrm{HS}^{-}+1,12 \times 10^{-2} \mathrm{H}_{2} \mathrm{O} \rightleftharpoons 8,91 \times 10^{-} \\
{ }^{3} \mathrm{C}_{5} \mathrm{H}_{7} \mathrm{O}_{2} \mathrm{NP}_{0,06} \mathrm{~S}_{0,1}+3,35 \times 10^{-2} \mathrm{C}_{4} \mathrm{H}_{7} \mathrm{O}_{2}^{-}+6,84 \times 10^{-4} \mathrm{C}_{4} \mathrm{H}_{8} \mathrm{O}_{2}+6,84 \times 10^{-2} \mathrm{H}_{2} \\
+2,74 \times 10^{-2} \mathrm{CO}_{2}+4,12 \times 10^{-2} \mathrm{HCO}_{3}^{-}+8,01 \times 10^{-2} \mathrm{H}^{+}\end{array}$ & 0,18 & $\begin{array}{c}-12,6 \\
-3,6\end{array}$ \\
\hline $\begin{array}{l}n \\
n \\
n \\
2\end{array}$ & 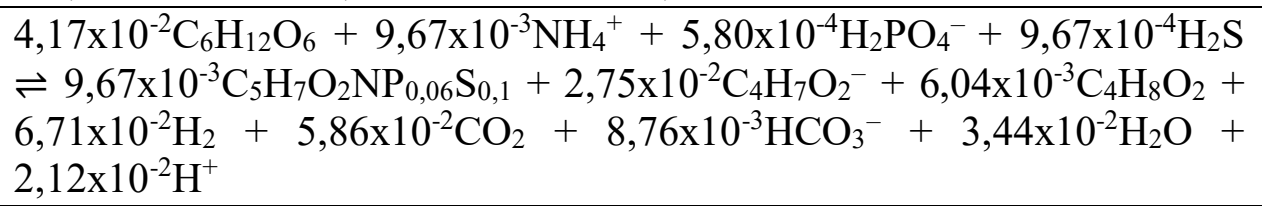 & 0,19 & $\begin{array}{c}-13,6 \\
-6,8\end{array}$ \\
\hline
\end{tabular}
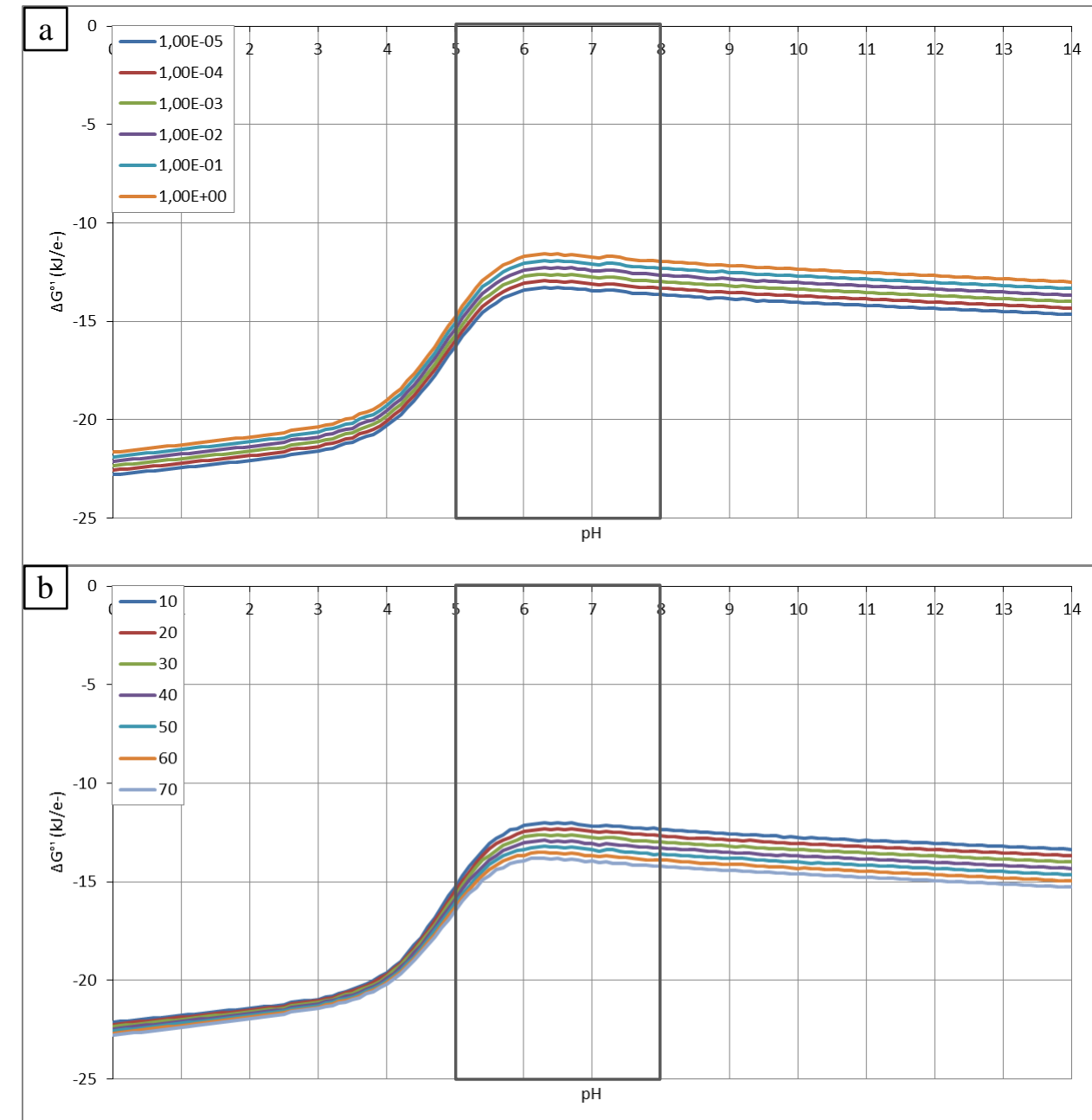

Figura 13. Energia livre da fermentação de glicose para produção de butirato como função a) do $\mathrm{pH}$ e pressão parcial de hidrogênio (atm) e b) do $\mathrm{pH}$ e temperatura $\left({ }^{\circ} \mathrm{C}\right)$. 
Tabela 5. Biorreação do modelo biotermodinâmico e estequiometria $\left(\mathrm{T}=30^{\circ} \mathrm{C}\right) \mathrm{da}$ fermentação de glicose para produção de lactato (fermentação homoláctica).

Reação 45

$$
\mathrm{R}=f s^{\circ} 22+f e \sqrt{35}-30
$$

$f_{s}^{\circ} \quad \Delta_{r} H^{\circ}$

$\left(\mathrm{kJ} \mathrm{e}^{-} \mathrm{eq}^{-1}\right)$

\begin{tabular}{|c|c|c|c|}
\hline 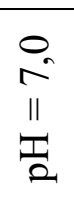 & $\begin{array}{l}4,17 \times 10^{-2} \mathrm{C}_{6} \mathrm{H}_{12} \mathrm{O}_{6}+3,71 \times 10^{-4} \mathrm{CO}_{2}+5,82 \times 10^{-3} \mathrm{NH}_{4}^{+}+5,88 \times 10^{-5} \mathrm{NH}_{3}+ \\
2,35 \times 10^{-4} \mathrm{H}_{2} \mathrm{PO}_{4}^{-}+1,18 \times 10^{-4} \mathrm{HPO}_{4}^{2-}+2,94 \times 10^{-4} \mathrm{H}_{2} \mathrm{~S}+2,94 \times 10^{-4} \mathrm{HS}^{-} \rightleftharpoons \\
5,88 \times 10^{-3} \mathrm{C}_{5} \mathrm{H}_{7} \mathrm{O}_{2} \mathrm{NP}_{0,06} \mathrm{~S}_{0,1}+7,35 \times 10^{-2} \mathrm{C}_{3} \mathrm{H}_{5} \mathrm{O}_{3}^{-}+5,18 \times 10^{-4} \mathrm{HCO}_{3}^{-}+ \\
1,84 \times 10^{-2} \mathrm{H}_{2} \mathrm{O}+7,91 \times 10^{-2} \mathrm{H}^{+}\end{array}$ & 0,12 & $\begin{array}{l}-8,3 \\
-4,0\end{array}$ \\
\hline $\begin{array}{l}n \\
\sigma^{n} \\
\mathbb{T}_{2}\end{array}$ & $\begin{array}{l}4,17 \times 10^{-2} \mathrm{C}_{6} \mathrm{H}_{12} \mathrm{O}_{6}+3,20 \times 10^{-4} \mathrm{CO}_{2}+5,75 \times 10^{-3} \mathrm{NH}_{4}^{+}+2,87 \times 10^{-4} \mathrm{H}_{2} \mathrm{PO}_{4}^{-} \\
+5,75 \times 10^{-5} \mathrm{HPO}_{4}{ }^{2-}+4,60 \times 10^{-4} \mathrm{H}_{2} \mathrm{~S}+1,15 \times 10^{-4} \mathrm{HS}^{-} \rightleftharpoons 5,75 \times 10^{-} \\
{ }^{3} \mathrm{C}_{5} \mathrm{H}_{7} \mathrm{O}_{2} \mathrm{NP}_{0,06} \mathrm{~S}_{0,1}+7,37 \times 10^{-2} \mathrm{C}_{3} \mathrm{H}_{5} \mathrm{O}_{3}{ }^{-}+4,64 \times 10^{-4} \mathrm{HCO}_{3}{ }^{-}+1,80 \times 10^{-} \\
{ }^{2} \mathrm{H}_{2} \mathrm{O}+7,94 \times 10^{-2} \mathrm{H}^{+}\end{array}$ & 0,12 & $\begin{array}{l}-8,1 \\
-4,0\end{array}$ \\
\hline$\stackrel{n}{n}_{i}^{n}$ & $\begin{array}{l}4,17 \times 10^{-2} \mathrm{C}_{6} \mathrm{H}_{12} \mathrm{O}_{6}+6,15 \times 10^{-3} \mathrm{NH}_{4}^{+}+3,69 \times 10^{-4} \mathrm{H}_{2} \mathrm{PO}_{4}^{-}+6,15 \times 10^{-4} \mathrm{H}_{2} \mathrm{~S} \\
\rightleftharpoons 6,15 \times 10^{-3} \mathrm{C}_{5} \mathrm{H}_{7} \mathrm{O}_{2} \mathrm{NP}_{0,06} \mathrm{~S}_{0,1}+7,08 \times 10^{-2} \mathrm{C}_{3} \mathrm{H}_{5} \mathrm{O}_{3}^{-}+2,19 \times 10^{-3} \mathrm{C}_{3} \mathrm{H}_{6} \mathrm{O}_{3}+ \\
1,34 \times 10^{-4} \mathrm{CO}_{2}+2,00 \times 10^{-5} \mathrm{HCO}_{3}^{-}+2,63 \times 10^{-2} \mathrm{H}_{2} \mathrm{O}+6,35 \times 10^{-2} \mathrm{H}^{+}\end{array}$ & 0,12 & $\begin{array}{l}-8,6 \\
-5,7\end{array}$ \\
\hline
\end{tabular}
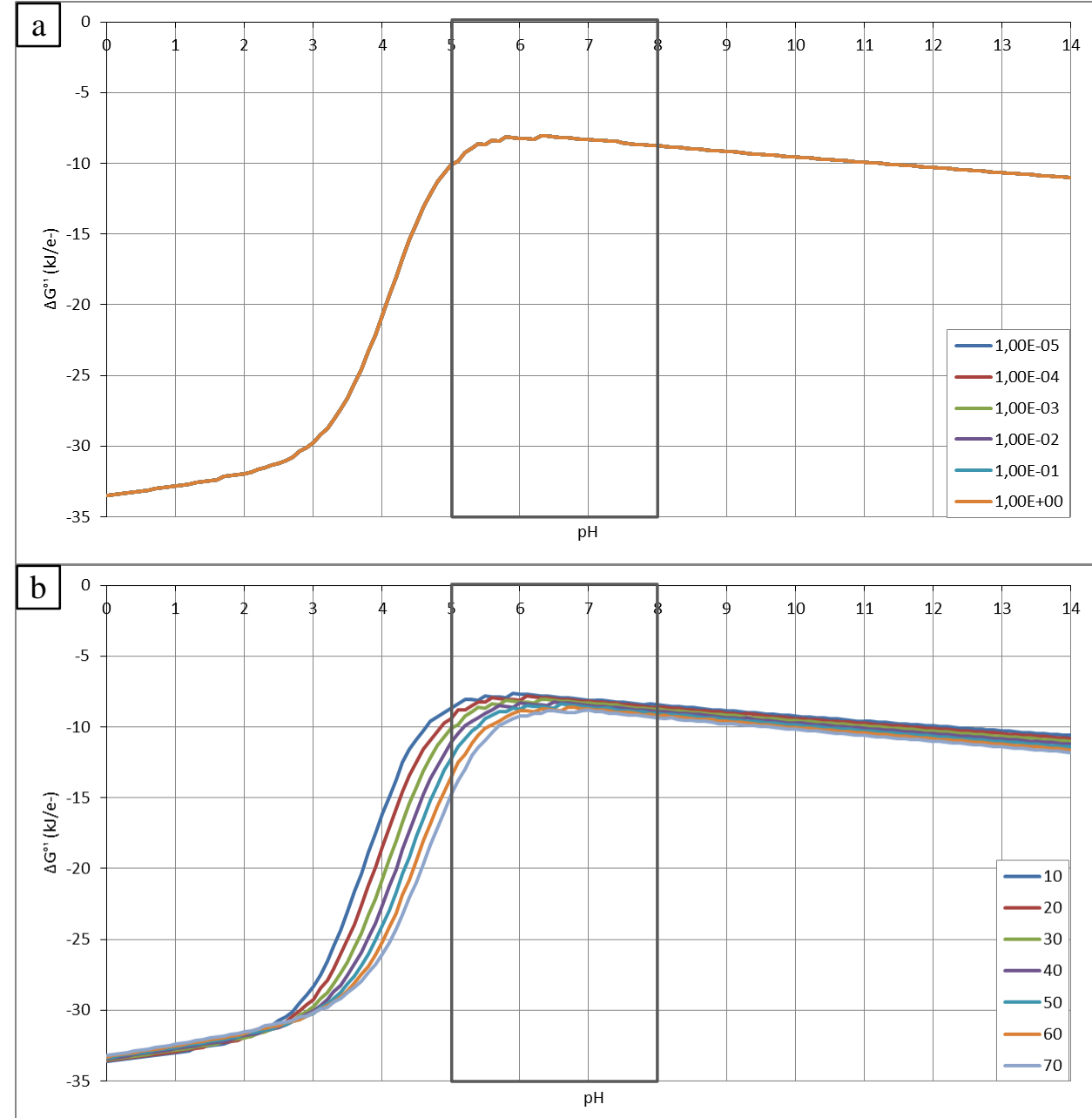

Figura 14. Energia livre da fermentação de glicose para produção de lactato (fermentação homoláctica) como função a) do pH e pressão parcial de hidrogênio (atm) e b) do pH e temperatura $\left({ }^{\circ} \mathrm{C}\right)$. 
Tabela 6. Biorreação do modelo biotermodinâmico e estequiometria $\left(T=30^{\circ} \mathrm{C}\right)$ da fermentação de glicose para produção de lactato e etanol (fermentação heteroláctica).

Reação 46

$$
\mathrm{R}=f_{S} 22+f e^{0}(1 / 235+1 / 236)-30
$$

$\Delta_{r} G^{\circ}$

$\Delta_{r} H^{\circ}$

$\left(\mathrm{kJ} \mathrm{e}^{-} \mathrm{eq}^{-1}\right)$

\begin{tabular}{|c|c|c|c|}
\hline 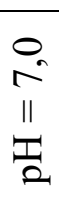 & $\begin{array}{l}4,17 \times 10^{-2} \mathrm{C}_{6} \mathrm{H}_{12} \mathrm{O}_{6}+6,84 \times 10^{-3} \mathrm{NH}_{4}^{+}+6,91 \times 10^{-5} \mathrm{NH}_{3}+2,76 \times 10^{-4} \mathrm{H}_{2} \mathrm{PO}_{4}^{-} \\
+1,38 \times 10^{-4} \mathrm{HPO}_{4}{ }^{2-}+3,45 \times 10^{-4} \mathrm{H}_{2} \mathrm{~S}+3,45 \times 10^{-4} \mathrm{HS}^{-}+7,74 \times 10^{-3} \mathrm{H}_{2} \mathrm{O} \rightleftharpoons \\
6,91 \times 10^{-3} \mathrm{C}_{5} \mathrm{H}_{7} \mathrm{O}_{2} \mathrm{NP}_{0,06} \mathrm{~S}_{0,1}+3,59 \times 10^{-2} \mathrm{C}_{3} \mathrm{H}_{5} \mathrm{O}_{3}^{-}+3,59 \times 10^{-2} \mathrm{C}_{2} \mathrm{H}_{6} \mathrm{O}+ \\
6,10 \times 10^{-3} \mathrm{CO}_{2}+3,00 \times 10^{-2} \mathrm{HCO}_{3}{ }^{-}+7,18 \times 10^{-2} \mathrm{H}^{+}\end{array}$ & 0,14 & $\begin{array}{l}-9,8 \\
-4,1\end{array}$ \\
\hline 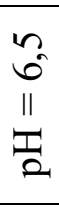 & $\begin{array}{l}4,17 \times 10^{-2} \mathrm{C}_{6} \mathrm{H}_{12} \mathrm{O}_{6}+6,78 \times 10^{-3} \mathrm{NH}_{4}^{+}+3,40 \times 10^{-4} \mathrm{H}_{2} \mathrm{PO}_{4}^{-}+6,79 \times 10^{-} \\
{ }^{5} \mathrm{HPO}_{4}{ }^{2-}+5,43 \times 10^{-4} \mathrm{H}_{2} \mathrm{~S}+1,36 \times 10^{-4} \mathrm{HS}^{-} \rightleftharpoons 6,79 \times 10^{-3} \mathrm{C}_{5} \mathrm{H}_{7} \mathrm{O}_{2} \mathrm{NP}_{0,06} \mathrm{~S}_{0,1}+ \\
3,60 \times 10^{-2} \mathrm{C}_{3} \mathrm{H}_{5} \mathrm{O}_{3}^{-}+3,60 \times 10^{-2} \mathrm{C}_{2} \mathrm{H}_{6} \mathrm{O}+1,44 \times 10^{-2} \mathrm{CO}_{2}+2,17 \times 10^{-2} \mathrm{HCO}_{3} \\
+1,40 \times 10^{-4} \mathrm{H}_{2} \mathrm{O}+6,39 \times 10^{-2} \mathrm{H}^{+}\end{array}$ & 0,14 & $\begin{array}{l}-9,6 \\
-4,2\end{array}$ \\
\hline$n^{n}$ & 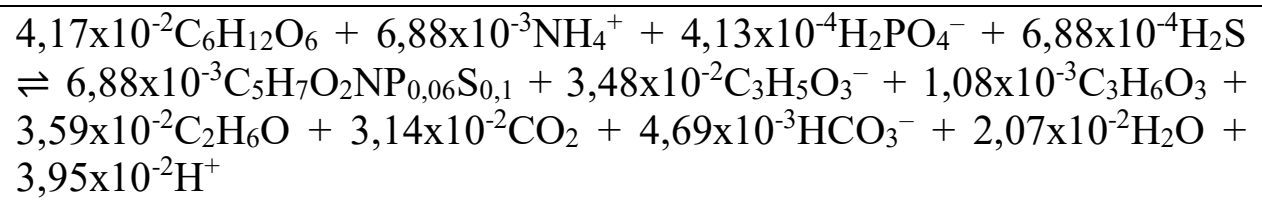 & 0,14 & $\begin{array}{l}-9,7 \\
-5,2\end{array}$ \\
\hline
\end{tabular}
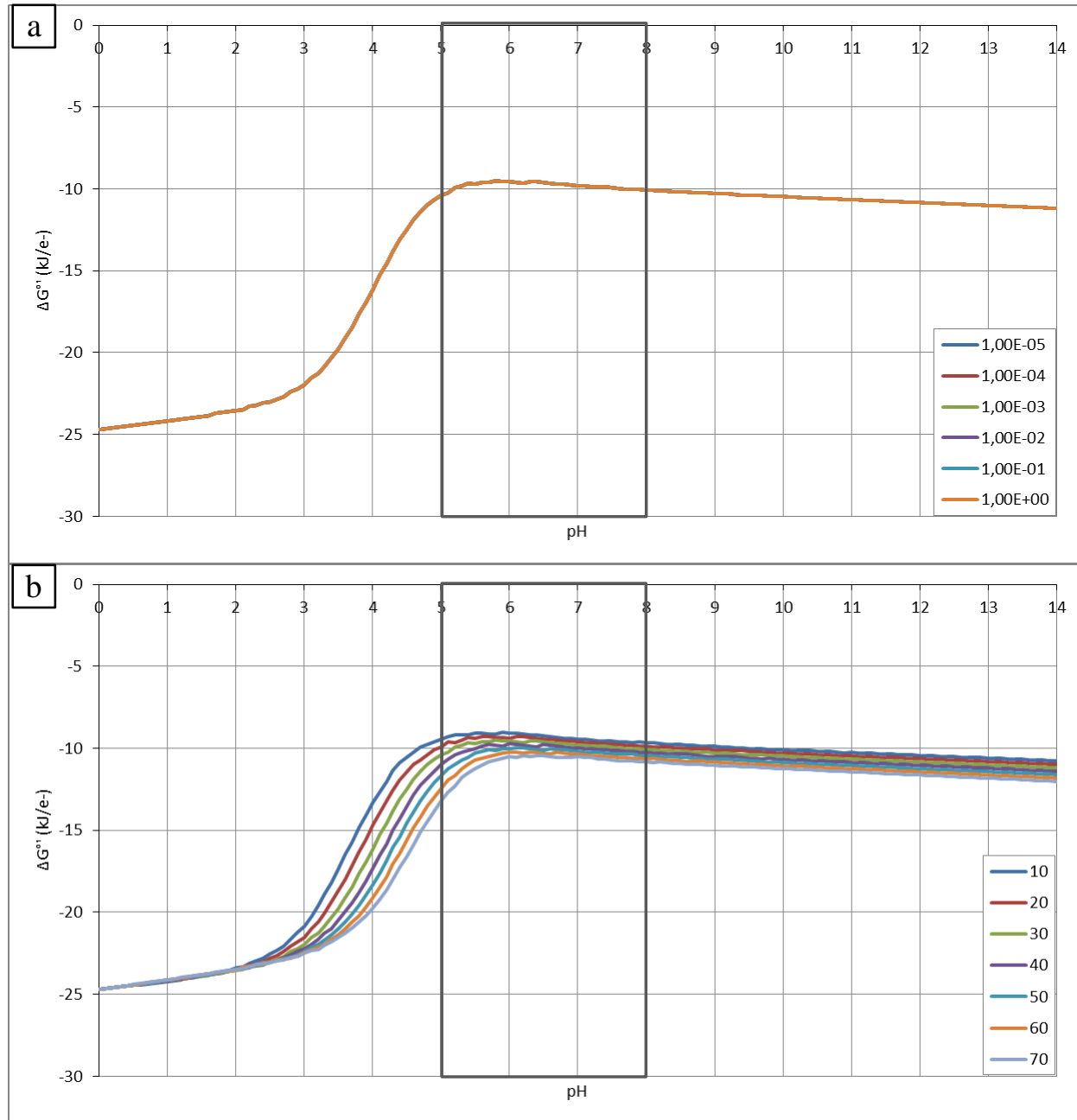

Figura 15. Energia livre da fermentação de glicose para produção de lactato e etanol (fermentação heteroláctica) como função a) do $\mathrm{pH}$ e pressão parcial de hidrogênio (atm) e b) do $\mathrm{pH}$ e temperatura $\left({ }^{\circ} \mathrm{C}\right)$. 
Tabela 7. Biorreação do modelo biotermodinâmico e estequiometria $\left(\mathrm{T}=30^{\circ} \mathrm{C}\right) \mathrm{da}$ fermentação de glicose para produção de acetato (fermentação homoacética).

\begin{tabular}{|c|c|c|c|}
\hline \multicolumn{2}{|c|}{ Reação 47} & $f_{s}^{\circ}$ & $\begin{array}{c}\Delta_{r} G^{\circ} \\
\Delta_{r} H^{\circ} \\
\left(\mathrm{kJ} \mathrm{e}^{-} \mathrm{eq}^{-1}\right)\end{array}$ \\
\hline 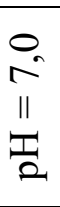 & $\begin{array}{l}4,17 \times 10^{-2} \mathrm{C}_{6} \mathrm{H}_{12} \mathrm{O}_{6}+9,48 \times 10^{-3} \mathrm{NH}_{4}^{+}+9,58 \times 10^{-5} \mathrm{NH}_{3}+3,83 \times 10^{-4} \mathrm{H}_{2} \mathrm{PO}_{4}^{-} \\
+1,92 \times 10^{-4} \mathrm{HPO}_{4}{ }^{2-}+4,79 \times 10^{-4} \mathrm{H}_{2} \mathrm{~S}+4,79 \times 10^{-4} \mathrm{HS}^{-}+9,09 \times 10^{-2} \mathrm{H}_{2} \mathrm{O} \rightleftharpoons \\
9,58 \times 10^{-3} \mathrm{C}_{5} \mathrm{H}_{7} \mathrm{O}_{2} \mathrm{NP}_{0,06} \mathrm{~S}_{0,1}+6,66 \times 10^{-2} \mathrm{C}_{2} \mathrm{H}_{3} \mathrm{O}_{2}^{-}+6,73 \times 10^{-4} \mathrm{C}_{2} \mathrm{H}_{4} \mathrm{O}_{2}+ \\
1,35 \times 10^{-1} \mathrm{H}_{2}+1,18 \times 10^{-2} \mathrm{CO}_{2}+5,58 \times 10^{-2} \mathrm{HCO}_{3}+1,28 \times 10^{-1} \mathrm{H}^{+}\end{array}$ & 0,19 & $\begin{array}{c}-13,5 \\
0,8\end{array}$ \\
\hline $\begin{array}{l}n \\
n_{0} \\
11 \\
\tilde{I}_{2}\end{array}$ & $\begin{array}{l}4,17 \times 10^{-2} \mathrm{C}_{6} \mathrm{H}_{12} \mathrm{O}_{6}+9,50 \times 10^{-3} \mathrm{NH}_{4}^{+}+4,75 \times 10^{-4} \mathrm{H}_{2} \mathrm{PO}_{4}^{-}+9,50 \times 10^{-} \\
{ }^{5} \mathrm{HPO}_{4}{ }^{2-}+7,60 \times 10^{-4} \mathrm{H}_{2} \mathrm{~S}+1,90 \times 10^{-4} \mathrm{HS}^{-}+7,45 \times 10^{-2} \mathrm{H}_{2} \mathrm{O} \rightleftharpoons 9,50 \times 10^{-} \\
{ }^{3} \mathrm{C}_{5} \mathrm{H}_{7} \mathrm{O}_{2} \mathrm{NP}_{0,06} \mathrm{~S}_{0,1}+6,61 \times 10^{-2} \mathrm{C}_{2} \mathrm{H}_{3} \mathrm{O}_{2}^{-}+1,35 \times 10^{-3} \mathrm{C}_{2} \mathrm{H}_{4} \mathrm{O}_{2}+1,35 \times 10^{-1} \mathrm{H}_{2} \\
+2,74 \times 10^{-2} \mathrm{CO}_{2}+4,03 \times 10^{-2} \mathrm{HCO}_{3}+1,10 \times 10^{-1} \mathrm{H}^{+}\end{array}$ & 0,19 & $\begin{array}{c}-13,4 \\
0,4\end{array}$ \\
\hline $\begin{array}{l}n \\
n \\
11 \\
\frac{\pi}{2}\end{array}$ & $\begin{array}{l}4,17 \times 10^{-2} \mathrm{C}_{6} \mathrm{H}_{12} \mathrm{O}_{6}+1,08 \times 10^{-2} \mathrm{NH}_{4}{ }^{+}+6,47 \times 10^{-4} \mathrm{H}_{2} \mathrm{PO}_{4}^{-}+1,08 \times 10^{-3} \mathrm{H}_{2} \mathrm{~S}+ \\
1,96 \times 10^{-2} \mathrm{H}_{2} \mathrm{O} \rightleftharpoons 1,08 \times 10^{-2} \mathrm{C}_{5} \mathrm{H}_{7} \mathrm{O}_{2} \mathrm{NP}_{0,06} \mathrm{~S}_{0,1}+5,55 \times 10^{-2} \mathrm{C}_{2} \mathrm{H}_{3} \mathrm{O}_{2}{ }^{-}+ \\
9,79 \times 10^{-3} \mathrm{C}_{2} \mathrm{H}_{4} \mathrm{O}_{2}+1,31 \times 10^{-1} \mathrm{H}_{2}+5,70 \times 10^{-2} \mathrm{CO}_{2}+8,52 \times 10^{-3} \mathrm{HCO}_{3}+ \\
3,50 \times 10^{-2} \mathrm{H}^{+}\end{array}$ & 0,22 & $\begin{array}{c}-15,1 \\
-4,7\end{array}$ \\
\hline
\end{tabular}
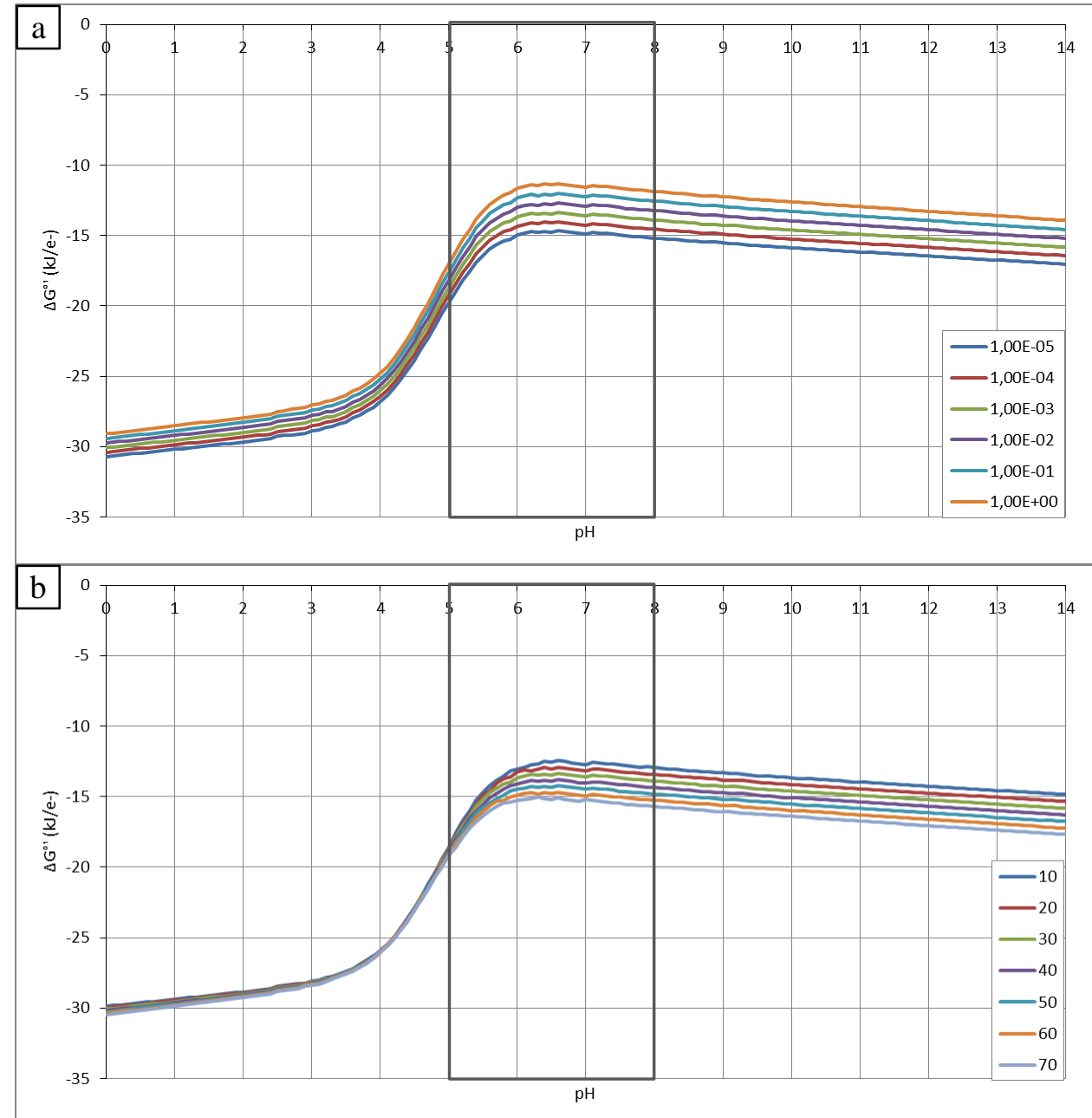

Figura 16. Energia livre da fermentação de glicose para produção de acetato (fermentação homoacética) como função a) do $\mathrm{pH}$ e pressão parcial de hidrogênio (atm) e b) do pH e temperatura $\left({ }^{\circ} \mathrm{C}\right)$. 
Tabela 8. Biorreação do modelo biotermodinâmico e estequiometria $\left(\mathrm{T}=30^{\circ} \mathrm{C}\right) \mathrm{da}$ fermentação de lactato para produção de acetato e propionato.

Reação 48

$$
\mathrm{R}=f_{s} 22+f e^{\circ}(7 / 932+2 / 933)-35
$$

$\Delta_{r} G^{\circ}$

$\Delta_{r} H^{\circ}$

$\left(\mathrm{kJ} \mathrm{e}^{-} \mathrm{eq}^{-1}\right)$

\begin{tabular}{|c|c|c|c|}
\hline & $\begin{array}{l}8,33 \times 10^{-2} \mathrm{C}_{3} \mathrm{H}_{5} \mathrm{O}_{3}^{-}+2,73 \times 10^{-3} \mathrm{NH}_{4}^{+}+2,76 \times 10^{-5} \mathrm{NH}_{3}+1,10 \times 10^{-4} \mathrm{H}_{2} \mathrm{PO}_{4}^{-}+ \\
5,51 \times 10^{-5} \mathrm{HPO}_{4}{ }^{2-}+1,38 \times 10^{-4} \mathrm{H}_{2} \mathrm{~S}+1,38 \times 10^{-4} \mathrm{HS}^{-} \rightleftharpoons 2,76 \times 10^{-} \\
{ }^{3} \mathrm{C}_{5} \mathrm{H}_{7} \mathrm{O}_{2} \mathrm{NP}_{0,06} \mathrm{~S}_{0,1}+5,20 \times 10^{-2} \mathrm{C}_{3} \mathrm{H}_{5} \mathrm{O}_{2}^{-}+5,25 \times 10^{-4} \mathrm{C}_{3} \mathrm{H}_{6} \mathrm{O}_{2}+2,60 \times 10^{-} \\
{ }^{2} \mathrm{C}_{2} \mathrm{H}_{3} \mathrm{O}_{2}^{-}+2,62 \times 10^{-4} \mathrm{C}_{2} \mathrm{H}_{4} \mathrm{O}_{2}+4,74 \times 10^{-3} \mathrm{CO}_{2}+2,20 \times 10^{-2} \mathrm{HCO}_{3}^{-}+ \\
1,51 \times 10^{-2} \mathrm{H}_{2} \mathrm{O}+1,54 \times 10^{-2} \mathrm{H}^{+}\end{array}$ & 0,06 & $\begin{array}{l}-4,8 \\
-3,7\end{array}$ \\
\hline & $\begin{array}{l}8,33 \times 10^{-2} \mathrm{C}_{3} \mathrm{H}_{5} \mathrm{O}_{3}^{-}+2,85 \times 10^{-3} \mathrm{NH}_{4}^{+}+1,43 \times 10^{-4} \mathrm{H}_{2} \mathrm{PO}_{4}^{-}+2,85 \times 10^{-5} \mathrm{HPO}_{4}{ }^{2-} \\
+2,28 \times 10^{-4} \mathrm{H}_{2} \mathrm{~S}+5,70 \times 10^{-5} \mathrm{HS}^{-} \rightleftharpoons 2,85 \times 10^{-3} \mathrm{C}_{5} \mathrm{H}_{7} \mathrm{O}_{2} \mathrm{NP}_{0,06} \mathrm{~S}_{0,1}+5,13 \times 10^{-} \\
{ }^{2} \mathrm{C}_{3} \mathrm{H}_{5} \mathrm{O}_{2}^{-}+1,05 \times 10^{-3} \mathrm{C}_{3} \mathrm{H}_{6} \mathrm{O}_{2}+2,57 \times 10^{-2} \mathrm{C}_{2} \mathrm{H}_{3} \mathrm{O}_{2}^{-}+5,24 \times 10^{-4} \mathrm{C}_{2} \mathrm{H}_{4} \mathrm{O}_{2}+ \\
1,08 \times 10^{-2} \mathrm{CO}_{2}+1,59 \times 10^{-2} \mathrm{HCO}_{3}+2,30 \times 10^{-2} \mathrm{H}_{2} \mathrm{O}+5,44 \times 10^{-3} \mathrm{H}^{+}\end{array}$ & 0,06 & $\begin{array}{l}-5,0 \\
-4,2\end{array}$ \\
\hline & $\begin{array}{l}8,08 \times 10^{-2} \mathrm{C}_{3} \mathrm{H}_{5} \mathrm{O}_{3}^{-}+2,50 \times 10^{-3} \mathrm{C}_{3} \mathrm{H}_{6} \mathrm{O}_{3}+4,24 \times 10^{-3} \mathrm{NH}_{4}^{+}+2,54 \times 10^{-4} \mathrm{H}_{2} \mathrm{PO}_{4}^{-} \\
+4,24 \times 10^{-4} \mathrm{H}_{2} \mathrm{~S}+4,96 \times 10^{-2} \mathrm{H}^{+} \rightleftharpoons 4,24 \times 10^{-3} \mathrm{C}_{5} \mathrm{H}_{7} \mathrm{O}_{2} \mathrm{NP}_{0,06} \mathrm{~S}_{0,1}+4,12 \times 10^{-} \\
{ }^{2} \mathrm{C}_{3} \mathrm{H}_{5} \mathrm{O}_{2}^{-}+9,66 \times 10^{-3} \mathrm{C}_{3} \mathrm{H}_{6} \mathrm{O}_{2}+2,16 \times 10^{-2} \mathrm{C}_{2} \mathrm{H}_{3} \mathrm{O}_{2}^{-}+3,81 \times 10^{-3} \mathrm{C}_{2} \mathrm{H}_{4} \mathrm{O}_{2}+ \\
3,59 \times 10^{-2} \mathrm{C}_{2} \mathrm{H}_{6} \mathrm{O}+2,22 \times 10^{-2} \mathrm{CO}_{2}+3,32 \times 10^{-3} \mathrm{HCO}_{3}+5,52 \times 10^{-2} \mathrm{H}_{2} \mathrm{O}\end{array}$ & 0,09 & $\begin{array}{l}-7,3 \\
-8,8\end{array}$ \\
\hline
\end{tabular}
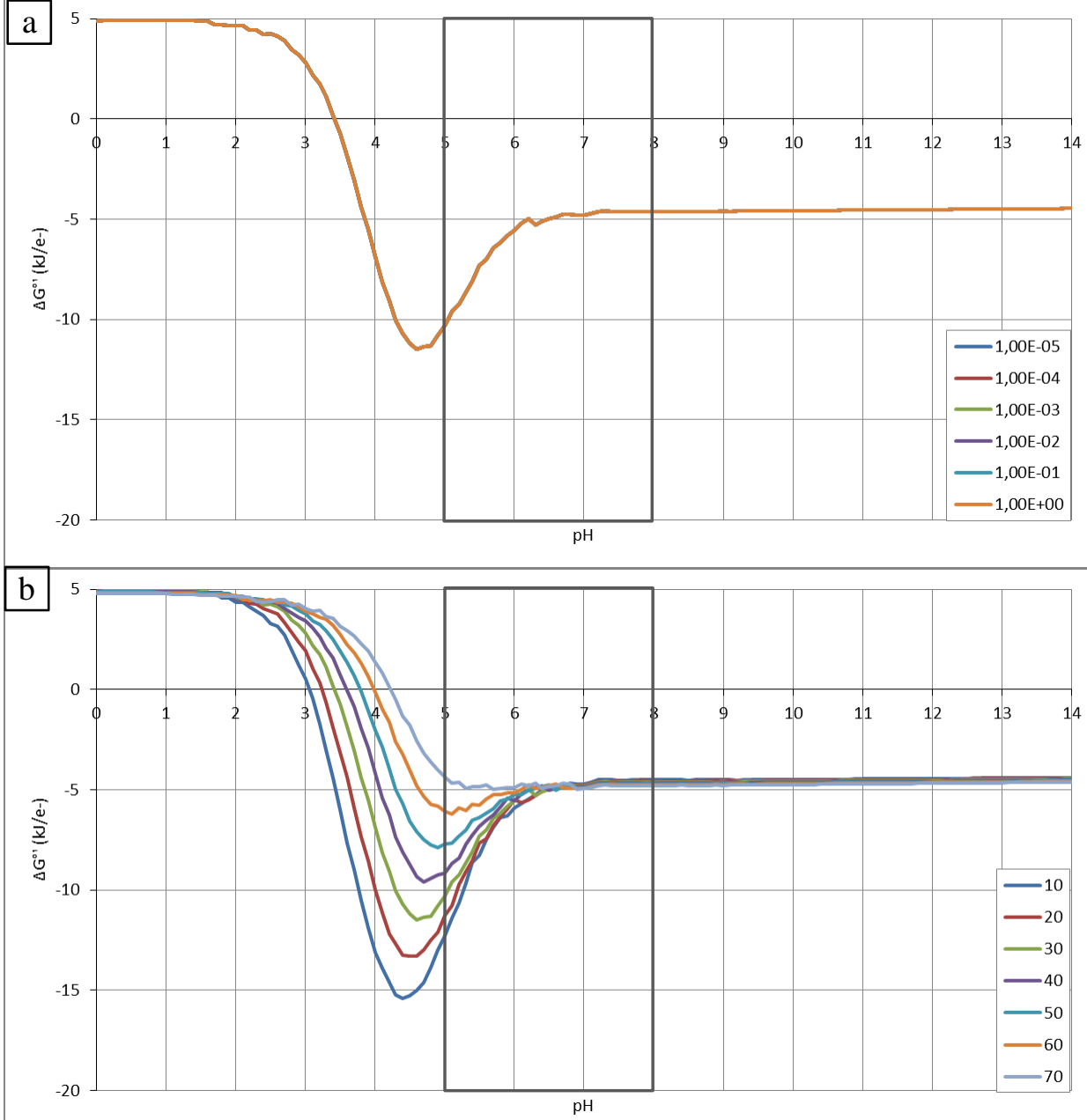

Figura 17. Energia livre da fermentação de lactato para produção de acetato e propionato como função a) do $\mathrm{pH}$ e pressão parcial de hidrogênio (atm) e b) do $\mathrm{pH}$ e temperatura $\left({ }^{\circ} \mathrm{C}\right)$. 
Tabela 9. Biorreação do modelo biotermodinâmico e estequiometria $\left(\mathrm{T}=30^{\circ} \mathrm{C}\right) \mathrm{da}$ fermentação de lactato para produção de propionato.

Reação 49

$$
\mathrm{R}=f_{s}\left[22+f e^{0} 33-(1 / 729+6 / 735)\right.
$$

$\Delta_{r} G^{\circ}$

$\Delta_{r} H^{\circ}$

$\left(\mathrm{kJ} \mathrm{e}^{-} \mathrm{eq}^{-1}\right)$

\begin{tabular}{|c|c|c|c|}
\hline$\stackrel{0}{11}$ & $\begin{array}{l}7,14 \times 10^{-2} \mathrm{C}_{3} \mathrm{H}_{5} \mathrm{O}_{3}^{-}+7,14 \times 10^{-2} \mathrm{H}_{2}+2,34 \times 10^{-4} \mathrm{CO}_{2}+1,13 \times 10^{-3} \mathrm{HCO}_{3}^{-}+ \\
1,95 \times 10^{-3} \mathrm{NH}_{4}^{+}+1,97 \times 10^{-5} \mathrm{NH}_{3}+7,87 \times 10^{-5} \mathrm{H}_{2} \mathrm{PO}_{4}^{-}+3,94 \times 10^{-5} \mathrm{HPO}_{4}{ }^{2-}+ \\
9,84 \times 10^{-5} \mathrm{H}_{2} \mathrm{~S}+9,84 \times 10^{-5} \mathrm{HS}^{-}+5,69 \times 10^{-3} \mathrm{H}^{+} \rightleftharpoons 1,97 \times 10^{-3} \mathrm{C}_{5} \mathrm{H}_{7} \mathrm{O}_{2} \mathrm{NP}_{0,06} \mathrm{~S}_{0,1} \\
+6,79 \times 10^{-2} \mathrm{C}_{3} \mathrm{H}_{5} \mathrm{O}_{2}+6,86 \times 10^{-4} \mathrm{C}_{3} \mathrm{H}_{6} \mathrm{O}_{2}+7,88 \times 10^{-2} \mathrm{H}_{2} \mathrm{O}\end{array}$ & 0,04 & $\begin{array}{l}-3,5 \\
-7,4\end{array}$ \\
\hline $\begin{array}{l}n \\
6 \\
11 \\
\frac{\pi}{2}\end{array}$ & $\begin{array}{l}7,14 \times 10^{-2} \mathrm{C}_{3} \mathrm{H}_{5} \mathrm{O}_{3}^{-}+7,14 \times 10^{-2} \mathrm{H}_{2}+5,66 \times 10^{-4} \mathrm{CO}_{2}+8,72 \times 10^{-4} \mathrm{HCO}_{3}^{-}+ \\
2,80 \times 10^{-3} \mathrm{NH}_{4}^{+}+1,04 \times 10^{-4} \mathrm{H}_{2} \mathrm{PO}_{4}^{-}+2,08 \times 10^{-5} \mathrm{HPO}_{4}{ }^{2-}+1,66 \times 10^{-4} \mathrm{H}_{2} \mathrm{~S}+ \\
4,15 \times 10^{-5} \mathrm{HS}^{-}+8,81 \times 10^{-3} \mathrm{H}^{+} \rightleftharpoons 2,08 \times 10^{-3} \mathrm{C}_{5} \mathrm{H}_{7} \mathrm{O}_{2} \mathrm{NP}_{0,06} \mathrm{~S}_{0,1}+6,71 \times 10^{-} \\
{ }^{2} \mathrm{C}_{3} \mathrm{H}_{5} \mathrm{O}_{2}^{-}+1,37 \times 10^{-3} \mathrm{C}_{3} \mathrm{H}_{6} \mathrm{O}_{2}+8,02 \times 10^{-2} \mathrm{H}_{2} \mathrm{O}\end{array}$ & 0,04 & $\begin{array}{l}-3,7 \\
-7,8\end{array}$ \\
\hline & $\begin{array}{l}6,93 \times 10^{-2} \mathrm{C}_{3} \mathrm{H}_{5} \mathrm{O}_{3}^{-}+2,14 \times 10^{-3} \mathrm{C}_{3} \mathrm{H}_{6} \mathrm{O}_{3}+7,14 \times 10^{-2} \mathrm{H}_{2}+2,08 \times 10^{-3} \mathrm{CO}_{2}+ \\
3,11 \times 10^{-4} \mathrm{HCO}_{3}^{-}+3,45 \times 10^{-3} \mathrm{NH}_{4}^{+}+2,07 \times 10^{-4} \mathrm{H}_{2} \mathrm{PO}_{4}^{-}+3,45 \times 10^{-4} \mathrm{H}_{2} \mathrm{~S}+ \\
5,02 \times 10^{-2} \mathrm{H}^{+} \rightleftharpoons 3,45 \times 10^{-3} \mathrm{C}_{5} \mathrm{H}_{7} \mathrm{O}_{2} \mathrm{NP}_{0,06} \mathrm{~S}_{0,1}+5,38 \times 10^{-2} \mathrm{C}_{3} \mathrm{H}_{5} \mathrm{O}_{2}^{-}+1,26 \times 10^{-} \\
{ }^{2} \mathrm{C}_{3} \mathrm{H}_{6} \mathrm{O}_{2}+9,92 \times 10^{-2} \mathrm{H}_{2} \mathrm{O}\end{array}$ & 0,07 & $\begin{array}{c}-6,1 \\
-12,2\end{array}$ \\
\hline
\end{tabular}
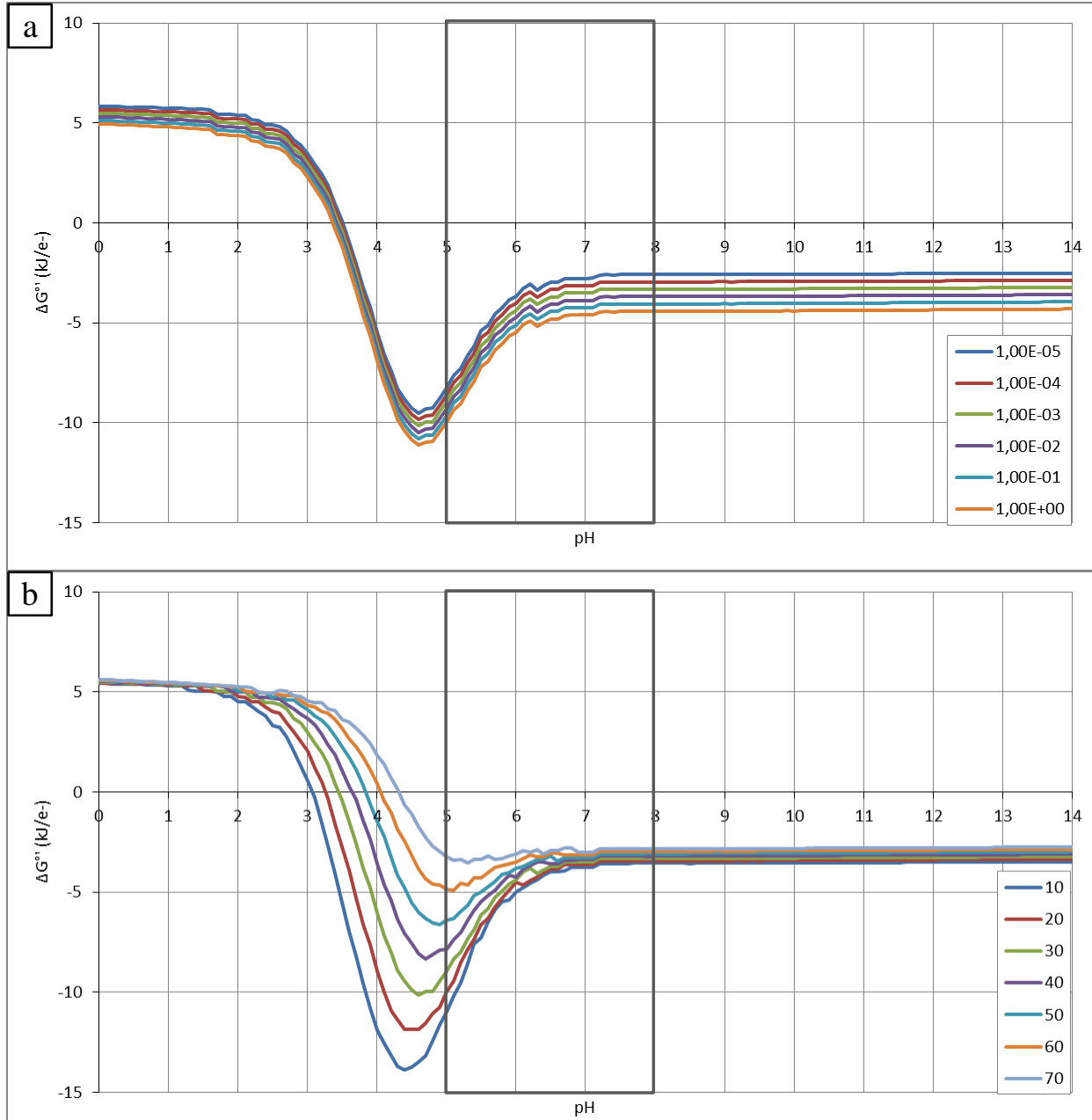

Figura 18. Energia livre da fermentação de lactato para produção de propionato como função a) do $\mathrm{pH}$ e pressão parcial de hidrogênio (atm) e b) do $\mathrm{pH}$ e temperatura $\left({ }^{\circ} \mathrm{C}\right)$. 
livre dissipada garante um maior deslocamento da reação para os produtos, ou seja, uma maior conversão (aumento da constante de equilíbrio).

Para as fermentações homoláctica (Figura 14a) e heteroláctica (Figura 15a), a energia livre dissipada aumenta significativamente para $\mathrm{pH}$ inferiores a 5,0 (a $\left.30^{\circ} \mathrm{C}\right)$, e para valores inferiores a 4,0 as diferenças entre ambas começam a ser significativas, favorecendo a fermentação homoláctica.

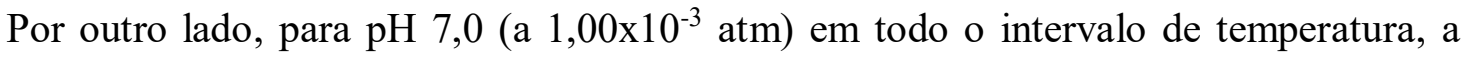
fermentação a butirato (Figura 13b) dissipa mais energia livre que a fermentação a lactato (Figuras 14b e 15b), mas menos que a fermentação a acetato (Figura 16b). A situação continua igual para pH 5,0, mas para pH aproximado a 3,0 a fermentação homoláctica (Figura 15b) dissipa mais energia livre que a fermentação a butirato (Figura 13b) e acetato (Figura 16b). Deste comportamento se conclui que para $\mathrm{pH}$ inferiores a aproximadamente $3,0\left(\mathrm{a} 1,00 \times 10^{-3}\right.$ atm), sem considerar a inibição biológica, a fermentação a lactato tem maiores conversões que a butirato e acetato; enquanto para $\mathrm{pH}$ superiores a maior conversão é para a fermentação a acetato.

Para todas essas fermentações, o aumento na temperatura aumenta a energia livre dissipada e o aumento na pressão parcial de hidrogênio a diminui nas fermentações a butirato e acetato, ainda até valores positivos. Nas fermentações homoláctica e heteroláctica, a pressão parcial de hidrogênio não influi porque o hidrogênio não faz parte da reação.

As fermentações de lactato a propionato e acetato (Figuras 17a e 18a) são espontâneas para $\mathrm{pH}$ aproximados a 3,5 e superiores (a $30^{\circ} \mathrm{C}$ ), com máximos de dissipação de energia livre em pH entre 4,0 e 5,0, favorecida pela diminuição na temperatura (Figuras 17b e 18b). Enquanto, para uma temperatura de $10^{\circ} \mathrm{C}$, o processo é espontâneo para $\mathrm{pH}$ aproximado a 3,0 e superiores, para $60{ }^{\circ} \mathrm{C}$ é espontâneo para $\mathrm{pH}$ aproximado a 4,0 e superiores (a $1,00 \times 10^{-3}$ atm). A fermentação "heteropropiónica" (Reação 48) não depende da pressão parcial de hidrogênio porque o hidrogênio não participa na reação, mas sim participa na “homopropiónica” (Reação 49).

\subsubsection{Comportamento dos processos acetogênicos}

Os resultados da aplicação do modelo biotermodinâmico aos metabolismos acetogénicos discutidos na Seção 4.1.2 se apresentam nas Tabelas 10 a 14 (Reações 50 a 54), nas quais se inclui a estequiometria da reação para diferentes $\mathrm{pH}\left(\right.$ temperatura de $30^{\circ} \mathrm{C}$ ), e 
Tabela 10. Biorreação do modelo biotermodinâmico e estequiometria $\left(\mathrm{T}=30{ }^{\circ} \mathrm{C}\right) \mathrm{da}$ fermentação de lactato para produção de acetato.

\begin{tabular}{|c|c|c|c|}
\hline \multicolumn{2}{|r|}{$\mathrm{R}=f s 22+f e^{\circ}(1 / 329+2 / 332)-35$} & $f_{s}^{0}$ & $\begin{array}{c}\Delta_{r} G^{\circ} \\
\Delta_{r} H^{\circ} \\
\left(\mathrm{kJ} \mathrm{e}^{-} \mathrm{eq}^{-1}\right)\end{array}$ \\
\hline 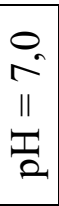 & $\begin{array}{l}8,33 \times 10^{-2} \mathrm{C}_{3} \mathrm{H}_{5} \mathrm{O}_{3}^{-}+3,49 \times 10^{-3} \mathrm{NH}_{4}^{+}+3,52 \times 10^{-5} \mathrm{NH}_{3}+1,41 \times 10^{-4} \mathrm{H}_{2} \mathrm{PO}_{4}^{-} \\
+7,04 \times 10^{-5} \mathrm{HPO}_{4}{ }^{2-}+1,76 \times 10^{-4} \mathrm{H}_{2} \mathrm{~S}+1,76 \times 10^{-4} \mathrm{HS}^{-}+1,28 \times 10^{-1} \mathrm{H}_{2} \mathrm{O} \rightleftharpoons \\
3,52 \times 10^{-3} \mathrm{C}_{5} \mathrm{H}_{7} \mathrm{O}_{2} \mathrm{NP}_{0,06} \mathrm{~S}_{0,1}+7,67 \times 10^{-2} \mathrm{C}_{2} \mathrm{H}_{3} \mathrm{O}_{2}^{-}+7,74 \times 10^{-4} \mathrm{C}_{2} \mathrm{H}_{4} \mathrm{O}_{2}+ \\
1,55 \times 10^{-1} \mathrm{H}_{2}+1,40 \times 10^{-2} \mathrm{CO}_{2}+6,36 \times 10^{-2} \mathrm{HCO}_{3}+5,68 \times 10^{-2} \mathrm{H}^{+}\end{array}$ & 0,07 & $\begin{array}{c}-6,1 \\
5,4\end{array}$ \\
\hline $\begin{array}{l}n \\
\sigma^{\prime} \\
\| \\
{ }^{2}\end{array}$ & $\begin{array}{l}8,33 \times 10^{-2} \mathrm{C}_{3} \mathrm{H}_{5} \mathrm{O}_{3}^{-}+3,56 \times 10^{-3} \mathrm{NH}_{4}^{+}+1,78 \times 10^{-4} \mathrm{H}_{2} \mathrm{PO}_{4}^{-}+3,56 \times 10^{-} \\
{ }^{5} \mathrm{HPO}_{4}{ }^{2-}+2,84 \times 10^{-4} \mathrm{H}_{2} \mathrm{~S}+7,11 \times 10^{-5} \mathrm{HS}^{-}+1,09 \times 10^{-1} \mathrm{H}_{2} \mathrm{O} \rightleftharpoons 3,56 \times 10^{-} \\
{ }^{3} \mathrm{C}_{5} \mathrm{H}_{7} \mathrm{O}_{2} \mathrm{NP}_{0,06} \mathrm{~S}_{0,1}+7,58 \times 10^{-2} \mathrm{C}_{2} \mathrm{H}_{3} \mathrm{O}_{2}^{-}+1,55 \times 10^{-3} \mathrm{C}_{2} \mathrm{H}_{4} \mathrm{O}_{2}+1,55 \times 10^{-1} \mathrm{H}_{2} \\
+3,18 \times 10^{-2} \mathrm{CO}_{2}+4,57 \times 10^{-2} \mathrm{HCO}_{3}{ }^{-}+3,52 \times 10^{-2} \mathrm{H}^{+}\end{array}$ & 0,07 & $\begin{array}{c}-6,2 \\
4,9\end{array}$ \\
\hline $\begin{array}{l}n \\
n \\
11 \\
2\end{array}$ & $\begin{array}{l}8,08 \times 10^{-2} \mathrm{C}_{3} \mathrm{H}_{5} \mathrm{O}_{3}^{-}+2,50 \times 10^{-3} \mathrm{C}_{3} \mathrm{H}_{6} \mathrm{O}_{3}+4,48 \times 10^{-3} \mathrm{NH}_{4}^{+}+2,69 \times 10^{-} \\
{ }^{4} \mathrm{H}_{2} \mathrm{PO}_{4}^{-}+4,48 \times 10^{-4} \mathrm{H}_{2} \mathrm{~S}+5,61 \times 10^{-2} \mathrm{H}_{2} \mathrm{O}+3,28 \times 10^{-2} \mathrm{H}^{+} \rightleftharpoons 4,48 \times 10^{-} \\
{ }^{3} \mathrm{C}_{5} \mathrm{H}_{7} \mathrm{O}_{2} \mathrm{NP}_{0,06} \mathrm{~S}_{0,1}+6,45 \times 10^{-2} \mathrm{C}_{2} \mathrm{H}_{3} \mathrm{O}_{2}^{-}+1,14 \times 10^{-2} \mathrm{C}_{2} \mathrm{H}_{4} \mathrm{O}_{2}+1,51 \times 10^{-1} \mathrm{H}_{2} \\
+6,61 \times 10^{-2} \mathrm{CO}_{2}+9,87 \times 10^{-3} \mathrm{HCO}_{3}^{-}\end{array}$ & 0,09 & $\begin{array}{c}-7,7 \\
1,1\end{array}$ \\
\hline
\end{tabular}
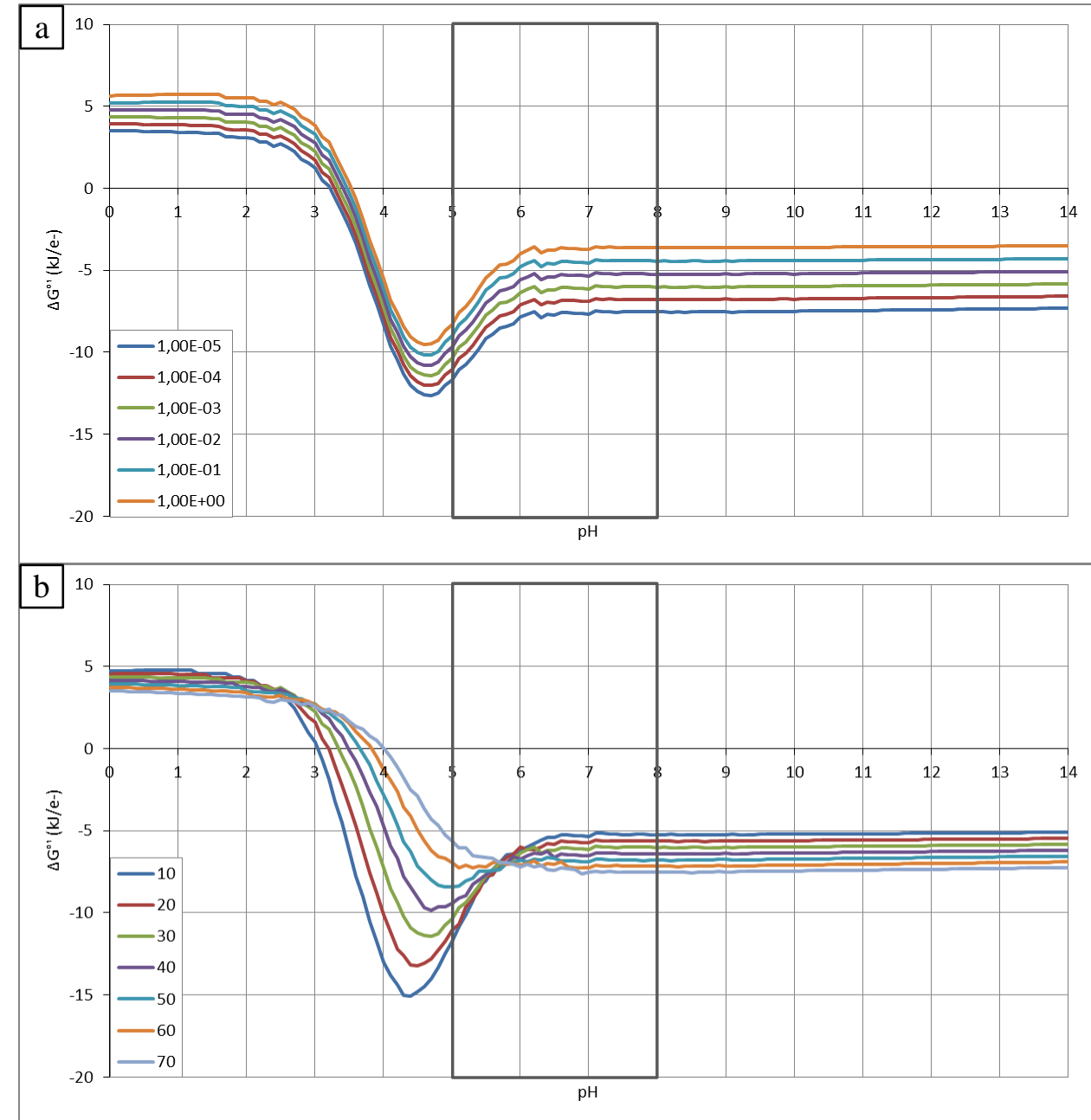

Figura 19. Energia livre da fermentação de lactato para produção de acetato como função a) do $\mathrm{pH}$ e pressão parcial de hidrogênio (atm) e b) do $\mathrm{pH}$ e temperatura $\left({ }^{\circ} \mathrm{C}\right)$. 
Tabela 11. Biorreação do modelo biotermodinâmico e estequiometria $\left(\mathrm{T}=30^{\circ} \mathrm{C}\right)$ da fermentação de propionato para produção de acetato.

\begin{tabular}{|c|c|c|c|}
\hline \multicolumn{2}{|c|}{ Reação 51} & $f_{s}^{\circ}$ & $\begin{array}{c}\Delta_{r} G^{\circ} \\
\Delta_{r} H^{\circ} \\
\left(\mathrm{kJ} \mathrm{e}^{-} \mathrm{eq}^{-1}\right)\end{array}$ \\
\hline 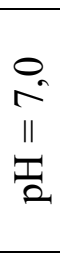 & $\begin{array}{l}7,07 \times 10^{-2} \mathrm{C}_{3} \mathrm{H}_{5} \mathrm{O}_{2}^{-}+7,14 \times 10^{-4} \mathrm{C}_{3} \mathrm{H}_{6} \mathrm{O}_{2}+9,39 \times 10^{-4} \mathrm{NH}_{4}^{+}+9,48 \times 10^{-6} \mathrm{NH}_{3} \\
+3,79 \times 10^{-5} \mathrm{H}_{2} \mathrm{PO}_{4}^{-}+1,90 \times 10^{-5} \mathrm{HPO}_{4}^{2-}+4,74 \times 10^{-5} \mathrm{H}_{2} \mathrm{~S}+4,74 \times 10^{-5} \mathrm{HS}^{-}+ \\
1,95 \times 10^{-1} \mathrm{H}_{2} \mathrm{O} \rightleftharpoons 9,48 \times 10^{-4} \mathrm{C}_{5} \mathrm{H}_{7} \mathrm{O}_{2} \mathrm{NP}_{0,06} \mathrm{~S}_{0,1}+6,94 \times 10^{-2} \mathrm{C}_{2} \mathrm{H}_{3} \mathrm{O}_{2}{ }^{-}+ \\
7,01 \times 10^{-4} \mathrm{C}_{2} \mathrm{H}_{4} \mathrm{O}_{2}+2,10 \times 10^{-1} \mathrm{H}_{2}+1,25 \times 10^{-2} \mathrm{CO}_{2}+5,69 \times 10^{-2} \mathrm{HCO}_{3}+ \\
5,64 \times 10^{-2} \mathrm{H}^{+}\end{array}$ & 0,02 & $\begin{array}{l}-1,8 \\
12,4\end{array}$ \\
\hline $\begin{array}{l}n \\
\sigma_{0} \\
11 \\
2\end{array}$ & $\begin{array}{l}7,00 \times 10^{-2} \mathrm{C}_{3} \mathrm{H}_{5} \mathrm{O}_{2}^{-}+1,43 \times 10^{-3} \mathrm{C}_{3} \mathrm{H}_{6} \mathrm{O}_{2}+8,77 \times 10^{-4} \mathrm{NH}_{4}+4,38 \times 10^{-} \\
{ }^{5} \mathrm{H}_{2} \mathrm{PO}_{4}{ }^{-}+8,77 \times 10^{-6} \mathrm{HPO}_{4}{ }^{2-}+7,02 \times 10^{-5} \mathrm{H}_{2} \mathrm{~S}+1,75 \times 10^{-5} \mathrm{HS}^{-}+1,79 \times 10^{-} \\
{ }^{1} \mathrm{H}_{2} \mathrm{O} \rightleftharpoons 8,77 \times 10^{-4} \mathrm{C}_{5} \mathrm{H}_{7} \mathrm{O}_{2} \mathrm{NP}_{0,06} \mathrm{~S}_{0,1}+6,88 \times 10^{-2} \mathrm{C}_{2} \mathrm{H}_{3} \mathrm{O}_{2}^{-}+1,40 \times 10^{-} \\
{ }^{3} \mathrm{C}_{2} \mathrm{H}_{4} \mathrm{O}_{2}+2,11 \times 10^{-1} \mathrm{H}_{2}+2,85 \times 10^{-2} \mathrm{CO}_{2}+4,10 \times 10^{-2} \mathrm{HCO}_{3}+4,07 \times 10^{-2} \mathrm{H}^{+}\end{array}$ & 0,02 & $\begin{array}{l}-1,7 \\
12,3\end{array}$ \\
\hline $\begin{array}{l}n \\
n \\
n \\
2\end{array}$ & $\begin{array}{l}5,97 \times 10^{-2} \mathrm{C}_{3} \mathrm{H}_{5} \mathrm{O}_{2}^{-}+1,36 \times 10^{-2} \mathrm{C}_{3} \mathrm{H}_{6} \mathrm{O}_{2}+3,18 \times 10^{-4} \mathrm{NH}_{4}^{+}+1,91 \times 10^{-} \\
{ }^{5} \mathrm{H}_{2} \mathrm{PO}_{4}^{-}+3,18 \times 10^{-5} \mathrm{H}_{2} \mathrm{~S}+1,56 \times 10^{-1} \mathrm{H}_{2} \mathrm{O} \rightleftharpoons 3,18 \times 10^{-4} \mathrm{C}_{5} \mathrm{H}_{7} \mathrm{O}_{2} \mathrm{NP}_{0,06} \mathrm{~S}_{0,1}+ \\
6,03 \times 10^{-2} \mathrm{C}_{2} \mathrm{H}_{3} \mathrm{O}_{2}^{-}+1,06 \times 10^{-2} \mathrm{C}_{2} \mathrm{H}_{4} \mathrm{O}_{2}+2,13 \times 10^{-1} \mathrm{H}_{2}+6,16 \times 10^{-2} \mathrm{CO}_{2}+ \\
9,20 \times 10^{-3} \mathrm{HCO}_{3}^{-}+2,37 \times 10^{-2} \mathrm{H}^{+}\end{array}$ & 0,01 & $\begin{array}{l}-0,6 \\
13,8\end{array}$ \\
\hline
\end{tabular}
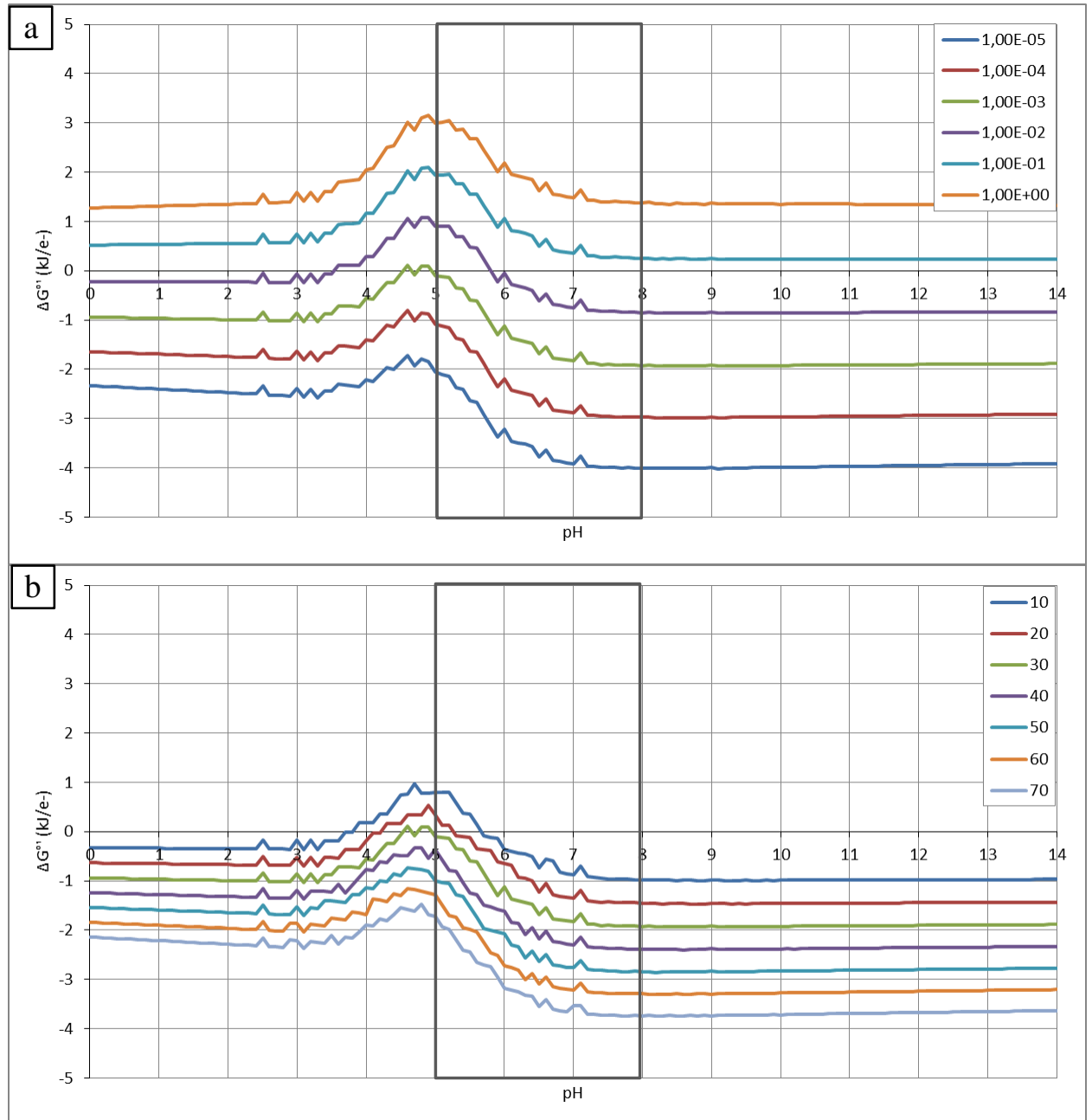

Figura 20. Energia livre da fermentação de propionato para produção de acetato como função a) do $\mathrm{pH}$ e pressão parcial de hidrogênio $(\mathrm{atm})$ e b) do $\mathrm{pH}$ e temperatura $\left({ }^{\circ} \mathrm{C}\right)$. 
Tabela 12. Biorreação do modelo biotermodinâmico e estequiometria $\left(\mathrm{T}=30{ }^{\circ} \mathrm{C}\right) \mathrm{da}$ fermentação de butirato para produção de acetato.

Reação 52

$$
\mathrm{R}=f_{s} 22+f e^{\circ}(1 / 529+4 / 532)-34
$$

$\Delta_{r} G^{\circ}$

$\Delta_{r} H^{\circ}$

$\left(\mathrm{kJ} \mathrm{e}^{-} \mathrm{eq}^{-1}\right)$

\begin{tabular}{|c|c|c|c|}
\hline م" & $\begin{array}{l}4,95 \times 10^{-2} \mathrm{C}_{4} \mathrm{H}_{7} \mathrm{O}_{2}^{-}+5,00 \times 10^{-4} \mathrm{C}_{4} \mathrm{H}_{8} \mathrm{O}_{2}+1,17 \times 10^{-4} \mathrm{CO}_{2}+5,32 \times 10^{-4} \mathrm{HCO}_{3}^{-}+ \\
6,56 \times 10^{-4} \mathrm{NH}_{4}^{+}+6,62 \times 10^{-6} \mathrm{NH}_{3}+2,65 \times 10^{-5} \mathrm{H}_{2} \mathrm{PO}_{4}^{-}+1,32 \times 10^{-5} \mathrm{HPO}_{4}^{2-}+ \\
3,31 \times 10^{-5} \mathrm{H}_{2} \mathrm{~S}+3,31 \times 10^{-5} \mathrm{HS}^{-}+9,57 \times 10^{-2} \mathrm{H}_{2} \mathrm{O} \rightleftharpoons 6,62 \times 10^{-4} \mathrm{C}_{5} \mathrm{H}_{7} \mathrm{O}_{2} \mathrm{NP}_{0,06} \mathrm{~S}_{0,1} \\
+9,97 \times 10^{-2} \mathrm{C}_{2} \mathrm{H}_{3} \mathrm{O}_{2}^{-}+9,87 \times 10^{-4} \mathrm{C}_{2} \mathrm{H}_{4} \mathrm{O}_{2}+9,87 \times 10^{-2} \mathrm{H}_{2}+4,63 \times 10^{-2} \mathrm{H}^{+}\end{array}$ & 0,01 & $\begin{array}{c}-1,3 \\
6,1\end{array}$ \\
\hline 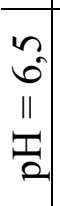 & $\begin{array}{l}4,90 \times 10^{-2} \mathrm{C}_{4} \mathrm{H}_{7} \mathrm{O}_{2}^{-}+1,00 \times 10^{-3} \mathrm{C}_{4} \mathrm{H}_{8} \mathrm{O}_{2}+8,86 \times 10^{-4} \mathrm{HCO}_{3}^{--}+6,67 \times 10^{-4} \mathrm{NH}_{4}^{+}+ \\
3,34 \times 10^{-5} \mathrm{H}_{2} \mathrm{PO}_{4}^{-}+6,67 \times 10^{-6} \mathrm{HPO}_{4}{ }^{2-}+5,34 \times 10^{-5} \mathrm{H}_{2} \mathrm{~S}+1,33 \times 10^{-5} \mathrm{HS}^{-}+ \\
9,44 \times 10^{-2} \mathrm{H}_{2} \mathrm{O} \rightleftharpoons 6,67 \times 10^{-4} \mathrm{C}_{5} \mathrm{H}_{7} \mathrm{O}_{2} \mathrm{NP}_{0,06} \mathrm{~S}_{0,1}+9,67 \times 10^{-2} \mathrm{C}_{2} \mathrm{H}_{3} \mathrm{O}_{2}+1,97 \times 10^{-} \\
{ }^{3} \mathrm{C}_{2} \mathrm{H}_{4} \mathrm{O}_{2}+9,87 \times 10^{-2} \mathrm{H}_{2}+2,32 \times 10^{-4} \mathrm{CO}_{2}+4,35 \times 10^{-2} \mathrm{H}^{+}\end{array}$ & 0,01 & $\begin{array}{c}-1,3 \\
5,8\end{array}$ \\
\hline$n^{n}$ & $\begin{array}{l}4,10 \times 10^{-2} \mathrm{C}_{4} \mathrm{H}_{7} \mathrm{O}_{2}^{-}+9,00 \times 10^{-3} \mathrm{C}_{4} \mathrm{H}_{8} \mathrm{O}_{2}+1,11 \times 10^{-3} \mathrm{CO}_{2}+1,65 \times 10^{-4} \mathrm{HCO}_{3}^{-+} \\
1,30 \times 10^{-3} \mathrm{NH}_{4}^{+}+7,79 \times 10^{-5} \mathrm{H}_{2} \mathrm{PO}_{4}^{-}+1,30 \times 10^{-4} \mathrm{H}_{2} \mathrm{~S}+8,31 \times 10^{-2} \mathrm{H}_{2} \mathrm{O} \rightleftharpoons \\
1,30 \times 10^{-3} \mathrm{C}_{5} \mathrm{H}_{7} \mathrm{O}_{2} \mathrm{NP}_{0,06} \mathrm{~S}_{0,1}+8,28 \times 10^{-2} \mathrm{C}_{2} \mathrm{H}_{3} \mathrm{O}_{2}^{-}+1,46 \times 10^{-2} \mathrm{C}_{2} \mathrm{H}_{4} \mathrm{O}_{2}+ \\
9,74 \times 10^{-2} \mathrm{H}_{2}+1,38 \times 10^{-4} \mathrm{HCO}_{3}^{-}+2,04 \times 10^{-2} \mathrm{H}^{+}\end{array}$ & 0,03 & $\begin{array}{c}-2,4 \\
3,2\end{array}$ \\
\hline
\end{tabular}
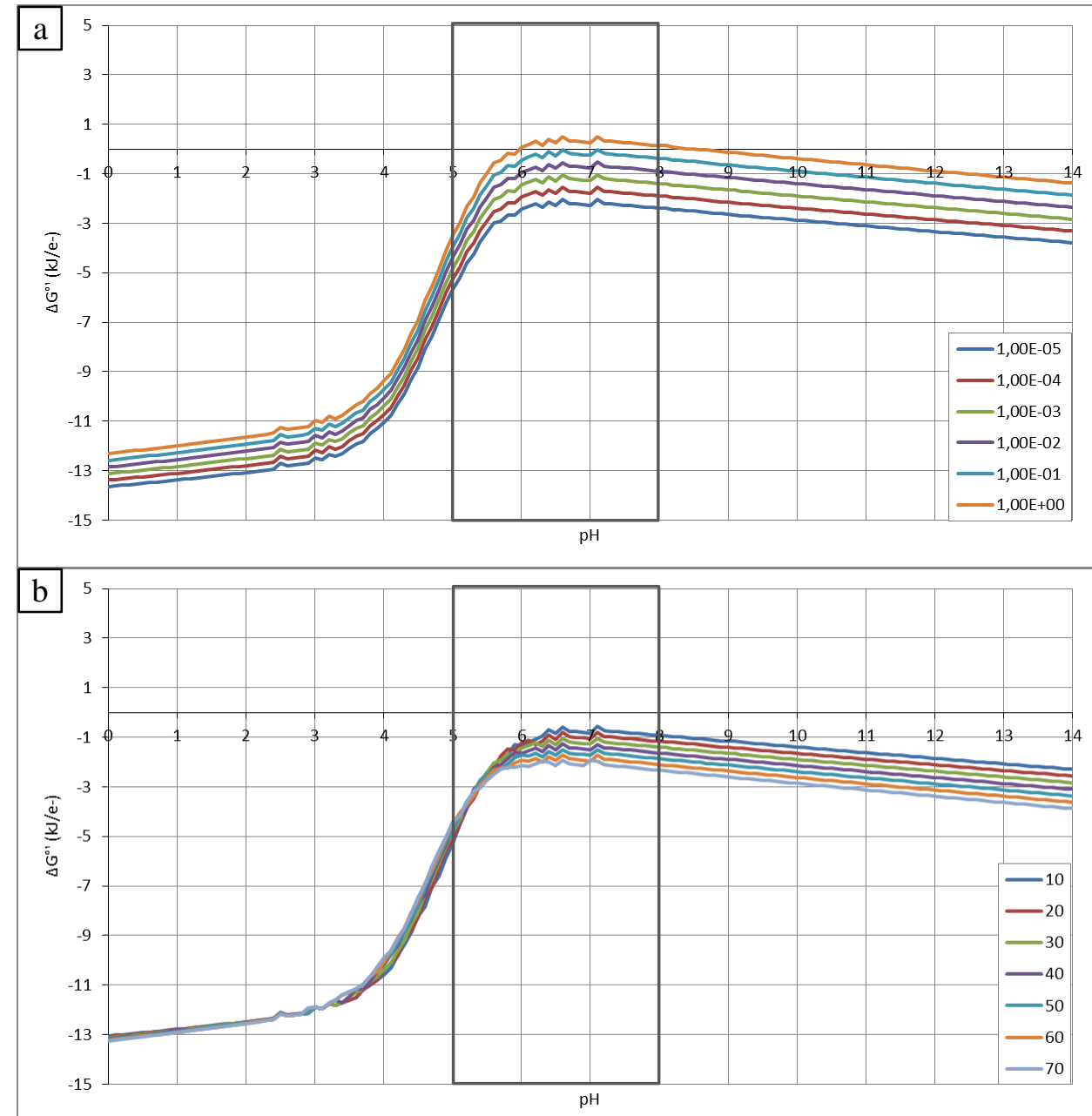

Figura 21. Energia livre da fermentação de butirato para produção de acetato como função a) do $\mathrm{pH}$ e pressão parcial de hidrogênio (atm) e b) do $\mathrm{pH}$ e temperatura $\left({ }^{\circ} \mathrm{C}\right)$. 
Tabela 13. Biorreação do modelo biotermodinâmico e estequiometria $\left(\mathrm{T}=30^{\circ} \mathrm{C}\right)$ da fermentação de etanol para produção de acetato.

\begin{tabular}{|c|c|c|c|}
\hline \multicolumn{2}{|r|}{$\mathrm{R}=f s 22+f e^{\circ}(1 / 329+2 / 332)-36$} & $f_{s}^{\circ}$ & $\begin{array}{c}\Delta_{r} G^{\circ} \\
\Delta_{r} H^{\circ} \\
\left(\mathrm{kJ} \mathrm{e}^{-} \mathrm{eq}^{-1}\right)\end{array}$ \\
\hline 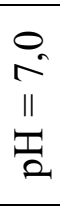 & $\begin{array}{l}8,33 \times 10^{-2} \mathrm{C}_{2} \mathrm{H}_{6} \mathrm{O}+4,66 \times 10^{-4} \mathrm{CO}_{2}+2,15 \times 10^{-3} \mathrm{HCO}_{3}^{-}+1,57 \times 10^{-3} \mathrm{NH}_{4}^{+}+ \\
1,59 \times 10^{-5} \mathrm{NH}_{3}+6,34 \times 10^{-5} \mathrm{H}_{2} \mathrm{PO}_{4}^{-}+3,17 \times 10^{-5} \mathrm{HPO}_{4}{ }^{2-}+7,93 \times 10^{-5} \mathrm{H}_{2} \mathrm{~S}+ \\
7,93 \times 10^{-5} \mathrm{HS}^{-}+7,18 \times 10^{-2} \mathrm{H}_{2} \mathrm{O} \rightleftharpoons 1,59 \times 10^{-3} \mathrm{C}_{5} \mathrm{H}_{7} \mathrm{O}_{2} \mathrm{NP}_{0,06} \mathrm{~S}_{0,1}+7,99 \times 10^{-} \\
{ }^{2} \mathrm{C}_{2} \mathrm{H}_{3} \mathrm{O}_{2}+8,07 \times 10^{-4} \mathrm{C}_{2} \mathrm{H}_{4} \mathrm{O}_{2}+1,61 \times 10^{-1} \mathrm{H}_{2}+7,59 \times 10^{-2} \mathrm{H}^{+}\end{array}$ & 0,03 & $\begin{array}{c}-3,0 \\
6,1\end{array}$ \\
\hline 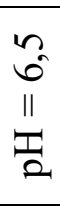 & $\begin{array}{l}8,33 \times 10^{-2} \mathrm{C}_{2} \mathrm{H}_{6} \mathrm{O}+1,07 \times 10^{-3} \mathrm{CO}_{2}+1,56 \times 10^{-3} \mathrm{HCO}_{3}^{-}+1,60 \times 10^{-3} \mathrm{NH}_{4}^{+}+ \\
7,98 \times 10^{-5} \mathrm{H}_{2} \mathrm{PO}_{4}{ }^{-}+1,60 \times 10^{-5} \mathrm{HPO}_{4}{ }^{2-}+1,28 \times 10^{-4} \mathrm{H}_{2} \mathrm{~S}+3,19 \times 10^{-5} \mathrm{HS}^{-} .+ \\
7,07 \times 10^{-2} \mathrm{H}_{2} \mathrm{O} \rightleftharpoons 1,60 \times 10^{-3} \mathrm{C}_{5} \mathrm{H}_{7} \mathrm{O}_{2} \mathrm{NP}_{0,06} \mathrm{~S}_{0,1}+7,90 \times 10^{-2} \mathrm{C}_{2} \mathrm{H}_{3} \mathrm{O}_{2}^{-}+ \\
1,61 \times 10^{-3} \mathrm{C}_{2} \mathrm{H}_{4} \mathrm{O}_{2}+1,61 \times 10^{-1} \mathrm{H}_{2}+7,25 \times 10^{-2} \mathrm{H}^{+}\end{array}$ & 0,03 & $\begin{array}{r}-3,0 \\
5,6\end{array}$ \\
\hline $\begin{array}{l}n \\
n \\
n \\
2\end{array}$ & $\begin{array}{l}8,33 \times 10^{-2} \mathrm{C}_{2} \mathrm{H}_{6} \mathrm{O}+4,27 \times 10^{-3} \mathrm{CO}_{2}+6,38 \times 10^{-4} \mathrm{HCO}_{3}^{-}+2,97 \times 10^{-3} \mathrm{NH}_{4}^{+}+ \\
1,78 \times 10^{-4} \mathrm{H}_{2} \mathrm{PO}_{4}^{-}+2,97 \times 10^{-4} \mathrm{H}_{2} \mathrm{~S}+4,46 \times 10^{-2} \mathrm{H}_{2} \mathrm{O} \rightleftharpoons 2,97 \times 10^{-} \\
{ }^{3} \mathrm{C}_{5} \mathrm{H}_{7} \mathrm{O}_{2} \mathrm{NP}_{0,06} \mathrm{~S}_{0,1}+6,66 \times 10^{-2} \mathrm{C}_{2} \mathrm{H}_{3} \mathrm{O}_{2}^{-}+1,18 \times 10^{-2} \mathrm{C}_{2} \mathrm{H}_{4} \mathrm{O}_{2}+1,57 \times 10^{-1} \mathrm{H}_{2} \\
+2,17 \times 10^{-2} \mathrm{H}^{+}\end{array}$ & 0,06 & $\begin{array}{l}-5,5 \\
-0,2\end{array}$ \\
\hline
\end{tabular}
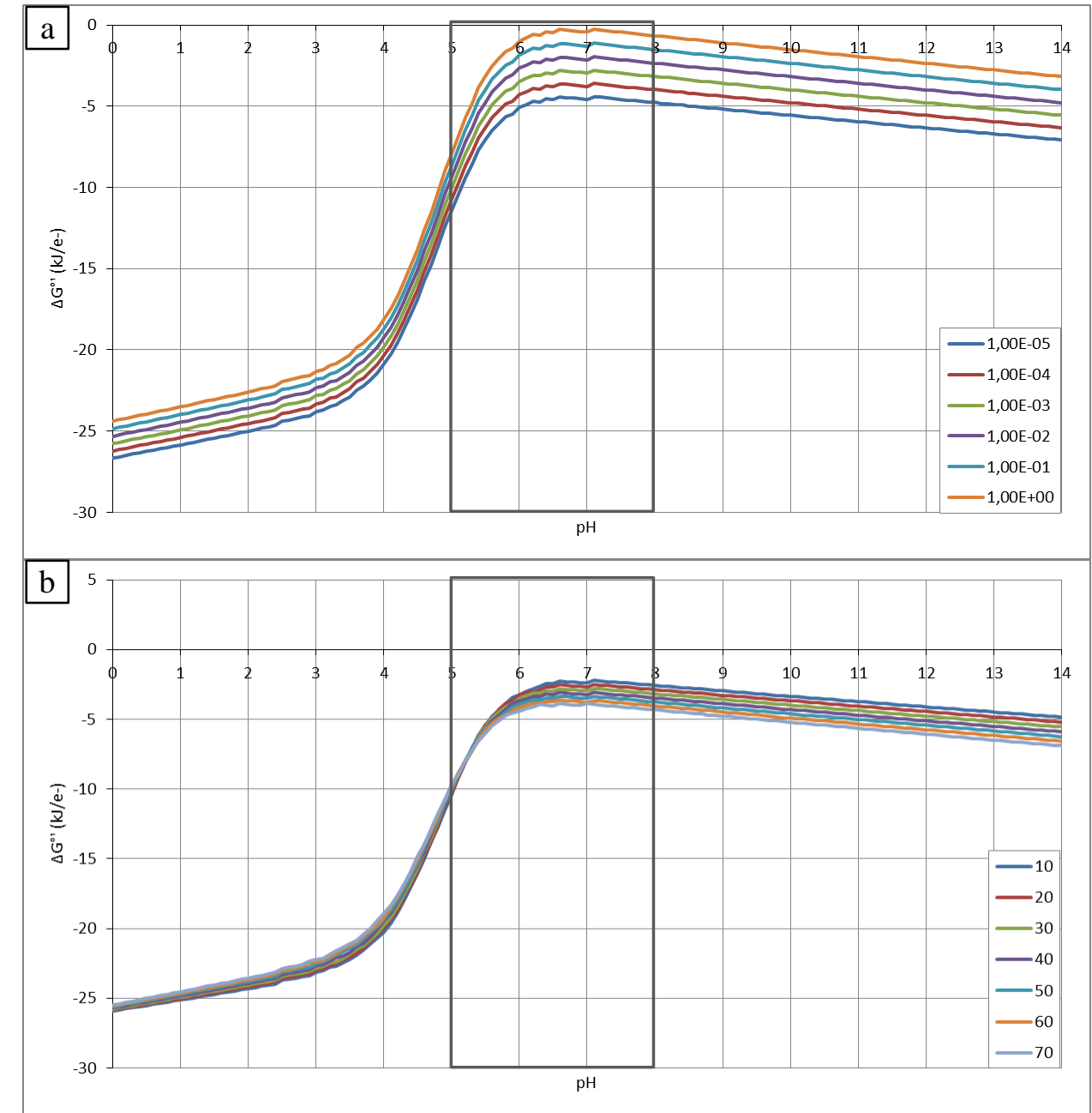

Figura 22. Energia livre da fermentação de etanol para produção de acetato como função a) do $\mathrm{pH}$ e pressão parcial de hidrogênio (atm) e b) do $\mathrm{pH}$ e temperatura $\left({ }^{\circ} \mathrm{C}\right)$. 
Tabela 14. Biorreação do modelo biotermodinâmico e estequiometria $\left(\mathrm{T}=30{ }^{\circ} \mathrm{C}\right) \mathrm{da}$ acetogênese hidrogeniotrófica (homoacetogênese).

\begin{tabular}{|c|c|c|c|}
\hline \multicolumn{2}{|c|}{ Reação 54} & $f_{s}^{\circ}$ & $\begin{array}{c}\Delta_{r} G^{\circ} \\
\Delta_{r} H^{\circ} \\
\left(\mathrm{kJ} \mathrm{e}^{-} \mathrm{eq}^{-1}\right) \\
\end{array}$ \\
\hline $\begin{array}{l}O \\
\text { N } \\
\| \\
\frac{1}{2}\end{array}$ & 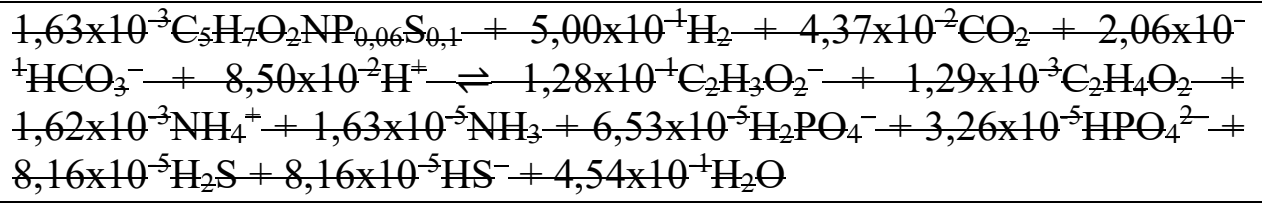 & $-0,03$ & $\begin{array}{c}3,3 \\
-29,3\end{array}$ \\
\hline $\begin{array}{l}n \\
\sigma^{\prime} \\
\| \\
{ }^{2}\end{array}$ & $\begin{array}{l}1,37 \times 10^{-3} \mathrm{C}_{5} \mathrm{H}_{7} \mathrm{O}_{z} \mathrm{NP}_{\theta, 06} \mathrm{~S}_{\theta, 1}+5,00 \times 10^{-1} \mathrm{H}_{z}+1,00 \times 10^{+} \mathrm{CO}_{z}+1,50 \times 10^{-} \\
{ }^{1} \mathrm{HCO}_{3}^{-}+3,57 \times 10^{-2} \mathrm{H}^{+} \underset{+}{\rightleftharpoons} 1,26 \times 10^{-} \mathrm{C}_{z} \mathrm{H}_{3} \mathrm{O}_{z}^{-}+2,57 \times 10^{-3} \mathrm{C}_{z} \mathrm{H}_{4} \mathrm{O}_{z}+ \\
1,37 \times 10^{-3} \mathrm{NH}_{4}^{+}+6,84 \times 10^{-5} \mathrm{H}_{2} \mathrm{PO}_{4}^{-}+1,37 \times 10^{-5} \mathrm{HPO}_{4}^{2}+1,09 \times 10^{-4} \mathrm{H}_{2} \mathrm{~S}+ \\
2,74 \times 10^{-5} \mathrm{HS}^{-}+4,01 \times 10^{-1} \mathrm{H}_{z} \mathrm{O}\end{array}$ & $-0,02$ & $\begin{array}{c}2,8 \\
-29,6\end{array}$ \\
\hline $\begin{array}{l}n \\
n \\
n \\
2 \\
2\end{array}$ & $\begin{array}{l}5,00 \times 10^{-1} \mathrm{H}_{2}+2,17 \times 10^{-1} \mathrm{CO}_{2}+3,25 \times 10^{-2} \mathrm{HCO}_{3}^{-}+1,12 \times 10^{-3} \mathrm{NH}_{4}^{+}+ \\
6,70 \times 10^{-5} \mathrm{H}_{2} \mathrm{PO}_{4}^{-}+1,12 \times 10^{-4} \mathrm{H}_{2} \mathrm{~S}+8,98 \times 10^{-4} \mathrm{H}^{+} \rightleftharpoons 1,12 \times 10^{-} \\
{ }^{3} \mathrm{C}_{5} \mathrm{H}_{7} \mathrm{O}_{2} \mathrm{NP}_{0,06} \mathrm{~S}_{0,1}+1,04 \times 10^{-1} \mathrm{C}_{2} \mathrm{H}_{3} \mathrm{O}_{2}^{-}+1,83 \times 10^{-2} \mathrm{C}_{2} \mathrm{H}_{4} \mathrm{O}_{2}+3,23 \times 10^{-} \\
{ }^{1} \mathrm{H}_{2} \mathrm{O}\end{array}$ & 0,06 & $\begin{array}{l}-5,5 \\
-0,2\end{array}$ \\
\hline
\end{tabular}
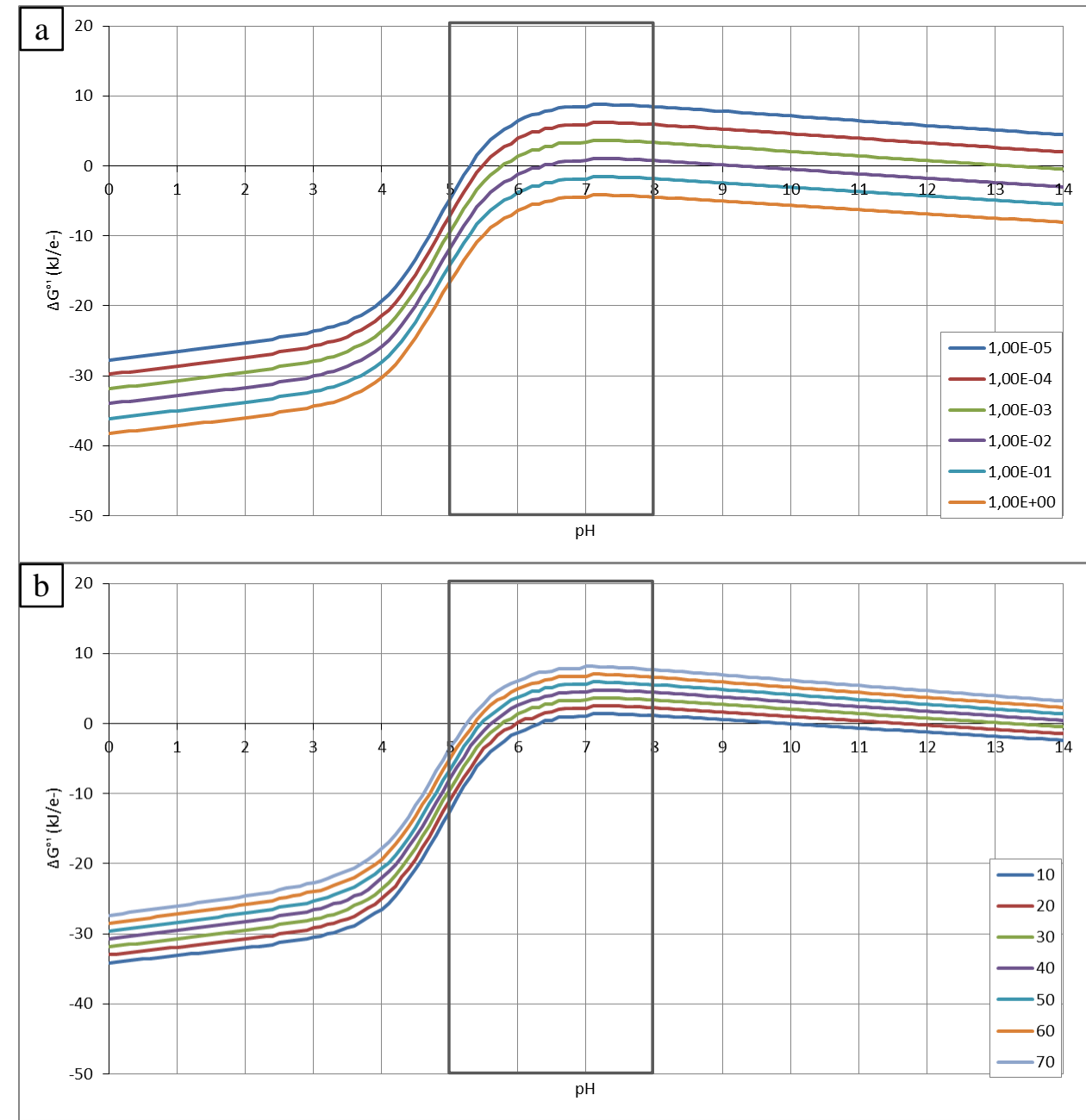

Figura 23. Energia livre da acetogênese hidrogeniotrófica (homoacetogênese) como função a) do $\mathrm{pH}$ e pressão parcial de hidrogênio (atm) e b) do $\mathrm{pH}$ e temperatura $\left({ }^{\circ} \mathrm{C}\right)$. 
nas Figuras 19 a 23, com o comportamento da energia livre dissipada como função do $\mathrm{pH}$ e pressão parcial de hidrogênio (temperatura constante de $30{ }^{\circ} \mathrm{C}$ ) e do $\mathrm{pH}$ e temperatura (pressão parcial de hidrogênio constante de $1,00 \times 10^{-3}$ atm).

O comportamento da fermentação de lactato a acetato (Figura 19) é muito similar às outras fermentações de lactato (Figura 17 e 18). Esta fermentação é espontânea para pH aproximados a 3,2 e superiores (a $30^{\circ} \mathrm{C}$ ), com máximos de dissipação de energia livre em pH entre 4,0 e 5,0, e favorecida pela diminuição na temperatura.

A fermentação de propionato a acetato (Figura 20a) não é termodinamicamente viável para pressões parciais de hidrogênio superiores a $1,00 \times 10^{-2}$ atm (a $30{ }^{\circ} \mathrm{C}$ ), enquanto para pressões iguais ou inferiores o processo é espontâneo, mas a energia livre dissipada é marginal (próxima a zero), originando constantes de equilíbrio baixas com pobres conversões. Respeito ao $\mathrm{pH}$, para pressões parciais de hidrogênio inferiores a $1,00 \times 10^{-2}$ atm $\left(\right.$ a $30{ }^{\circ} \mathrm{C}$ ), a fermentação se favorece em pH superiores a 7,0 nos quais a energia livre se torna constante, e desfavorecida no intervalo entre 4,0 e 6,0 no qual se presenta um mínimo (menos energia livre dissipada até positiva). Por outro lado, no mesmo intervalo se presentam valores positivos para a energia livre dissipada com a temperatura (Figura 20b), no qual esta fermentação deixa de ser espontânea para temperaturas iguais ou inferiores a $20^{\circ} \mathrm{C}$ (a $\left.1,00 \times 10^{-3} \mathrm{~atm}\right)$. Em todo o intervalo de $\mathrm{pH}$, o aumento da temperatura aumenta os valores de energia livre dissipada.

As fermentações de butirato e etanol a acetato (Figuras 21a e 22a) dissipam menos energia livre no intervalo aproximado de pH entre 6,0 e 7,0 e são inferiores na medida que aumenta a pressão parcial de hidrogênio. Os resultados podem atingir valores positivos na fermentação do butirato para uma pressão parcial superior a $1,00 \times 10^{-1}$ atm, voltando-a não espontânea. A energia livre dissipada das duas fermentações aumenta significativamente para $\mathrm{pH}$ inferiores a 5,0, o que garante uma maior conversão (aumento da constante de equilíbrio). Respeito à temperatura (Figuras 21 b e 22b), ambas as fermentações são espontâneas em todo o intervalo avaliado (a $\left.1,00 \times 10^{-3} \mathrm{~atm}\right)$.

Em geral, todas as fermentações são processos que aumentam as conversões de reagentes em produtos com a diminuição da pressão parcial de hidrogênio e, em algumas, esta dependência define até a espontaneidade do processo. Essa dependência exibe a natureza sintrófica entre as fermentações e a metanogênese hidrogeniotrófica; as primeiras produzem o substrato (hidrogênio) da segunda e esta o consume diminuindo sua pressão parcial. Porém, esse não é necessariamente o único sintrofismo na digestão anaeróbia; a homoacetogênese "inversa" pode também estabelecer uma relação sintrófica com as bactérias fermentativas, consumindo o hidrogênio produzido para manter pressões parciais baixas, garantindo a 
espontaneidade e melhorando as conversões das fermentações.

A homoacetogênese (Figura 23a) e desfavorecida em um pH 7,0 (a $30{ }^{\circ} \mathrm{C}$ ) no qual se presenta um mínimo de energia livre dissipada, com valores inferiores na medida que diminui a pressão parcial de hidrogênio (menos energia livre dissipada até positiva). O processo é espontâneo em todo o intervalo de $\mathrm{pH}$ para pressões parciais de hidrogênio superiores a aproximadamente $1,00 \times 10^{-2} \mathrm{~atm}$. Para uma pressão parcial de $1,00 \times 10^{-5} \mathrm{~atm}$, o processo é espontâneo em $\mathrm{pH}$ inferiores a aproximadamente 5,3; para 1,00×10 $10^{-4} \mathrm{~atm}$, em $\mathrm{pH}$ inferiores a aproximadamente 5,2; e para $1,00 \times 10^{-3} \mathrm{~atm}$, em $\mathrm{pH}$ inferiores a aproximadamente 5,7. A pressão parcial de $1,00 \times 10^{-2} \mathrm{~atm}$ tem dois intervalos de espontaneidade, em $\mathrm{pH}$ inferiores a aproximadamente 6,2 e superiores a 9,5. Devido a que o processo não é espontâneo em um pH superior a 5,7 para uma pressão parcial de hidrogênio de $1,00 \times 10^{-3} \mathrm{~atm}$, os resultados na Tabela 14 para pH 6,5 e 7,0 não têm sentido. Por outro lado, da Figura 23b, o processo é espontâneo para pH que oscilam entre, aproximadamente, 5,3 e 6,3 (a 1,00x10-3 atm), dependendo da temperatura.

Finalmente, a homoacetogênese "inversa" (comportamento inverso da Figura 23) tem máximos de energia livre dissipada em um $\mathrm{pH} 7,0$, é espontânea unicamente para pressões parciais de hidrogênio inferiores a $1,00 \times 10^{-2}$ atm e $\mathrm{pH}$ superiores a aproximadamente 5,3 (a $30{ }^{\circ} \mathrm{C}$ ), e se favorece pelo aumento da temperatura.

\subsubsection{Comportamento dos processos metanogênicos}

Os resultados da aplicação do modelo biotermodinâmico aos metabolismos metanogênicos discutidos na Seção 4.1 .3 se apresentam nas Tabelas 15 e 16 (Reações 55 e 56), nas quais se inclui a estequiometria da reação para diferentes $\mathrm{pH}$ (temperatura de $30^{\circ} \mathrm{C}$ ), e nas Figuras 24 e 25, com o comportamento da energia livre dissipada como função do $\mathrm{pH}$ e pressão parcial de hidrogênio (temperatura constante de $30{ }^{\circ} \mathrm{C}$ ) e do $\mathrm{pH}$ e temperatura (pressão parcial de hidrogênio constante de $1,00 \times 10^{-3} \mathrm{~atm}$ ).

A metanogênese acetoclástica (Figura 24a) tem valores máximos de energia livre dissipada em um pH aproximado de 7,0 (a $30^{\circ} \mathrm{C}$ ) e, independentemente da pressão parcial de hidrogênio, se torna espontânea aproximadamente em um pH 5,5; mas ainda espontânea, a energia livre dissipada é marginal originando pobres conversões. Um comportamento similar é observado respeito à temperatura (Figura 24b): o processo se torna espontâneo para $\mathrm{pH}$ aproximados de 5,3 para $70{ }^{\circ} \mathrm{C}$ e 5,5 para $10^{\circ} \mathrm{C}\left(\right.$ a $\left.1,00 \times 10^{-3} \mathrm{~atm}\right)$. 
Tabela 15. Biorreação do modelo biotermodinâmico e estequiometria $\left(\mathrm{T}=30^{\circ} \mathrm{C}\right)$ da metanogênese acetotrófica (metanogênese acetoclástica).

\begin{tabular}{|c|c|c|c|}
\hline \multicolumn{2}{|c|}{ Reação 55} & $f_{s}^{\circ}$ & $\begin{array}{c}\Delta_{r} G^{\circ} \\
\Delta_{r} H^{\circ} \\
\left(\mathrm{kJ} \mathrm{e}^{-} \mathrm{eq}^{-1}\right)\end{array}$ \\
\hline 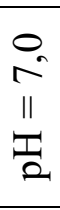 & $\begin{array}{l}1,24 \times 10^{-1} \mathrm{C}_{2} \mathrm{H}_{3} \mathrm{O}_{2}^{--}+1,25 \times 10^{-3} \mathrm{C}_{2} \mathrm{H}_{4} \mathrm{O}_{2}+3,14 \times 10^{-3} \mathrm{NH}_{4}^{+}+3,17 \times 10^{-5} \mathrm{NH}_{3} \\
+1,27 \times 10^{-4} \mathrm{H}_{2} \mathrm{PO}_{4}^{--}+6,34 \times 10^{-5} \mathrm{HPO}_{4}{ }^{2-}+1,59 \times 10^{-4} \mathrm{H}_{2} \mathrm{~S}+1,59 \times 10^{-4} \mathrm{HS}^{-}+ \\
8,95 \times 10^{-2} \mathrm{H}_{2} \mathrm{O}+1,88 \times 10^{-2} \mathrm{H}^{+} \rightleftharpoons 3,17 \times 10^{-3} \mathrm{C}_{5} \mathrm{H}_{7} \mathrm{O}_{2} \mathrm{NP}_{0,06} \mathrm{~S}_{0,1}+1,17 \times 10^{-} \\
{ }^{1} \mathrm{CH}_{4}+1,99 \times 10^{-2} \mathrm{CO}_{2}+9,72 \times 10^{-2} \mathrm{HCO}_{3}^{-}\end{array}$ & 0,06 & $\begin{array}{c}-6,2 \\
0,1\end{array}$ \\
\hline 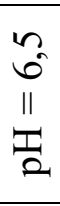 & $\begin{array}{l}1,23 \times 10^{-1} \mathrm{C}_{2} \mathrm{H}_{3} \mathrm{O}_{2}^{-}+2,50 \times 10^{-3} \mathrm{C}_{2} \mathrm{H}_{4} \mathrm{O}_{2}+3,04 \times 10^{-3} \mathrm{NH}_{4}^{+}+1,52 \times 10^{-} \\
{ }^{4} \mathrm{H}_{2} \mathrm{PO}_{4}^{-}+3,04 \times 10^{-5} \mathrm{HPO}_{4}{ }^{2-}+2,44 \times 10^{-4} \mathrm{H}_{2} \mathrm{~S}+6,09 \times 10^{-5} \mathrm{HS}^{-}+6,57 \times 10^{-} \\
{ }^{2} \mathrm{H}_{2} \mathrm{O}+3,92 \times 10^{-2} \mathrm{H}^{+} \rightleftharpoons 3,04 \times 10^{-3} \mathrm{C}_{5} \mathrm{H}_{7} \mathrm{O}_{2} \mathrm{NP}_{0,06} \mathrm{~S}_{0,1}+1,17 \times 10^{-1} \mathrm{CH}_{4}+ \\
4,69 \times 10^{-2} \mathrm{CO}_{2}+7,05 \times 10^{-2} \mathrm{HCO}_{3}^{-}\end{array}$ & 0,06 & $\begin{array}{c}-5,9 \\
0,6\end{array}$ \\
\hline $\begin{array}{l}n \\
n \\
n_{2}\end{array}$ & $\begin{array}{l}1,06 \times 10^{-1} \mathrm{C}_{2} \mathrm{H}_{3} \mathrm{O}_{2}^{-}+1,88 \times 10^{-2} \mathrm{C}_{2} \mathrm{H}_{4} \mathrm{O}_{2}+8,22 \times 10^{-4} \mathrm{NH}_{4}^{+}+4,93 \times 10^{-} \\
{ }^{5} \mathrm{H}_{2} \mathrm{PO}_{4}^{-}+8,22 \times 10^{-5} \mathrm{H}_{2} \mathrm{~S}+5,08 \times 10^{-2} \mathrm{H}_{2} \mathrm{O}+1,45 \times 10^{-2} \mathrm{H}^{+} \rightleftharpoons 8,22 \times 10^{-} \\
{ }^{4} \mathrm{C}_{5} \mathrm{H}_{7} \mathrm{O}_{2} \mathrm{NP}_{0,06} \mathrm{~S}_{0,1}+1,23 \times 10^{-1} \mathrm{CH}_{4}+1,07 \times 10^{-1} \mathrm{CO}_{2}+1,60 \times 10^{-2} \mathrm{HCO}_{3}^{-}\end{array}$ & 0,02 & $\begin{array}{c}-1,5 \\
9,1\end{array}$ \\
\hline
\end{tabular}
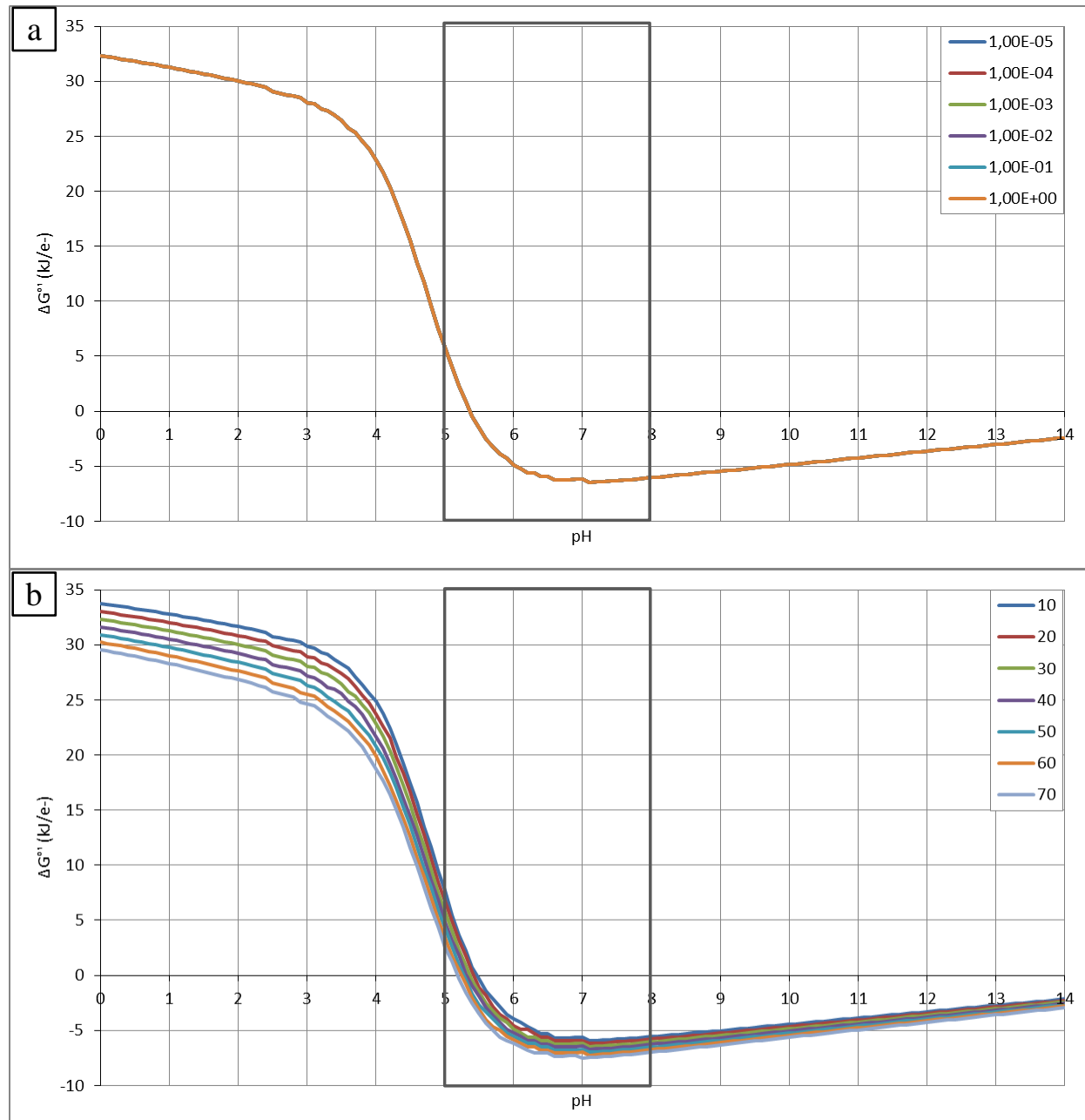

Figura 24. Energia livre da metanogênese acetotrófica (metanogênese acetoclástica) como função a) do $\mathrm{pH}$ e pressão parcial de hidrogênio (atm) e b) do $\mathrm{pH}$ e temperatura $\left({ }^{\circ} \mathrm{C}\right)$. 
Tabela 16. Biorreação do modelo biotermodinâmico e estequiometria $\left(\mathrm{T}=30{ }^{\circ} \mathrm{C}\right) \mathrm{da}$ metanogênese hidrogeniotrófica.

\begin{tabular}{|c|c|c|c|}
\hline \multicolumn{2}{|c|}{ Reação 56} & $f_{s}^{\circ}$ & $\begin{array}{c}\Delta_{r} G^{\circ}, \\
\Delta_{r} H^{\circ} \\
\left(\mathrm{kJ} \mathrm{e}^{-} \mathrm{eq}^{-1}\right)\end{array}$ \\
\hline $\begin{array}{l}O \\
\text { N } \\
\| \\
\frac{1}{2}\end{array}$ & $\begin{array}{l}5,00 \times 10^{-1} \mathrm{H}_{2}+2,31 \times 10^{-2} \mathrm{CO}_{2}+1,06 \times 10^{-1} \mathrm{HCO}_{3}^{-}+1,50 \times 10^{-3} \mathrm{NH}_{4}^{+}+ \\
1,51 \times 10^{-5} \mathrm{NH}_{3}+6,05 \times 10^{-5} \mathrm{H}_{2} \mathrm{PO}_{4}^{-}+3,03 \times 10^{-5} \mathrm{HPO}_{4}{ }^{2-}+7,56 \times 10^{-5} \mathrm{H}_{2} \mathrm{~S}+ \\
7,56 \times 10^{-5} \mathrm{HS}^{-}+1,04 \times 10^{-1} \mathrm{H}^{+} \rightleftharpoons 1,51 \times 10^{-3} \mathrm{C}_{5} \mathrm{H}_{7} \mathrm{O}_{2} \mathrm{NP}_{0,06} \mathrm{~S}_{0,1}+1,21 \times 10^{-} \\
{ }^{1} \mathrm{CH}_{4}+3,61 \times 10^{-1} \mathrm{H}_{2} \mathrm{O}\end{array}$ & 0,03 & $\begin{array}{c}-3,1 \\
-29,3\end{array}$ \\
\hline $\begin{array}{l}n \\
\sigma^{\prime} \\
\| \\
{ }^{2}\end{array}$ & $\begin{array}{l}5,00 \times 10^{-1} \mathrm{H}_{2}+5,16 \times 10^{-2} \mathrm{CO}_{2}+7,74 \times 10^{-2} \mathrm{HCO}_{3}^{-}+1,62 \times 10^{-3} \mathrm{NH}_{4}^{+}+ \\
8,10 \times 10^{-5} \mathrm{H}_{2} \mathrm{PO}_{4}^{-}+1,62 \times 10^{-5} \mathrm{HPO}_{4}{ }^{2-}+1,30 \times 10^{-4} \mathrm{H}_{2} \mathrm{~S}+3,24 \times 10^{-5} \mathrm{HS}^{-} \\
+7,59 \times 10^{-2} \mathrm{H}^{+} \rightleftharpoons 1,62 \times 10^{-3} \mathrm{C}_{5} \mathrm{H}_{7} \mathrm{O}_{2} \mathrm{NP}_{0,06} \mathrm{~S}_{0,1}+1,21 \times 10^{-1} \mathrm{CH}_{4}+3,33 \times 10^{-} \\
{ }^{1} \mathrm{H}_{2} \mathrm{O}\end{array}$ & 0,03 & $\begin{array}{l}-3,3 \\
-29,0\end{array}$ \\
\hline $\begin{array}{l}n \\
n \\
n \\
n_{2}\end{array}$ & $\begin{array}{l}5,00 \times 10^{-1} \mathrm{H}_{2}+1,13 \times 10^{-1} \mathrm{CO}_{2}+1,68 \times 10^{-2} \mathrm{HCO}_{3}^{-}+1,85 \times 10^{-3} \mathrm{NH}_{4}^{+}+ \\
1,11 \times 10^{-4} \mathrm{H}_{2} \mathrm{PO}_{4}^{-}+1,85 \times 10^{-4} \mathrm{H}_{2} \mathrm{~S}+1,51 \times 10^{-2} \mathrm{H}^{+} \rightleftharpoons 1,85 \times 10^{-} \\
{ }^{3} \mathrm{C}_{5} \mathrm{H}_{7} \mathrm{O}_{2} \mathrm{NP}_{0,06} \mathrm{~S}_{0,1}+1,20 \times 10^{-1} \mathrm{CH}_{4}+2,73 \times 10^{-1} \mathrm{H}_{2} \mathrm{O}\end{array}$ & 0,04 & $\begin{array}{l}-3,8 \\
-28,6\end{array}$ \\
\hline
\end{tabular}
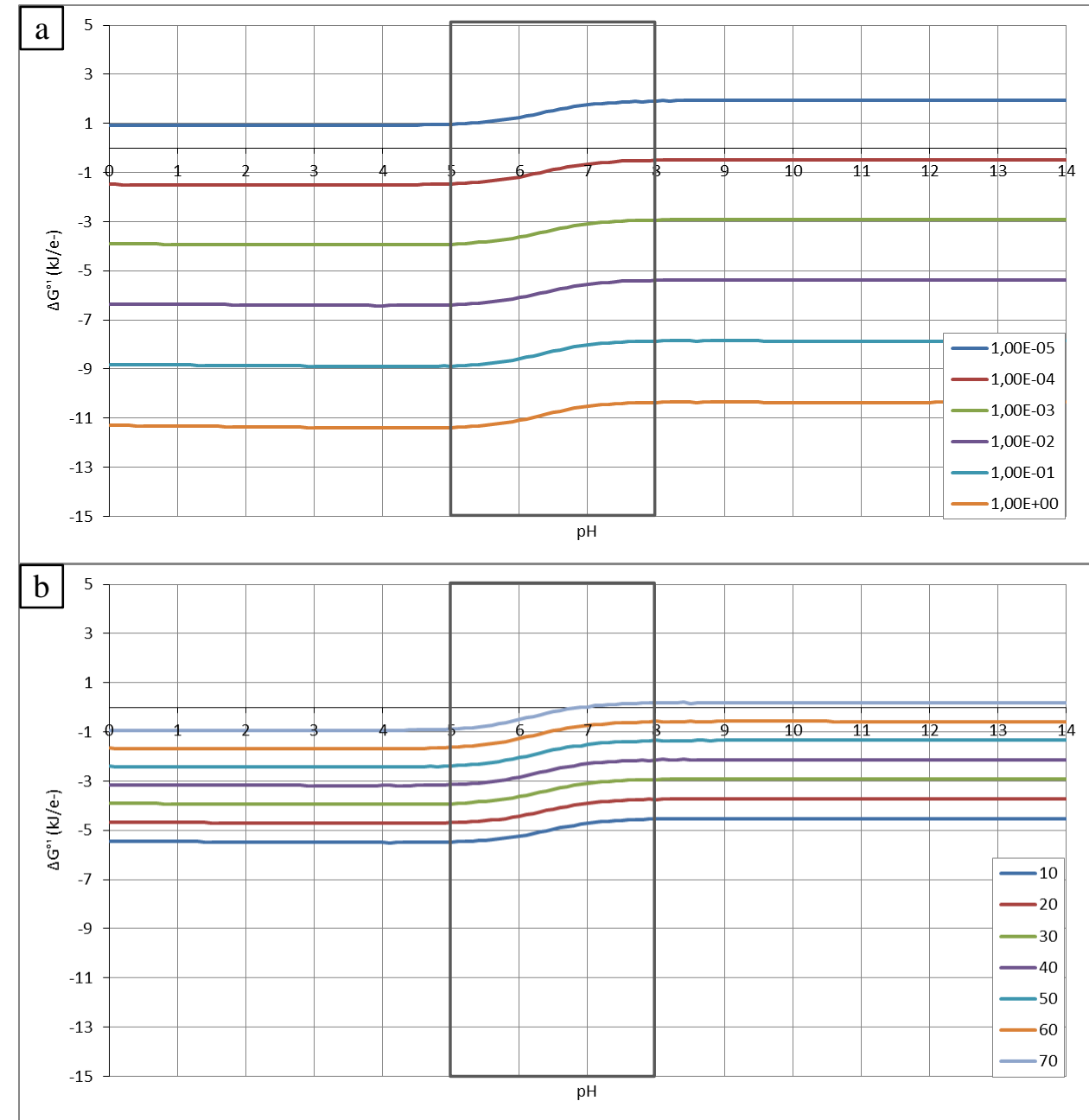

Figura 25. Energia livre da metanogênese hidrogeniotrófica como função a) do pH e pressão parcial de hidrogênio (atm) e b) do $\mathrm{pH}$ e temperatura $\left({ }^{\circ} \mathrm{C}\right)$. 
Finalmente, a metanogênese hidrogeniotrófica (Figura 25a) se favorece pelo aumento da pressão parcial e é espontânea para pressões parciais de hidrogênio iguais e superiores a $1,00 \times 10^{-4} \mathrm{~atm}\left(\mathrm{a} 30^{\circ} \mathrm{C}\right.$ ) em todo o intervalo de $\mathrm{pH}$. Por outro lado, a Figura $25 \mathrm{~b}$ apresenta o efeito é inverso: o processo se favorece com a diminuição da temperatura atingindo valores

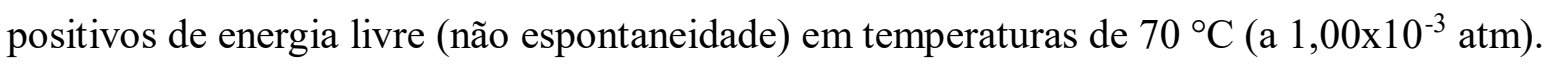

Em geral, o aumento da temperatura favorece o aumento da energia livre dissipada e, portanto, a conversão para todas as fermentações com exceção das fermentações de lactato e os processos hidrogeniotróficos (homoacetogênese e metanogênese). Este comportamento beneficia a produção de hidrogênio porque desfavorece as reações de consumo (Reações 49, 54 e 56) e favorece as reações de produção (Reações 44, 47, e 51 a 53).

\subsection{Rendimentos molares da digestão anaeróbia completa e separada}

A digestão anaeróbia, mediante as duas etapas em série que a compõem, produz uma mistura gasosa conhecida como biogás, composta principalmente por metano $\left(\mathrm{CH}_{4}\right)$, dióxido de carbono $\left(\mathrm{CO}_{2}\right)$ e traços de sulfeto de hidrogênio $\left(\mathrm{H}_{2} \mathrm{~S}\right)$, hidrogênio $\left(\mathrm{H}_{2}\right)$ e amoníaco $\left(\mathrm{NH}_{3}\right)$. Na primeira etapa (fermentação: acidogênese e acetogênese), todo o substrato ocasionalmente se transforma em acetato, dióxido de carbono $\left(\mathrm{CO}_{2}, \mathrm{HCO}_{3}{ }^{-}, \mathrm{CO}_{3}{ }^{2-}\right)$ e hidrogênio (Cooney et al., 2007), substratos da segunda etapa, a metanogênese, composta por dois processos paralelos: metanogênese acetoclástica e metanogênese hidrogeniotrófica. A metanogênese acetoclástica produz aproximadamente $70 \%$ do metano e $30 \%$ se produz pela metanogênese hidrogeniotrófica (Anderson, Sallis \& Uyanik, 2007; Chernicharo, 2007). Assim, todo o substrato pode ocasionalmente se transformar até biogás, composto principalmente por metano (Cooney et al., 2007).

O processo de digestão anaeróbia ideal completa para a produção de biogás pode-se entender como uma fermentação representada em síntese pela Reação 47 para a produção de acetato e hidrogênio a partir de glicose, seguida da Reação 55 de metanogênese acetoclástica e da Reação 56 de metanogênese hidrogeniotrófica para a conversão de acetato e hidrogênio, respetivamente, em metano. Nesta idealização se desconsidera a homoacetogênese.

Ao respeito, a partir da estequiometria estabelecida com o modelo biotermodinâmico podem-se obter os rendimentos dos produtos. Para a fermentação da glicose a acetato (Reação 47) a Figura 26 apresenta os rendimentos em mols produzidas por mol de glicose e a Figura 27 apresenta a distribuição dos elétrons transferidos do doador (glicose) aos produtos reduzidos produzidos, ambas em função do $\mathrm{pH}$ para $30^{\circ} \mathrm{C}$. 


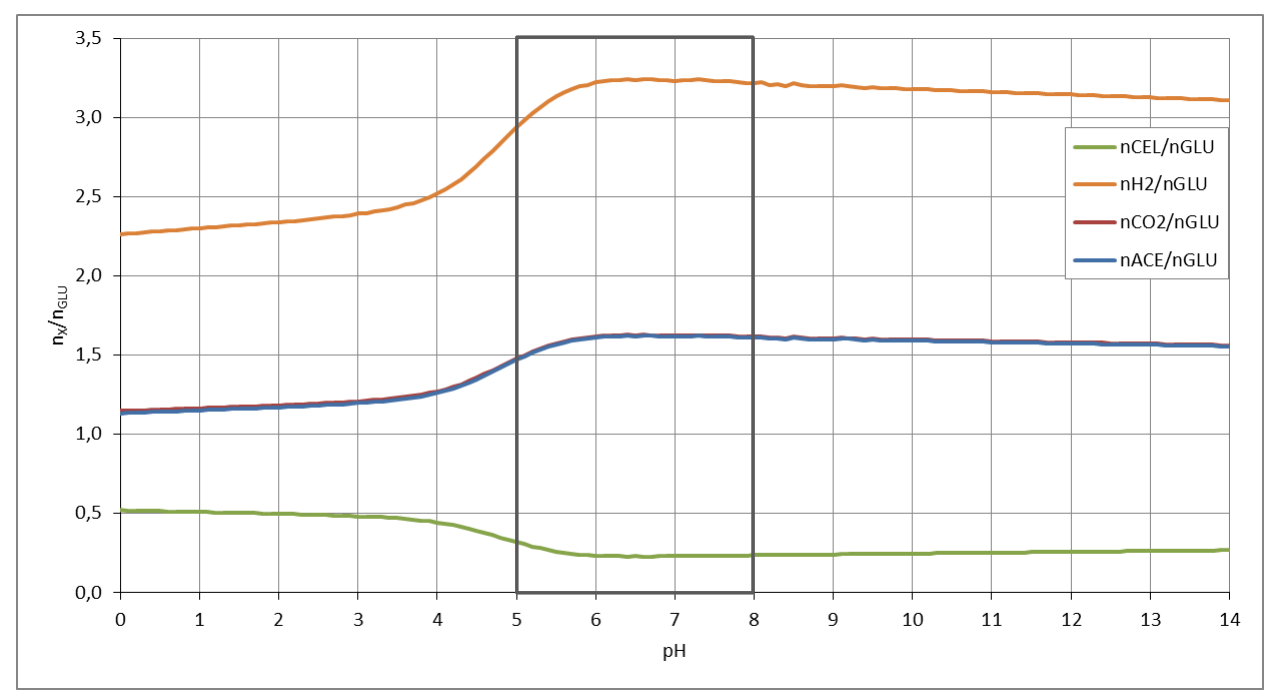

Figura 26. Rendimento dos produtos da fermentação de glicose a acetato, em mols produzidas por mol de glicose, em função do $\mathrm{pH}\left(\mathrm{T}=30^{\circ} \mathrm{C}, \mathrm{p}_{\mathrm{H} 2}=1,00 \times 10^{-3} \mathrm{~atm}\right)$.

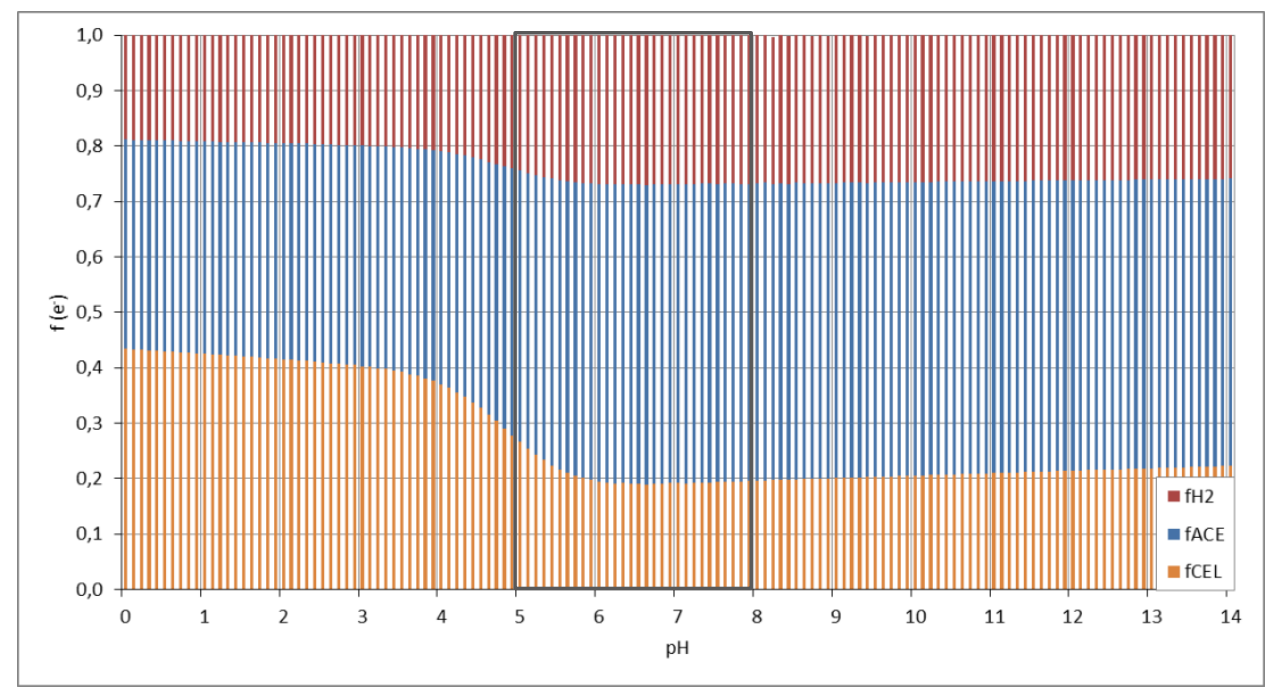

Figura 27. Fração de elétrons transferidos da glicose a cada produto reduzido na fermentação de glicose a acetato em função do $\mathrm{pH}\left(\mathrm{T}=30^{\circ} \mathrm{C}, \mathrm{p}_{\mathrm{H} 2}=1,00 \times 10^{-3}\right.$ atm $)$.

Os resultados mostram um máximo rendimento de hidrogênio em um pH aproximado de 6,0 que coincide com o máximo rendimento de acetato e mínimo rendimento de células; resultado óbvio porquanto a energia livre transferida pelo processo catabólico que não é usada para a produção células (processo anabólico), destina-se para os produtos.

Enquanto à temperatura, a Figura 28 mostra que o aumento dessa variável favorece levemente o rendimento das células provocando a diminuição no rendimento dos produtos, mas o efeito é marginal para os diferentes $\mathrm{pH}$. 

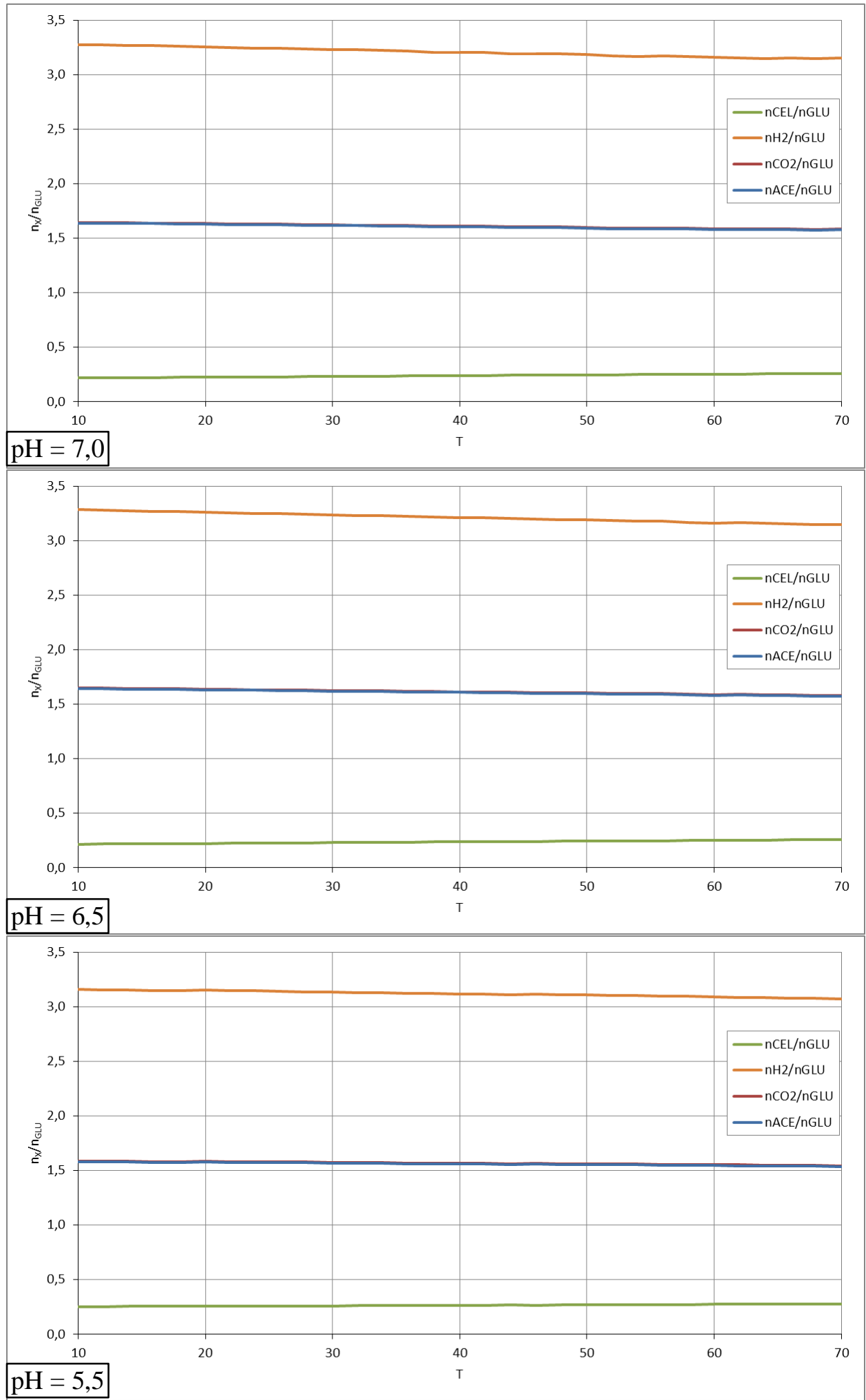

Figura 28. Rendimento dos produtos da fermentação de glicose a acetato, em mols produzidas por mol de glicose, em função da temperatura a diferentes $\mathrm{pH}\left(\mathrm{p}_{\mathrm{H} 2}=1,00 \times 10^{-3} \mathrm{~atm}\right)$.

Para a metanogênese acetoclástica (Reação 55) a Figura 29 apresenta os rendimentos em mols produzidas por mol de acetato e a Figura 30 apresenta a distribuição dos elétrons 
transferidos do doador (acetato) a os produtos reduzidos produzidos, ambas em função do pH para $30^{\circ} \mathrm{C}$.

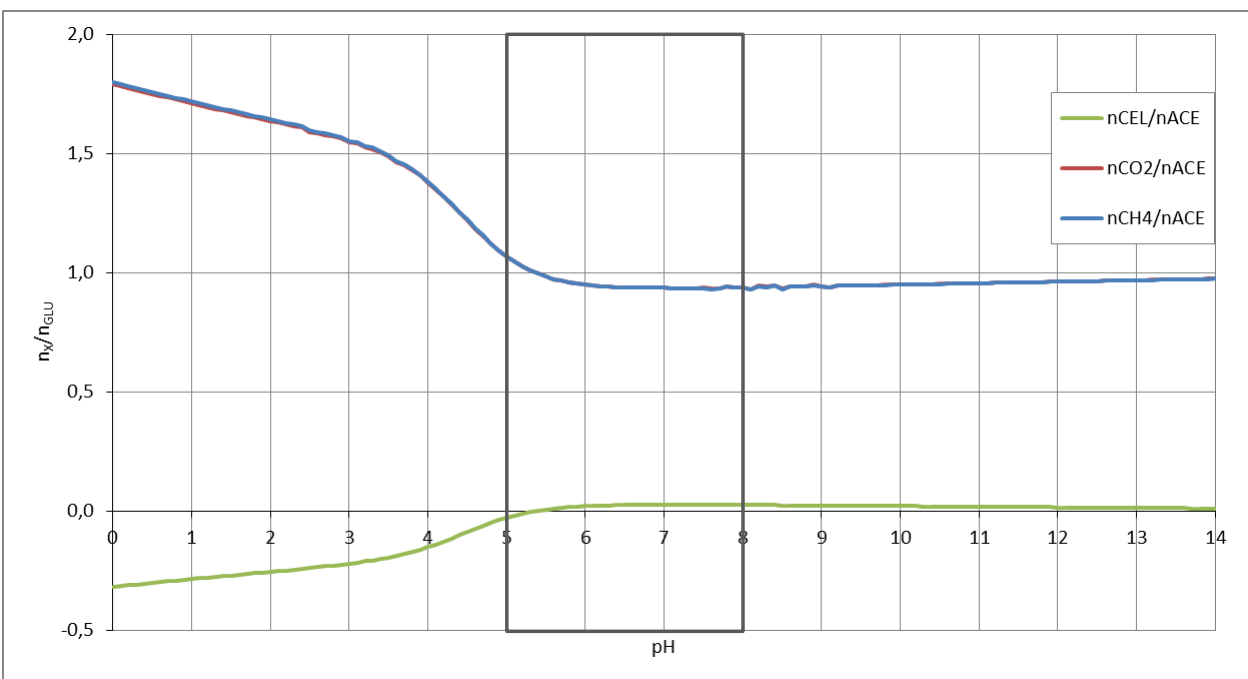

Figura 29. Rendimento dos produtos da metanogênese acetoclástica, em mols produzidas por mol de acetato, em função do $\mathrm{pH}\left(\mathrm{T}=30^{\circ} \mathrm{C}, \mathrm{p}_{\mathrm{H} 2}=1,00 \times 10^{-3}\right.$ atm $)$.

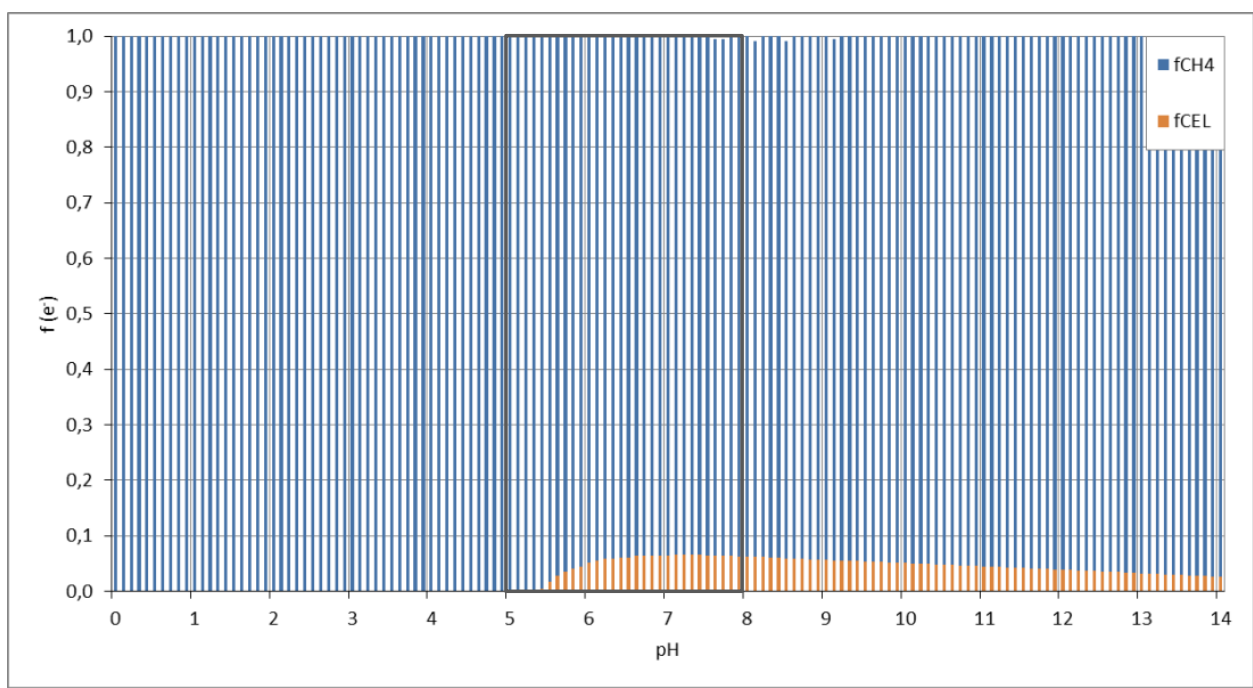

Figura 30. Fração de elétrons transferidos do acetato a cada produto reduzido na metanogênese acetoclástica em função do $\mathrm{pH}\left(\mathrm{T}=30^{\circ} \mathrm{C}, \mathrm{p}_{\mathrm{H} 2}=1,00 \times 10^{-3} \mathrm{~atm}\right)$.

Neste caso, os resultados têm sentido para $\mathrm{pH}$ superiores a aproximadamente 5,5 no qual o processo se torna espontâneo (Seção 4.2.3). Nesse preciso ponto o rendimento de metano é máximo e o rendimento das células é mínimo. Para a temperatura, a Figura 31 mostra que seu aumento favorece muito levemente o rendimento das células provocando a diminuição no rendimento dos produtos, mas o efeito é marginal para os diferentes $\mathrm{pH}$. 

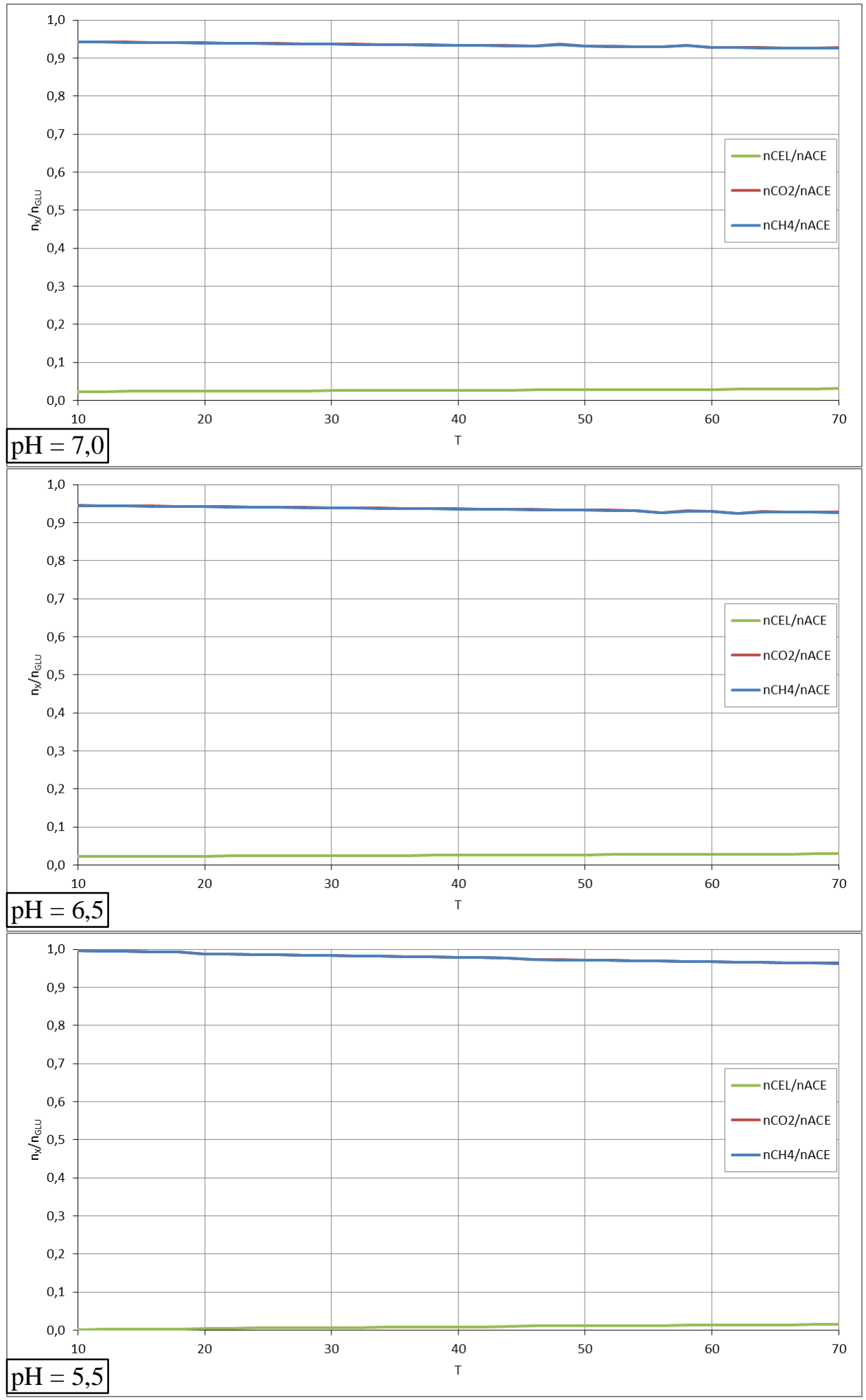

Figura 31. Rendimento dos produtos da metanogênese acetoclástica, em mols produzidas por mol de acetato, em função da temperatura para diferentes $\mathrm{pH}\left(\mathrm{p}_{\mathrm{H} 2}=1,00 \times 10^{-3} \mathrm{~atm}\right)$.

Para a metanogênese hidrogeniotrófica (Reação 56) a Figura 32 apresenta os rendimentos em mols produzidas por mol de hidrogênio e a Figura 33 apresenta a distribuição 
dos elétrons transferidos do doador (hidrogênio) a os produtos reduzidos produzidos, ambas em função do $\mathrm{pH}$ para $30^{\circ} \mathrm{C}$.

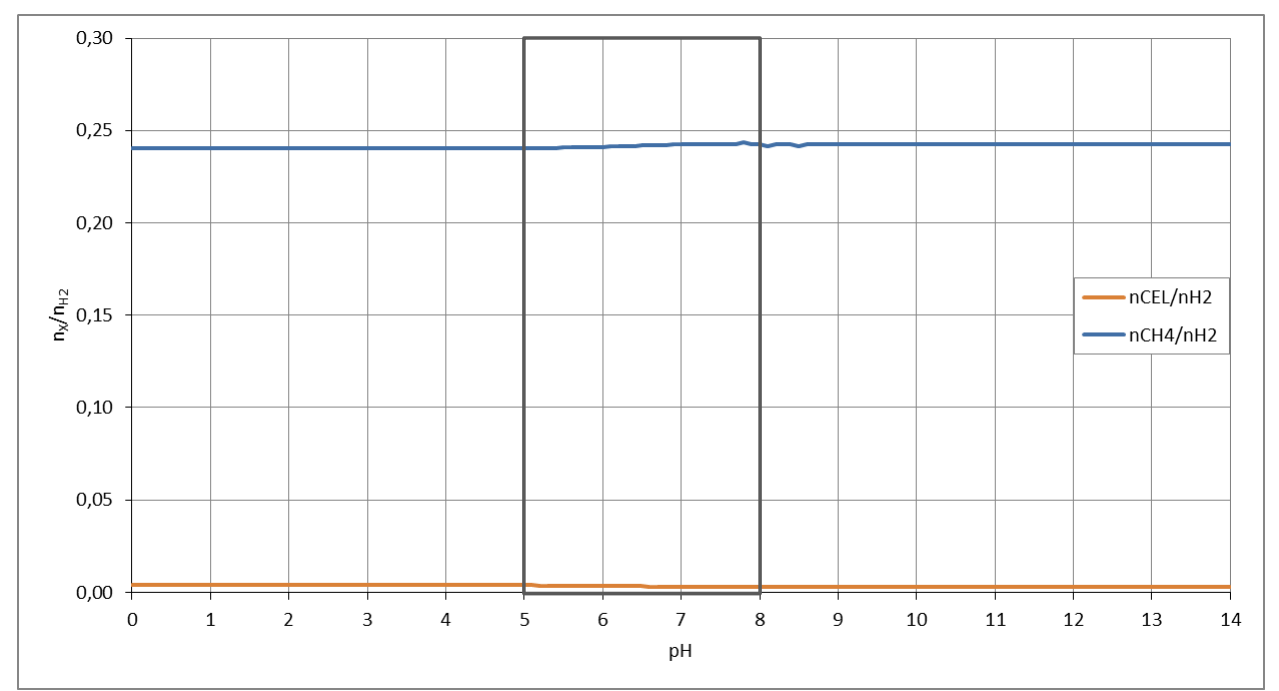

Figura 32. Rendimento dos produtos da metanogênese hidrogeniotrófica, em mols produzidas por mol de hidrogênio, em função do $\mathrm{pH}\left(\mathrm{T}=30^{\circ} \mathrm{C}, \mathrm{p}_{\mathrm{H} 2}=1,00 \times 10^{-3} \mathrm{~atm}\right)$.

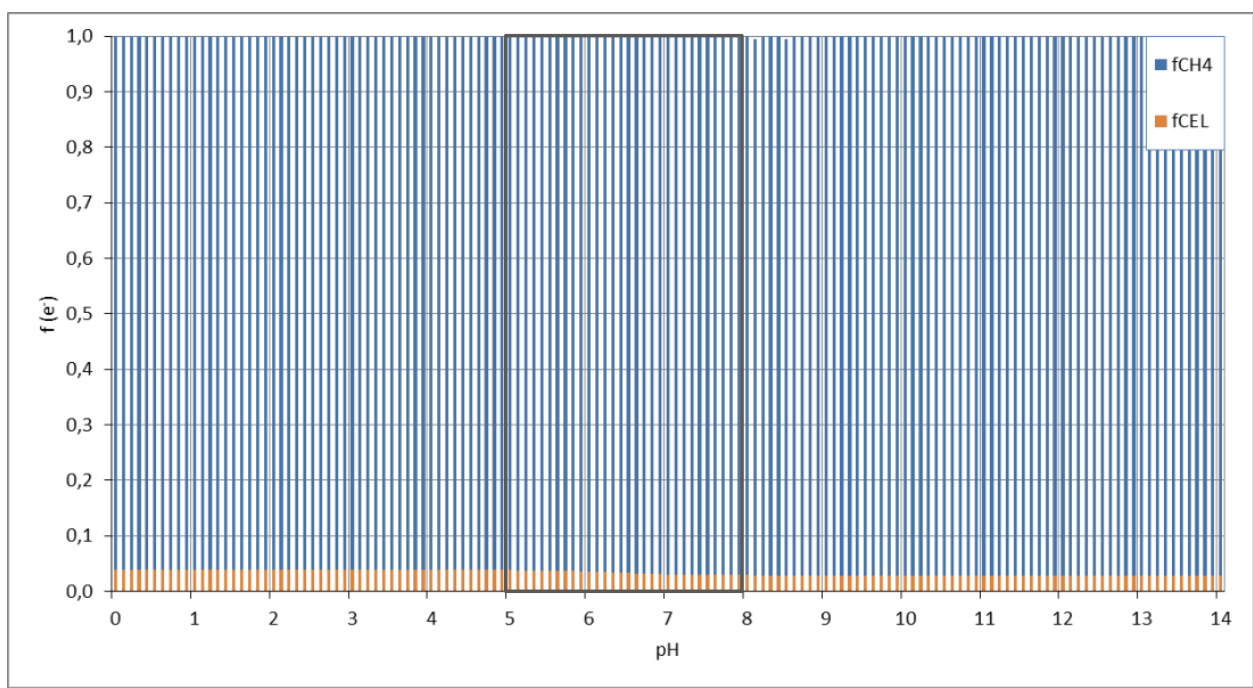

Figura 33. Fração de elétrons transferidos do hidrogênio a cada produto reduzido na metanogênese hidrogeniotrófica em função do $\mathrm{pH}\left(\mathrm{T}=30^{\circ} \mathrm{C}, \mathrm{p}_{\mathrm{H} 2}=1,00 \times 10^{-3} \mathrm{~atm}\right)$.

Os resultados mostram um rendimento de metano e células muito uniforme em todo o intervalo de $\mathrm{pH}$, com máximos para $\mathrm{pH}$ superiores a 7,0. Para a temperatura, a Figura 34 mostra que seu aumento favorece levemente o rendimento de metano, mas o efeito é marginal para os diferentes $\mathrm{pH}$. 

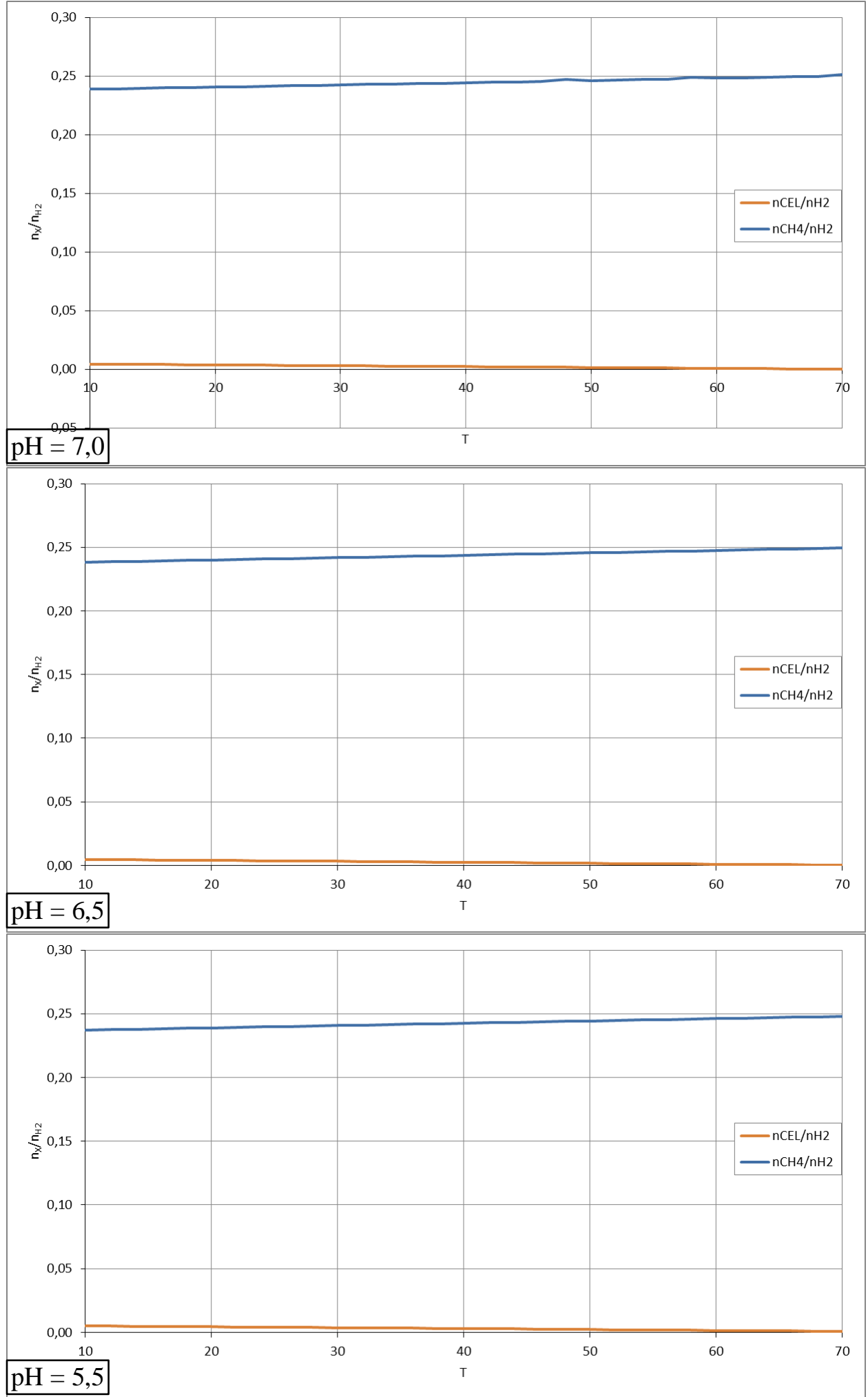

Figura 34. Rendimento dos produtos da metanogênese hidrogeniotrófica, em mols produzidas por mol de hidrogênio, em função da temperatura para diferentes $\mathrm{pH}\left(\mathrm{p}_{\mathrm{H} 2}=1,00 \times 10^{-3} \mathrm{~atm}\right)$.

Por outro lado, as duas etapas da digestão anaeróbia podem-se separar (Cooney et al., 2007; Kyazze et al., 2007) em uma primeira etapa de produção biológica de hidrogênio, 
denominada fermentação escura (acidogênese e acetogênese), e uma segunda etapa de metanogênese acetoclástica. Na primeira etapa todo o substrato ocasionalmente se transforma em acetato e um gás composto principalmente por hidrogênio $\left(\mathrm{H}_{2}\right)$, dióxido de carbono $\left(\mathrm{CO}_{2}\right)$ e traços de sulfeto de hidrogênio $\left(\mathrm{H}_{2} \mathrm{~S}\right)$ e amoníaco $\left(\mathrm{NH}_{3}\right)$. $\mathrm{O}$ gás produzido na primeira etapa se separa e o acetato continua como substrato da segunda etapa, a metanogênese acetoclástica, da que se obtém biogás composto principalmente, como mencionado antes, por: metano $\left(\mathrm{CH}_{4}\right)$, dióxido de carbono $\left(\mathrm{CO}_{2}\right)$ e traços de sulfeto de hidrogênio $\left(\mathrm{H}_{2} \mathrm{~S}\right)$, hidrogênio $\left(\mathrm{H}_{2}\right)$ e amoníaco $\left(\mathrm{NH}_{3}\right)$. Assim, todo o substrato ocasionalmente se transformar em dois gases: o gás de hidrogênio produzido na primeira etapa e o gás de metano produzido na segunda.

O processo de digestão anaeróbia ideal separada pode-se entender como uma fermentação escura (primeira etapa) representada em síntese pela Reação 47 para a produção de acetato e hidrogênio a partir de glicose seguida da Reação 55 de metanogênese acetoclástica (segunda etapa) para a produção de metano. Observe-se que na segunda etapa se desconsidera a metanogênese hidrogeniotrófica, porquanto o substrato (hidrogênio) é removido no gás produzido na primeira etapa; além disso, nesta idealização também se desconsidera a homoacetogênese.

Como apresentado antes, as Figuras 26 e 28 mostram os rendimentos dos produtos da fermentação de glicose (Reação 47) e as Figuras 29 e 31 os rendimentos dos produtos da metanogênese acetoclástica (Reação 55), em função do pH e da temperatura.

\subsection{Eficiências energéticas da digestão anaeróbia completa e separada}

A digestão anaeróbia completa se realiza em um intervalo de $\mathrm{pH}$ entre 6,0 e 8,0 (Chernicharo, 2007) e temperaturas de mesofílicas a termofílicas que podem variar entre $20 \mathrm{e}$ $70{ }^{\circ} \mathrm{C}$; porém, um cenário comum é realizar o processo em $\mathrm{pH} 6,5$ e temperatura de $30{ }^{\circ} \mathrm{C}$ com pressão parcial de hidrogênio de $1,00 \times 10^{-3}$ atm, mantida baixa pelo sintrofismo entre as bactérias fermentativas e as arqueias metanogênicas hidrogeniotróficas. Além disso, esse cenário justifica desconsiderar a homoacetogênese, porquanto sob essas condições esta última não é espontânea.

Neste cenário, considerando o processo de digestão anaeróbia ideal completa (Seção 4.2.4), a partir da fermentação da glicose (Reação 47) se produzem 1,618 mols de acetato e 3,236 mols de hidrogênio por mol de glicose. Posteriormente, acetato e hidrogênio são transformados em metano pela metanogênese acetoclástica (Reação 55) e hidrogeniotrófica (Reação 56), respetivamente, para produzir 0,939 mols de metano por mol de acetato (ou 
1,519 mols de metano por mol de glicose) e 0,242 mols de metano por mol de hidrogênio (ou 0,783 mols de metano por mol de glicose). Neste cenário, o rendimento total equivale a 2,302 mols de metano por mol de glicose, com 66,0\% aportado pela via acetoclástica e 34,0\% pela via hidrogeniotrófica. A Figura 35 apresenta os resultados da aplicação do modelo para o rendimento de metano para este cenário e, em geral, para todo o intervalo de $\mathrm{pH}$ a $30{ }^{\circ} \mathrm{C}$, discriminado pelos aportes das metanogênese acetoclástica e hidrogeniotrófica.

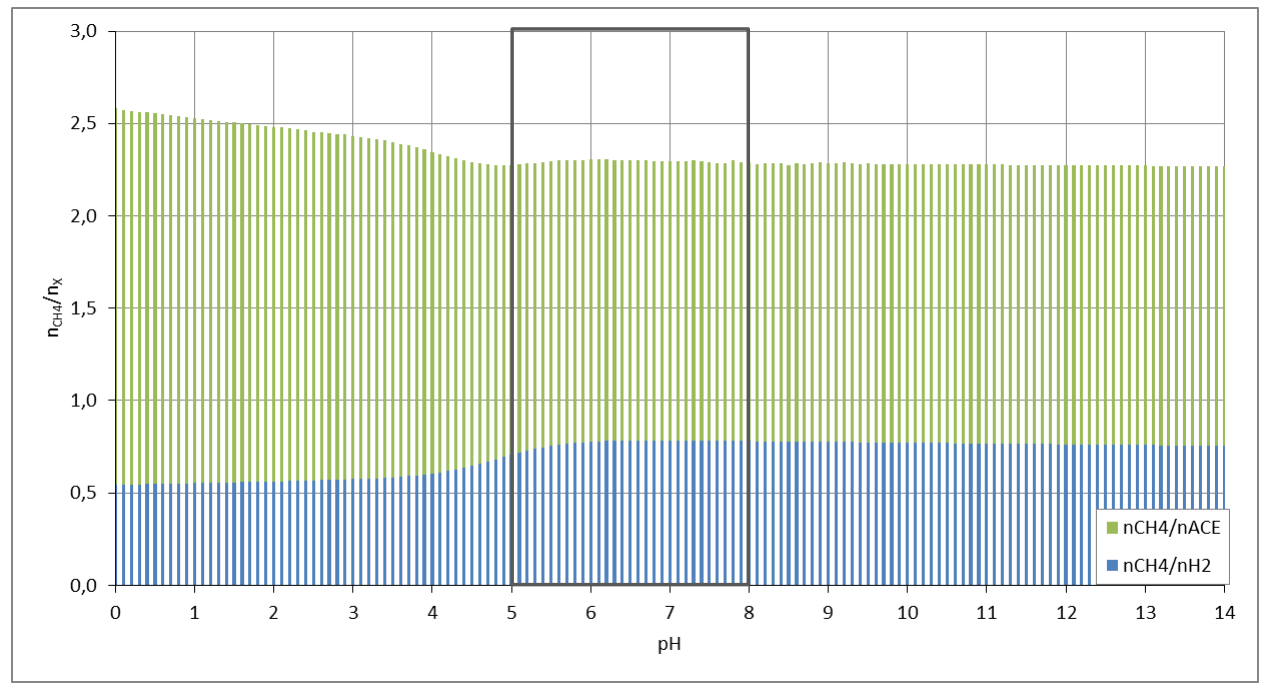

Figura 35. Rendimento de metano das metanogênese acetoclástica e hidrogeniotrófica, em mols de metano por mol de substrato, em função do $\mathrm{pH}\left(\mathrm{T}=30^{\circ} \mathrm{C}, \mathrm{p}_{\mathrm{H} 2}=1,00 \times 10^{-3} \mathrm{~atm}\right)$.

Os 2,302 mols de metano por mol de glicose produzidas fornecem $2049,9 \mathrm{~kJ}^{\text {mol }_{\mathrm{GLU}}}{ }^{-1}$ de energia quando se considera sua entalpia padrão de combustão $\left(-890,5 \mathrm{~kJ} \mathrm{~mol}_{\mathrm{CH}}{ }^{-1}\right)$. Comparando com a entalpia padrão de combustão da glicose $\left(-2801,4 \mathrm{~kJ}\right.$ mol $\left._{\mathrm{GLU}}{ }^{-1}\right)$, se calcula a eficiência da recuperação de energia na digestão anaeróbia ideal com a Equação 89.

$$
\eta=\frac{\left({ }^{n_{C H_{4}}} / n_{G L U} \times \Delta_{C} H_{C H_{4}}^{\circ}\right)}{\Delta_{C} H_{G L U}^{\circ}} \times 100=73,2 \%
$$

Na qual $\eta$ é a eficiência de recuperação de energia, $n_{i}$ é o número de mols do componente $i$ e $\Delta_{C} H_{i}^{\circ}$ é a entalpia padrão de combustão do componente $i$.

Com fins comparativos, desconsideremos a formação de células no modelo biotermodinâmico $\left(f_{s}=0,00\right)$. Nessas condições, na fermentação da glicose se produzem 2,000 mols de acetato e 4,000 mols de hidrogênio por mol de glicose, que são transformados na metanogênese acetoclástica em 1,000 mols de metano por mol de acetato (ou 2,000 mols 
de metano por mol de glicose) e 0,250 mols de metano por mol de hidrogênio (ou 1,000 mols de metano por mol de glicose) na metanogênese hidrogeniotrófica. O rendimento total equivale a 3,000 mols de metano por mol de glicose, com 66,7\% aportado pela via acetoclástica e 33,3\% pela via hidrogeniotrófica. A energia produzida por essa quantidade de metano é $2671,5 \mathrm{~kJ}$ mol $_{\mathrm{GLU}}{ }^{-1}$ considerando sua entalpia padrão de combustão $(-890,5 \mathrm{~kJ}$ mol $\left._{\mathrm{CH}_{4}}{ }^{-1}\right)$ que, comparada com a entalpia padrão de combustão da glicose $\left(-2801,4\right.$ kJ mol ${ }_{\mathrm{GLU}}{ }^{-}$ ${ }^{1}$ ), resulta em uma eficiência de recuperação de energia de 94,5\%.

Nos dois cenários, os aportes à produção de metano das metanogênese acetoclástica e hidrogeniotrófica coincidem com os reportes bibliográficos de duas terceiras partes para a acetoclástica e uma terceira parte para a metanogênica (Bitton, 2005; Chernicharo, 2007); resultado evidente para o pH típico da digestão anaeróbia (entre 6,0 e 8,0) na Figura 35.

Finalmente, a Figura 35 mostra que no intervalo de $\mathrm{pH}$ para a digestão anaeróbia completa $(6,0$ a 8,0$)$ o rendimento máximo de metano atingi aproximadamente 2,3 mols de metano por mol de glicose, $23,3 \%$ a menos que os 3,0 mols de metano por mol de glicose quando se desconsidera a produção de células.

A digestão anaeróbia separada permite dividir os $\mathrm{pH}$ para cada etapa. A primeira etapa de fermentação escura se realiza em um intervalo de pH entre 5,0 e 6,0 (Chernicharo, 2007), e a segunda etapa de metanogênese acetoclástica em um intervalo entre 6,6 e 7,4 (Chernicharo, 2007, Khanal, 2008); ambas em temperaturas de mesofílicas a termofílicas que podem variar entre 20 e $70{ }^{\circ} \mathrm{C}$.

Um cenário comum para a primeira etapa é realizar o processo em $\mathrm{pH} 5,5 \mathrm{e}$ temperatura de $30^{\circ} \mathrm{C}$ com pressão parcial de hidrogênio de $1,00 \times 10^{-1}$ atm; superior à pressão parcial no cenário da digestão anaeróbia completa devido a que ao separar as etapas se rompe o sintrofismo entre as bactérias fermentativas e as arqueias metanogênicas hidrogeniotróficas e, portanto, aumenta a pressão parcial de hidrogênio.

Neste cenário, considerando o processo de digestão anaeróbia ideal separada (Seção 4.3), a partir da fermentação escura (Reação 47) se produzem 3,205 mols de hidrogênio por mol de glicose que se separam e 1,602 mols de acetato por mol de glicose que continuam para a segunda etapa.

Um cenário comum para a segunda etapa é realizar o processo em $\mathrm{pH} \mathrm{7,0} \mathrm{e}$ temperatura de $30{ }^{\circ} \mathrm{C}$ sem presença de hidrogênio. Assim, neste cenário se produzem 0,936 mols de metano por mol de acetato (ou 1,500 mols de metano por mol de glicose) pela metanogênese acetoclástica (Reação 55), a partir do acetato produzido na primeira etapa. A Figura 36 apresenta os resultados da aplicação do modelo para o rendimento de hidrogênio e 
metano para estes cenários e, em geral, para todo o intervalo de $\mathrm{pH}$ a $30{ }^{\circ} \mathrm{C}$.

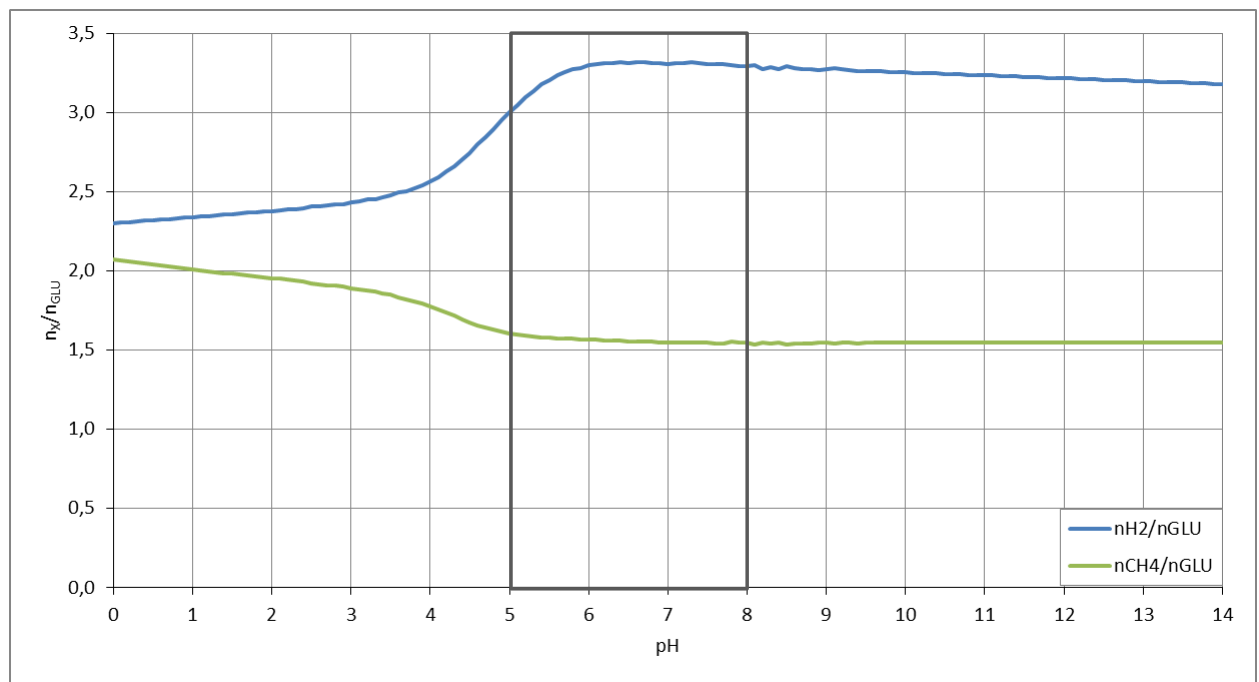

Figura 36. Rendimento de hidrogênio da fermentação de glicose $\left(\mathrm{T}=30^{\circ} \mathrm{C}, \mathrm{p}_{\mathrm{H} 2}=1,00 \times 10^{-1}\right.$ atm) e metano da metanogênese acetoclástica $\left(\mathrm{T}=30^{\circ} \mathrm{C}, \mathrm{p}_{\mathrm{H} 2}=0 \mathrm{~atm}\right)$, em mols de produto por mol de glicose, em função do $\mathrm{pH}$.

Os 3,205 mols de hidrogênio por mol de glicose produzidas fornecem 916,0 kJ mol $_{\mathrm{GLU}}{ }^{-1}$ de energia e os 1,500 mols de metano por mol de glicose fornecem $1335,8 \mathrm{~kJ}$

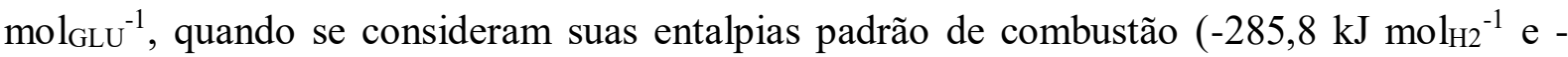
$\left.890,5 \mathrm{~kJ} \mathrm{~mol}_{\mathrm{CH}^{-1}}{ }^{-1}\right)$.

Combinados, a digestão anaeróbia ideal separada produz $2251,7 \mathrm{~kJ}^{m_{0}} \mathrm{GLU}^{-1} \mathrm{de}$ energia que, comparada com a entalpia padrão de combustão da glicose $\left(-2801,4\right.$ kJ mol $\left._{\mathrm{GLU}}{ }^{-1}\right)$, equivale a 80,4\% de eficiência na recuperação de energia usando a Equação 90.

$$
\eta=\frac{\left(n_{H_{2}} / n_{G L U} \times \Delta_{C} H_{H_{2}}^{\circ}+n_{C H_{4}} / n_{G L U} \times \Delta_{C} H_{C H_{4}}^{\circ}\right)}{\Delta_{C} H_{G L U}^{\circ}} \times 100=80,4 \% \quad \text { [90] }
$$

Desconsiderando novamente a formação de células no modelo biotermodinâmico $\left(f_{s}=\right.$ 0,00), com fins comparativos, na fermentação escura se produzem 4,000 mols de hidrogênio e 2,000 mols de acetato por mol de glicose. Os mols de acetato são transformados na metanogênese acetoclástica em 1,000 mols de metano por mol de acetato (ou 2,000 mols de metano por mol de glicose). Assim, os 4,000 mols de hidrogênio por mol de glicose fornecem $1143,2 \mathrm{~kJ} \mathrm{~mol}_{\mathrm{GLU}^{-1}}$ de energia e os 2,000 mols de metano por mol de glicose fornecem 1781,0

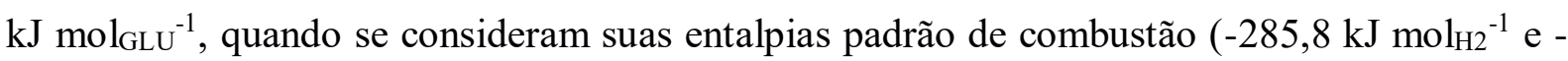


$890,5 \mathrm{~kJ} \mathrm{~mol}_{\mathrm{CH}^{-1}}{ }^{-1}$ ), e combinados produzem 2924,2 $\mathrm{kJ}^{\text {mol }} \mathrm{GLU}^{-1}$. Comparando com a entalpia padrão de combustão da glicose $\left(-2801,4 \mathrm{~kJ}\right.$ mol $\left._{\mathrm{GLU}}{ }^{-1}\right)$, resulta em uma eficiência de recuperação de energia de 104,4\%, um impossível termodinâmico.

Finalmente, a Figura 36 mostra que para a digestão anaeróbia separada, no intervalo de pH para a fermentação escura $(5,0$ a 6,0), o rendimento máximo de hidrogênio atinge aproximadamente 3,3 mols de hidrogênio por mol de glicose, $17,5 \%$ a menos que os 4,0 mols de hidrogênio por mol de glicose quando se desconsidera a produção de células. Esse rendimento máximo acontece em um $\mathrm{pH}$ aproximadamente 6,0. Segundo a Figura 36, no intervalo de pH para a metanogênese acetoclástica $(6,6$, a 7,4), o rendimento de metano é praticamente constante e atingi aproximadamente 1,6 mols de metano por mol de glicose, $20,0 \%$ a menos que os 2,0 mols de metano por mol de glicose produzidas quando se desconsidera a produção de células.

A Figura 37 apresenta a comparação entre as eficiências da recuperação de energia atingidas para a digestão anaeróbia completa e separada em função do $\mathrm{pH}$ e da temperatura para os cenários analisados aplicando o modelo biotermodinâmico. Os resultados mostram que a separação das etapas da digestão anaeróbia conduz consistentemente a uma maior eficiência (entre 10 e 12\% aproximadamente), com máximos em um pH aproximado de 6,0 e favorecida pela diminuição da temperatura. Assim, do ponto de vista termodinâmico e sob iguais condições experimentais, a separação das etapas da digestão anaeróbia gerará, mínimo, entre 10 e $12 \%$ maior recuperação de energia que a digestão anaeróbia completa.

Os rendimentos molares e as eficiências energéticas determinadas com o modelo biotermodinâmico dependem das relações estequiométricas entre reagentes e produtos obtidas pela distribuição das espécies (Seção 3.2.3). Essa distribuição das espécies pode ser influída pelas incertezas nos dados termodinâmicos por duas vias; a primeira, a través das energias livres padrão de reação $\left(\Delta_{r} G^{\circ}\right)$ que afetam os resultados dos valores $f_{s}$ e $f_{e}$ do modelo, e a segunda, a traves das entalpias padrão de reação $\left(\Delta_{r} H^{\circ}\right)$ que afetam as constantes de equilíbrio.

Não obstante, incertezas de $\pm 5 \%$ em todas as energias livres e entalpias de reação geram variações de $\pm 1 \%$, aproximadamente, nos resultados de rendimentos molares e eficiências energéticas e, em consequência, é possível concluir que essas incertezas não afetam significativamente a distribuição das espécies no modelo biotermodinâmico. Assim, as únicas variáveis que no modelo influem na distribuição das espécies são o $\mathrm{pH}$, a temperatura e as concentrações ou pressões parciais de reagentes e produtos.

$\mathrm{Na}$ Figura 37 são apresentadas as variações nas eficiências de recuperação de energia 
para a digestão anaeróbia completa e separada geradas por incertezas de $\pm 5 \%$ nas propriedades termodinâmicas do modelo.

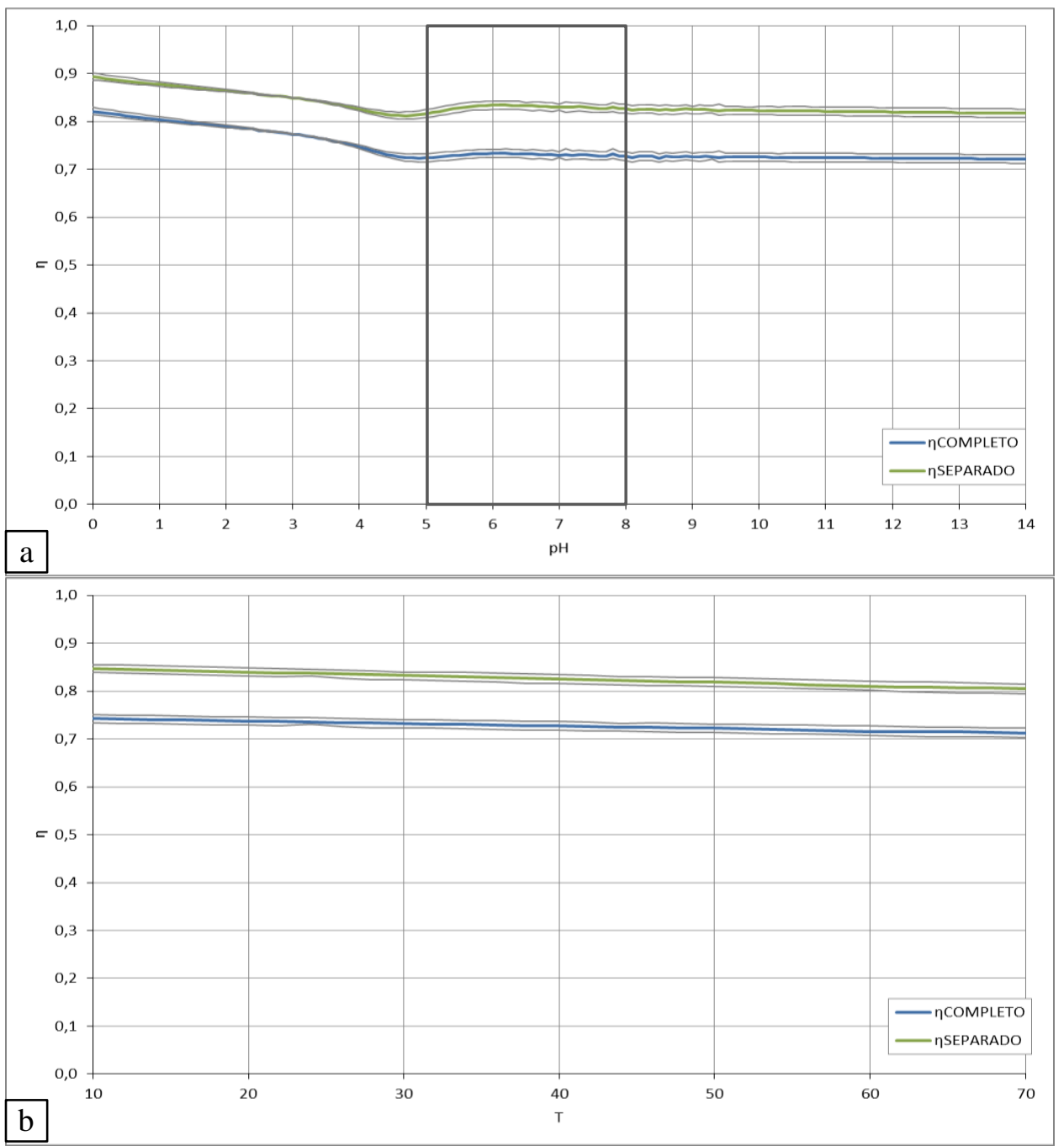

Figura 37. Eficiências de recuperação de energia para a digestão anaeróbia completa $(\mathrm{pH}=$ $\left.6,5, \mathrm{~T}=30^{\circ} \mathrm{C}, \mathrm{p}_{\mathrm{H} 2}=1,00 \times 10^{-3} \mathrm{~atm}\right)$ e separada $\left(\mathrm{pH}=5,5, \mathrm{~T}=30^{\circ} \mathrm{C}, \mathrm{p}_{\mathrm{H} 2}=1,00 \times 10^{-1}\right.$ atm na primeira etapa e $\mathrm{pH}=7,0, \mathrm{~T}=30^{\circ} \mathrm{C}, \mathrm{p}_{\mathrm{H} 2}=0$ atm na segunda etapa) em função a) do $\mathrm{pH}$ e b) da temperatura.

Por fim, no cenário suposto para a fermentação escura da digestão anaeróbia separada $\left(\mathrm{T}=30^{\circ} \mathrm{C}, \mathrm{p}_{\mathrm{H} 2}=1,00 \times 10^{-1} \mathrm{~atm}\right)$, a homoacetogênese é espontânea em todo o intervalo de $\mathrm{pH}$. Esso pode conduzir a que parte do hidrogênio seja transformado a acetato, diminuindo o rendimento da produção de hidrogênio e a eficiência da fermentação escura, mas aumentando o rendimento da produção de metano e a eficiência da metanogênese acetoclástica. 


\subsection{Conclusões}

- Todas as fermentações da glicose consideradas na acidogênese no modelo biotermodinâmico são processos espontâneos nos intervalos de $\mathrm{pH}$, pressões parciais de hidrogênio e temperaturas avaliados.

- Em geral, a diminuição da pressão parcial na acetogênese favorece a conversão das reações, sinal do sintrofismo com os processos hidrogeniotróficos (metanogênese e, possivelmente, homoacetogênese "inversa").

- Processos de digestão anaeróbia com pH abaixo de 5,5 (a $\left.30{ }^{\circ} \mathrm{C}\right)$ são inibidores da metanogênese acetoclástica do ponto de vista termodinâmico, independente de considerações biológicas.

- Independentemente de considerações cinéticas ou biológicas, o aumento da temperatura na digestão anaeróbia favorece levemente o rendimento das células do ponto de vista termodinâmico, com exceção da metanogênese hidrogeniotrófica.

- As arqueias metanogênicas têm baixos rendimentos celulares associados às baixas energias livres produzidas, convertendo a estes microorganismos em sistemas biológicos que prosperam a partir de ganhos energéticos marginais.

- Do ponto de vista termodinâmico, nos cenários analisados e sob iguais condições experimentais, a separação da digestão anaeróbia em duas etapas aumenta a eficiência de recuperação de energia, mínimo, entre 10 e 12\% aproximadamente, quando comparada com a digestão anaeróbia completa.

- A aplicação do modelo biotermodinâmico permite determinar valores mais próximos à realidade para rendimentos molares e energéticos porquanto ignorar as células pode conduzir a resultados impossíveis termodinamicamente. 


\section{FOTOSSÍNTESE OXIGÊNICA}

\subsection{Metabolismo}

Em microorganismos fototróficos oxigênicos (microalgas e cianobactérias) o modo de crescimento preferencial é o fotolitotrófico, no qual a água é o doador de elétrons para fixar carbono inorgânico $\left(\mathrm{CO}_{2}, \mathrm{HCO}_{3}{ }^{-}, \mathrm{CO}_{3}{ }^{2-}\right)$ e a biossíntese de compostos orgânicos de armazenamento (Boichenko, Greenbaum \& Seibert, 2004), por meio de dois fotossistemas unidos (PSII e PSI), comuns a todas as espécies de algas e cianobactérias, que atuam em serie no esquema $Z$ da fotossíntese (Archer \& Barber, 2004; Madigan et al., 2015). Porém, outros modos de metabolismo são possíveis dependendo das condições do meio.

Os diferentes metabolismos das microalgas e cianobactérias se esboçam a seguir.

\subsubsection{Bioquímica do metabolismo das microalgas}

As microalgas são um grupo muito diverso de microorganismos eucariotas com alta variedade de produtos metabólicos como: polissacarídeos, lipídeos, pigmentos, entre outros (Gimpel, Henríquez \& Mayfield, 2015). Exibem metabolismo fototrófico (fotoorganotrófico e fotolitotrófico) e quimioorganotrófico; mas a ampla maioria são aeróbias estritamente fotolitotróficas que usam a água como doador de elétrons (Archer \& Barber, 2004; Madigan et al., 2015).

Em organismos fotossintéticos oxigênicos, a energia luminosa alimenta a maquinaria fotossintética que produz a energia química (ATP) e o poder redutor (NADPH) requeridos nas reações subsequentes de fixação de carbono e outros processos metabólicos (Spilling \& Seppälä, 2012). Em microalgas, em metabolismo fotolitotrófico, a atividade do fotossistema II (PSII) oxida água produzindo oxigênio, íons hidrogênio e elétrons (Archer \& Barber, 2004; Beer et al., 2009). Os elétrons se transportam pelas clorofilas P680 (PSII) e P700 (PSI), excitadas pelos fótons, por meio de uma cadeia de transporte que os entrega para, por fim, reduzir $\mathrm{NADP}^{+}$a NADPH (geração de poder redutor) por meio da ferredoxina (Madigan et al., 2015). Enquanto os elétrons fluem de PSII a PSI, gera-se uma força próton-motriz que produz ATP (energia química) por fotofosforilação não cíclica (Madigan et al., 2015). O poder redutor (NADPH) e a energia química (ATP) gerados se usam no ciclo redutivo das pentosesfosfato (ciclo de Calvin) para fotoassimilação de carbono inorgânico $\left(\mathrm{CO}_{2}, \mathrm{HCO}_{3}{ }^{-}, \mathrm{CO}_{3}{ }^{2-}\right)$ e 
síntese de material celular e compostos de armazenamento (polissacarídeos e lipídeos, principalmente amido e triacilglicerídeos) (Archer \& Barber, 2004; Spilling \& Seppälä, 2012). Não obstante, como o ciclo precisa mais NADPH que ATP, a energia química extra é obtida pela fotofosforilação cíclica na qual os elétrons não reduzem $\mathrm{NADP}^{+}$senão que se retornam de PSI à cadeia de transporte e geram uma força próton-motriz que suporta a síntese adicional de ATP (Madigan et al., 2015). Na escuridão, as microalgas realizam uma respiração aeróbia endógena na qual consumem os compostos de armazenamento (Dubini \& Gonzalez-Ballester, 2016; Perez-Garcia et al., 2011) pelo ciclo dos ácidos tricarboxílicos (ciclo de Krebs), e produzem ATP por glicólise e fosforilação oxidativa para continuar com os processos metabólicos (Spilling \& Seppälä, 2012). Estes processos se apresentam na Figura 38.

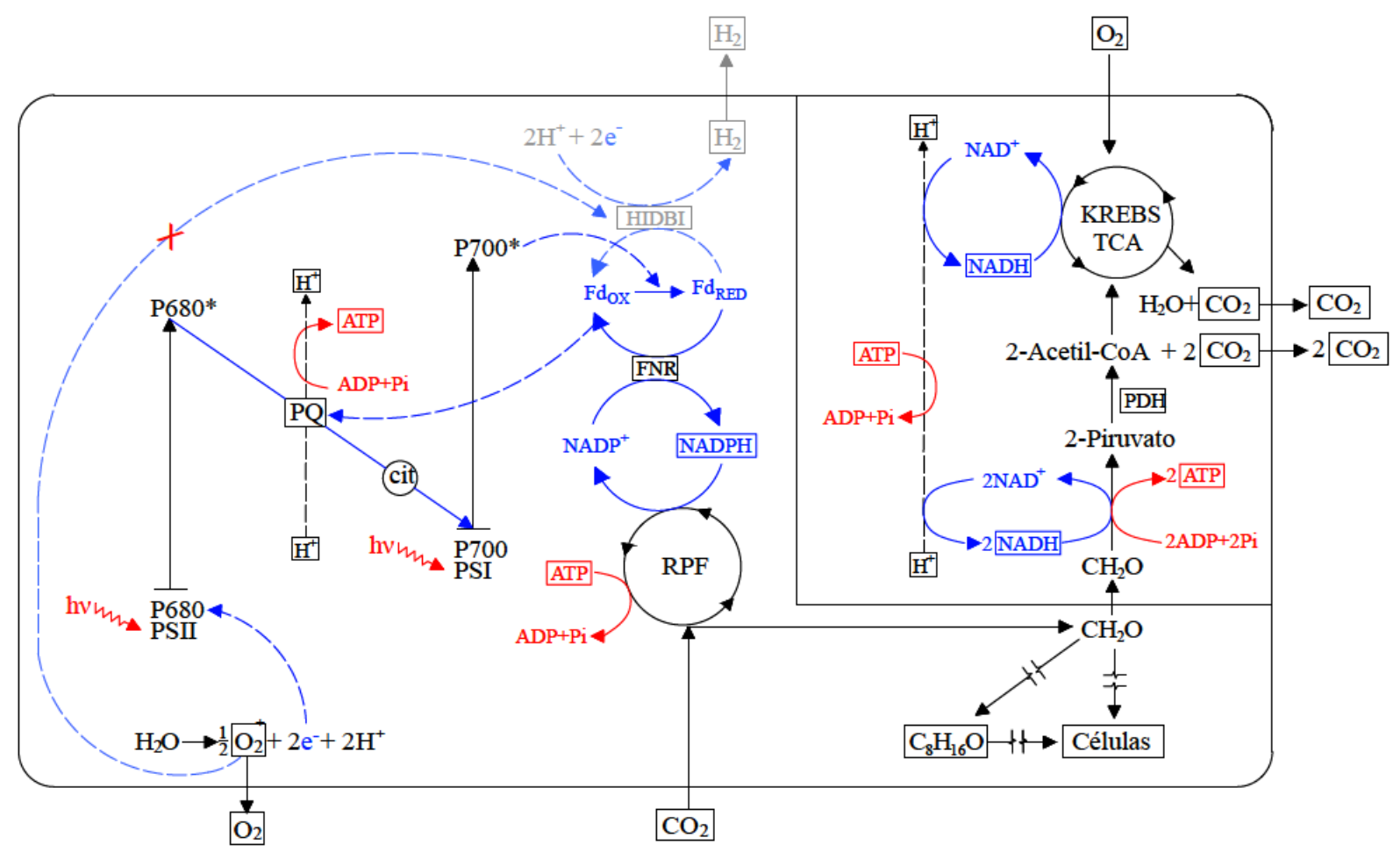

Figura 38. Fotossíntese oxigênica em microalgas.

A figura detalha o processo catabólico. No processo anabólico de, por exemplo, a formação de novas células, se produz um intermediário energético como acetil-CoA. A via de produção de hidrogênio pela biofotólise direta se inativa pela inibição da hidrogenase pelo oxigênio. NADPH e NADP ${ }^{+}$: Forma reduzida e oxidada, respetivamente, da nicotinamida adenina dinucleótido fosfato. PDH: Piruvato desidrogenase. FNR: Ferredoxina $\mathrm{NAD}(\mathrm{P})^{+}$redutase. HIDB: Hidrogenase bidirecional. PQ: Plastoquinona. cit: Citocromo. RPF: Ciclo redutivo das pentoses-fosfato. TCA: Ciclo dos ácidos tricarboxílicos.

Sob condições anóxicas, algumas microalgas metabolizam os compostos orgânicos 
armazenados mediante a fermentação (metabolismo endógeno) que permite obter a energia química (ATP) e o poder redutor (NADPH) necessários para seus processos metabólicos de manutenção celular (Catalanotti et al., 2013). Por exemplo, a glicose contida nos compostos orgânicos de armazenamento pode-se fermentar a acetato pelo processo fermentativo apresentado na Seção 4.1.1 (Figura 4). Nessas condições, na luz, a fermentação pode-se articular com a fotofosforilação cíclica dirigindo os elétrons do NADH ou da ferredoxina reduzida à cadeia de transporte e PSI (Antal et al., 2012; Beer et al., 2009) para suportar a síntese adicional de ATP. Na escuridão, a síntese adicional de ATP não é possível pela ausência da fotofosforilação cíclica e a manutenção celular deve-se realizar com a energia química obtida exclusivamente da fermentação pela fosforilação a nível de substrato. Poder redutor formado em excesso no metabolismo fermentativo pode-se eliminar pela produção de hidrogênio por meio da hidrogenase bidirecional que, em anaerobiose estrita (o oxigênio inibe sua síntese e atividade), catalisa a Reação 57 reversível (Antal et al., 2012; Boichenko, Greenbaum \& Seibert, 2004; Srirangan, Pyne \& Perry, 2011; Yeager et al., 2011).

$$
2 \mathrm{H}^{+}+2 \mathrm{Fd}_{\mathrm{RED}} \rightleftharpoons \mathrm{H}_{2}+2 \mathrm{Fd}_{\mathrm{OX}}
$$

Reação 57

Estes processos sob condições anóxicas se apresentam na Figura 39.

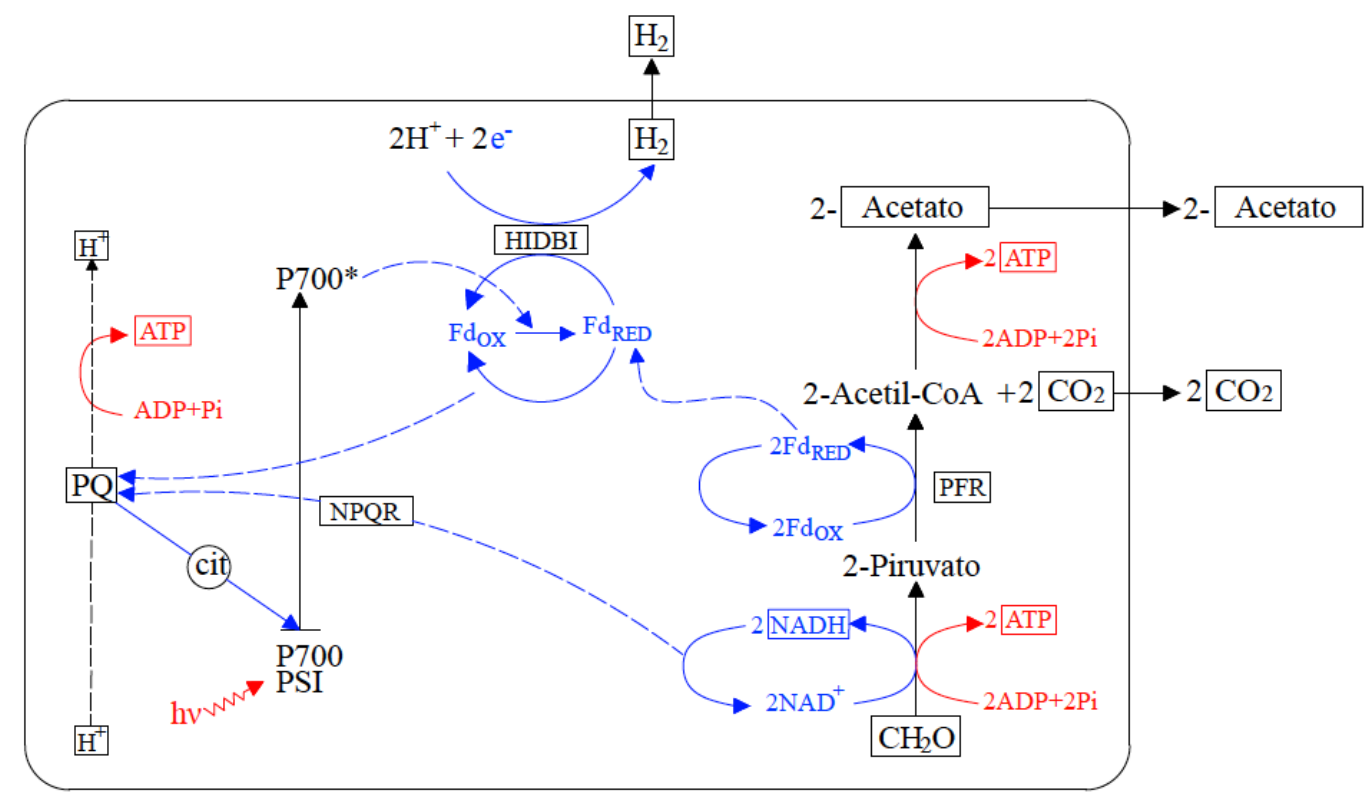

Figura 39. Fermentação (metabolismo endógeno) em microalgas.

NPQR: NAD(P)H-plastoquinona oxidorredutase. PFR: Piruvato ferredoxina oxidorredutase. HIDB: Hidrogenase bidirecional. PQ: Plastoquinona. cit: Citocromo. 
Outras microalgas, também sob condições anóxicas, podem continuar com seus processos metabólicos usando o hidrogênio molecular $\left(\mathrm{H}_{2}\right)$ como doador de elétrons em um metabolismo fotolitotrófico anaeróbio (uma fotossíntese anoxigênica em algas) (Catalanotti et al., 2013; Madigan et al., 2015). Nesse metabolismo, a hidrogenase bidirecional catalisa a reação inversa da Reação 57, produzindo poder redutor (NADPH) e energia química (ATP) a través da fotofosforilação cíclica (Catalanotti et al., 2013).

Finalmente, algumas microalgas também podem usar compostos orgânicos exógenos em metabolismo fotoorganotrófico (luz) ou quimioorganotrófico (escuridão) (Gimpel, Henríquez \& Mayfield, 2015), assimilando-os diretamente em material celular produzindo um incremento na taxa de crescimento e um alto rendimento de biomassa celular (Sirevåg, 1995). Não obstante, o metabolismo organotrófico a partir de compostos de carbono orgânico dissolvido (glicose, galactose, frutose, glicerol, acetato, citrato, fumarato, lactato, malato, piruvato e succinato) é restringido a poucas espécies de microalgas (Perez-Garcia et al., 2011) altamente seletivas (Gimpel, Henríquez \& Mayfield, 2015). Algumas microalgas assimilam simultaneamente carbono inorgânico (ciclo de Calvin) e orgânico (Perez-Garcia et al., 2011), como a assimilação de acetato pelo ciclo do glioxilato para convertê-lo em acetil-CoA (Dubini \& Gonzalez-Ballester, 2016).

Como apresentado na Figura 38, o metabolismo fotolitotrófico das microalgas pode produzir amido e triglicerídeos como produtos de armazenamento. Estes produtos metabólicos podem-se usar para a produção indireta de biocombustíveis (Beer et al., 2009; Subramanian, Dubini \& Seibert, 2012) como: etanol pela extração e fermentação alcoólica do amido por leveduras e bactérias, metano ou hidrogênio pela extração e digestão anaeróbia completa ou separada, respetivamente, do amido (Seção 4.2) (Dębowski et al., 2013), e diesel pela extração e transesterificação dos triglicerídeos (Chen et al., 2011; Chisti, 2007; Mata, Martins \& Caetano, 2010; Radakovits et al., 2010; Scott et al., 2010; Topf et al., 2012). Além desses biocombustíveis, as microalgas podem também produzir hidrogênio $\left(\mathrm{H}_{2}\right)$ diretamente no metabolismo (Beer et al., 2009; Yu \& Takahashi, 2007).

Em microalgas, o processo mais simples para produzir hidrogênio envolve a transferência direta de elétrons da hidrolise d'água à hidrogenase com produção simultânea de oxigênio (biofotólise direta) (Antal et al., 2012) em metabolismo fotolitotrófico. Porém, como mencionado antes, a enzima hidrogenase que catalisada a produção de hidrogênio é fortemente inibida pelo oxigênio, pelo que se precisa de anaerobiose estrita no sitio de ação (Boichenko, Greenbaum \& Seibert, 2004; Ghirardi et al., 2000). Uma alternativa para atingir as condições anaeróbias é ajustar a hidrólise d'água e a respiração (biofotólise direta) 
(Degrenne, Pruvost \& Legrand. 2011); outra é separar temporalmente a hidrólise d'água da produção de hidrogênio (biofotólise indireta) (Yu \& Takahashi, 2007). Nesta última alternativa, na primeira etapa, a hidrolise d'água com produção de oxigênio (fotossíntese oxigênica) conduz à síntese e acumulação de carboidratos por fixação fotossintética de dióxido de carbono (Figura 38). Posteriormente, na segunda etapa, os carboidratos se fermentam (metabolismo endógeno), na luz ou na escuridão, para liberar o poder redutor (NADH) necessário para produzir hidrogênio (Figura 39) (Antal et al., 2012).

Embora a produção de hidrogênio pela hidrogenase em microalgas precisa de anaerobiose estrita no sitio de ação, a biofotólise direta pode ser parcialmente atingida, aportando $70 \%$ da produção de hidrogênio pela hidrólise d'água em PSII, em sistemas com limitação de enxofre sob iluminação constante (Melis, 2007; Melis \& Happe, 2001; Melis et al., 2000; Srirangan, Pyne \& Perry, 2011). O 30\% restante se produz pela fermentação dos carboidratos armazenados (metabolismo endógeno) para liberar o poder redutor (NADH) necessário para produzir hidrogênio, em uma transferência de elétrons mediada por PSI (Antal et al., 2012).

\subsubsection{Bioquímica do metabolismo das cianobactérias}

As cianobactérias são microorganismos procariotas fotossintéticos muito heterogêneos, com formas unicelulares e filamentosas e metabolismo fototrófico (fotoorganotrófico e fotolitotrófico) e quimioorganotrófico (Madigan et al., 2015). Fotoassimilam carbono inorgânico $\left(\mathrm{CO}_{2}, \mathrm{HCO}_{3}{ }^{-}, \mathrm{CO}_{3}{ }^{2-}\right)$ pelo ciclo redutivo das pentosesfosfato (ciclo de Calvin) (Madigan et al., 2015) para síntese de material celular e compostos de armazenamento, principalmente glicogênio (Yu \& Takahashi, 2007). Na escuridão, as cianobactérias adotam um metabolismo endógeno consumindo o glicogênio por respiração aeróbia ou, sob condições anóxicas, por fermentação (Madigan et al., 2015). Cada metabolismo é o mesmo explicado antes (Seção 5.1.1) para microalgas (Figura 38).

Por outro lado, excesso de poder redutor gerado no metabolismo pode-se eliminar em anaerobiose estrita mediante a produção de hidrogênio por meio da hidrogenase bidirecional (Reação 57) (Yeager et al., 2011), enzima encontrada em quase todas as cianobactérias unicelulares e em algumas filamentosas (Boichenko, Greenbaum \& Seibert, 2004).

Quando as concentrações de sulfeto $\left(\mathrm{H}_{2} \mathrm{~S}, \mathrm{HS}^{-}\right)$são altas, algumas cianobactérias podem usá-lo como doador de elétrons no PSII no lugar d'água, passando da fotossíntese oxigênica a fotossíntese anoxigênica e produzindo enxofre elementar $\left(\mathrm{S}^{0}\right)$ que é armazenado 
em glóbulos extracelulares (Madigan et al., 2015).

Finalmente, algumas cianobactérias podem crescer fotoorganotroficamente (luz) usando substratos orgânicos simples como glicose e acetato como fontes de carbono, e umas poucas, principalmente espécies filamentosas, podem crescer quimioorganotroficamente (escuridão) assimilando glicose ou sacarose (Madigan et al., 2015).

Todas as cianobactérias filamentosas e algumas unicelulares são diazotróficas que fixam nitrogênio atmosférico $\left(\mathrm{N}_{2}\right)$ sob limitação de formas assimiláveis de nitrogênio por meio da nitrogenase, uma enzima exclusiva de microorganismos procariotas fixadores de nitrogênio (Prince \& Kheshgi, 2005), que se pode descrever como uma hidrogenase dependente de ATP (Boichenko, Greenbaum \& Seibert, 2004), e que catalisa a redução irreversível de nitrogênio a amoníaco $\left(\mathrm{NH}_{4}{ }^{+}, \mathrm{NH}_{3}\right.$ ) (Reação 58) (Antal et al., 2012; Boichenko, Greenbaum \& Seibert, 2004; Dasgupta et al., 2010; Rey, Heiniger \& Harwood, 2007; Yu \& Takahashi, 2007):

$$
\begin{array}{r}
\mathrm{N}_{2}+8 \mathrm{H}^{+}+8 \mathrm{Fd}_{\mathrm{RED}}+16 \mathrm{ATP}+16 \mathrm{H}_{2} \mathrm{O} \rightarrow 2 \mathrm{NH}_{3}+\mathrm{H}_{2}+8 \mathrm{Fd}_{\mathrm{OX}}+16 \mathrm{ADP}+16 \mathrm{Pi} \\
\text { Reação } 58
\end{array}
$$

Esta reação de fixação de nitrogênio é uma reação de redução endergônica, pelo que precisa de poder redutor (NADPH) e energia química (ATP); os elétrons se obtêm a partir do substrato enquanto à energia é geralmente aceito que, sob ótimas condições, duas moléculas de ATP se hidrolisam por elétron transferido (Prince \& Kheshgi, 2005; Yeager et al., 2011).

Além de inibidores como as formas assimiláveis de nitrogênio (e.g. amoníaco), o principal inibidor da nitrogenase é o oxigênio $\left(\mathrm{O}_{2}\right)$; porém, a inibição é reversível e a nitrogenase recupera sua atividade uma vez o oxigênio é removido ou consumido (Boichenko, Greenbaum \& Seibert, 2004; Koku et al., 2002). Para se proteger do oxigênio, algumas cianobactérias filamentosas têm desenvolvido uma separação espacial denominada heterocisto; células especializadas fotosinteticamente inativas (possuem PSI, mas carecem de PSII) que proveem um ambiente altamente reduzido e anóxico, necessário para o funcionamento da nitrogenase na ausência de nitrogênio assimilável (Bergman et al., 1997; Dasgupta et al., 2010; Madigan et al., 2015; Srirangan, Pyne \& Perry, 2011; Yeager et al., 2011). No heterocisto, a energia química (ATP) e o poder redutor (NADPH) necessários para a atividade da nitrogenase, se obtêm pela desassimilação dos compostos orgânicos de armazenamento importados das células vegetativas vizinhas (Dasgupta et al., 2010; Madigan et al., 2015). Esta desassimilação se realiza por meio da respiração aeróbia endógena pelo 
ciclo oxidativo das pentoses fosfato (Böhme, 1998; Boichenko, Greenbaum \& Seibert, 2004) e a fosforilação oxidativa que consume o oxigênio que entra no heterocisto (Böhme, 1998; Yeager et al., 2011). No ciclo oxidativo das pentoses fosfato, a glicose pode ser quase completamente oxidada até dióxido de carbono produzindo principalmente poder redutor (NADPH) para a fixação do nitrogênio (Böhme, 1998). Energia química adicional se gera pela fotofosforilação cíclica no PSI (Böhme, 1998; Boichenko, Greenbaum \& Seibert, 2004; Yeager et al., 2011) Estes processos se apresentam na Figura 40.

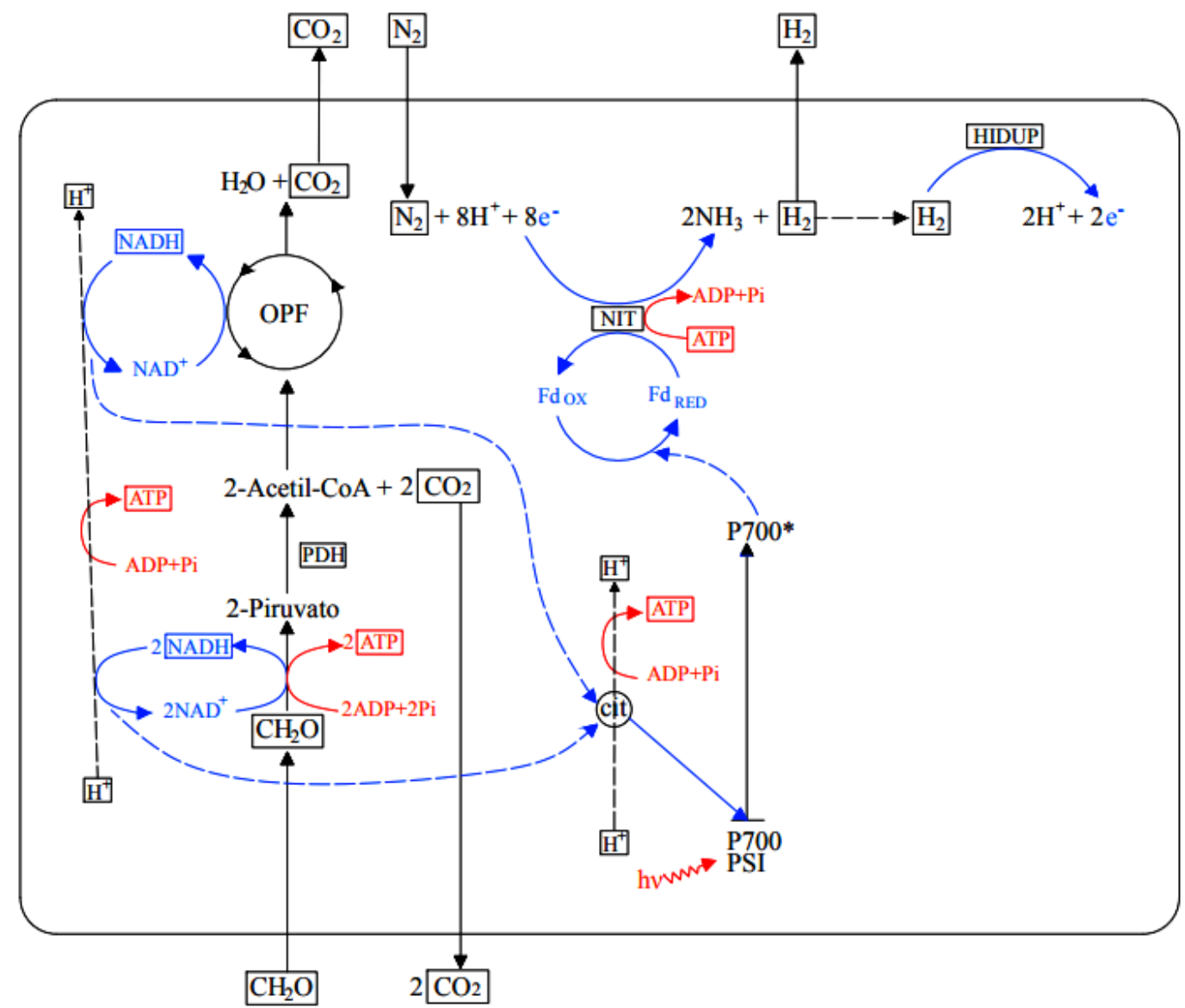

Figura 40. Fixação de nitrogênio em cianobactérias diazotróficas.

PDH: Piruvato desidrogenase. NIT: Nitrogenase. HIDUP: Hidrogenase de assimilação. cit: Citocromo. OPF: Ciclo oxidativo das pentoses-fosfato.

O hidrogênio produzido irreversivelmente como subproduto da atividade da nitrogenase (Reação 58) pode-se oxidar pela hidrogenase de assimilação ligada à membrana celular, prevenindo a perda de energia e poder redutor (Antal et al., 2012; Boichenko, Greenbaum \& Seibert, 2004; Yeager et al., 2011) e consumindo oxigênio (inibidor da nitrogenase) para melhorar a eficiência da fixação de nitrogênio (Tamagnini et al., 2007) 
(Figura 40). Assim, embora para a atividade da nitrogenase devesse existir uma razão teórica de 1:1 entre a fixação de nitrogênio e a produção de hidrogênio, esta última é menor dada a atividade da hidrogenase de assimilação (Boichenko, Greenbaum \& Seibert, 2004; Yeager et al., 2011), e incluso, pode ser insignificante se existir (Koku et al., 2002). Estas hidrogenases estão presentes apenas nas bactérias diazotróficas (Boichenko, Greenbaum \& Seibert, 2004; Tamagnini et al., 2007) e catalisam a Reação 59 irreversível:

$$
\mathrm{H}_{2}+2 \mathrm{Fd}_{\mathrm{OX}} \rightarrow 2 \mathrm{H}^{+}+2 \mathrm{Fd}_{\mathrm{RED}} \quad \text { Reação } 59
$$

Embora as cianobactérias contêm hidrogenase, comumente fotoproduzem hidrogênio usando a nitrogenase quando energia química (ATP) e poder redutor (NADPH) estão disponíveis para a ferredoxina (Figura 40) (Boichenko, Greenbaum \& Seibert, 2004; Yeager et al., 2011). Na ausência de nitrogênio gasoso $\left(\mathrm{N}_{2}\right)$, inibidor da produção de hidrogênio $\left(\mathrm{H}_{2}\right)$ pela nitrogenase porque é seu substrato natural (Koku et al., 2002), a nitrogenase catalisa unicamente a síntese de hidrogênio pela Reação 60 (Antal et al., 2012; Eroglu \& Melis, 2011):

$$
2 \mathrm{H}^{+}+2 \mathrm{Fd}_{\mathrm{RED}}+4 \mathrm{ATP}+4 \mathrm{H}_{2} \mathrm{O} \rightarrow \mathrm{H}_{2}+2 \mathrm{Fd}_{\mathrm{OX}}+4 \mathrm{ADP}+4 \mathrm{Pi} \quad \text { Reação } 60
$$

Por outro lado, cianobactérias filamentosas não heterocísticas e algumas unicelulares também são diazotróficas que fixam nitrogênio principalmente na escuridão sob condições anóxicas (Castenholz, 2015; Madigan et al., 2015), evitando a inibição por meio da separação temporal da produção de oxigênio e a fixação de nitrogênio (Boichenko, Greenbaum \& Seibert, 2004). Porém, outras cianobactérias diazotróficas têm estratégias fisiológicas que permitem fixar nitrogênio sob condições micro-óxicas até bem oxigenadas (Bergman et al., 1997; Whitton \& Potts, 2012).

Por fim, cianobactérias não fixadoras de nitrogênio podem produzir hidrogênio por meio da hidrogenase (Reação 57), como nas microalgas (Figura 39), por separação temporal entre a hidrólise d'água e a produção de hidrogênio (biofotólise indireta); esta última, por fermentação (metabolismo endógeno) na escuridão (Yu \& Takahashi, 2007).

\subsection{Aplicação do modelo-resultados e discussão}

Ao aplicar o modelo biotermodinâmico aos metabolismos dos processos 
fotossintéticos oxigênicos discutidos, para condições diferentes da padrão, se obtêm as biorreações apresentados nas Seções 5.2.1 e 5.2.2, baseadas nas semi-reações da Tabela 3. Cabe lembrar que, para todas as figuras apresentadas nessas seções, o quadro representa o intervalo biológico típico de $\mathrm{pH}$ no qual são realizados os processos e, portanto, onde os resultados do modelo fazem maior sentido.

Por outro lado, nesta análise se desconsidera o efeito da hidrogenase de assimilação (Reação 59) na produção de hidrogênio pela nitrogenase em cianobactérias, com o escopo de estimar as produções máximas de hidrogênio.

\subsubsection{Comportamento da fotossíntese oxigênica com microalgas}

Os resultados da aplicação do modelo biotermodinâmico aos metabolismos das microalgas discutidos na Seção 5.1.1, para um comprimento de onda de $680 \mathrm{~nm}$, se apresentam nas Tabelas 17 a 21 (Reações 61 a 65), nas quais se inclui a estequiometria da reação para diferentes $\mathrm{pH}$ (temperatura de $25{ }^{\circ} \mathrm{C}$ ), e nas Figuras 41 a 45, com o comportamento da energia livre dissipada como função do $\mathrm{pH}$ e pressão parcial de hidrogênio (temperatura constante de $25^{\circ} \mathrm{C}$ ) e do $\mathrm{pH}$ e temperatura (pressão parcial de hidrogênio constante de $\left.1,00 \times 10^{-3} \mathrm{~atm}\right)$.

A Figura 41 mostra que o $\mathrm{pH}$ não influi na biofotólise direta, resultado das características neutras desta reação na qual não se consume nem se produze acidez ou alcalinidade; por outro lado, o aumento da pressão parcial de hidrogênio, um produto da reação, diminui a energia livre dissipada, enquanto as mudanças de temperatura não produzem um efeito percentualmente significativo. A grande energia livre dissipada pelos fótons assegura a espontaneidade do processo e garantem altas conversões.

Para a produção de microalgas (Figuras 42 e 45) o comportamento é muito parecido independentemente do produto de armazenamento (carboidrato ou lipídeo): a energia livre dissipada permanece praticamente constante em todo o intervalo de $\mathrm{pH}$, a pressão parcial de hidrogênio não influi devido a que não é consumido nem produzido (Figuras 42a e 45a) enquanto o aumento da temperatura diminui a energia livre dissipada desfavorecendo a conversão (Figuras 42b e 45b), mas em uma pequena percentagem. Como na biofotólise direta, nestes processos de crescimento celular a grande energia livre dissipada é gerada pela captação da energia dos fótons, garantindo altas conversões. 
Tabela 17. Biorreação do modelo biotermodinâmico e estequiometria $\left(\mathrm{T}=25^{\circ} \mathrm{C}\right) \mathrm{da}$ biofotólise direta com microalgas.

\begin{tabular}{|c|c|c|c|}
\hline \multicolumn{2}{|r|}{$\mathrm{R}=29-38$} & $f_{s}^{\circ}$ & $\begin{array}{c}\Delta_{r} G^{\circ} \\
\Delta_{r} H^{\circ} \\
\left(\mathrm{kJ} \mathrm{e}^{-} \mathrm{eq}^{-1}\right)\end{array}$ \\
\hline $\begin{array}{c}0 \\
\stackrel{0}{ } \\
I I \\
\underline{2} \\
2\end{array}$ & $5,00 \times 10^{-1} \mathrm{H}_{2} \mathrm{O}+2,00 \mathrm{~h} v \rightleftharpoons 2,50 \times 10^{-1} \mathrm{O}_{2}+5,00 \times 10^{-1} \mathrm{H}_{2}$ & - & $\begin{array}{l}-223,7 \\
-214,0\end{array}$ \\
\hline $\begin{array}{c}n \\
\\
\frac{\pi}{2} \\
\underline{2}\end{array}$ & $5,00 \times 10^{-1} \mathrm{H}_{2} \mathrm{O}+2,00 \mathrm{~h} v \rightleftharpoons 2,50 \times 10^{-1} \mathrm{O}_{2}+5,00 \times 10^{-1} \mathrm{H}_{2}$ & - & $\begin{array}{l}-223,7 \\
-214,0\end{array}$ \\
\hline $\begin{array}{c}0 \\
\infty \\
\| \\
\| \\
\mathbb{L}_{2}\end{array}$ & $5,00 \times 10^{-1} \mathrm{H}_{2} \mathrm{O}+2,00 \mathrm{~h} v \rightleftharpoons 2,50 \times 10^{-1} \mathrm{O}_{2}+5,00 \times 10^{-1} \mathrm{H}_{2}$ & - & $\begin{array}{l}-223,7 \\
-214,0\end{array}$ \\
\hline
\end{tabular}
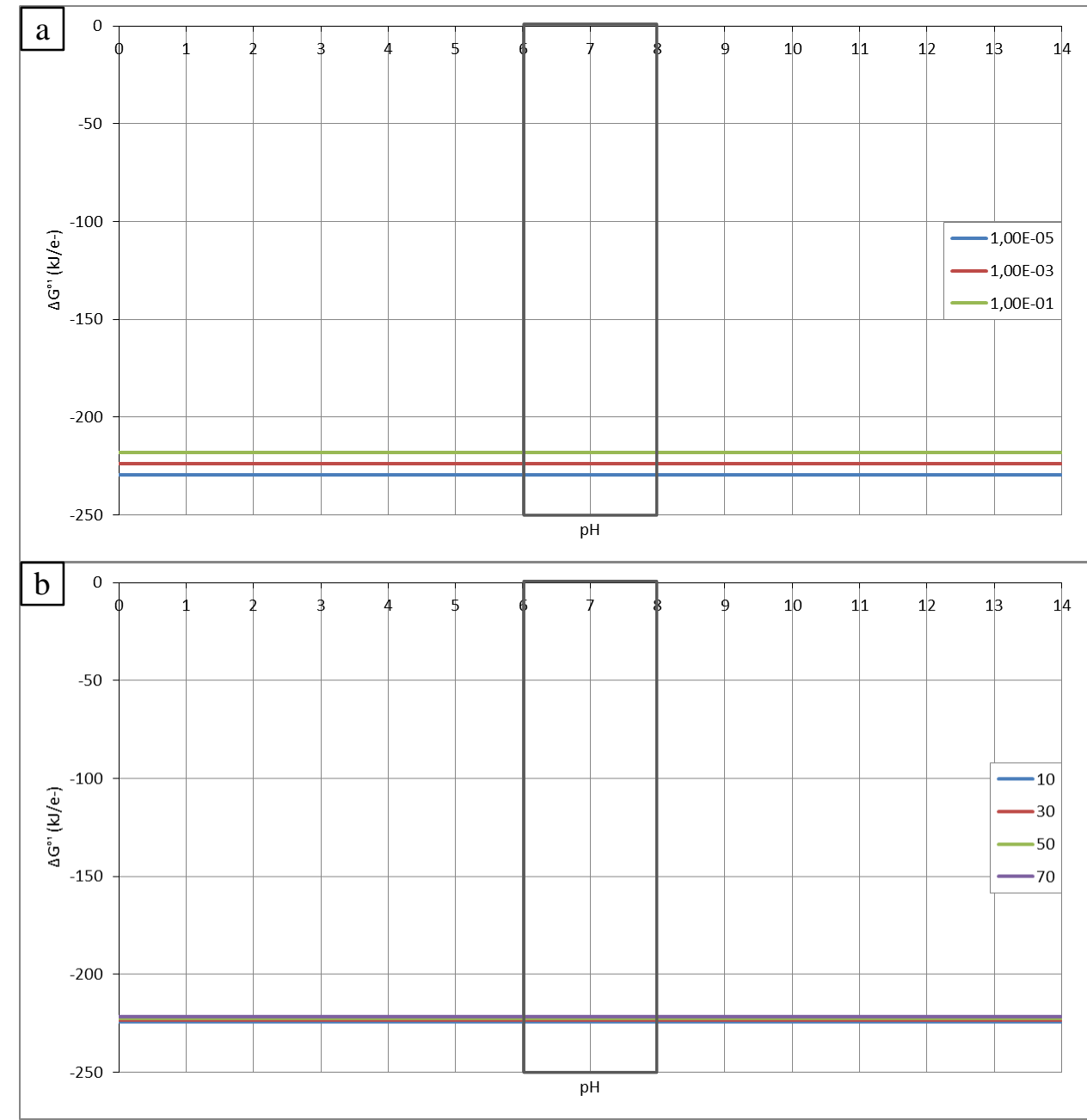

Figura 41. Energia livre da biofotólise direta com microalgas como função a) do pH e pressão parcial de hidrogênio (atm) e b) do $\mathrm{pH}$ e temperatura $\left({ }^{\circ} \mathrm{C}\right)$. 
Tabela 18. Biorreação do modelo biotermodinâmico e estequiometria $\left(\mathrm{T}=25^{\circ} \mathrm{C}\right)$ da produção de glicose por fotossíntese oxigênica com microalgas.

\begin{tabular}{|c|c|c|c|}
\hline \multicolumn{2}{|c|}{ Reação 62} & $f_{s}^{\circ}$ & $\begin{array}{c}\Delta_{r} G^{\circ} \\
\Delta_{r} H^{\circ} \\
\left(\mathrm{kJ} \mathrm{e}^{-} \mathrm{eq}^{-1}\right)\end{array}$ \\
\hline 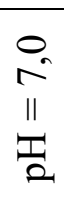 & $\begin{array}{l}4,55 \times 10^{-2} \mathrm{CO}_{2}+2,05 \times 10^{-1} \mathrm{HCO}_{3}^{-}+3,07 \times 10^{-5} \mathrm{CO}_{3}{ }^{2-}+1,22 \times 10^{-2} \mathrm{NH}_{4}^{+}+ \\
6,91 \times 10^{-5} \mathrm{NH}_{3}+4,76 \times 10^{-4} \mathrm{H}_{2} \mathrm{PO}_{4}^{-}+2,92 \times 10^{-4} \mathrm{HPO}_{4}{ }^{2-}+4,07 \times 10^{-4} \mathrm{H}_{2} \mathrm{~S}+ \\
3,61 \times 10^{-4} \mathrm{HS}^{-}+4,47 \times 10^{-2} \mathrm{H}_{2} \mathrm{O}+1,94 \times 10^{-1} \mathrm{H}^{+}+2,00 \mathrm{~h} v \rightleftharpoons 7,67 \times 10^{-} \\
{ }^{4} \mathrm{C}_{106} \mathrm{H}_{263} \mathrm{O}_{110} \mathrm{~N}_{16} \mathrm{PS}+2,82 \times 10^{-2} \mathrm{C}_{6} \mathrm{H}_{12} \mathrm{O}_{6}+2,50 \times 10^{-1} \mathrm{O}_{2}\end{array}$ & 0,32 & $\begin{array}{l}-206,7 \\
-234,1\end{array}$ \\
\hline 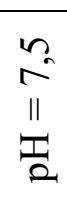 & $\begin{array}{l}1,63 \times 10^{-2} \mathrm{CO}_{2}+2,34 \times 10^{-1} \mathrm{HCO}_{3}{ }^{-}+3,97 \times 10^{-4} \mathrm{CO}_{3}{ }^{2-}+1,20 \times 10^{-2} \mathrm{NH}_{4}^{+}+ \\
2,15 \times 10^{-4} \mathrm{NH}_{3}+2,61 \times 10^{-4} \mathrm{H}_{2} \mathrm{PO}_{4}^{-}+5,06 \times 10^{-4} \mathrm{HPO}_{4}{ }^{2-}+1,99 \times 10^{-4} \mathrm{H}_{2} \mathrm{~S}+ \\
5,67 \times 10^{-4} \mathrm{HS}^{-}+1,56 \times 10^{-2} \mathrm{H}_{2} \mathrm{O}+2,24 \times 10^{-1} \mathrm{H}^{+}+2,00 \mathrm{hv} \rightleftharpoons 7,67 \times 10^{-} \\
{ }^{4} \mathrm{C}_{106} \mathrm{H}_{263} \mathrm{O}_{110} \mathrm{~N}_{16} \mathrm{PS}+2,82 \times 10^{-2} \mathrm{C}_{6} \mathrm{H}_{12} \mathrm{O}_{6}+2,50 \times 10^{-1} \mathrm{O}_{2}\end{array}$ & 0,32 & $\begin{array}{l}-206,5 \\
-234,3\end{array}$ \\
\hline 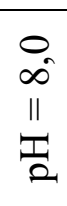 & $\begin{array}{l}5,42 \times 10^{-3} \mathrm{CO}_{2}+2,44 \times 10^{-1} \mathrm{HCO}_{3}{ }^{-}+1,22 \times 10^{-3} \mathrm{CO}_{3}{ }^{2-}+1,16 \times 10^{-2} \mathrm{NH}_{4}^{+}+ \\
6,44 \times 10^{-4} \mathrm{NH}_{3}+1,07 \times 10^{-4} \mathrm{H}_{2} \mathrm{PO}_{4}^{-}+6,59 \times 10^{-4} \mathrm{HPO}_{4}{ }^{2-}+7,66 \times 10^{-5} \mathrm{H}_{2} \mathrm{~S}+ \\
6,90 \times 10^{-4} \mathrm{HS}^{-}+4,65 \times 10^{-3} \mathrm{H}_{2} \mathrm{O}+2,37 \times 10^{-1} \mathrm{H}^{+}+2,00 \mathrm{~h} v \rightleftharpoons 7,66 \times 10^{-} \\
{ }^{4} \mathrm{C}_{106} \mathrm{H}_{263} \mathrm{O}_{110} \mathrm{~N}_{16} \mathrm{PS}+2,82 \times 10^{-2} \mathrm{C}_{6} \mathrm{H}_{12} \mathrm{O}_{6}+2,50 \times 10^{-1} \mathrm{O}_{2}\end{array}$ & 0,32 & $\begin{array}{l}-206,4 \\
-234,4\end{array}$ \\
\hline
\end{tabular}
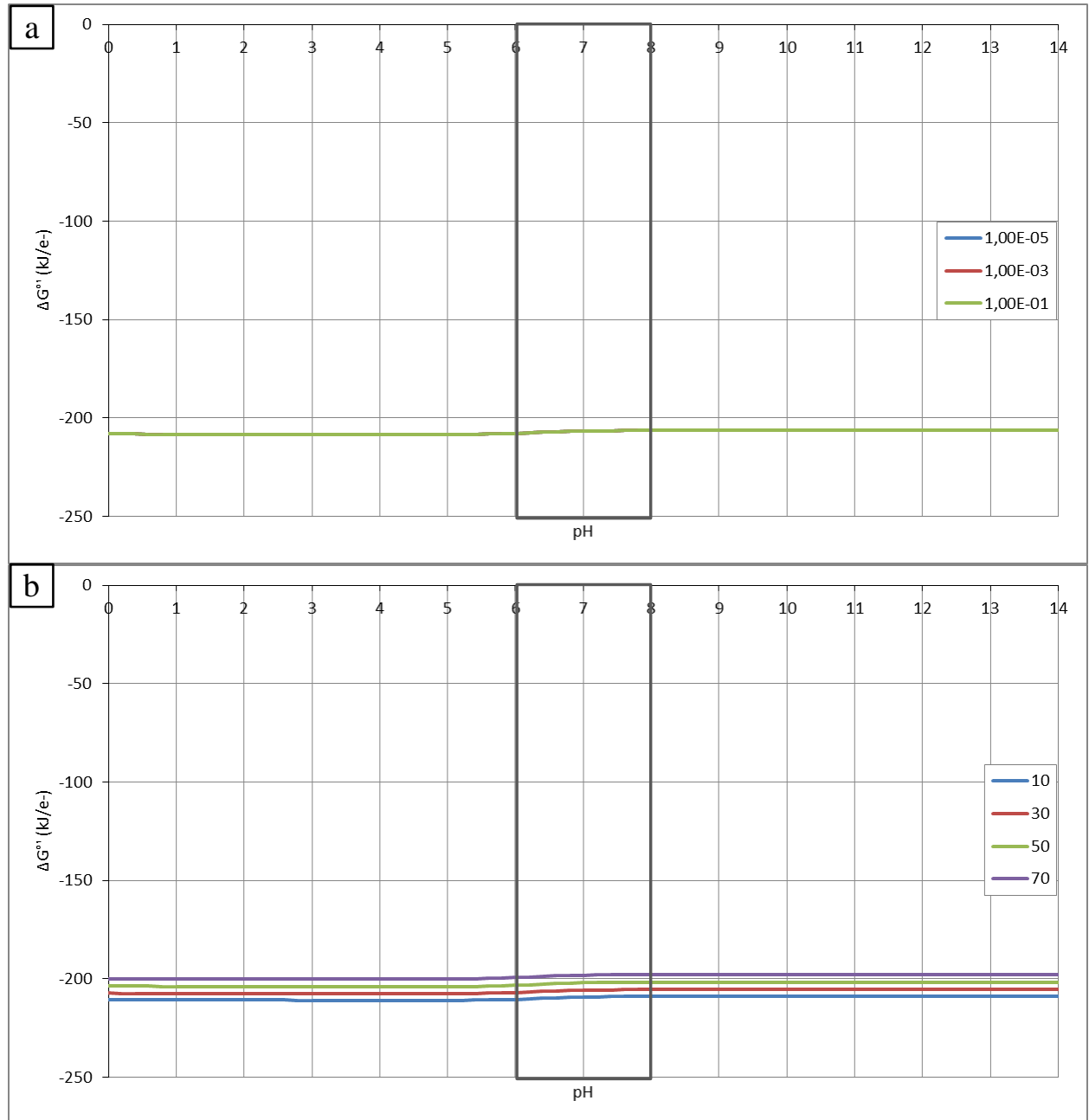

Figura 42. Energia livre da produção de glicose por fotossíntese oxigênica com microalgas como função a) do $\mathrm{pH}$ e pressão parcial de hidrogênio (atm) e b) do $\mathrm{pH}$ e temperatura $\left({ }^{\circ} \mathrm{C}\right)$. 
Tabela 19. Biorreação do modelo biotermodinâmico e estequiometria $\left(\mathrm{T}=25^{\circ} \mathrm{C}\right)$ da fermentação de glicose na luz (biofotólise indireta) com microalgas.

\begin{tabular}{|c|c|c|c|}
\hline \multicolumn{2}{|c|}{ Reação 63} & \multirow{2}{*}{$\begin{array}{c}f_{s}^{\circ} \\
- \\
-\end{array}$} & \multirow{2}{*}{$\begin{array}{c}\Delta_{r} G^{\circ}, \\
\Delta_{r} H^{\circ} \\
\left(\mathrm{kJ} \mathrm{e}^{-} \mathrm{eq}^{-1}\right) \\
\\
-13,7 \\
0,5\end{array}$} \\
\hline $\begin{array}{l}O_{n} \\
\text { II } \\
\frac{\pi}{2}\end{array}$ & $\begin{array}{l}4,17 \times 10^{-2} \mathrm{C}_{6} \mathrm{H}_{12} \mathrm{O}_{6}+9,62 \times 10^{-2} \mathrm{H}_{2} \mathrm{O} \rightleftharpoons 8,00 \times 10^{-2} \mathrm{CHO}_{2}^{-}+7,92 \times 10^{-} \\
{ }^{2} \mathrm{C}_{2} \mathrm{H}_{3} \mathrm{O}_{2}^{-}+8,00 \times 10^{-4} \mathrm{C}_{2} \mathrm{H}_{4} \mathrm{O}_{2}+2,22 \times 10^{-3} \mathrm{CO}_{2}+7,78 \times 10^{-3} \mathrm{HCO}_{3}^{-}+ \\
1,00 \times 10^{-1} \mathrm{H}_{2}+1,64 \times 10^{-1} \mathrm{H}^{+}\end{array}$ & & \\
\hline $\begin{array}{l}n \\
\text { n } \\
\text { II } \\
\frac{\pi}{2}\end{array}$ & $\begin{array}{l}4,17 \times 10^{-2} \mathrm{C}_{6} \mathrm{H}_{12} \mathrm{O}_{6}+9,98 \times 10^{-2} \mathrm{H}_{2} \mathrm{O} \rightleftharpoons 8,00 \times 10^{-2} \mathrm{CHO}_{2}^{-}+8,00 \times 10^{-} \\
{ }^{2} \mathrm{C}_{2} \mathrm{H}_{3} \mathrm{O}_{2}^{-}+2,50 \times 10^{-4} \mathrm{CO}_{2}+9,33 \times 10^{-3} \mathrm{HCO}_{3}^{-}+4,17 \times 10^{-4} \mathrm{CO}_{3}^{2-}+ \\
1,00 \times 10^{-1} \mathrm{H}_{2}+1,70 \times 10^{-1} \mathrm{H}^{+}\end{array}$ & - & $\begin{array}{c}-13,9 \\
0,9\end{array}$ \\
\hline $\begin{array}{l}\infty \\
\infty \\
11 \\
\frac{\pi}{2}\end{array}$ & $\begin{array}{l}4,17 \times 10^{-2} \mathrm{C}_{6} \mathrm{H}_{12} \mathrm{O}_{6}+1,01 \times 10^{-1} \mathrm{H}_{2} \mathrm{O} \rightleftharpoons 8,03 \times 10^{-2} \mathrm{CHO}_{2}^{-}+8,03 \times 10^{-} \\
{ }^{2} \mathrm{C}_{2} \mathrm{H}_{3} \mathrm{O}_{2}^{-}+6,01 \times 10^{-4} \mathrm{CO}_{2}+8,98 \times 10^{-3} \mathrm{HCO}_{3}^{-}+4,47 \times 10^{-4} \mathrm{CO}_{3}^{2-}+ \\
1,00 \times 10^{-1} \mathrm{H}_{2}+1,70 \times 10^{-1} \mathrm{H}^{+}\end{array}$ & - & $\begin{array}{c}-14,3 \\
1,0\end{array}$ \\
\hline
\end{tabular}
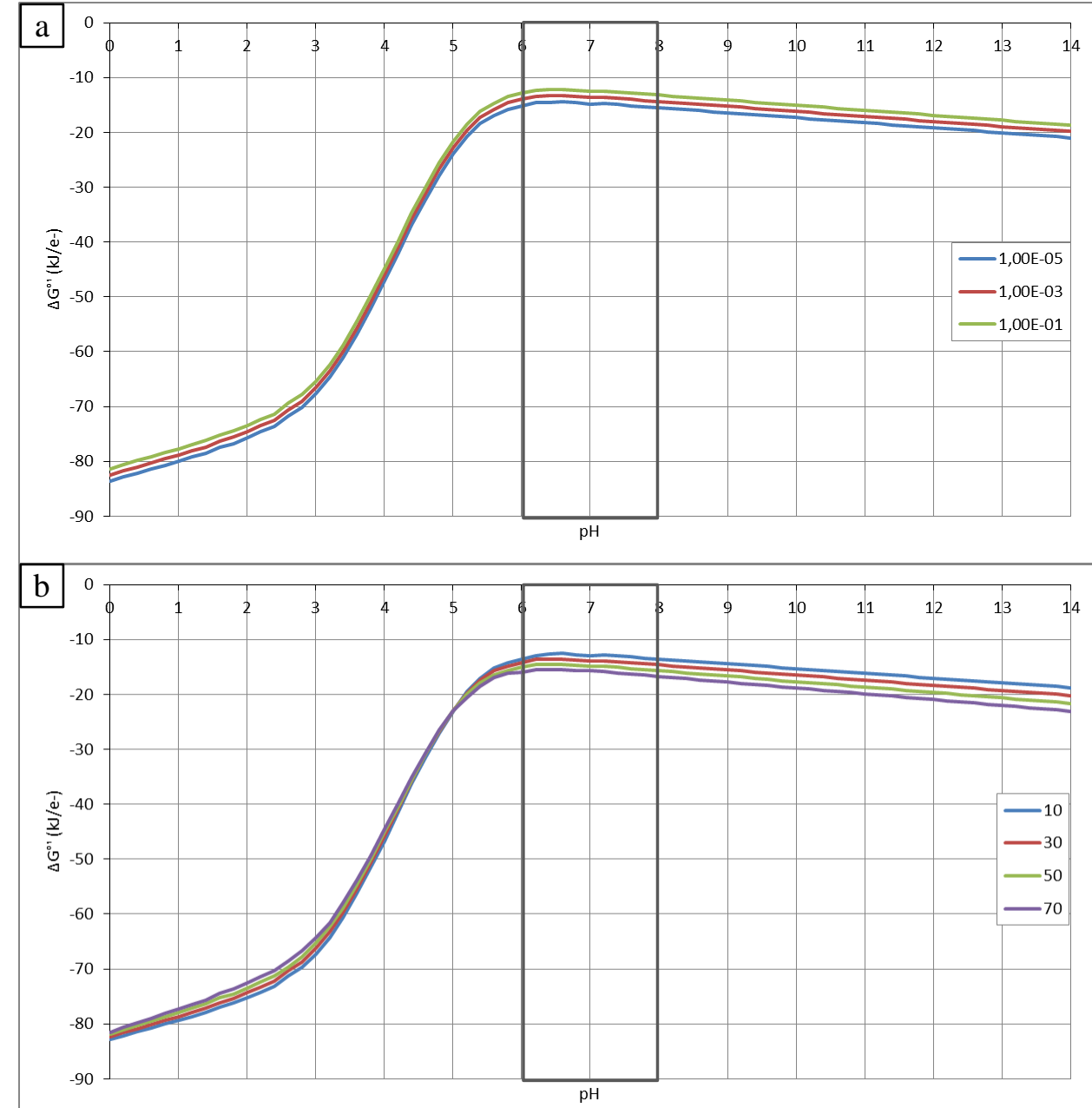

Figura 43. Energia livre da fermentação de glicose na luz (biofotólise indireta) com microalgas como função a) do pH e pressão parcial de hidrogênio (atm) e b) do pH e temperatura $\left({ }^{\circ} \mathrm{C}\right)$. 
Tabela 20. Biorreação do modelo biotermodinâmico e estequiometria $\left(\mathrm{T}=25^{\circ} \mathrm{C}\right)$ da fermentação de glicose na escuridão (biofotólise indireta) com microalgas.

\begin{tabular}{|c|c|c|c|}
\hline \multicolumn{2}{|c|}{ Reação 64} & $f_{s}^{\circ}$ & $\begin{array}{c}\Delta_{r} G^{\circ} \\
\Delta_{r} H^{\circ}\end{array}$ \\
\hline $\begin{array}{l}O \\
\text { r } \\
\text { II } \\
\frac{1}{2}\end{array}$ & $\begin{array}{l}4,17 \times 10^{-2} \mathrm{C}_{6} \mathrm{H}_{12} \mathrm{O}_{6}+5,38 \times 10^{-2} \mathrm{H}_{2} \mathrm{O} \rightleftharpoons 8,06 \times 10^{-2} \mathrm{CHO}_{2}^{-}+3,99 \times 10^{-} \\
{ }^{2} \mathrm{C}_{2} \mathrm{H}_{3} \mathrm{O}_{2}^{-}+4,03 \times 10^{-4} \mathrm{C}_{2} \mathrm{H}_{4} \mathrm{O}_{2}+4,03 \times 10^{-2} \mathrm{C}_{2} \mathrm{H}_{6} \mathrm{O}+1,87 \times 10^{-3} \mathrm{CO}_{2}+ \\
6,20 \times 10^{-3} \mathrm{HCO}_{3}^{-}+1,61 \times 10^{-2} \mathrm{H}_{2}+1,25 \times 10^{-1} \mathrm{H}^{+}\end{array}$ & - & $\begin{array}{l}-12,1 \\
-2,6\end{array}$ \\
\hline 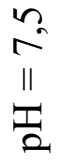 & $\begin{array}{l}4,17 \times 10^{-2} \mathrm{C}_{6} \mathrm{H}_{12} \mathrm{O}_{6}+5,63 \times 10^{-2} \mathrm{H}_{2} \mathrm{O} \rightleftharpoons 8,06 \times 10^{-2} \mathrm{CHO}_{2}^{-}+4,03 \times 10^{-} \\
{ }^{2} \mathrm{C}_{2} \mathrm{H}_{3} \mathrm{O}_{2}^{-}+4,03 \times 10^{-2} \mathrm{C}_{2} \mathrm{H}_{6} \mathrm{O}+1,21 \times 10^{-4} \mathrm{CO}_{2}+7,53 \times 10^{-3} \mathrm{HCO}_{3}^{-}+ \\
4,17 \times 10^{-4} \mathrm{CO}_{3}^{2-}+1,61 \times 10^{-2} \mathrm{H}_{2}+1,29 \times 10^{-1} \mathrm{H}^{+}\end{array}$ & - & $\begin{array}{l}-12,3 \\
-2,4\end{array}$ \\
\hline $\begin{array}{l}\infty \\
\infty \\
\| \\
\stackrel{2}{2}\end{array}$ & $\begin{array}{l}4,17 \times 10^{-2} \mathrm{C}_{6} \mathrm{H}_{12} \mathrm{O}_{6}+5,69 \times 10^{-2} \mathrm{H}_{2} \mathrm{O} \rightleftharpoons 8,09 \times 10^{-2} \mathrm{CHO}_{2}^{-}+4,05 \times 10^{-} \\
{ }^{2} \mathrm{C}_{2} \mathrm{H}_{3} \mathrm{O}_{2}^{-}+4,05 \times 10^{-2} \mathrm{C}_{2} \mathrm{H}_{6} \mathrm{O}+5,62 \times 10^{-4} \mathrm{CO}_{2}+7,09 \times 10^{-3} \mathrm{HCO}_{3}^{-}+ \\
4,41 \times 10^{-4} \mathrm{CO}_{3}{ }^{2-}+1,62 \times 10^{-2} \mathrm{H}_{2}+1,29 \times 10^{-1} \mathrm{H}^{+}\end{array}$ & - & $\begin{array}{l}-12,6 \\
-2,3\end{array}$ \\
\hline
\end{tabular}
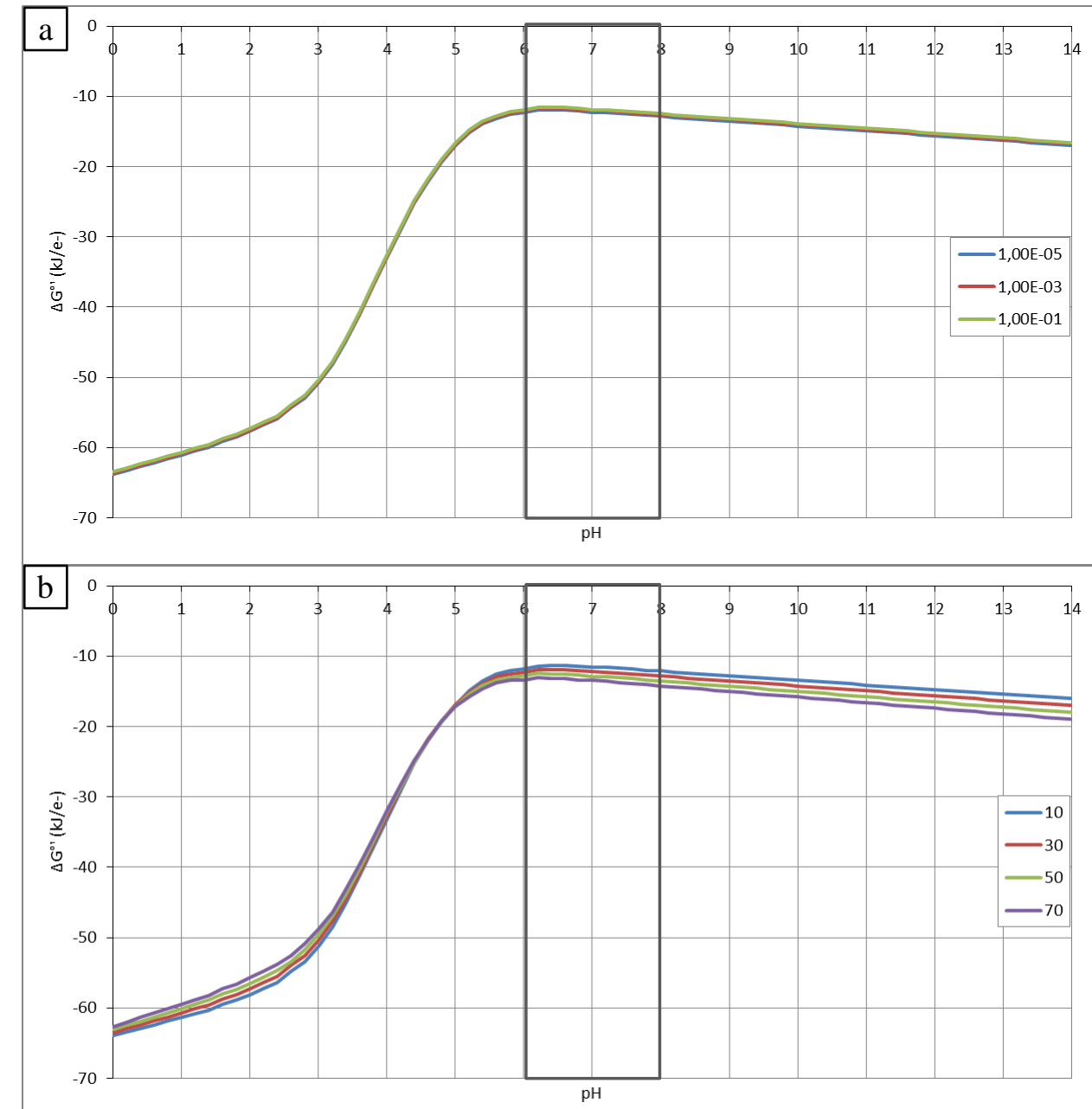

Figura 44. Energia livre da fermentação de glicose na escuridão (biofotólise indireta) com microalgas como função a) do pH e pressão parcial de hidrogênio (atm) e b) do pH e temperatura $\left({ }^{\circ} \mathrm{C}\right)$. 
Tabela 21. Biorreação do modelo biotermodinâmico e estequiometria $\left(\mathrm{T}=25^{\circ} \mathrm{C}\right)$ da produção de ácido palmítico por fotossíntese oxigênica com microalgas.

\begin{tabular}{|c|c|c|c|}
\hline \multicolumn{2}{|c|}{ Reação 65} & $f_{s}^{\circ}$ & $\begin{array}{c}\Delta_{r} G^{\circ} \\
\Delta_{r} H^{\circ} \\
\left(\mathrm{kJ} \mathrm{e}^{-} \mathrm{eq}^{-1}\right)\end{array}$ \\
\hline 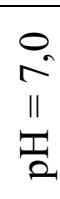 & $\begin{array}{l}3,64 \times 10^{-2} \mathrm{CO}_{2}+1,64 \times 10^{-1} \mathrm{HCO}_{3}^{-}+1,04 \times 10^{-4} \mathrm{CO}_{3}{ }^{2-}+1,27 \times 10^{-2} \mathrm{NH}_{4}^{+}+ \\
7,21 \times 10^{-5} \mathrm{NH}_{3}+4,97 \times 10^{-4} \mathrm{H}_{2} \mathrm{PO}_{4}^{-}+3,04 \times 10^{-4} \mathrm{HPO}_{4}{ }^{2-}+4,25 \times 10^{-4} \mathrm{H}_{2} \mathrm{~S}+ \\
3,77 \times 10^{-4} \mathrm{HS}^{-}+3,55 \times 10^{-2} \mathrm{H}_{2} \mathrm{O}+1,53 \times 10^{-1} \mathrm{H}^{+}+2,00 \mathrm{~h} v \rightleftharpoons 8,01 \times 10^{-} \\
{ }^{4} \mathrm{C}_{106} \mathrm{H}_{263} \mathrm{O}_{110} \mathrm{~N}_{16} \mathrm{PS}+7,19 \times 10^{-3} \mathrm{C}_{16} \mathrm{H}_{32} \mathrm{O}_{2}+2,50 \times 10^{-1} \mathrm{O}_{2}\end{array}$ & 0,34 & $\begin{array}{l}-215,8 \\
-240,2\end{array}$ \\
\hline$\stackrel{n}{n}$ & $\begin{array}{l}1,31 \times 10^{-2} \mathrm{CO}_{2}+1,87 \times 10^{-1} \mathrm{HCO}_{3}^{-}+2,64 \times 10^{-4} \mathrm{CO}_{3}{ }^{2-}+1,26 \times 10^{-2} \mathrm{NH}_{4}^{+}+ \\
2,24 \times 10^{-4} \mathrm{NH}_{3}+2,72 \times 10^{-4} \mathrm{H}_{2} \mathrm{PO}_{4}^{-}+5,28 \times 10^{-4} \mathrm{HPO}_{4}{ }^{2-}+2,08 \times 10^{-4} \mathrm{H}_{2} \mathrm{~S}+ \\
5,92 \times 10^{-4} \mathrm{HS}^{-}+1,23 \times 10^{-2} \mathrm{H}_{2} \mathrm{O}+1,76 \times 10^{-1} \mathrm{H}^{+}+2,00 \mathrm{~h} v \rightleftharpoons 8,01 \times 10^{-} \\
{ }^{4} \mathrm{C}_{106} \mathrm{H}_{263} \mathrm{O}_{110} \mathrm{~N}_{16} \mathrm{PS}+7,20 \times 10^{-3} \mathrm{C}_{16} \mathrm{H}_{32} \mathrm{O}_{2}+2,50 \times 10^{-1} \mathrm{O}_{2}\end{array}$ & 0,34 & $\begin{array}{l}-215,6 \\
-240,4\end{array}$ \\
\hline $\begin{array}{l}0 \\
\infty \\
\| \\
\frac{1}{2}\end{array}$ & $\begin{array}{l}4,35 \times 10^{-3} \mathrm{CO}_{2}+1,95 \times 10^{-1} \mathrm{HCO}_{3}^{-}+8,96 \times 10^{-4} \mathrm{CO}_{3}{ }^{2-}+1,21 \mid \times 10^{-2} \mathrm{NH}_{4}^{+}+ \\
6,72 \times 10^{-4} \mathrm{NH}_{3}+1,12 \times 10^{-4} \mathrm{H}_{2} \mathrm{PO}_{4}^{-}+6,88 \times 10^{-4} \mathrm{HPO}_{4}{ }^{2-}+8,00 \times 10^{-5} \mathrm{H}_{2} \mathrm{~S}+ \\
7,20 \times 10^{-4} \mathrm{HS}^{-}+3,55 \times 10^{-3} \mathrm{H}_{2} \mathrm{O}+1,87 \times 10^{-1} \mathrm{H}^{+}+2,00 \mathrm{~h} v \rightleftharpoons 8,00 \times 10^{-} \\
{ }^{4} \mathrm{C}_{106} \mathrm{H}_{263} \mathrm{O}_{110} \mathrm{~N}_{16} \mathrm{PS}+7,20 \times 10^{-3} \mathrm{C}_{16} \mathrm{H}_{32} \mathrm{O}_{2}+2,50 \times 10^{-1} \mathrm{O}_{2}\end{array}$ & 0,34 & $\begin{array}{l}-215,6 \\
-240,5\end{array}$ \\
\hline
\end{tabular}
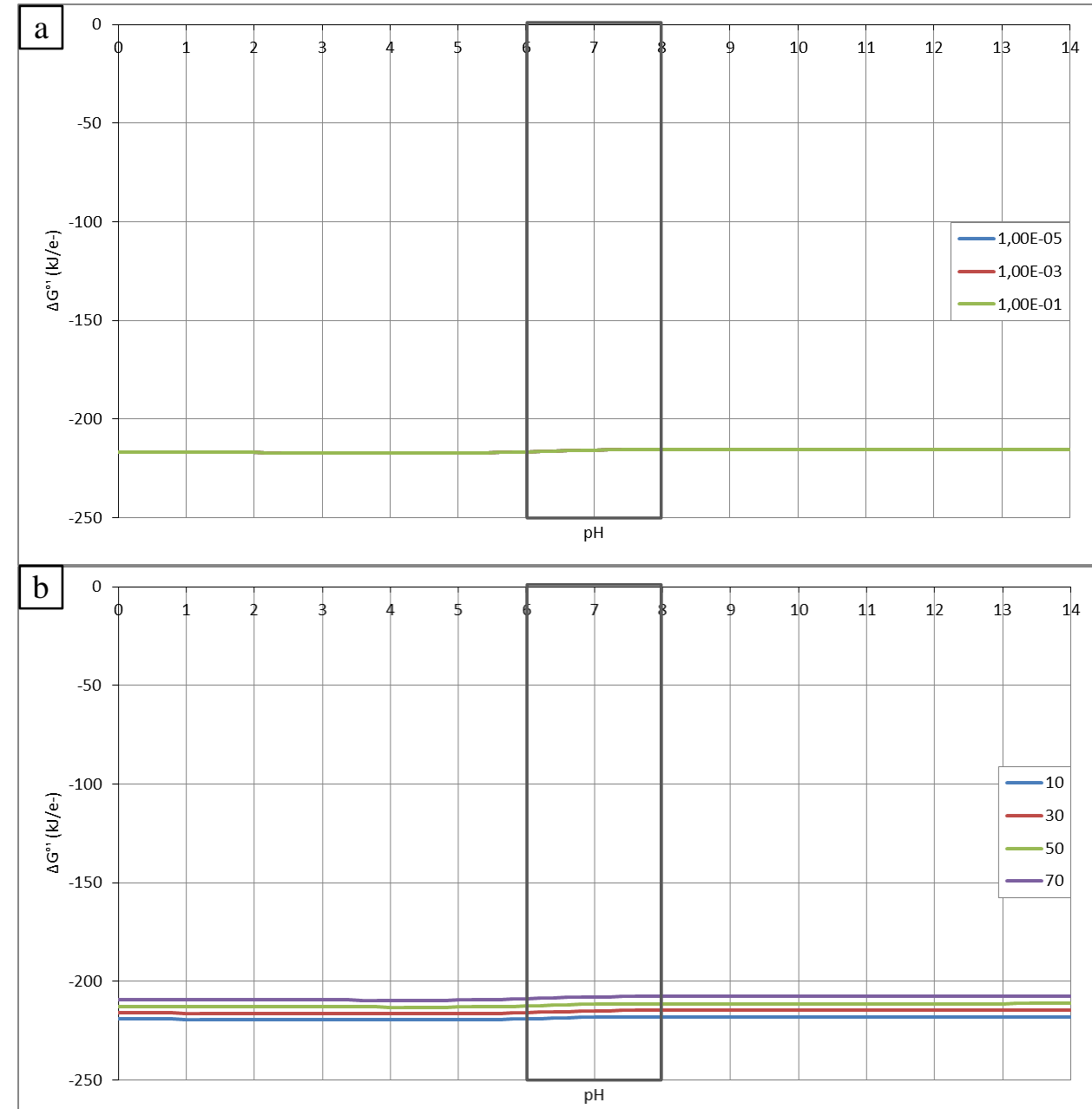

Figura 45. Energia livre da produção de ácido palmítico por fotossíntese oxigênica com microalgas como função a) do $\mathrm{pH}$ e pressão parcial de hidrogênio (atm) e b) do pH e temperatura $\left({ }^{\circ} \mathrm{C}\right)$. 
Em geral, a conversão em reações com entalpia negativa (exotérmicas) se favorece pela diminuição da temperatura, enquanto em reações com entalpia positiva (endotérmicas) a conversão se favorece pelo aumento da temperatura.

Os resultados de energia livre dissipada e entalpia das Tabelas 18 e 21 para as reações de crescimento celular (Reações 62 e 65) evidenciam que o metabolismo fotossintético oxigênico diminui a entropia do sistema pela transformação de reagentes de entropia alta em produtos de entropia baixa. Assim, na fotossíntese oxigênica, o aumento da entropia do universo se produz pela transferência de calor (entalpia) dos microorganismos aos redores.

As biofotólise indiretas para a produção de hidrogênio (Figuras 43 e 44) são fermentações de glicose espontâneas nos intervalos de pH (l 0 a 14), pressões parciais de hidrogênio $\left(1,00 \times 10^{-5}\right.$ a $\left.1,00 \mathrm{~atm}\right)$ e temperatura $\left(10\right.$ a $\left.70{ }^{\circ} \mathrm{C}\right)$ avaliados; portanto, acontecem naturalmente sob condições químicas adequadas. A energia livre dissipada nessas fermentações aumenta significativamente para $\mathrm{pH}$ inferior a $6,0\left(\right.$ a $\left.25^{\circ} \mathrm{C}\right)$. Para a fermentação na luz (Figura $43^{9}$ ), a diminuição na pressão parcial de hidrogênio e o aumento da temperatura favorece levemente a dissipação de energia livre e, portanto, as conversões. Para a fermentação na escuridão (Figura $44^{10}$ ), o aumento da temperatura também favorece levemente a dissipação de energia livre, mas a pressão parcial de hidrogênio não influi sobre a energia livre dissipada dado a baixo rendimento de hidrogênio nesta biofotólise indireta.

\footnotetext{
${ }^{9}$ A estequiometria da fermentação de glicose na luz (Reação 63) se baseia nos resultados de Gfeller \& Gibbs (1984), que usaram uma espécie de microalga sob inibição da produção de etanol, e encontraram uma produção de 2,13 mols de hidrogênio, 1,71 mols de formiato, 2,01 mols de acetato e 0,08 mols de etanol por mol de glicose.

${ }^{10}$ A estequiometria da fermentação de glicose na escuridão (Reação 64) se baseia na relação para formiato:acetato:etanol de 2:1:1 sugerida na bibliografia (Catalanotti et al., 2013; Gfeller \& Gibbs, 1984; Kreuzberg, 1984; Mus et al., 2007). Kreuzberg (1984) encontrou, na fermentação escura de glicose com uma espécie de microalga, produção de 0,01 mols de hidrogênio, 1,76 mols de formiato, 0,95 mols de acetato e 0,93 mols de etanol por mol de glicose; e Gfeller \& Gibbs (1984) encontraram 0,43 mols de hidrogênio, 2,07 mols de formiato, 1,07 mols de acetato e 0,91 mols de etanol por mol de glicose. Yu \& Takahashi (2007) mencionam que a produção de hidrogênio no processo autotrófico anaeróbio na escuridão é 1/6 da produção no processo autotrófico anaeróbio na luz.
} 


\subsubsection{Comportamento da fotossíntese oxigênica com cianobactérias}

Os resultados da aplicação do modelo biotermodinâmico aos metabolismos das cianobactérias discutidos na Seção 5.1.2, para um comprimento de onda de $680 \mathrm{~nm}$, se apresentam nas Tabelas 22 a 25 (Reações 66 a 69), nas quais se inclui a estequiometria da reação para diferentes $\mathrm{pH}$ (temperatura de $25{ }^{\circ} \mathrm{C}$ ), e nas Figuras 46 a 49, com o comportamento da energia livre dissipada como função do $\mathrm{pH}$ e pressão parcial de hidrogênio (temperatura constante de $25{ }^{\circ} \mathrm{C}$ ) e do $\mathrm{pH}$ e temperatura (pressão parcial de hidrogênio constante de $\left.1,00 \times 10^{-3} \mathrm{~atm}\right)$.

A produção de cianobactérias (Figura 46) tem um comportamento praticamente igual ao das microalgas com produção de glicose como produto de armazenamento (Figura 42): a energia livre dissipada permanece praticamente constante em todo o intervalo de $\mathrm{pH}$, e como o hidrogênio não é consumido nem produzido, sua pressão parcial não influi na energia livre (Figura 46a). A única variável das avaliadas que produz efeito na energia livre, embora pequeno, é a temperatura (Figura 46b); seu aumento diminui a energia livre dissipada e desfavorece a conversão. Neste processo de crescimento celular a grande energia livre dissipada é gerada pela captação da energia dos fótons, garantindo altas conversões.

Como nas microalgas, os resultados de energia livre dissipada e entalpia da Tabela 22 para a reação de crescimento celular (Reação 66) evidenciam que o metabolismo fotossintético oxigênico diminui a entropia do sistema pela transformação de reagentes de entropia alta em produtos de entropia baixa. Assim, na fotossíntese oxigênica, o aumento da entropia do universo se produz pela transferência de calor (entalpia) dos microorganismos aos redores.

As reações de biofotólise indireta para a produção de hidrogênio pela nitrogenase no heterocisto (Figuras 47 e 48), são espontâneas nos intervalos de pH ( 0 a 14), pressões parciais de hidrogênio $\left(1,00 \times 10^{-5}\right.$ a 1,00 atm $)$ e temperatura $\left(10\right.$ a $\left.70{ }^{\circ} \mathrm{C}\right)$ avaliados; portanto, acontecem naturalmente sob condições químicas adequadas. Essas reações se comportam diferente dependendo da disponibilidade de nitrogênio gasoso. Quando o nitrogênio gasoso está disponível (Reação 67), a energia livre dissipada aumenta quando o pH diminui para valores inferiores de 8,0 favorecendo a conversão. A conversão também se favorece pela diminuição na pressão parcial de hidrogênio (Figura 47a), um dos produtos do metabolismo da nitrogenase. Respeito à temperatura (Figura 47b), o comportamento depende do pH: para $\mathrm{pH}$ inferiores a aproximadamente $3,5\left(\right.$ a $\left.25^{\circ} \mathrm{C}\right)$, o aumento da temperatura aumenta a energia 
Tabela 22. Biorreação do modelo biotermodinâmico e estequiometria $\left(\mathrm{T}=25^{\circ} \mathrm{C}\right)$ da produção de glicose por fotossíntese oxigênica com cianobactérias.

\begin{tabular}{|c|c|c|c|}
\hline \multicolumn{2}{|c|}{ Reação 66} & $f_{s}^{\circ}$ & $\begin{array}{c}\Delta_{r} G^{\circ} \\
\Delta_{r} H^{\circ} \\
\left(\mathrm{kJ} \mathrm{e}^{-} \mathrm{eq}^{-1}\right)\end{array}$ \\
\hline 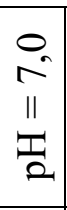 & $\begin{array}{l}4,54 \times 10^{-2} \mathrm{CO}_{2}+6,84 \times 10^{-2} \mathrm{HCO}_{3}^{-}+1,66 \times 10^{-2} \mathrm{NH}_{4}^{+}+1,67 \times 10^{-4} \mathrm{NH}_{3}+ \\
6,69 \times 10^{-4} \mathrm{H}_{2} \mathrm{PO}_{4}^{-}+3,34 \times 10^{-4} \mathrm{HPO}_{4}{ }^{2-}+8,36 \times 10^{-4} \mathrm{H}_{2} \mathrm{~S}+8,34 \times 10^{-4} \mathrm{HS}^{-}+ \\
7,97 \times 10^{-3} \mathrm{H}_{2} \mathrm{O}+1,90 \times 10^{-1} \mathrm{H}^{+}+2,00 \mathrm{~h} v \rightleftharpoons 1,67 \times 10^{-2} \mathrm{C}_{5} \mathrm{H}_{7} \mathrm{O}_{2} \mathrm{NP}_{0,06} \mathrm{~S}_{0,1}+ \\
2,77 \times 10^{-2} \mathrm{C}_{6} \mathrm{H}_{12} \mathrm{O}_{6}+2,50 \times 10^{-1} \mathrm{O}_{2}\end{array}$ & 0,34 & $\begin{array}{l}-206,5 \\
-233,8\end{array}$ \\
\hline 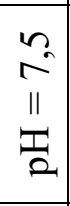 & $\begin{array}{l}1,63 \times 10^{-2} \mathrm{CO}_{2}+7,79 \times 10^{-2} \mathrm{HCO}_{3}^{-}+4,43 \times 10^{-4} \mathrm{CO}_{3}^{2-}+1,63 \times 10^{-2} \mathrm{NH}_{4}^{+}+ \\
3,33 \times 10^{-4} \mathrm{NH}_{3}+3,33 \times 10^{-4} \mathrm{H}_{2} \mathrm{PO}_{4}^{-}+6,67 \times 10^{-4} \mathrm{HPO}_{4}{ }^{2-}+5,00 \times 10^{-4} \mathrm{H}_{2} \mathrm{~S}+ \\
1,17 \times 10^{-3} \mathrm{HS}^{-}+2,20 \times 10^{-1} \mathrm{H}^{+}+2,00 \mathrm{~h} v \rightleftharpoons 1,67 \times 10^{-2} \mathrm{C}_{5} \mathrm{H}_{7} \mathrm{O}_{2} \mathrm{NP}_{0,06} \mathrm{~S}_{0,1}+ \\
2,77 \times 10^{-2} \mathrm{C}_{6} \mathrm{H}_{12} \mathrm{O}_{6}+3,71 \times 10^{-2} \mathrm{H}_{2} \mathrm{O}+2,50 \times 10^{-1} \mathrm{O}_{2}\end{array}$ & 0,34 & $\begin{array}{l}-206,3 \\
-234,0\end{array}$ \\
\hline $\begin{array}{l}0 \\
\infty \\
\| \\
\text { II } \\
\stackrel{2}{2}\end{array}$ & $\begin{array}{l}5,44 \times 10^{-3} \mathrm{CO}_{2}+8,13 \times 10^{-2} \mathrm{HCO}_{3}^{-}+1,16 \times 10^{-3} \mathrm{CO}_{3}{ }^{2-}+1,59 \times 10^{-2} \mathrm{NH}_{4}^{+}+ \\
8,35 \times 10^{-4} \mathrm{NH}_{3}+1,67 \times 10^{-4} \mathrm{H}_{2} \mathrm{PO}_{4}^{-}+8,35 \times 10^{-4} \mathrm{HPO}_{4}{ }^{2-}+1,67 \times 10^{-4} \mathrm{H}_{2} \mathrm{~S}+ \\
1,50 \times 10^{-3} \mathrm{HS}^{-}+2,33 \times 10^{-1} \mathrm{H}^{+}+2,00 \mathrm{~h} v \rightleftharpoons 1,67 \times 10^{-2} \mathrm{C}_{5} \mathrm{H}_{7} \mathrm{O}_{2} \mathrm{NP}_{0,06} \mathrm{~S}_{0,1}+ \\
2,77 \times 10^{-2} \mathrm{C}_{6} \mathrm{H}_{12} \mathrm{O}_{6}+4,78 \times 10^{-2} \mathrm{H}_{2} \mathrm{O}+2,50 \times 10^{-1} \mathrm{O}_{2}\end{array}$ & 0,34 & $\begin{array}{l}-206,2 \\
-234,1\end{array}$ \\
\hline
\end{tabular}
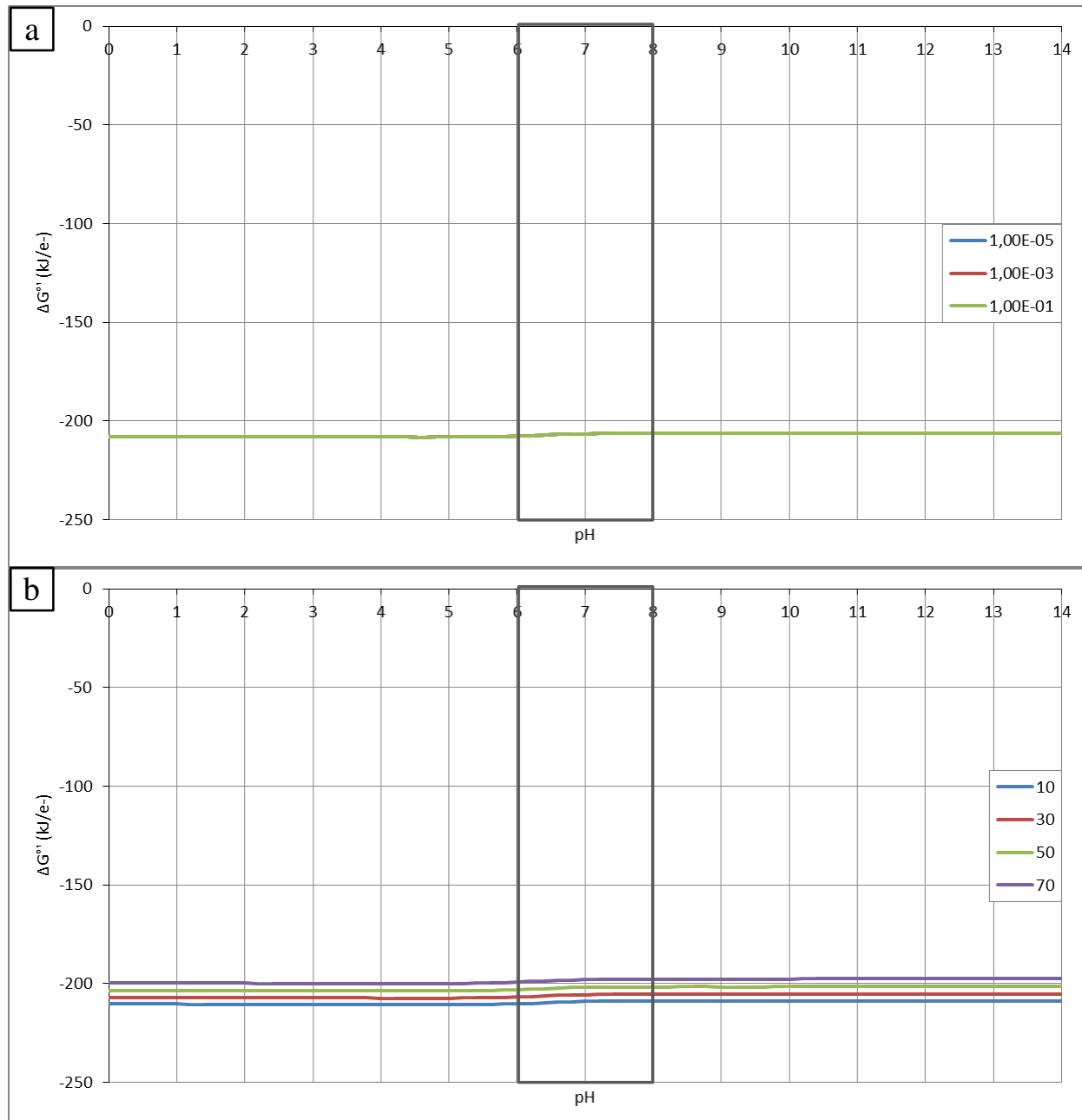

Figura 46. Energia livre da produção de glicose por fotossíntese oxigênica com cianobactérias como função a) do $\mathrm{pH}$ e pressão parcial de hidrogênio (atm) e b) do $\mathrm{pH}$ e temperatura $\left({ }^{\circ} \mathrm{C}\right)$. 
Tabela 23. Biorreação do modelo biotermodinâmico e estequiometria $\left(\mathrm{T}=25^{\circ} \mathrm{C}\right)$ da fixação de nitrogênio com cianobactérias diazotróficas (biofotólise indireta).

\begin{tabular}{|c|c|c|c|}
\hline \multicolumn{2}{|c|}{ Reação 67} & $f_{s}^{\circ}$ & $\begin{array}{c}\Delta_{r} G^{\circ} \\
\Delta_{r} H^{\circ} \\
\left(\mathrm{kJ} \mathrm{e}^{-} \mathrm{eq}^{-1}\right)\end{array}$ \\
\hline $\begin{array}{l}\overbrace{n} \\
\text { II } \\
\frac{\pi}{2}\end{array}$ & $\begin{array}{l}4,17 \times 10^{-2} \mathrm{C}_{6} \mathrm{H}_{12} \mathrm{O}_{6}+1,25 \times 10^{-1} \mathrm{~N}_{2}+4,55 \times 10^{-1} \mathrm{H}_{2} \mathrm{O}+4,42 \times 10^{-2} \mathrm{H}^{+} \rightleftharpoons \\
4,54 \times 10^{-2} \mathrm{CO}_{2}+2,05 \times 10^{-1} \mathrm{HCO}_{3}^{-}+2,49 \times 10^{-1} \mathrm{NH}_{4}^{+}+1,25 \times 10^{-3} \mathrm{NH}_{3}+ \\
1,25 \times 10^{-1} \mathrm{H}_{2}\end{array}$ & - & $\begin{array}{c}-25,5 \\
-9,9\end{array}$ \\
\hline $\begin{array}{l}n \\
n \\
\frac{\pi}{2}\end{array}$ & $\begin{array}{l}4,17 \times 10^{-2} \mathrm{C}_{6} \mathrm{H}_{12} \mathrm{O}_{6}+1,25 \times 10^{-1} \mathrm{~N}_{2}+4,84 \times 10^{-1} \mathrm{H}_{2} \mathrm{O}+1,21 \times 10^{-2} \mathrm{H}^{+} \rightleftharpoons \\
1,63 \times 10^{-2} \mathrm{CO}_{2}+2,33 \times 10^{-1} \mathrm{HCO}_{3}^{-}+4,17 \times 10^{-4} \mathrm{CO}_{3}^{2-}+2,46 \times 10^{-1} \mathrm{NH}_{4}^{+}+ \\
3,75 \times 10^{-3} \mathrm{NH}_{3}+1,25 \times 10^{-1} \mathrm{H}_{2}\end{array}$ & - & $\begin{array}{c}-25,1 \\
-9,6\end{array}$ \\
\hline $\begin{array}{l}\infty \\
\infty \\
\| \\
\frac{\pi}{2}\end{array}$ & $\begin{array}{l}4,17 \times 10^{-2} \mathrm{C}_{6} \mathrm{H}_{12} \mathrm{O}_{6}+1,25 \times 10^{-1} \mathrm{~N}_{2}+4,95 \times 10^{-1} \mathrm{H}_{2} \mathrm{O} \rightleftharpoons 5,42 \times 10^{-3} \mathrm{CO}_{2}+ \\
2,43 \times 10^{-1} \mathrm{HCO}_{3}^{-}+1,25 \times 10^{-3} \mathrm{CO}_{3}^{2-}+2,36 \times 10^{-1} \mathrm{NH}_{4}^{+}+1,38 \times 10^{-2} \mathrm{NH}_{3}+ \\
1,25 \times 10^{-1} \mathrm{H}_{2}+9,58 \times 10^{-3} \mathrm{H}^{+}\end{array}$ & - & $\begin{array}{l}-24,5 \\
-9,0\end{array}$ \\
\hline
\end{tabular}
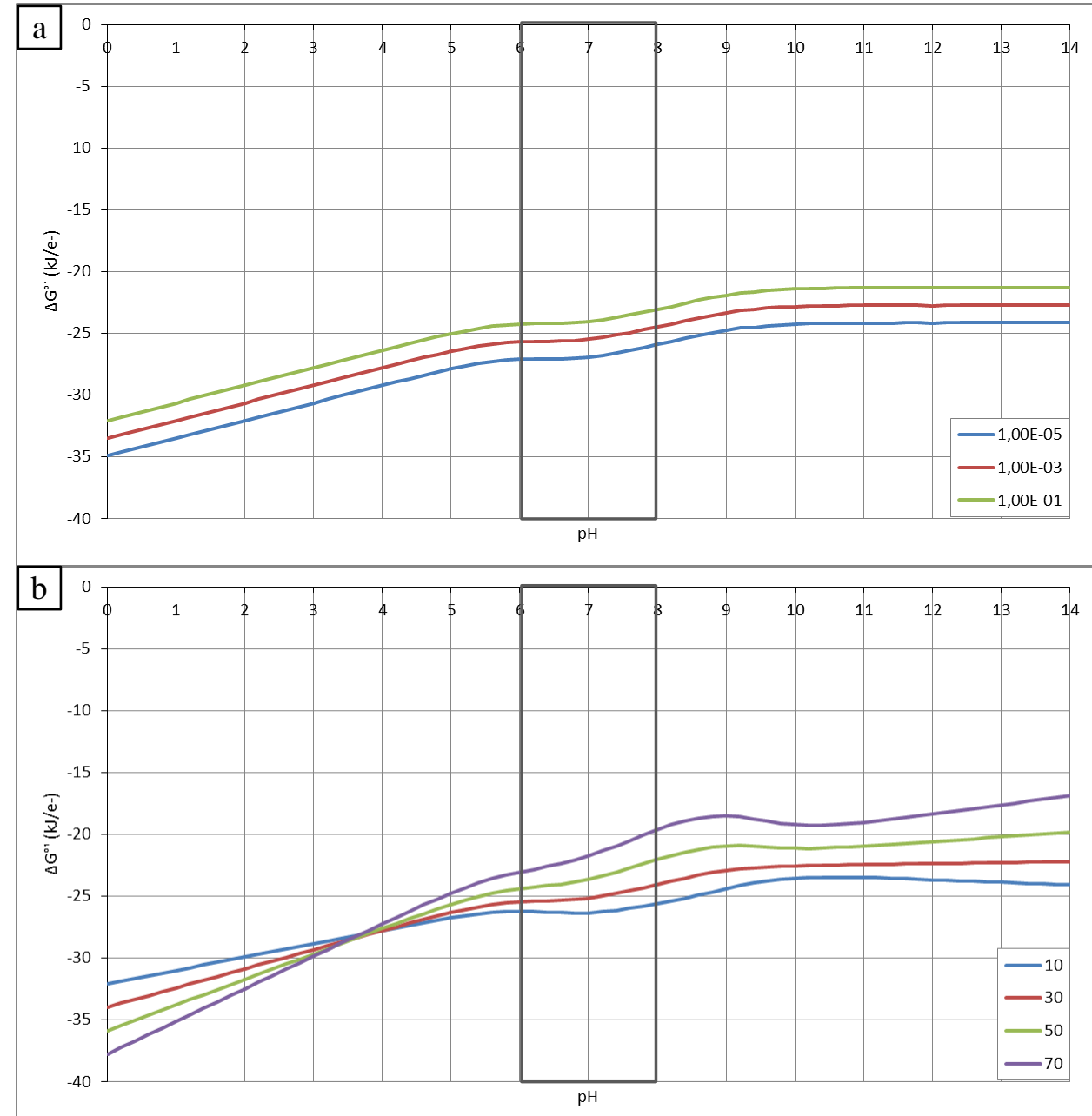

Figura 47. Energia livre da fixação de nitrogênio com cianobactérias diazotróficas (biofotólise indireta) como função a) do pH e pressão parcial de hidrogênio (atm) e b) do pH e temperatura $\left({ }^{\circ} \mathrm{C}\right)$. 
Tabela 24. Biorreação do modelo biotermodinâmico e estequiometria $\left(\mathrm{T}=25^{\circ} \mathrm{C}\right)$ da fixação em ausência de nitrogênio gasoso com cianobactérias diazotróficas (biofotólise indireta).

\begin{tabular}{|c|c|c|c|}
\hline \multicolumn{2}{|c|}{ Reação 68} & $f_{s}^{\circ}$ & $\begin{array}{c}\Delta_{r} G^{\circ} \\
\Delta_{r} H^{\circ} \\
\left(\mathrm{kJ} \mathrm{e}^{-} \mathrm{eq}^{-1}\right)\end{array}$ \\
\hline $\begin{array}{l}0 \\
0 \\
\text { II } \\
\frac{\pi}{2}\end{array}$ & $\begin{array}{l}4,17 \times 10^{-2} \mathrm{C}_{6} \mathrm{H}_{12} \mathrm{O}_{6}+4,55 \times 10^{-1} \mathrm{H}_{2} \mathrm{O} \rightleftharpoons 4,54 \times 10^{-2} \mathrm{CO}_{2}+2,05 \times 10^{-1} \mathrm{HCO}_{3}^{-}+ \\
5,00 \times 10^{-1} \mathrm{H}_{2}+2,05 \times 10^{-1} \mathrm{H}^{+}\end{array}$ & - & $\begin{array}{l}-17,9 \\
20,1\end{array}$ \\
\hline $\begin{array}{l}n \\
n \\
\frac{n}{2} \\
\frac{\pi}{2}\end{array}$ & $\begin{array}{l}4,17 \times 10^{-2} \mathrm{C}_{6} \mathrm{H}_{12} \mathrm{O}_{6}+4,84 \times 10^{-1} \mathrm{H}_{2} \mathrm{O} \rightleftharpoons 1,63 \times 10^{-2} \mathrm{CO}_{2}+2,33 \times 10^{-1} \mathrm{HCO}_{3}^{-}+ \\
4,17 \times 10^{-4} \mathrm{CO}_{3}^{2-}+5,00 \times 10^{-1} \mathrm{H}_{2}+2,34 \times 10^{-1} \mathrm{H}^{+}\end{array}$ & - & $\begin{array}{l}-18,3 \\
20,4\end{array}$ \\
\hline $\begin{array}{l}0 \\
\infty \\
\| \\
\frac{\pi}{2}\end{array}$ & $\begin{array}{l}4,17 \times 10^{-2} \mathrm{C}_{6} \mathrm{H}_{12} \mathrm{O}_{6}+4,95 \times 10^{-1} \mathrm{H}_{2} \mathrm{O} \rightleftharpoons 5,42 \times 10^{-3} \mathrm{CO}_{2}+2,43 \times 10^{-1} \mathrm{HCO}_{3}^{-}+ \\
1,25 \times 10^{-3} \mathrm{CO}_{3}{ }^{2-}+5,00 \times 10^{-1} \mathrm{H}_{2}+2,46 \times 10^{-1} \mathrm{H}^{+}\end{array}$ & - & $\begin{array}{c}-18,2 \\
20,3\end{array}$ \\
\hline
\end{tabular}
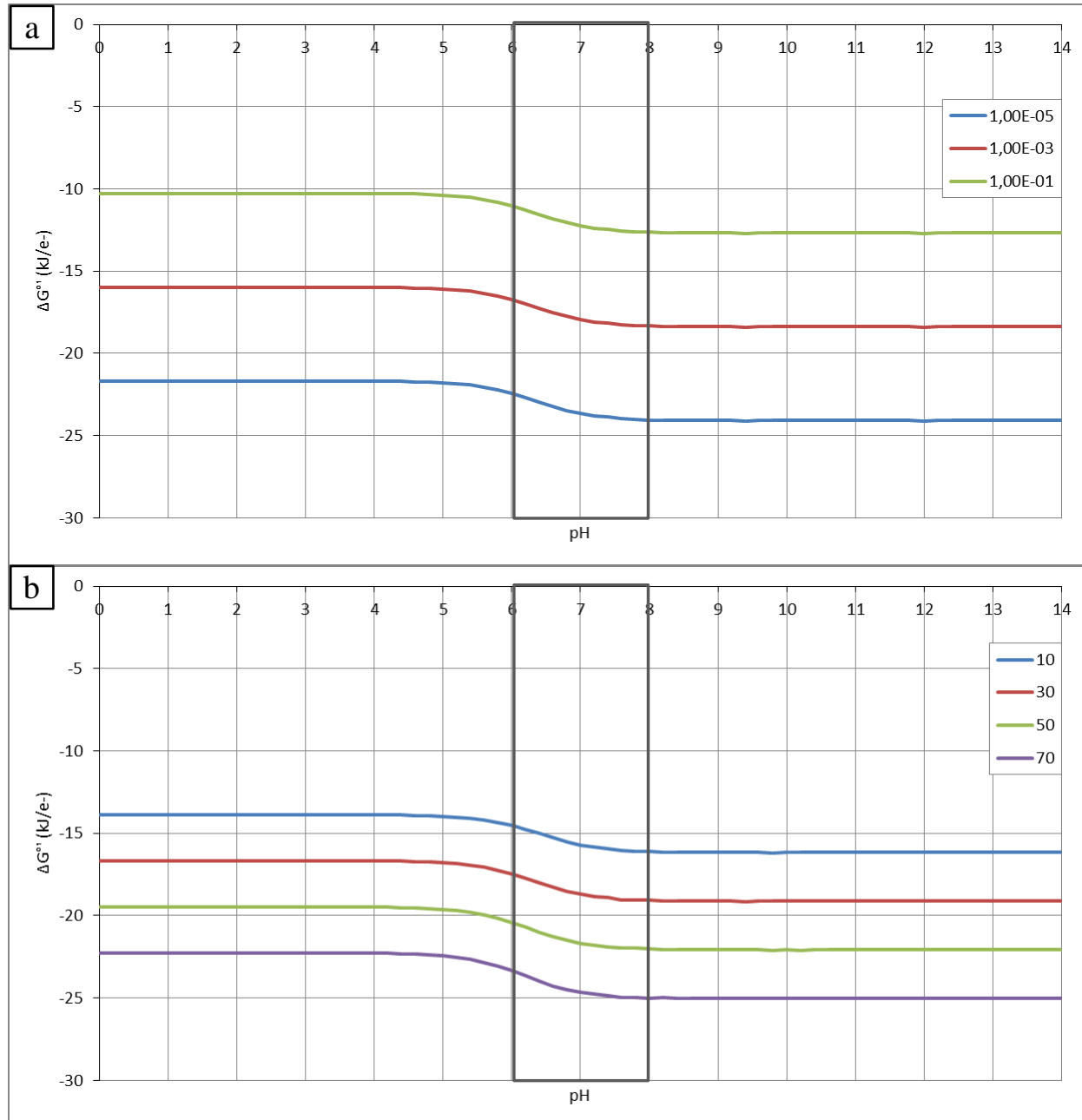

Figura 48. Energia livre da fixação em ausência de nitrogênio gasoso com cianobactérias diazotróficas (biofotólise indireta) como função a) do $\mathrm{pH}$ e pressão parcial de hidrogênio (atm) e b) do $\mathrm{pH}$ e temperatura $\left({ }^{\circ} \mathrm{C}\right)$. 
Tabela 25. Biorreação do modelo biotermodinâmico e estequiometria $\left(\mathrm{T}=25^{\circ} \mathrm{C}\right)$ da fermentação de glicose na escuridão com cianobactérias não diazotróficas (biofotólise indireta).

\begin{tabular}{|c|c|c|c|}
\hline \multicolumn{2}{|c|}{ Reação 69} & $f_{s}^{\circ}$ & $\begin{array}{c}\Delta_{r} G^{\circ} \\
\Delta_{r} H^{\circ} \\
\left(\mathrm{kJ} \mathrm{e}^{-} \mathrm{eq}^{-1}\right) \\
\end{array}$ \\
\hline 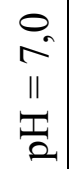 & $\begin{array}{l}4,17 \times 10^{-2} \mathrm{C}_{6} \mathrm{H}_{12} \mathrm{O}_{6}+1,50 \times 10^{-1} \mathrm{H}_{2} \mathrm{O} \rightleftharpoons 8,25 \times 10^{-2} \mathrm{C}_{2} \mathrm{H}_{3} \mathrm{O}_{2}^{-}+8,33 \times 10^{-} \\
{ }^{4} \mathrm{C}_{2} \mathrm{H}_{4} \mathrm{O}_{2}+1,54 \times 10^{-2} \mathrm{CO}_{2}+6,79 \times 10^{-2} \mathrm{HCO}_{3}^{-}+1,67 \times 10^{-1} \mathrm{H}_{2}+1,47 \times 10^{-} \\
{ }^{1} \mathrm{H}^{+}\end{array}$ & - & $\begin{array}{c}-15,9 \\
0,8\end{array}$ \\
\hline 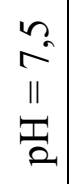 & $\begin{array}{l}4,17 \times 10^{-2} \mathrm{C}_{6} \mathrm{H}_{12} \mathrm{O}_{6}+1,61 \times 10^{-1} \mathrm{H}_{2} \mathrm{O} \rightleftharpoons 8,33 \times 10^{-2} \mathrm{C}_{2} \mathrm{H}_{3} \mathrm{O}_{2}^{-}+5,42 \times 10^{-3} \mathrm{CO}_{2} \\
+7,75 \times 10^{-2} \mathrm{HCO}_{3}+4,17 \times 10^{-4} \mathrm{CO}_{3}{ }^{2-}+1,67 \times 10^{-1} \mathrm{H}_{2}+1,62 \times 10^{-1} \mathrm{H}^{+}\end{array}$ & - & $\begin{array}{c}-16,0 \\
1,4\end{array}$ \\
\hline 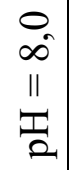 & $\begin{array}{l}4,17 \times 10^{-2} \mathrm{C}_{6} \mathrm{H}_{12} \mathrm{O}_{6}+1,65 \times 10^{-1} \mathrm{H}_{2} \mathrm{O} \rightleftharpoons 8,33 \times 10^{-2} \mathrm{C}_{2} \mathrm{H}_{3} \mathrm{O}_{2}^{-}+2,08 \times 10^{-3} \mathrm{CO}_{2} \\
+8,08 \times 10^{-2} \mathrm{HCO}_{3}+4,17 \times 10^{-4} \mathrm{CO}_{3}{ }^{2-}+1,67 \times 10^{-1} \mathrm{H}_{2}+1,65 \times 10^{-1} \mathrm{H}^{+}\end{array}$ & - & $\begin{array}{l}-16,2 \\
1,4\end{array}$ \\
\hline
\end{tabular}
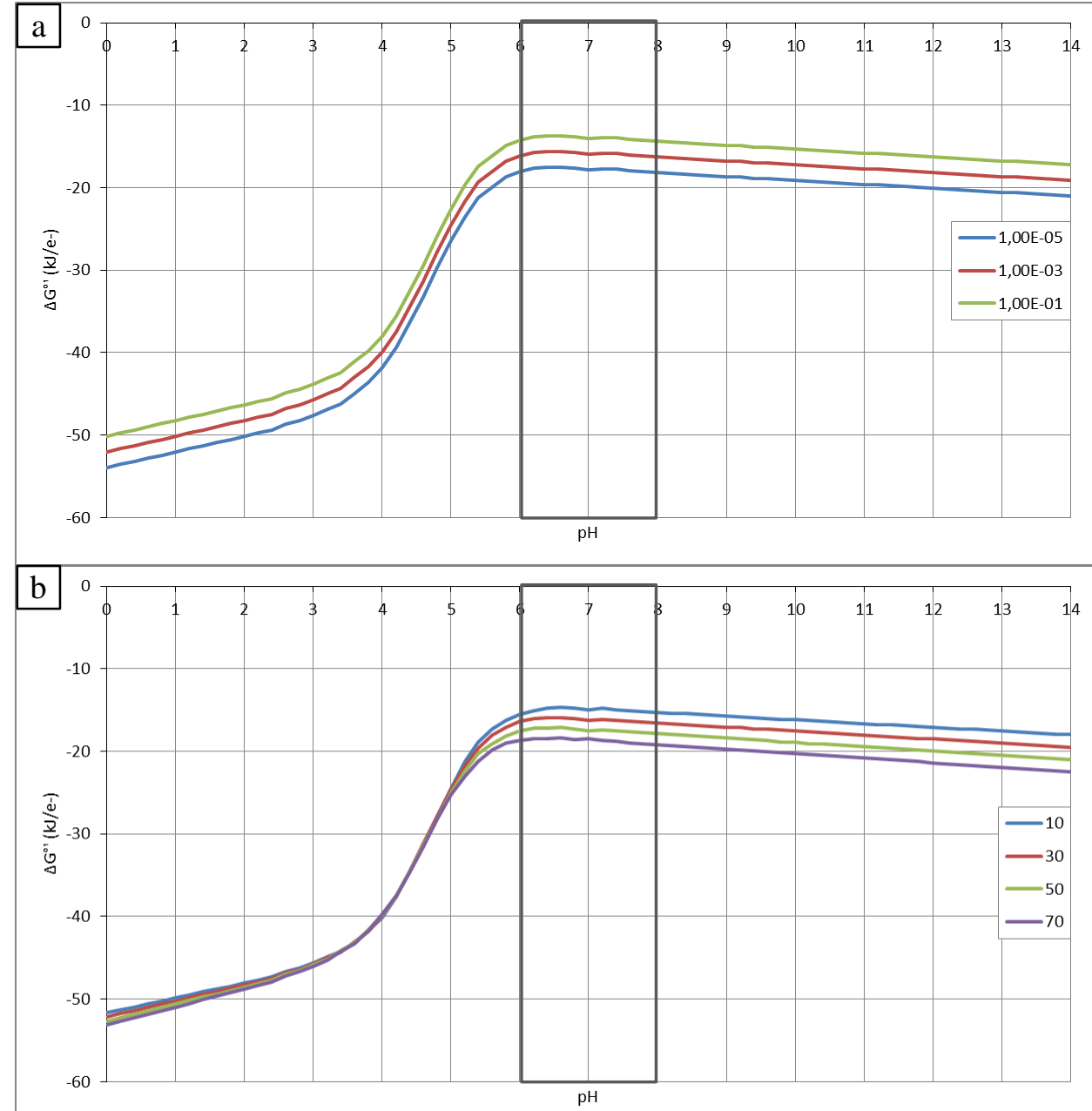

Figura 49. Energia livre da fermentação de glicose na escuridão com cianobactérias não diazotróficas (biofotólise indireta) como função a) do $\mathrm{pH}$ e pressão parcial de hidrogênio (atm) e b) do $\mathrm{pH}$ e temperatura $\left({ }^{\circ} \mathrm{C}\right)$. 
livre dissipada, enquanto para $\mathrm{pH}$ superiores, a energia livre dissipada diminui pela diminuição da temperatura e, portanto, a conversão. Quando o nitrogênio gasoso não está disponível (Reação 68), o comportamento da energia livre dissipada é estável no intervalo de $\mathrm{pH}$, com um intervalo de variação entre 6,0 e 7,0 (a $\left.25^{\circ} \mathrm{C}\right)$. O aumento do pH para valores superiores a 7,0 aumenta a energia livre dissipada, mas apenas marginalmente. Para a pressão parcial de hidrogênio, um produto do metabolismo da nitrogenase, sua diminuição produz o aumento da energia livre dissipada e a conversão (Figura 48a), enquanto à temperatura, seu aumento produz o aumento da energia livre dissipada (Figura 48b).

Finalmente, a biofotólise indireta para produção de hidrogênio com cianobactérias não diazotróficas na escuridão (Figura $49^{11}$ ) é uma fermentação de glicose com comportamento muito parecido com as fermentações em microalgas (Figuras 43 e 44). A energia livre dissipada aumenta significativamente para $\mathrm{pH}$ inferior a $6,0\left(\right.$ a $\left.25^{\circ} \mathrm{C}\right)$; a diminuição na pressão parcial de hidrogênio (Figura 49a) e o aumento da temperatura (Figura 49b) favorece levemente o aumento da energia livre dissipada e, portanto, as conversões.

\subsection{Rendimentos molares da fotossíntese oxigênica}

A partir da estequiometria estabelecida pelo modelo biotermodinâmico se obtêm os rendimentos dos produtos da fotossíntese oxigênica. A Figura 50 apresenta os rendimentos com microalgas quando o produto de armazenamento é glicose (Reação 62) ou ácido palmítico (Reação 65) e o rendimento com cianobactérias (Reação 66), em mols produzidas por $8 \mathrm{~mol}$ de fótons em função do $\mathrm{pH}$ para $25^{\circ} \mathrm{C}$.

A Figura 51 apresenta os mesmos rendimentos com microalgas e cianobactérias, mas em função da temperatura para um pH 7,00.

Os resultados mostram que os rendimentos celulares, tanto para microalgas quanto para cianobactérias, não são influídos pelo pH (Figura 50) e são debilmente influídos pela

\footnotetext{
${ }^{11}$ A estequiometria da fermentação de glicose na escuridão com cianobactérias não diazotróficas (Reação 69) se baseia nos resultados de Yu \& Takahashi (2007) que encontraram, na fermentação escura de glicose com uma espécie de cianobactéria, produção de 3,92 mols de hidrogênio, 1,97 mols de acetato, por mol de glicose, e pequenas quantidades de lactato e etanol. Estes resultados mostram quase uma fermentação homoacética (Figura 4, Reação 47) que produz a máxima quantidade teórica de hidrogênio (4 mols).
} 


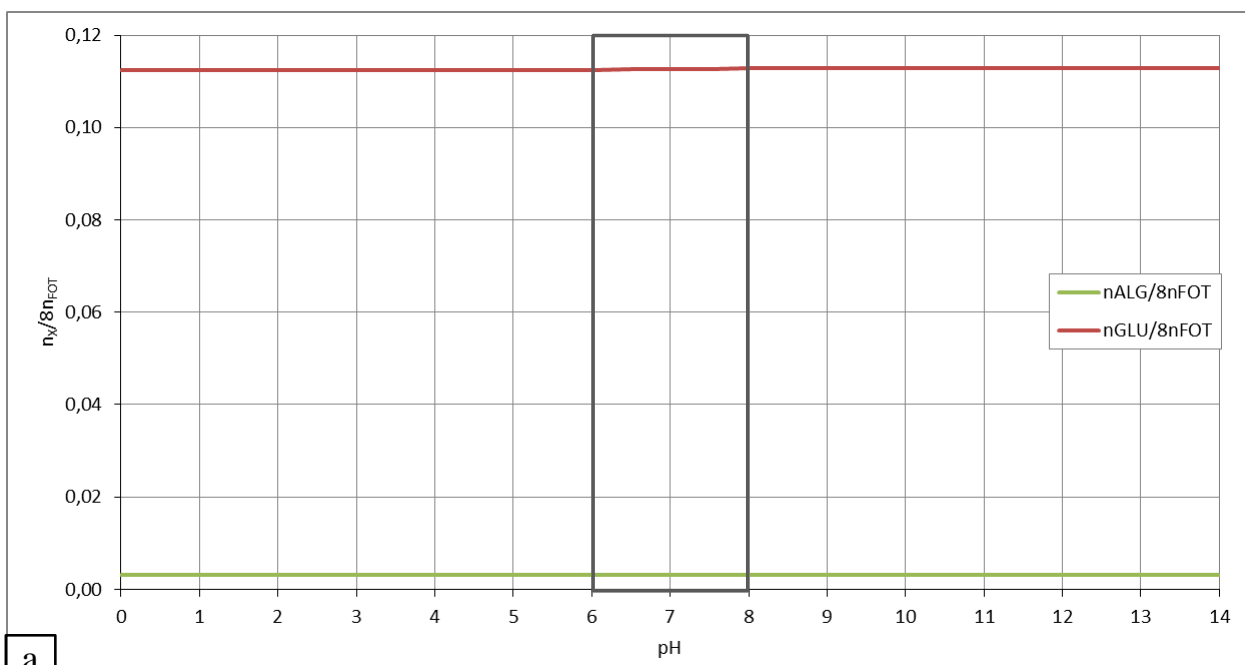

$\mathrm{a}$

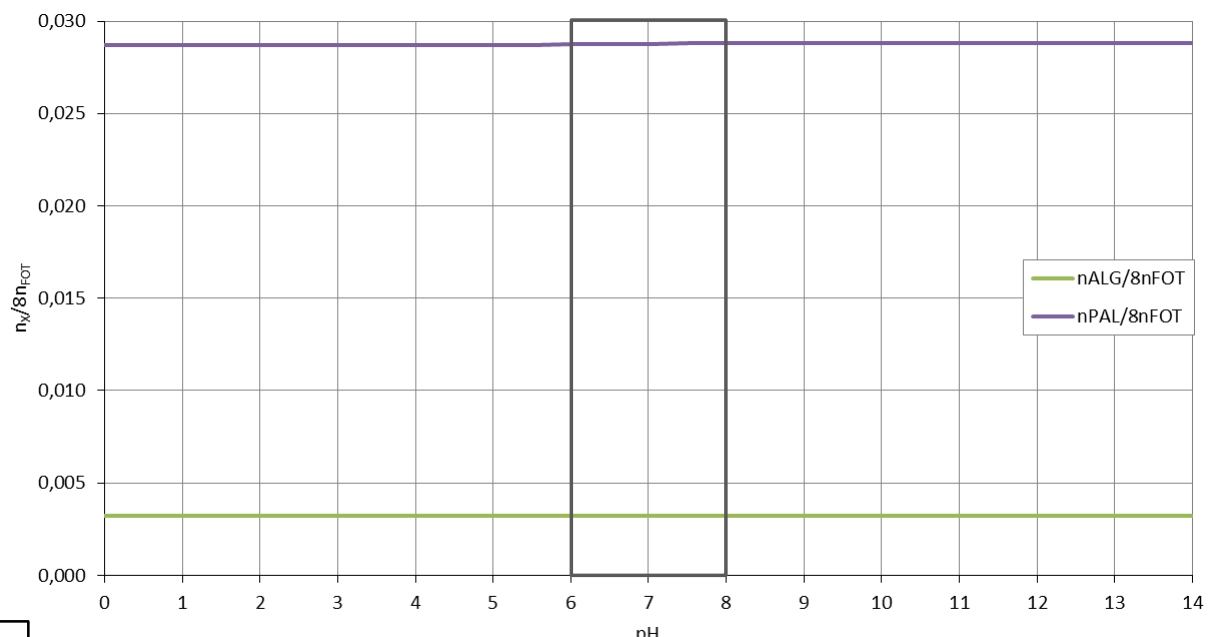

b

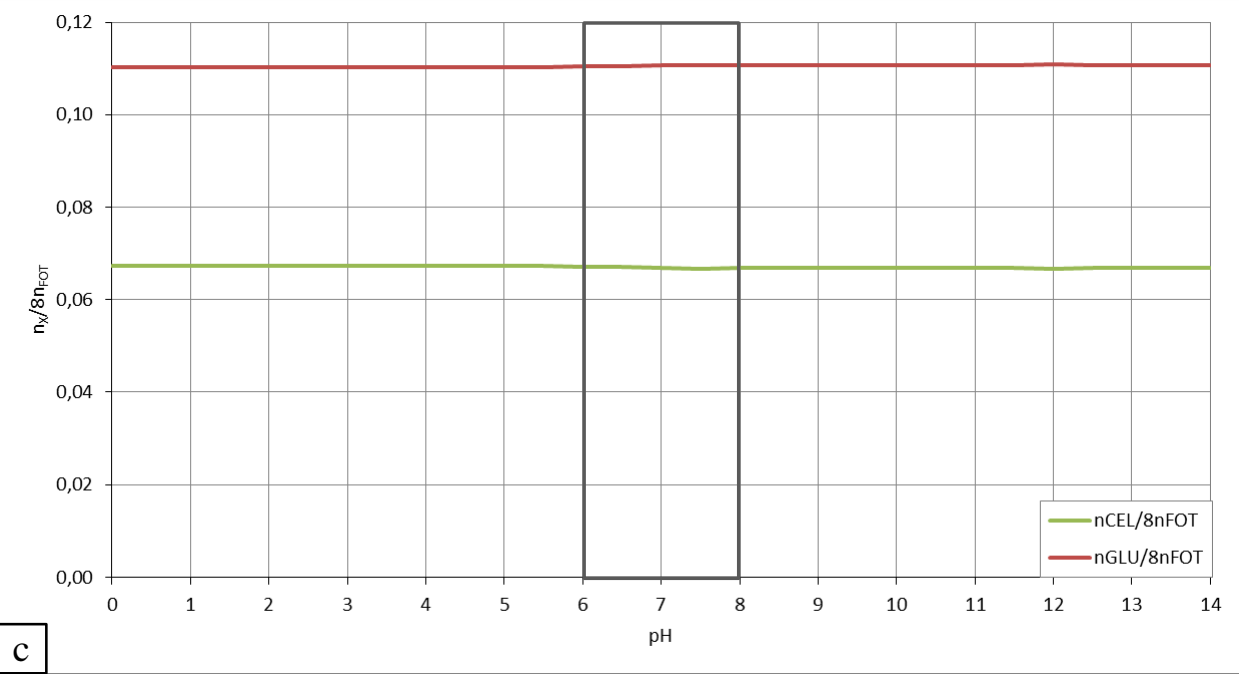

Figura 50. Rendimento dos produtos da fotossíntese oxigênica com a) microalgas para produção de glicose, b) microalgas para produção de ácido palmítico e c) cianobactérias, em mols produzidas por 8 mols de fótons em função do $\mathrm{pH}\left(\mathrm{T}=25^{\circ} \mathrm{C}, \mathrm{p}_{\mathrm{H} 2}=1,00 \times 10^{-3} \mathrm{~atm}\right)$. 


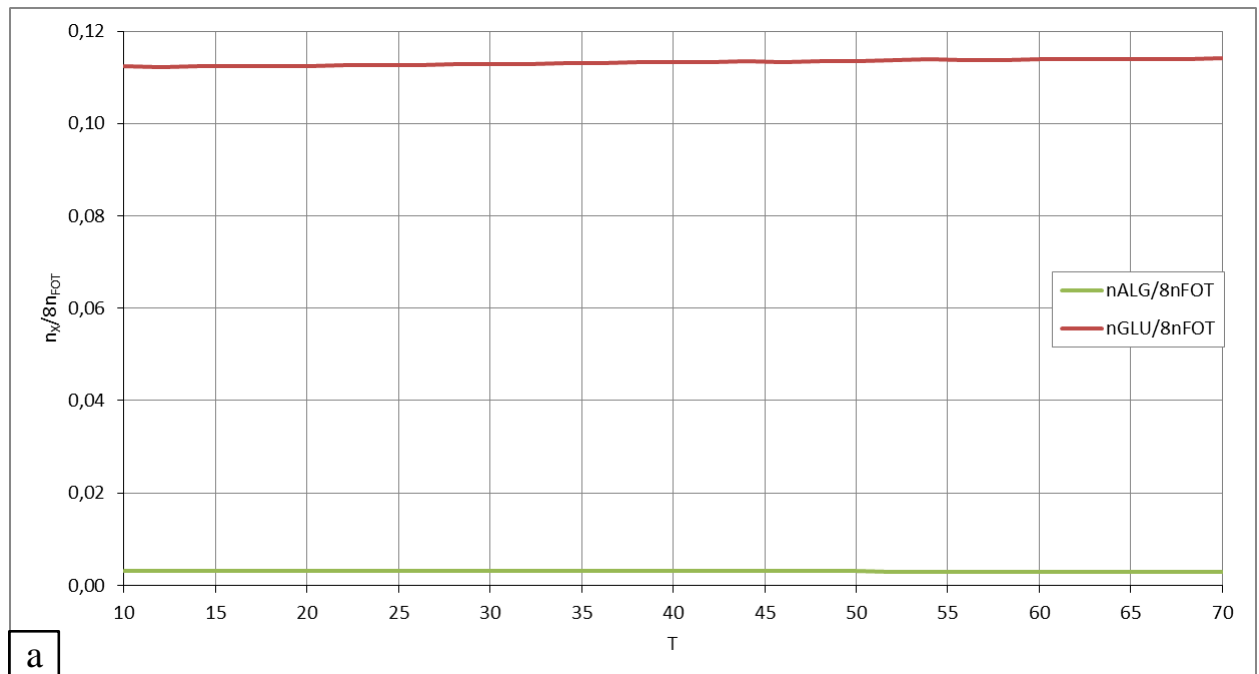

a

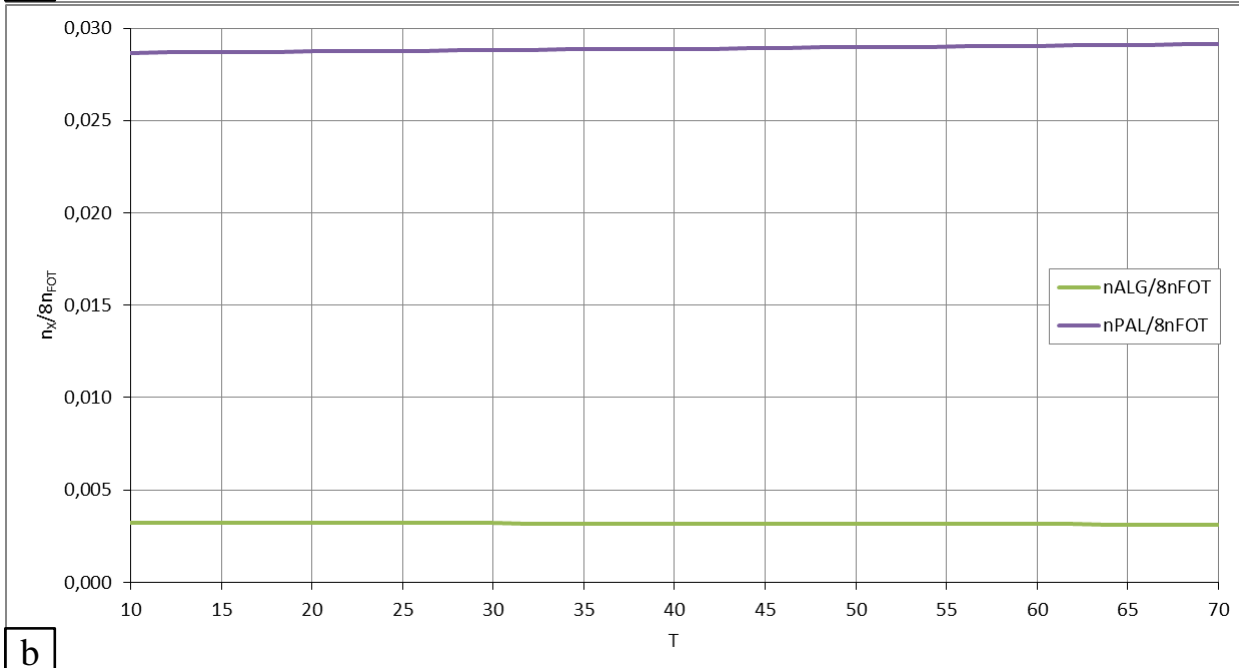

b

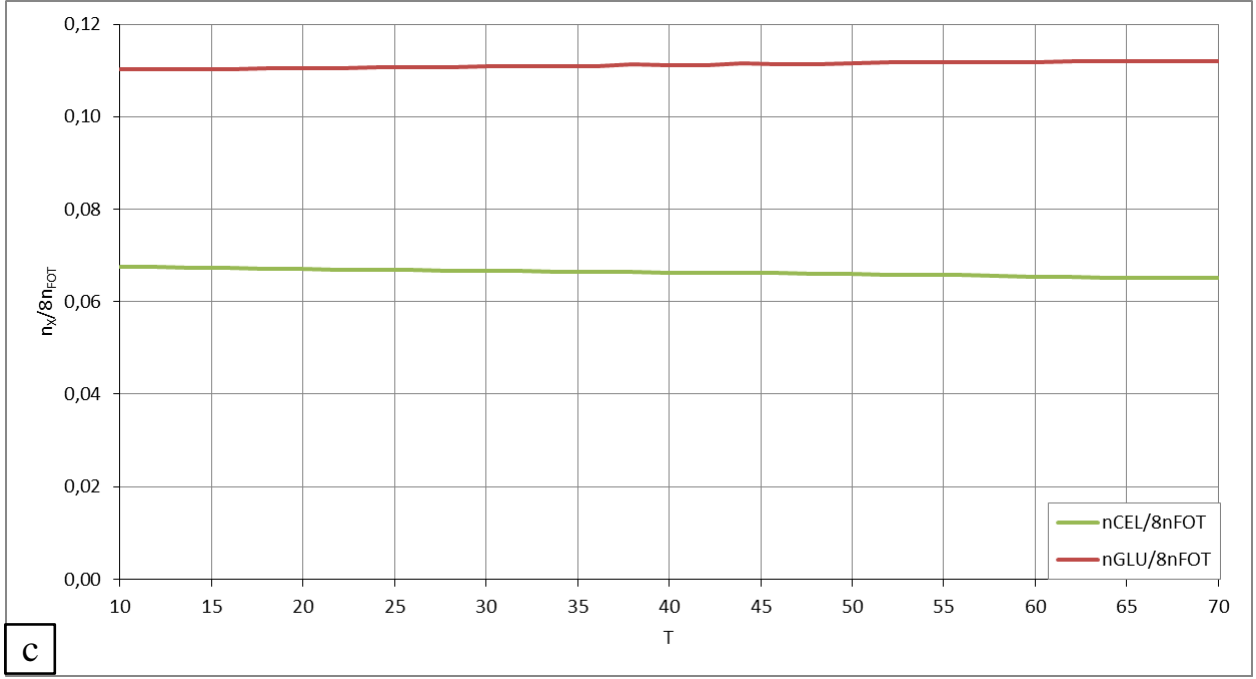

Figura 51. Rendimento dos produtos da fotossíntese oxigênica com a) microalgas para produção de glicose, b) microalgas para produção de ácido palmítico e c) cianobactérias, em mols produzidas por 8 mols de fótons em função da temperatura $\left(\mathrm{pH}=7,00, \mathrm{p}_{\mathrm{H} 2}=1,00 \times 10^{-3}\right.$ atm). 
temperatura (Figura 51). Para microalgas, o rendimento das células é aproximadamente de 0,0035 mols de células por 8 mols de fótons independentemente do produto de armazenamento, enquanto para cianobactérias é aproximadamente de 0,065 mols de células por 8 mols de fótons, quase 20 vezes o rendimento das microalgas. $\mathrm{O}$ aumento da temperatura favorece debilmente o rendimento dos produtos de armazenamento e, em consequência, desfavorece o rendimento das células. O rendimento da glicose é levemente superior em microalgas que em cianobactérias no intervalo de $\mathrm{pH}$ e o rendimento de glicose em microalgas é quase 4 vezes o rendimento de ácido palmítico.

A Figura 52 apresenta a distribuição dos elétrons transferidos do doador (água) aos produtos reduzidos produzidos na fotossíntese oxigênica com microalgas quando o produto de armazenamento é glicose (Reação 62) ou ácido palmítico (Reação 65) e a distribuição com cianobactérias (Reação 66), em função do pH para $25^{\circ} \mathrm{C}$.

Os resultados evidenciam que a fração de elétrons destinada aos produtos do metabolismo da fotossíntese oxigênica é quase a mesma independentemente dos produtos de armazenamento ou o microorganismo involucrado.

A glicose produzida como produto de armazenamento na fotossíntese oxigênica pode ser fermentada pelas microalgas e cianobactérias, gerando diferentes produtos reduzidos como formiato, acetato, etanol e hidrogênio. Nessas fermentações, os elétrons transferidos aos produtos reduzidos a partir da glicose provêm originalmente d'água hidrolisada na fotossíntese oxigênica e, portanto, podem-se estabelecer os rendimentos dos produtos das fermentações respeito aos fótons que participam na fotossíntese. Para essas fermentações, a Figura 53 apresenta os rendimentos dos produtos da biofotólise indireta por fermentação com microalgas na luz (Reações 62 e 63) e na escuridão (Reações 62 e 64) e o rendimento com cianobactérias na escuridão (Reações 66 e 69), em mols produzidas por 8 mol de fótons em função do $\mathrm{pH}$ para $25^{\circ} \mathrm{C}$.

A Figura 54 apresenta os mesmos rendimentos com microalgas e cianobactérias, mas em função da temperatura para um pH 7,00.

Os rendimentos dos produtos das fermentações com microalgas e cianobactérias não são influídos pelo pH (Figura 53) enquanto a temperatura tem um efeito muito débil (Figura 54). A fermentação da glicose na luz com microalgas produz os mesmos rendimentos para formiato e acetato, e a fermentação na escuridão os mesmos rendimentos para acetato e etanol. A produção de outros produtos reduzidos diferentes do hidrogênio diminui seu rendimento devido a que os elétrons do doador (água) são distribuídos entre todos os 


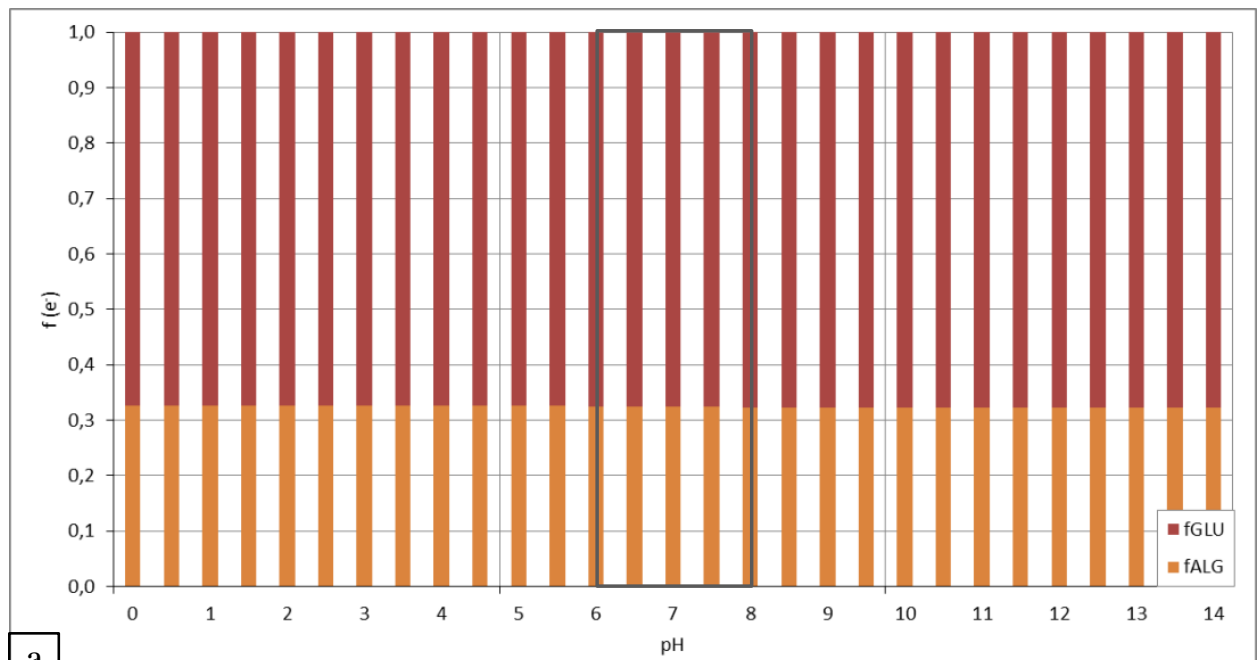

a

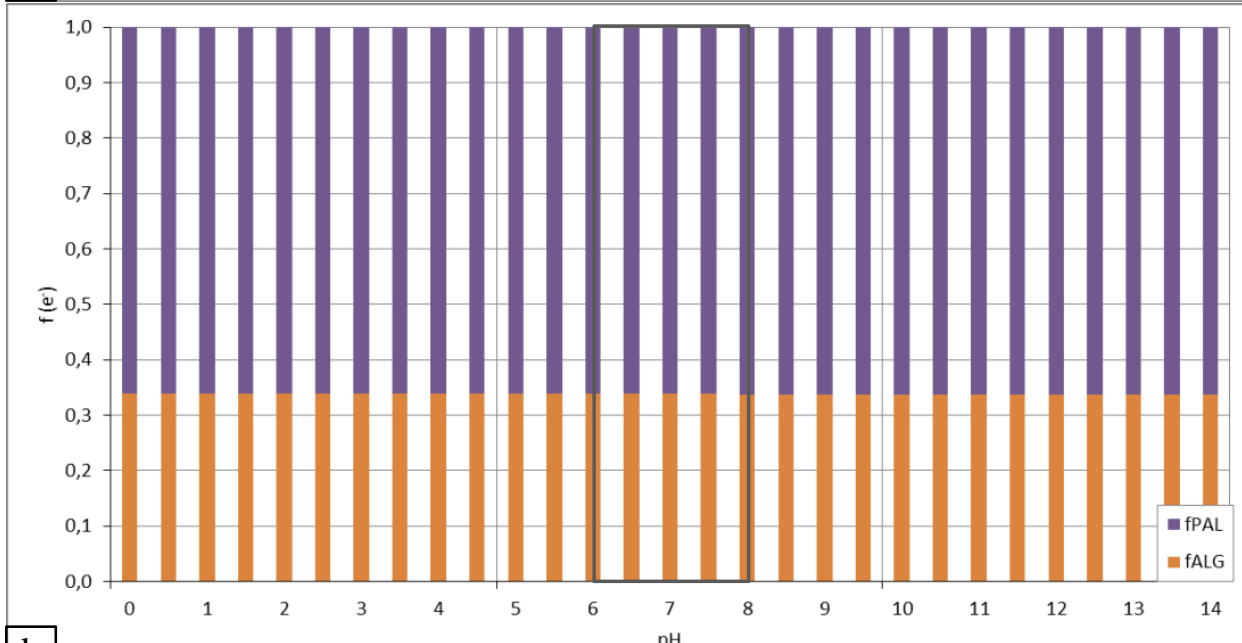

$\mathrm{b}$

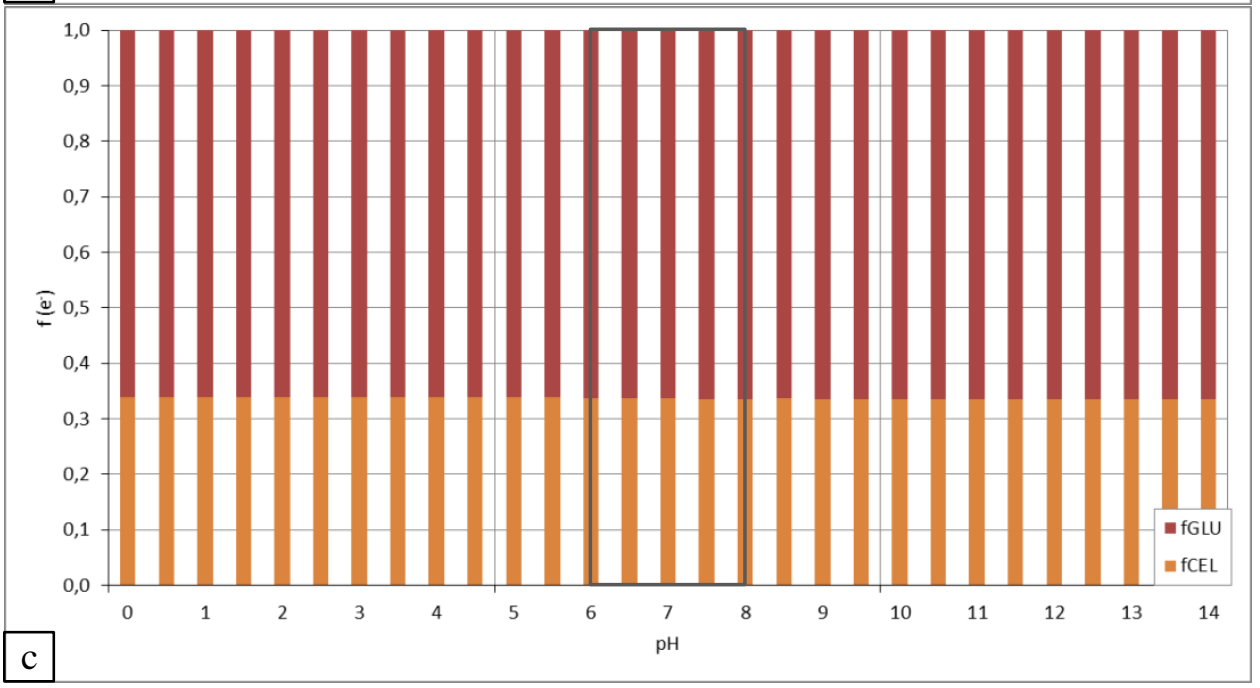

Figura 52. Fração de elétrons transferidos d'água a cada produto reduzido na fotossíntese oxigênica com a) microalgas para produção de glicose, b) microalgas para produção de ácido palmítico e c) cianobactérias, em função do $\mathrm{pH}\left(\mathrm{T}=25^{\circ} \mathrm{C}, \mathrm{p}_{\mathrm{H} 2}=1,00 \times 10^{-3} \mathrm{~atm}\right)$. 


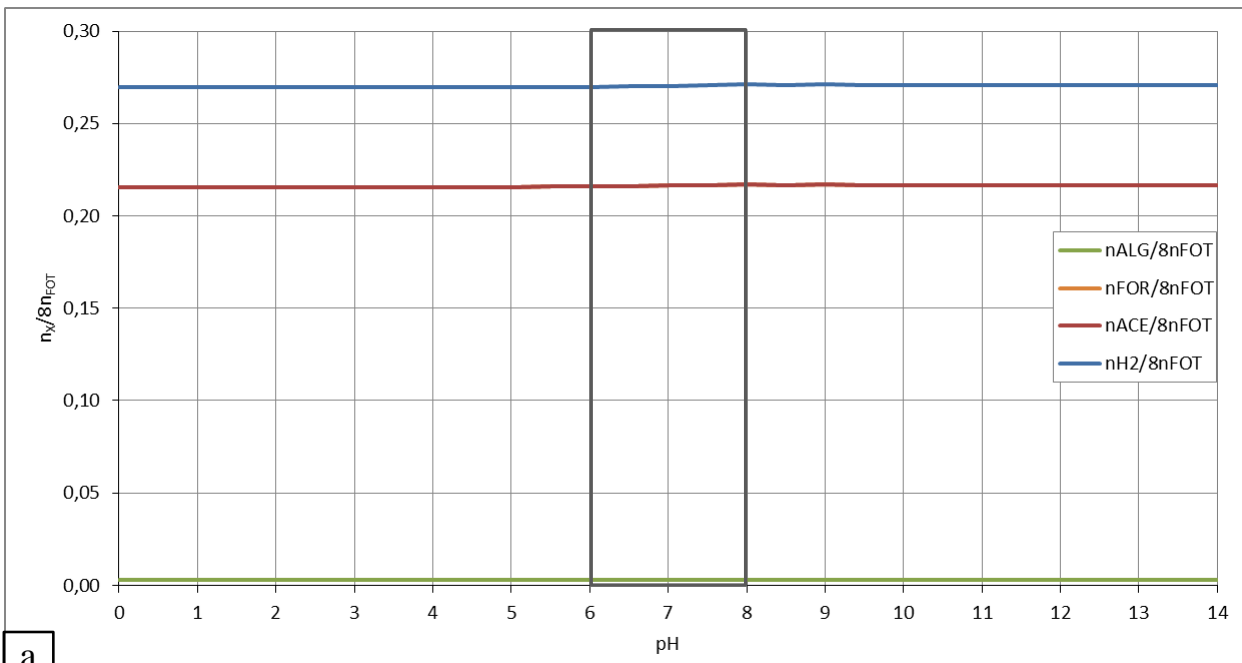

a

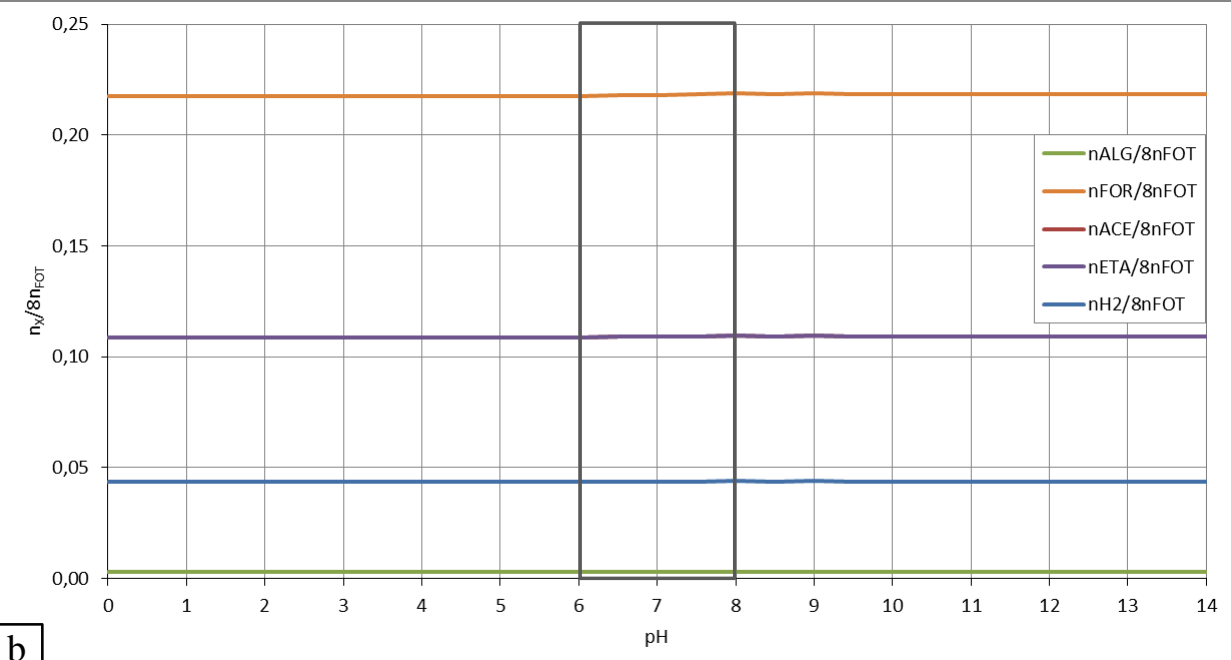

b

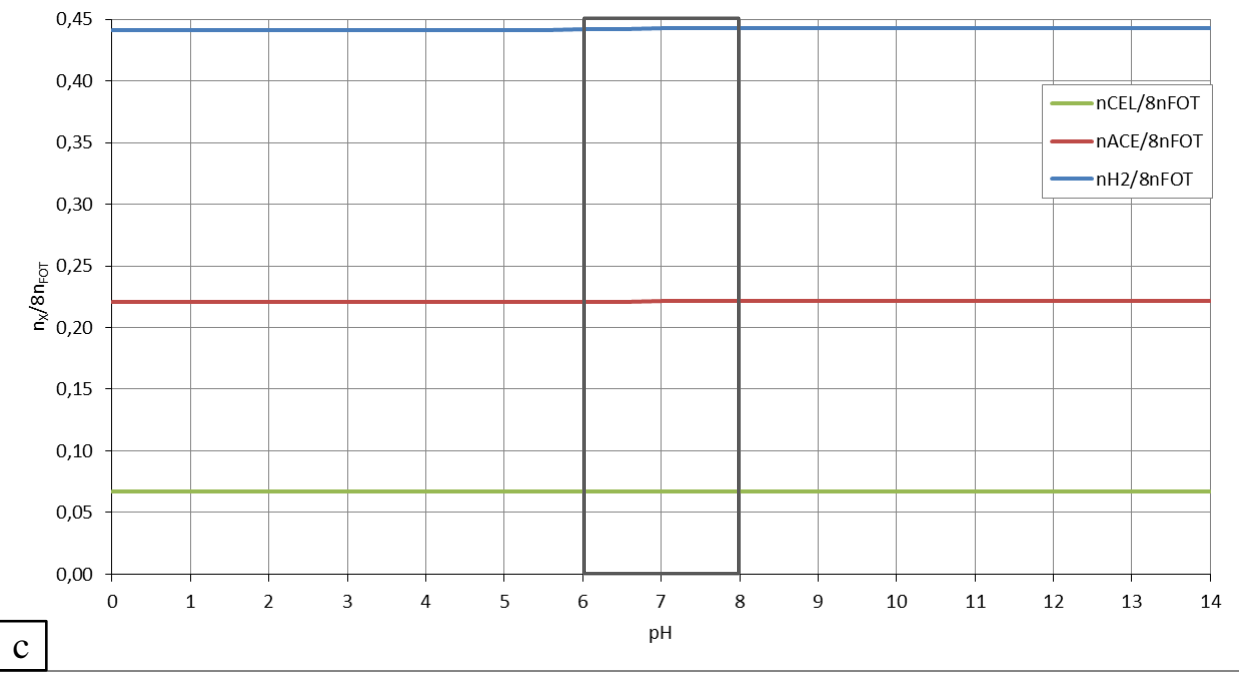

Figura 53. Rendimento dos produtos da biofotólise indireta por fermentação com a) microalgas na luz, b) microalgas na escuridão e c) cianobactérias na escuridão, em mols produzidas por 8 mols de fótons em função do $\mathrm{pH}\left(\mathrm{T}=25^{\circ} \mathrm{C}, \mathrm{p}_{\mathrm{H} 2}=1,00 \times 10^{-3} \mathrm{~atm}\right)$. 


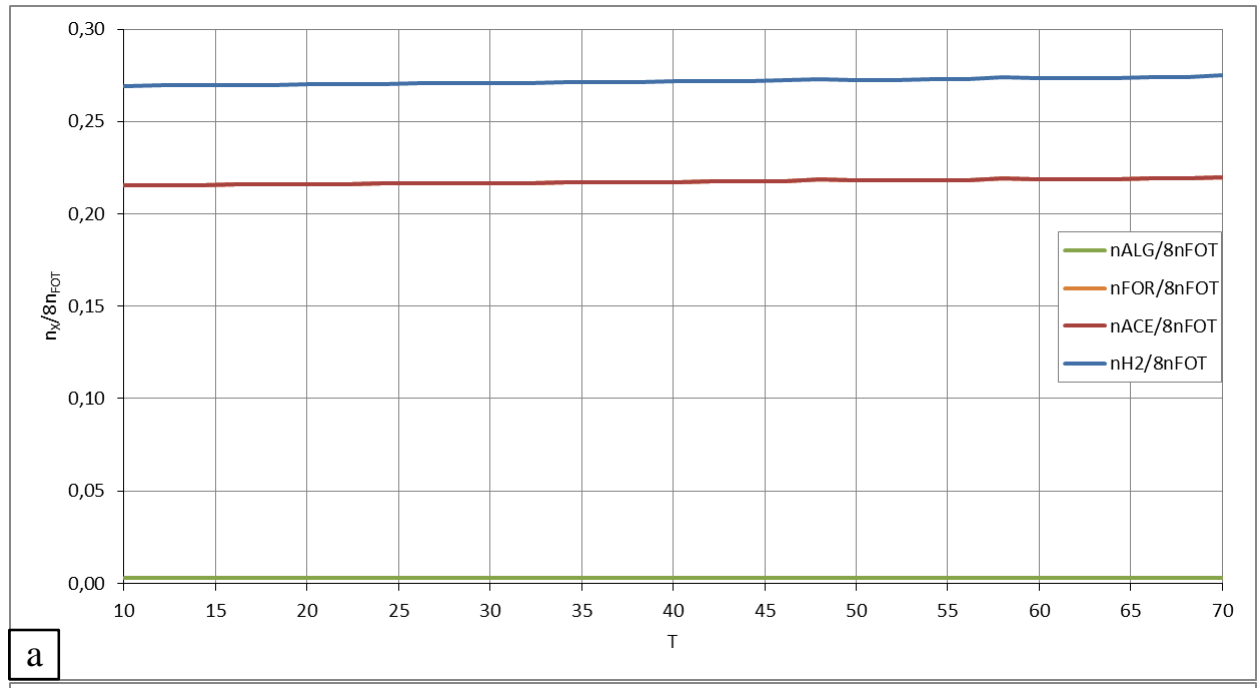

a

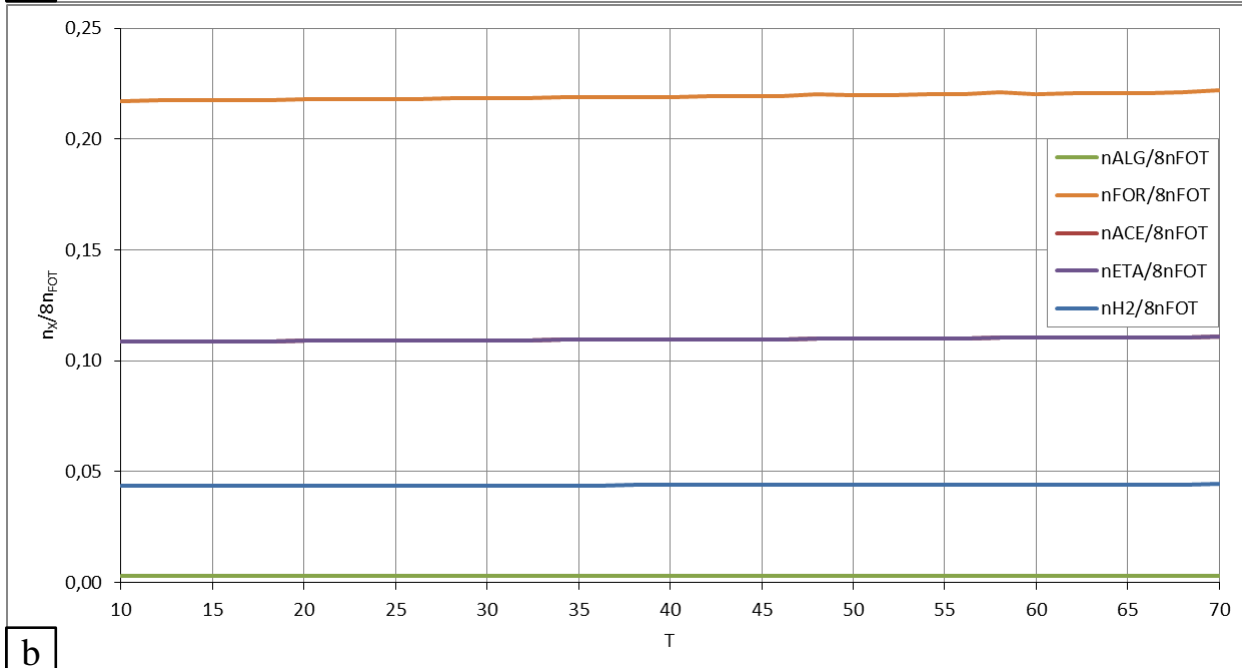

$\mathrm{b}$

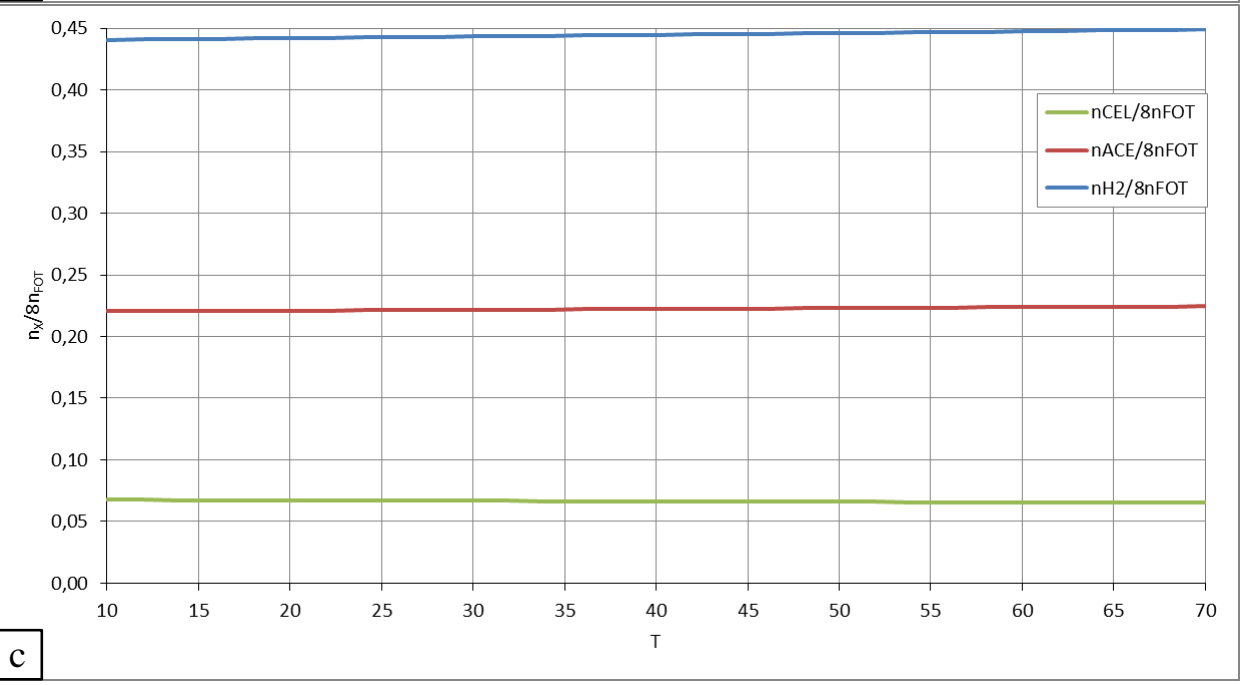

Figura 54. Rendimento dos produtos da biofotólise indireta por fermentação com a)

microalgas na luz, b) microalgas na escuridão e c) cianobactérias na escuridão, em mols produzidas por 8 mols de fótons em função da temperatura $\left(\mathrm{pH}=7,00, \mathrm{p}_{\mathrm{H} 2}=1,00 \times 10^{-3} \mathrm{~atm}\right)$. 
produtos. Assim, a fermentação da glicose na escuridão com cianobactérias (Reação 69) tem o maior rendimento de hidrogênio, porquanto nessa fermentação homoacética o acetato é o único produto extra da fermentação. Por outro lado, a fermentação da glicose na escuridão com microalgas (Reação 64) tem o menor rendimento de hidrogênio, dada a variedade de outros produtos reduzidos produzidos. Comparativamente, a fermentação da glicose na escuridão com cianobactérias (Reação 69) tem aproximadamente 10 vezes o rendimento de hidrogênio da fermentação na escuridão com microalgas (Reação 64), e esta última tem aproximadamente 6 vezes o rendimento da fermentação na luz com microalgas (Reação 63).

A Figura 55 apresenta a distribuição dos elétrons transferidos do doador (água) aos produtos reduzidos produzidos na biofotólise indireta por fermentação com microalgas na luz (Reações 62 e 63) e na escuridão (Reações 62 e 64) e a distribuição com cianobactérias na escuridão (Reações 66 e 69), em função do $\mathrm{pH}$ para $25^{\circ} \mathrm{C}$.

Os resultados das frações de elétrons confirmam a quantidade marginal de elétrons destinados à produção de hidrogênio na fermentação da glicose na escuridão com microalgas, quando comparados com os elétrons destinados ao mesmo fim na fermentação da glicose na escuridão com cianobactérias. Esses resultados também confirmam as mesmas proporções de rendimentos de hidrogênio mencionadas antes.

Finalmente, similar às fermentações, a glicose produzida como produto de armazenamento na fotossíntese oxigênica pode ser usada como doador de elétrons para a fixação de nitrogênio gasoso pela nitrogenase produzindo amoníaco e hidrogênio (Reação 58) ou unicamente hidrogênio na ausência de nitrogênio gasoso (Reação 60). Nessa fixação, os elétrons transferidos aos produtos reduzidos a partir da glicose provêm originalmente d'água hidrolisada na fotossíntese oxigênica e, portanto, podem-se estabelecer os rendimentos dos produtos das fixações respeito aos fótons que participam na fotossíntese. Para essas fixações, a Figura 56 apresenta os rendimentos dos produtos da biofotólise indireta pela atividade da nitrogenase com cianobactérias em presença (Reações 66 e 67) e ausência (Reações 66 e 68) de nitrogênio gasoso, em mols produzidas por $8 \mathrm{~mol}$ de fótons em função do $\mathrm{pH}$ para $25^{\circ} \mathrm{C}$.

A Figura 57 apresenta os mesmos rendimentos, mas em função da temperatura para um $\mathrm{pH} 7,00$.

Como nas fermentações, os rendimentos dos produtos das fixações não são influídos pelo pH (Figura 56) enquanto a temperatura tem um efeito muito débil (Figura 57). Quando o nitrogênio gasoso está ausente, todos os elétrons produzidos pela oxidação da glicose se usam para a produção de hidrogênio; como consequência, o rendimento de hidrogênio quando o nitrogênio está ausente é 4 vezes o rendimento quando está presente. 


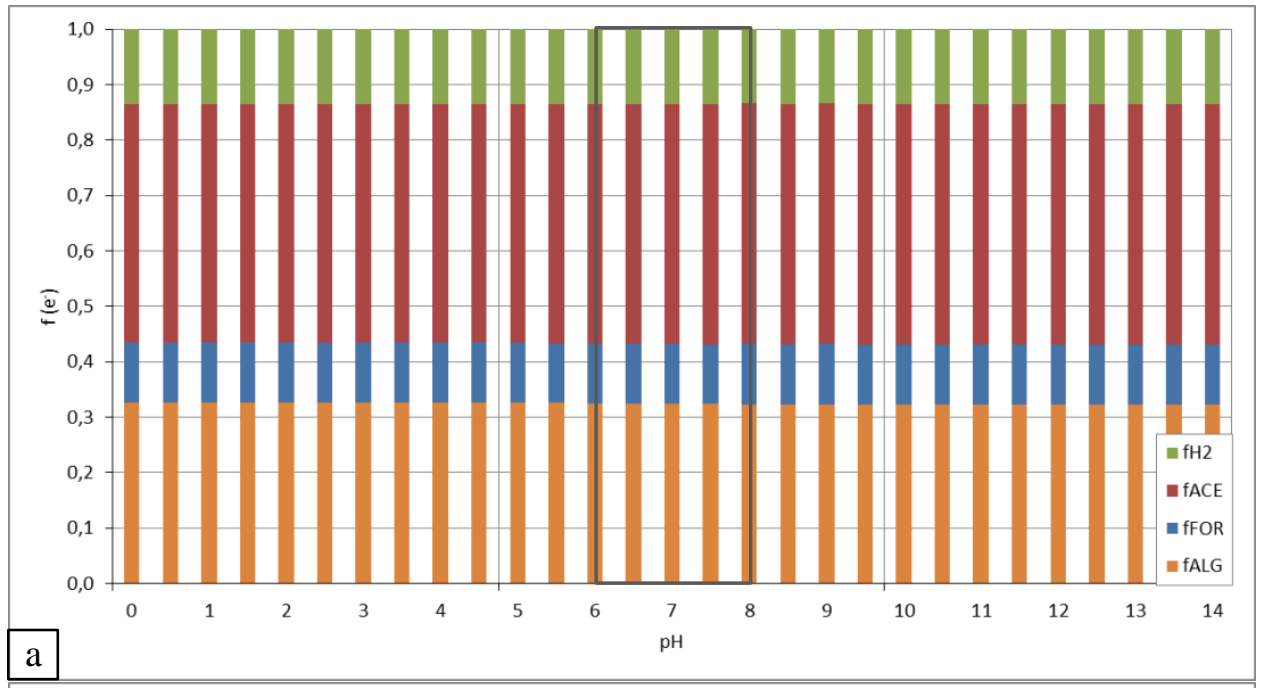

a

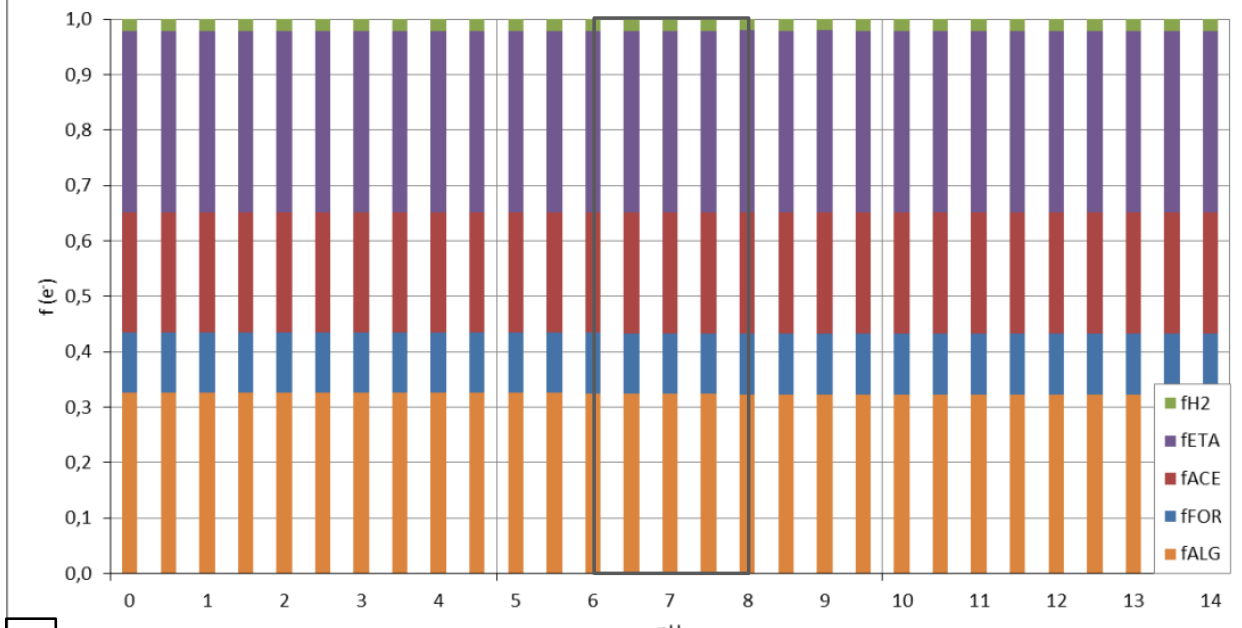

$\mathrm{b}$

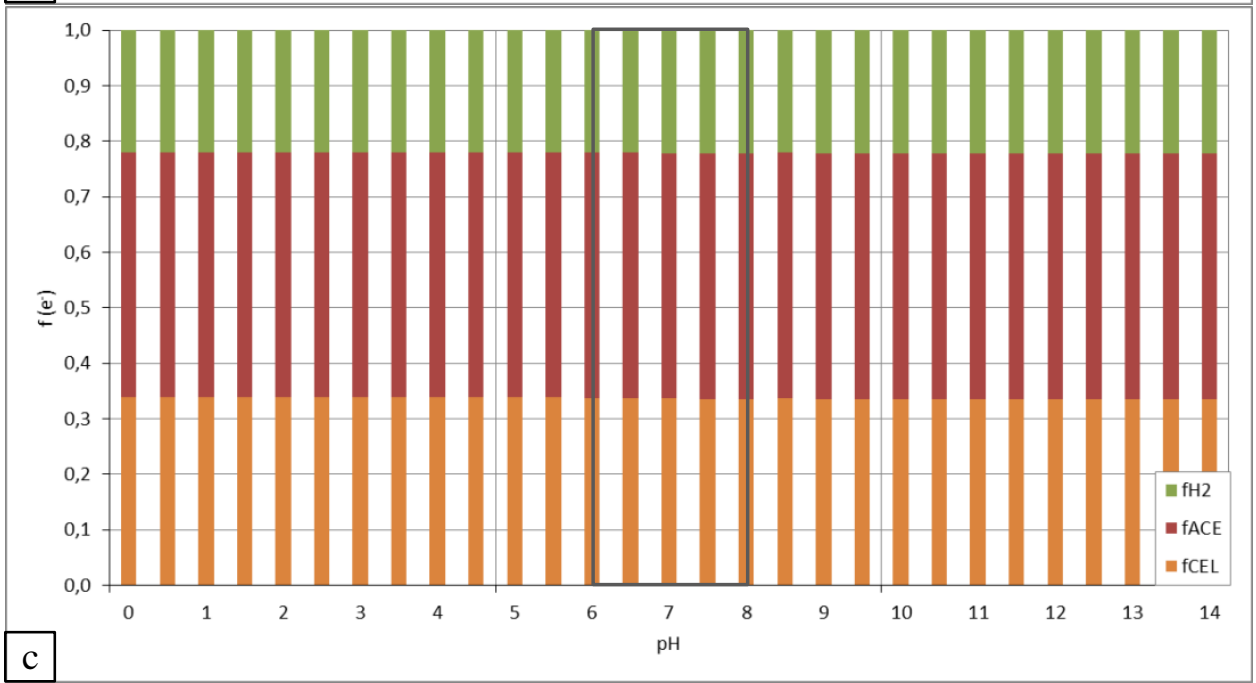

Figura 55. Fração de elétrons transferidos d'água a cada produto reduzido na biofotólise indireta por fermentação com a) microalgas na luz, b) microalgas na escuridão e c) cianobactérias na escuridão, em função do $\mathrm{pH}\left(\mathrm{T}=25^{\circ} \mathrm{C}, \mathrm{p}_{\mathrm{H} 2}=1,00 \times 10^{-3} \mathrm{~atm}\right)$. 


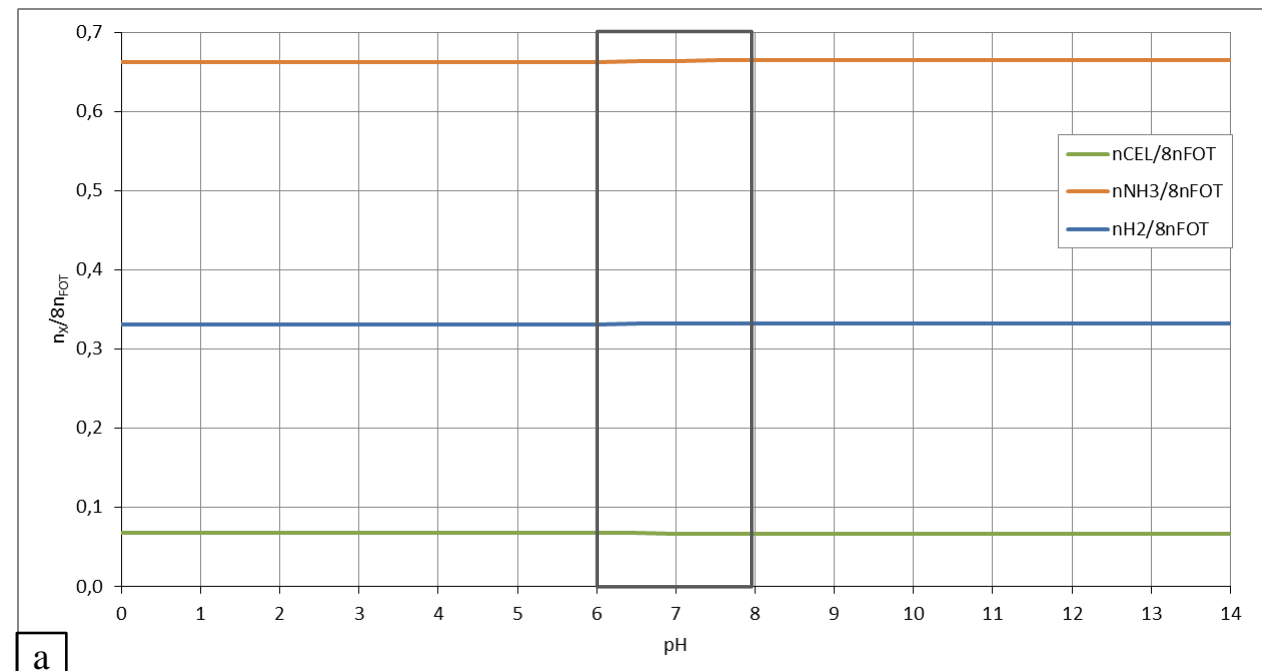

a

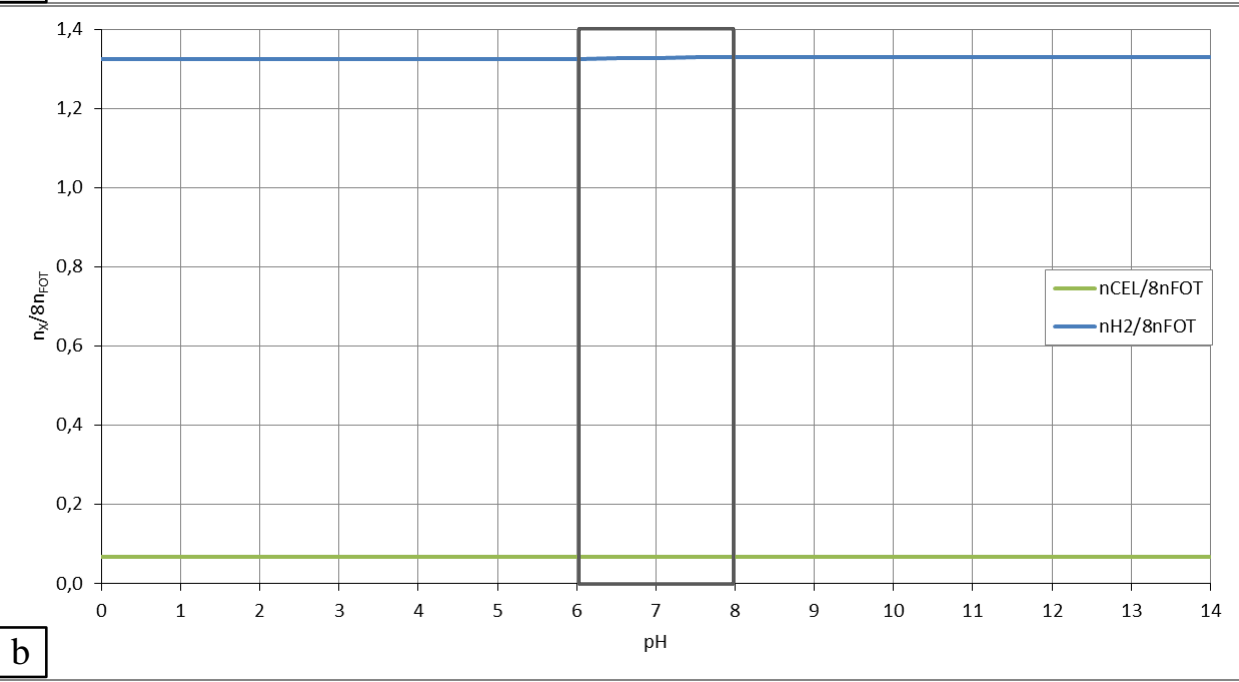

Figura 56. Rendimento dos produtos da biofotólise indireta pela atividade da nitrogenase com cianobactérias a) em presença e b) ausência de nitrogênio gasoso, em mols produzidas por 8 mols de fótons em função do $\mathrm{pH}\left(\mathrm{T}=25^{\circ} \mathrm{C}, \mathrm{p}_{\mathrm{H} 2}=1,00 \times 10^{-3} \mathrm{~atm}\right)$.

A Figura 58 apresenta a distribuição dos elétrons transferidos do doador (água) aos produtos reduzidos produzidos na biofotólise indireta pela atividade da nitrogenase com cianobactérias em presença (Reações 66 e 67) e ausência (Reações 66 e 68) de nitrogênio gasoso, em função do $\mathrm{pH}$ para $25^{\circ} \mathrm{C}$.

Os resultados das frações de elétrons quando o nitrogênio gasoso está presente ou ausente confirmam a distribuição e a proporção enquanto aos rendimentos mencionadas antes.

\subsection{Eficiências energéticas da fotossíntese oxigênica}

A partir dos rendimentos dos produtos de armazenamento da fotossíntese oxigênica 
(Figuras 50 e 51) se determinam as eficiências na conversão de energia solar em energia química atingidas pelas microalgas e as cianobactérias usando a Equação 91.

$$
\eta=\frac{\left(n_{i} / 8 n_{F O T} \times \Delta_{C} H_{i}^{\circ}\right)}{8 E_{f}(\lambda)} \times 100
$$

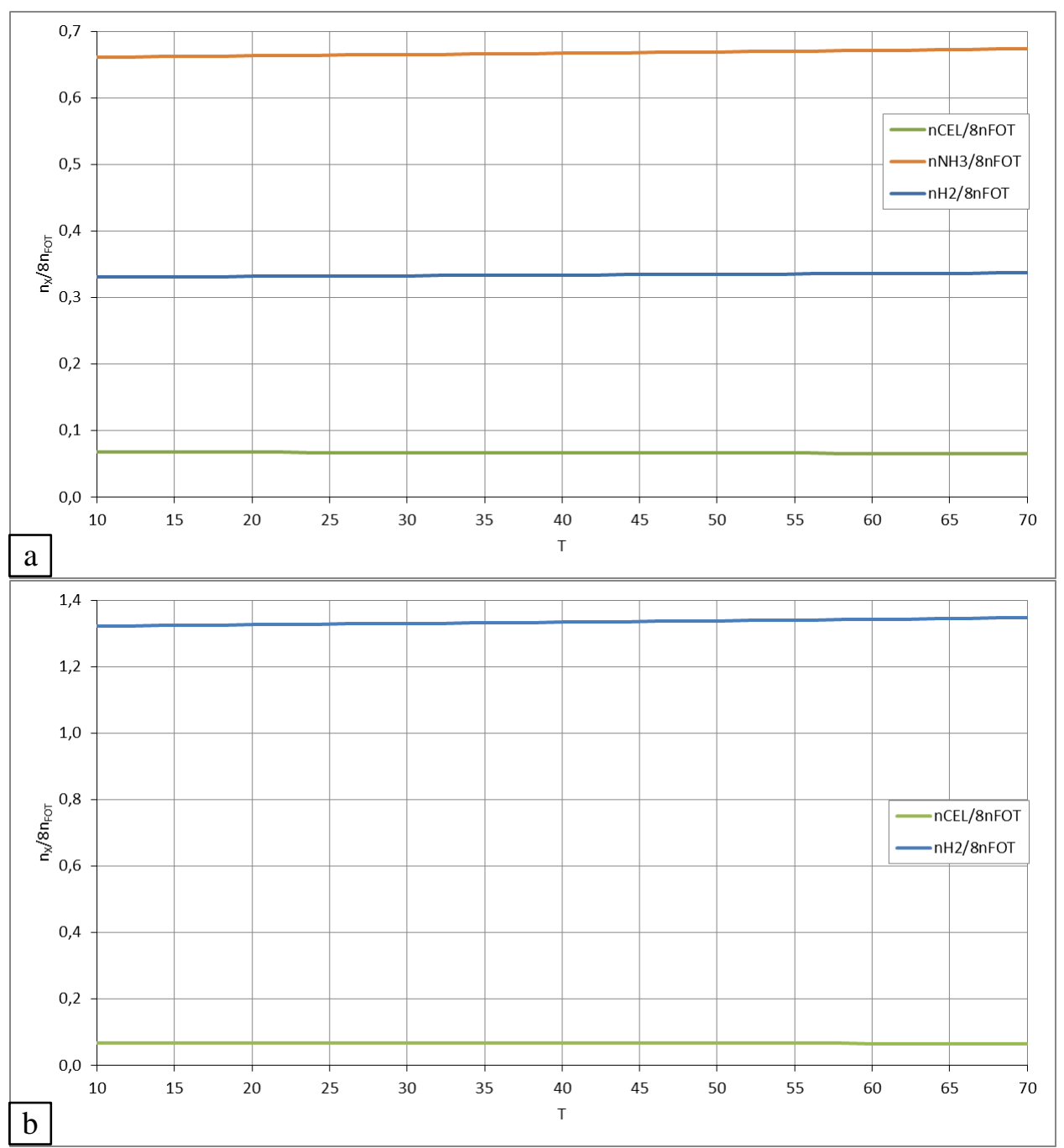

Figura 57. Rendimento dos produtos da biofotólise indireta pela atividade da nitrogenase com cianobactérias a) em presença e b) ausência de nitrogênio gasoso, em mols produzidas por 8 mols de fótons em função da temperatura $\left(\mathrm{pH}=7,00, \mathrm{p}_{\mathrm{H} 2}=1,00 \times 10^{-3} \mathrm{~atm}\right)$.

$\mathrm{Na}$ qual $\eta$ é a eficiência da fotossíntese oxigênica, $n_{i}$ é o número de mols do componente $i$ (glicose ou ácido palmítico) e $\Delta_{C} H_{i}^{\circ}$ é a entalpia padrão de combustão do componente $i\left(-2801,4 \mathrm{~kJ}^{m_{0}} l_{\mathrm{GLU}^{-1}}\right.$ para glicose e $-10030,7 \mathrm{~kJ}^{\text {mol}} \mathrm{PAL}^{-1}$ para ácido palmítico). Cabe salientar que nestas estimativas não se considera a fração da energia solar que se 
converte em energia química representada pelas células dos microorganismos.

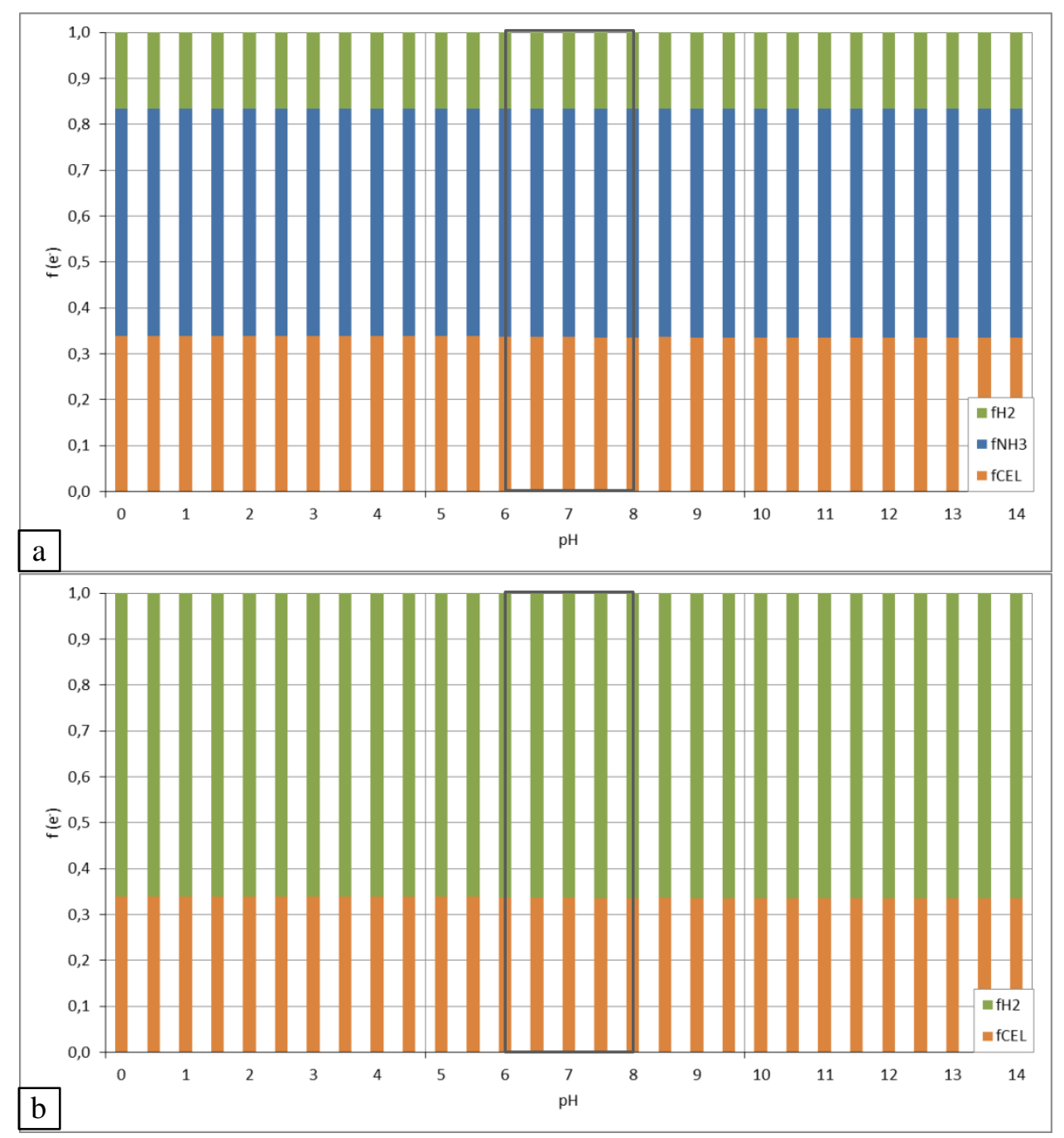

Figura 58. Fração de elétrons transferidos d'água a cada produto reduzido na biofotólise indireta pela atividade da nitrogenase com cianobactérias a) em presença e b) ausência de nitrogênio gasoso, em função do $\mathrm{pH}\left(\mathrm{T}=25^{\circ} \mathrm{C}, \mathrm{p}_{\mathrm{H} 2}=1,00 \times 10^{-3} \mathrm{~atm}\right)$.

Os resultados da eficiência da fotossíntese oxigênica para produção de glicose com microalgas (Reação 62) e cianobactérias (Reação 66) e ácido palmítico com microalgas (Reação 65) são apresentados na Figura 59, em função do pH e da temperatura.

Os resultados mostram que as eficiências da fotossíntese oxigênica na conversão de energia solar em energia química não são influídos pelo $\mathrm{pH}$ enquanto a temperatura tem um efeito muito débil. As eficiências atingidas pela fotossíntese oxigênica para a produção de glicose são muito parecidas para microalgas e cianobactérias, sendo um pouco maior a eficiência com microalgas. Além disso, essas eficiências são aproximadamente um 10\% 
superiores que as obtidas para a produção de ácido palmítico.

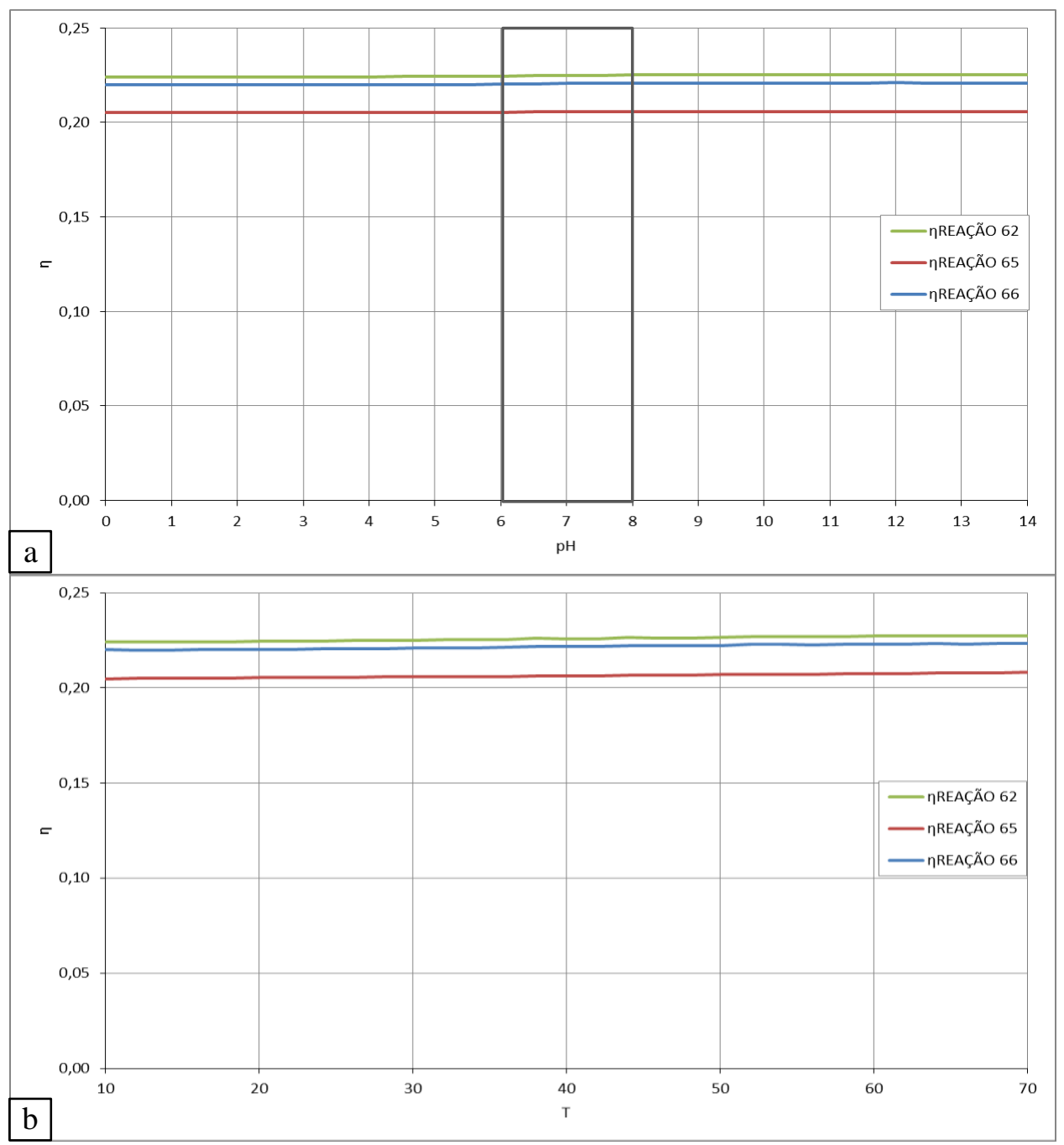

Figura 59. Eficiência da fotossíntese oxigênica para produção de glicose com microalgas e cianobactérias e ácido palmítico com microalgas, em função a) do $\mathrm{pH}\left(\mathrm{T}=25^{\circ} \mathrm{C}, \mathrm{p}_{\mathrm{H} 2}=\right.$ $\left.1,00 \times 10^{-3} \mathrm{~atm}\right)$ e b) da temperatura $\left(\mathrm{pH}=7,00, \mathrm{p}_{\mathrm{H} 2}=1,00 \times 10^{-3} \mathrm{~atm}\right)$.

A energia solar contida nos fótons que efetivamente participam nas reações fotossintéticas e que não é usada para a síntese celular e de produtos de armazenamento se transfere como calor (entalpia) aos redores (universo).

Por outro lado, a partir dos rendimentos da biofotólise indireta para a produção de hidrogênio por fermentação com microalgas e cianobactérias (Figuras 53 e 54) e por fixação de nitrogênio com cianobactérias (Figuras 56 e 57) se determinam as eficiências na conversão de energia solar em energia química usando a Equação 91, mas com o número de mols de hidrogênio e a entalpia padrão de combustão de hidrogênio $\left(-285,8 \mathrm{~kJ}\right.$ mol $\left._{\mathrm{H} 2}{ }^{-1}\right)$. Nestes processos, o hidrogênio representa a energia química recuperada, mas se produze a partir da 
glicose que atua como intermediário nos processos de biofotólise indireta. Cabe salientar também que nestas estimativas da eficiência, parte da energia solar fica contida nas células dos microorganismos e nos outros produtos das fermentações e não se considera nos cálculos.

Os resultados da eficiência da biofotólise indireta por fermentação com microalgas na luz (Reações 62 e 63) e na escuridão (Reações 62 e 64), e cianobactérias na escuridão (Reações 66 e 69), e pela atividade da nitrogenase em cianobactérias em presença (Reações 66 e 67) e ausência de nitrogênio gasoso (Reações 66 e 68) são apresentados na Figura 60, em função do $\mathrm{pH}$ e da temperatura.

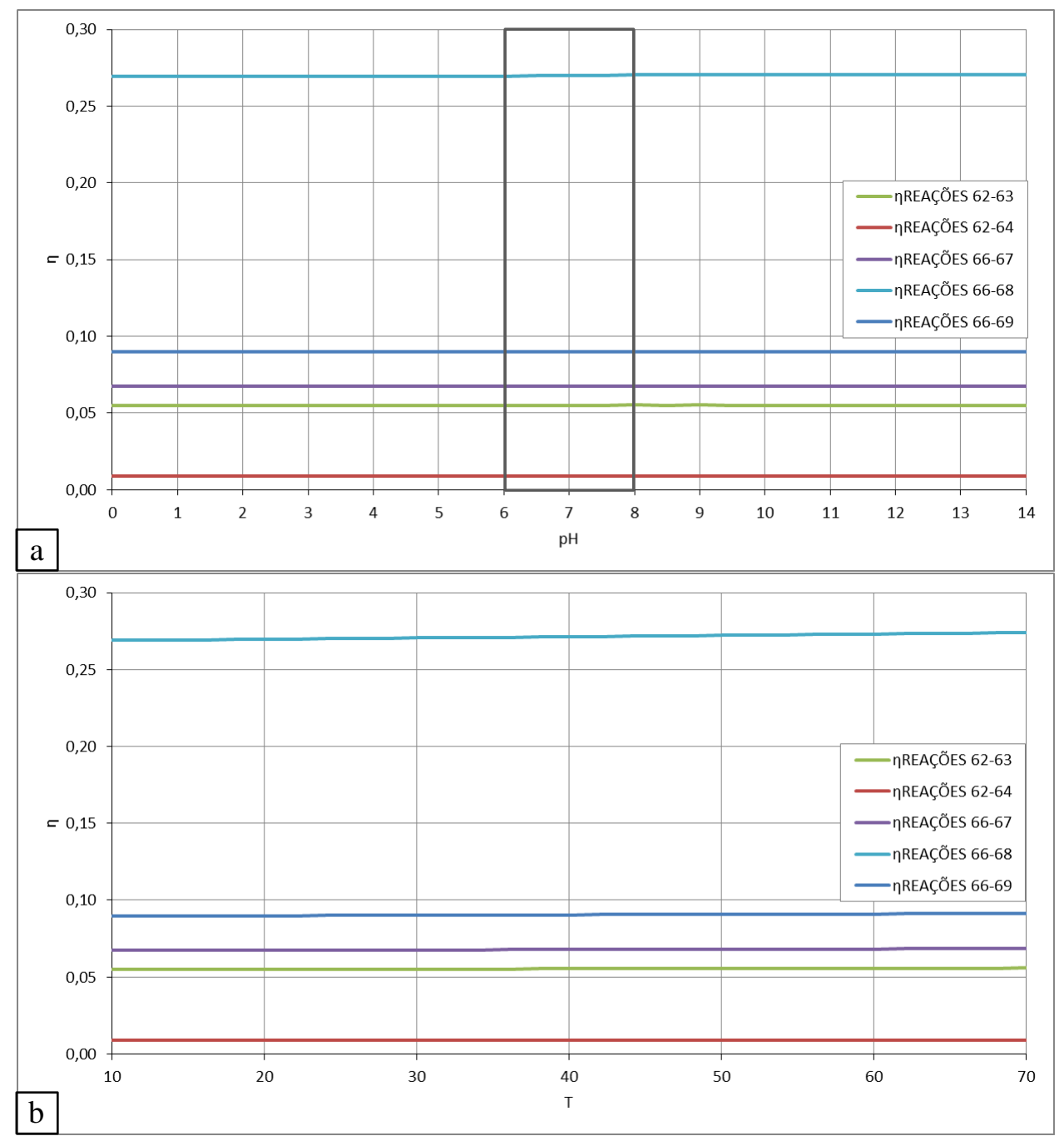

Figura 60. Eficiência da biofotólise indireta por fermentação com microalgas e cianobactérias e pela atividade da nitrogenase com cianobactérias, em função a) do $\mathrm{pH}\left(\mathrm{T}=25^{\circ} \mathrm{C}, \mathrm{p}_{\mathrm{H} 2}=\right.$ $\left.1,00 \times 10^{-3} \mathrm{~atm}\right)$ e b) da temperatura $\left(\mathrm{pH}=7,00, \mathrm{p}_{\mathrm{H} 2}=1,00 \times 10^{-3} \mathrm{~atm}\right)$. 
Neste caso, os resultados mostram que as eficiências da biofotólise indireta na conversão de energia solar em energia química não são influídos pelo $\mathrm{pH}$ nem pela temperatura. Para as fermentações, a maior eficiência se atinge pelas cianobactérias porquanto se trata de uma fermentação homoacética na qual o acetato é o único produto extra da fermentação. Nesta fermentação, as eficiências são da ordem de 40 e $90 \%$ superiores que as atingidas pela fermentação com microalgas na luz e na escuridão, respetivamente. Essas fermentações com microalgas atingem menores eficiências dada a maior quantidade de outros produtos reduzidos diferentes do hidrogênio. Para a atividade da nitrogenase, obviamente a maior eficiência se atinge quando o nitrogênio gasoso está ausente porquanto todos os elétrons produzidos pela oxidação da glicose se usam para a produção de hidrogênio. Nesse caso, a eficiência é aproximadamente $75 \%$ superior que quando o nitrogênio gasoso está presente.

Nos resultados da eficiência da fotossíntese oxigênica da Figura 59, incertezas de \pm $5 \%$ em todas as energias livres e entalpias de reação geram variações de $\pm 1,5 \%$, aproximadamente, e na Figura 60, variações entre 0 para as eficiências menores e $\pm 1,5 \%$ para as eficiências maiores. Assim, como na digestão anaeróbia, é possível concluir que essas incertezas não afetam significativamente a distribuição das espécies no modelo biotermodinâmico.

\subsection{Conclusões}

- Na fotossíntese oxigênica, a espontaneidade do crescimento celular é garantida pelos altos valores de energia livre gerada pela captação da energia solar dos fótons nos sistemas fotossintéticos.

- O modelo biotermodinâmico para a fotossíntese oxigênica evidencia que a entropia do sistema diminui pela geração de produtos de menos entropia que os reagentes, e a exportação de entropia para o universo ocorre pela transferência de calor (entalpia).

- Independentemente de considerações cinéticas ou biológicas, o aumento da temperatura desfavorece levemente o rendimento das células na fotossíntese oxigênica, do ponto de vista termodinâmico.

- Todas as produções de hidrogênio por biofotólise indireta, tanto pelas fermentações da glicose quanto pela atividade da nitrogenase (cianobactérias), são processos espontâneos nos intervalos de $\mathrm{pH}$, pressões parciais de hidrogênio e temperaturas avaliados. 
- A produção de hidrogênio por fermentação atinge o maior rendimento em cianobactérias, nas quais se realiza uma fermentação homoacética, quando comparada com as fermentações em microalgas que são "heteroacéticas".

- Enquanto à produção de hidrogênio pela atividade da nitrogenase (cianobactérias), os resultados mostram que o rendimento quando o nitrogênio gasoso está ausente é 4 vezes superior que quando está presente, o que concorda com a estequiometria da fixação.

- Desconsiderando a fração da energia solar que se converte em células, a maior eficiência da produção de hidrogênio por biofotólise indireta se atinge com cianobactérias, tanto pela atividade da nitrogenase quanto por fermentação. 


\section{FOTOSSÍNTESE ANOXIGÊNICA}

\subsection{Metabolismo}

Os microorganismos fototróficos anoxigênicos aproveitam comprimentos de onda da luz solar complementarias às usadas pelos microorganismos fotossintéticos oxigênicos (Melnicki, Eroglu \& Melis, 2009). São, com poucas exceções, diazotróficos que fixam nitrogênio atmosférico $\left(\mathrm{N}_{2}\right)$ sob condições anóxicas e limitação de formas assimiláveis de nitrogênio (Boichenko, Greenbaum \& Seibert, 2004; Melnicki, Eroglu \& Melis, 2009). Ao contrário dos fototróficos oxigênicos, os fototróficos anoxigênicos possuem um único sistema fotossintético (PSI ou PSII) pelo que não geram uma força oxidante suficientemente forte para usar água como doador de elétrons (não produzem oxigênio) (Antal et al., 2012; Brune, 1995). Portanto, esses microorganismos requerem substratos orgânicos ou inorgânicos ricos em energia como doadores de elétrons, com potencial redox inferior (mais reduzidos) que a água (Boichenko, Greenbaum \& Seibert, 2004; Imhoff, 1995; Imhoff, Hiraishi \& Süling, 2015).

Nos microorganismos fototróficos anoxigênicos, polissacarídeos, poli- $\beta$ hidroxibutirato e poli-fosfatos podem estar presentes como produtos da biossíntese para armazenamento de energia (Imhoff, Hiraishi \& Süling, 2015; Koku et al., 2002). Na ausência de aceptores externos de elétrons estes substratos podem-se metabolizar na escuridão por fermentação (metabolismo endógeno) (Koku et al., 2002), porém muito lento (Imhoff, 1995).

Dentre os microorganismos fototróficos anoxigênicos classificam-se as bactérias verdes e púrpuras sulfurosas, bactérias verdes e púrpuras não sulfurosas e heliobactérias. As heliobactérias (Heliobacteriaceae) são microorganismos fotoorganotróficos estritamente anaeróbios, mas ao contrário das outras bactérias fototróficas anoxigênicas, encontra-se principalmente em solos (Madigan, 2015), pelo que não se consideram no desenvolvimento desta pesquisa.

Os metabolismos das bactérias verdes e púrpuras sulfurosas e não sulfurosas se esboçam a seguir.

\subsubsection{Bioquímica do metabolismo das bactérias verdes sulfurosas}

As bactérias verdes sulfurosas (Chlorobiaceae) possuem características fisiológicas 
altamente semelhantes (Imhoff, 1995) e pouca versatilidade metabólica (Madigan et al., 2015). São microorganismos com um único fotossistema similar a PSI (Dasgupta et al., 2010; Madigan et al., 2015; Sirevåg, 1995), estritamente anaeróbios e obrigatoriamente fotossintéticos, com metabolismo fotolitotrófico (Sirevåg, 1995). Como doadores de elétrons podem usar sulfeto $\left(\mathrm{H}_{2} \mathrm{~S}, \mathrm{HS}^{-}\right)$, principalmente, ou íon tiossulfato $\left(\mathrm{S}_{2} \mathrm{O}_{3}{ }^{2-}\right)$, ferro (II) e hidrogênio $\left(\mathrm{H}_{2}\right)$ (Overmann, 2015). O sulfeto usado como doador de elétrons e fonte de enxofre é oxidado a sulfato $\left(\mathrm{HSO}_{4}^{-}, \mathrm{SO}_{4}{ }^{2-}\right)$ com acumulação de enxofre elementar $\left(\mathrm{S}^{0}\right)$ como intermediário em glóbulos extracelulares (Imhoff, 1995; Madigan et al., 2015).

Nestas bactérias, os elétrons obtidos da oxidação do doador pela atividade do PSI se transportam pela bacterioclorofila P840, excitada pelos fótons, para reduzir $\mathrm{NAD}^{+}$a NADH (geração de poder redutor) por meio da ferredoxina (Boichenko, Greenbaum \& Seibert, 2004; Sirevåg, 1995). O poder redutor se usa para fotoassimilar a fonte de carbono inorgânico $\left(\mathrm{CO}_{2}\right.$, $\mathrm{HCO}_{3}{ }^{-}, \mathrm{CO}_{3}{ }^{2-}$ ) no ciclo redutivo dos ácidos tricarboxílicos (Sirevåg, 1995), que requer menos ATP por molécula fixada que o ciclo redutivo das pentoses-fosfato (ciclo de Calvin) (Overmann, 2015) usado por microalgas, cianobactérias e bactérias púrpuras sulfurosas e não sulfurosas (Madigan et al., 2015). A energia química (ATP) para este processo é obtida pela fotofosforilação cíclica na qual os elétrons não reduzem $\mathrm{NAD}^{+}$senão que se retornam de PSI à cadeia de transporte e geram uma força próton-motriz que suporta a síntese de ATP (Madigan et al., 2015). A fotoassimilação de carbono inorgânico produz material celular e glicogênio como único composto de armazenamento (Sirevåg, 1995). Na escuridão, o glicogênio é fermentado para manutenção (metabolismo endógeno) produzindo acetato, propionato, caproato e succinato em um metabolismo muito lento (Overmann, 2015). Para a formação de acetato, por exemplo, a glicose (do glicogênio) pode seguir o processo fermentativo apresentado na Seção 4.1.1 (Figura 4) produzindo o poder redutor (NADH) e a energia química (ATP) necessários para a manutenção celular. Estes processos se apresentam na Figura 61.

As bactérias verdes sulfurosas podem fotoassimilar substratos orgânicos simples na presença de sulfeto $\left(\mathrm{H}_{2} \mathrm{~S}, \mathrm{HS}^{-}\right)$e bicarbonato $\left(\mathrm{CO}_{2}, \mathrm{HCO}_{3}{ }^{-}, \mathrm{CO}_{3}{ }^{2-}\right)$ em um metabolismo mixotrófico (Imhoff, 1995; Overmann, 2015; Sirevåg, 1995). Dos substratos orgânicos que se podem fotoassimilar (acetato, propionato, piruvato, lactato, glutamato e glicose), o acetato é, por muito, o melhor substrato para o metabolismo (Imhoff, 1995; Sirevåg, 1995). A fotoassimilação do acetato se realiza pelo ciclo redutivo dos ácidos tricarboxílicos (Sirevåg, 1995) que precisa da oxidação de equivalentes de doador de elétrons e involucra uma ferredoxina reduzida (Overmann, 2015). 


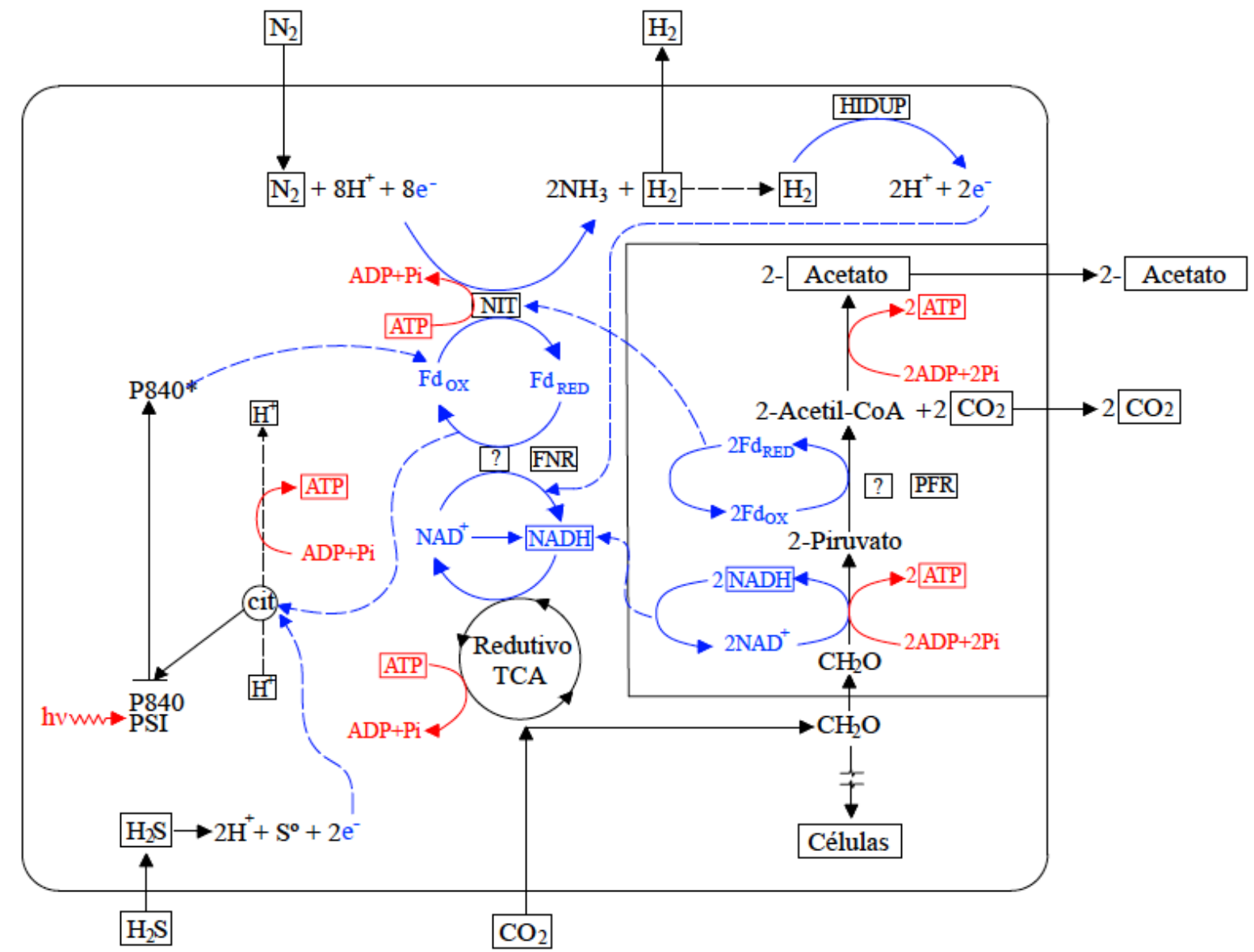

Figura 61. Fotossíntese anoxigênica em bactérias verdes sulfurosas.

Se a enzima PFR atua no processo, a transferência de elétrons pode ser direta à ferredoxina. Se essa transferência se realiza por meio do $\mathrm{NAD}(\mathrm{P}) \mathrm{H}$, a enzima FNR ou uma similar deve estar presente na transferência de elétrons do $\mathrm{NAD}(\mathrm{P}) \mathrm{H}$ à ferredoxina. A figura detalha o processo catabólico. No processo anabólico de, por exemplo, a formação de novas células, se produz um intermediário energético como acetil-CoA. PFR: Piruvato ferredoxina oxidorredutase. FNR: Ferredoxina NAD(P) ${ }^{+}$ redutase. NIT: Nitrogenase. HIDUP: Hidrogenase de assimilação. cit: Citocromo. Redutivo TCA: Ciclo redutivo dos ácidos tricarboxílicos.

Metabolismo quimiolitotrófico nunca tem sido observado sob nenhuma condição nutricional (Verméglio, Joliot \& Joliot I., 1995).

Finalmente, a evidência indica que a fixação de nitrogênio atmosférico $\left(\mathrm{N}_{2}\right)$ é uma característica metabólica amplamente difundida no gênero das bactérias verdes sulfurosas (Madigan, 1995). A fixação ocorre em anaerobiose estrita e sob limitação de formas assimiláveis de nitrogênio por meio da nitrogenase (Reação 58), que obtém o poder redutor (NADH) e a energia química (ATP) necessários por meio do metabolismo fotossintético (luz) ou fermentativo (escuridão) apresentados. O hidrogênio produzido como subproduto pode-se oxidar pela hidrogenase de assimilação (Reação 59) (Dasgupta et al., 2010), prevenindo a 
perda de energia e poder redutor (Boichenko, Greenbaum \& Seibert, 2004; Yeager et al., 2011).

\subsubsection{Bioquímica do metabolismo das bactérias púrpuras sulfurosas}

As bactérias púrpuras sulfurosas (Chromatiaceae e Ectothiorhodospiraceae) são microorganismos com metabolismo fototrófico e quimiotrófico, que podem usar sulfeto $\left(\mathrm{H}_{2} \mathrm{~S}\right.$, $\mathrm{HS}^{-}$), íon tiossulfato $\left(\mathrm{S}_{2} \mathrm{O}_{3}{ }^{2-}\right)$, ferro (II), hidrogênio $\left(\mathrm{H}_{2}\right)$ e compostos orgânicos como doadores de elétrons (Imhoff, 2015). Os microorganismos fototróficos são fotossintéticos anoxigênicos com um único fotossistema similar a PSII (Boichenko, Greenbaum \& Seibert, 2004; Dasgupta et al., 2010; Madigan et al., 2015).

$\mathrm{Na}$ família Chromatiaceae se distinguem dois grupos: especializadas e versáteis. As especializadas são estritamente anaeróbias e obrigatoriamente fotossintéticas, com metabolismo fotolitotrófico sobre sulfeto $\left(\mathrm{H}_{2} \mathrm{~S}, \mathrm{HS}^{-}\right)$como doador de elétrons e fonte de enxofre, e podem fotoassimilar substratos orgânicos simples (acetato, propionato ou piruvato) na presença de sulfeto e bicarbonato $\left(\mathrm{CO}_{2}, \mathrm{HCO}_{3}{ }^{-}, \mathrm{CO}_{3}{ }^{2-}\right)$ em um metabolismo mixotrófico (Imhoff, 1995). As versáteis são anaeróbias e fotossintéticas, com metabolismo fotolitotrófico sobre enxofre reduzido como doador de elétrons (sulfeto e tiossulfato) e, na ausência de enxofre reduzido, metabolismo fotoorganotrófico sobre doadores de elétrons orgânicos e sulfato $\left(\mathrm{HSO}_{4}^{-}, \mathrm{SO}_{4}{ }^{2-}\right)$ como fonte de enxofre. Podem exibir metabolismo mixotrófico ao fotoassimilar um grande número de substratos orgânicos na presença de sulfeto e bicarbonato e crescer também quimiotroficamente (Imhoff, 1995). Muitas espécies podem crescer fotolitotrófica ou fotoorganotroficamente, algumas espécies na escuridão podem fazê-lo quimiolitotroficamente e poucas espécies quimioorganotroficamente (Imhoff, 1995). O metabolismo quimiolitotrófico destas espécies na escuridão, com compostos de enxofre reduzidos como doador de elétrons (Brune, 1995), suporta condições micro-óxicas até óxicas com taxas de crescimento extremamente baixas, o que sugere que esta via metabólica não é essencial no metabolismo energético destes microorganismos (Verméglio, Joliot \& Joliot I., 1995). Sob condições apropriadas de crescimento (anaeróbias e fotolitotróficas), as bactérias da família Chromatiaceae oxidam sulfeto a sulfato com acumulação de enxofre elementar $\left(\mathrm{S}^{0}\right)$ como intermediário em glóbulos intracelulares (Imhoff, 1995; Madigan et al., 2015).

Nas bactérias púrpuras sulfurosas, os elétrons obtidos da oxidação do doador pela atividade do PSII se transportam pela bacterioclorofila P870, excitada pelos fótons, a uma quinona; mas, diferentemente das bactérias verdes sulfurosas, esta quinona não têm potencial 
redox suficientemente baixo para fotoreduzir a ferredoxina (Boichenko, Greenbaum \& Seibert, 2004; Sirevåg, 1995) e produzir NADH diretamente (Dasgupta et al., 2010). Para gerar poder redutor $(\mathrm{NADH})$, os elétrons se forçam a regressar desde a quinona para reduzir $\mathrm{NAD}^{+}$a NADH por meio de um fluxo reverso de elétrons (Boichenko, Greenbaum \& Seibert, 2004; Dasgupta et al., 2010). Não obstante, o PSII pode gerar energia química (ATP) pela fotofosforilação cíclica (Boichenko, Greenbaum \& Seibert, 2004; Dasgupta et al., 2010). O poder redutor e a energia química se usam para fotoassimilar a fonte de carbono inorgânico $\left(\mathrm{CO}_{2}, \mathrm{HCO}_{3}{ }^{-}, \mathrm{CO}_{3}{ }^{2-}\right)$, realizada pelo ciclo redutivo das pentoses-fosfato (ciclo de Calvin) (Imhoff, 2015; Madigan et al., 2015), para produzir material celular e compostos de armazenamento; estes últimos podem-se fermentar na escuridão para manutenção (metabolismo endógeno) mediante fermentação como apresentado na Seção 4.1.1 (Figura 4) e discutido para bactérias verdes sulfurosas (Seção 6.1.1). Estes processos se apresentam na Figura 62.

As bactérias da família Ectothiorhodospiraceae crescem fototrófica e quimiotroficamente em ambientes salinos e alcalinos; muitas espécies são extremamente halófilas e alcalófilas e estão entre as bactérias mais extremas conhecidas (Madigan et al., 2015). Quando o metabolismo é fotolitotrófico oxidam sulfeto a sulfato com acumulação de enxofre elementar $\left(\mathrm{S}^{0}\right)$ como intermediário em glóbulos extracelulares, e alguns gêneros são estritamente quimiotróficos (Imhoff, 1995; Imhoff, 2015).

Nas bactérias verdes e púrpuras sulfurosas, os glóbulos de enxofre elementar $\left(\mathrm{S}^{0}\right)$ permanecem enquanto a fonte de enxofre reduzido está presente; quando se esgota, o enxofre elementar é oxidado a sulfato $\left(\mathrm{HSO}_{4}^{-}, \mathrm{SO}_{4}{ }^{2-}\right.$ ) (Madigan et al., 2015). Por outro lado, nas bactérias púrpura sulfurosas a afinidade pelo acetato é uma ordem de magnitude menor que nas bactérias verdes sulfurosas, mas a afinidade pelo sulfeto é uma ordem maior (Overmann, 2015). Finalmente, ao igual que as bactérias verdes sulfurosas, a fotoassimilação de substratos orgânicos se realiza pelo ciclo redutivo dos ácidos tricarboxílicos (Boichenko, Greenbaum \& Seibert, 2004) e a fixação de nitrogênio é uma característica metabólica amplamente difundida entre os gêneros destas bactérias (Madigan, 1995). O metabolismo fotossintético apresentado e fermentativo fornecem o poder redutor (NADH) e a energia química (ATP) à nitrogenase para fixar nitrogênio em anaerobiose estrita e sob limitação de formas assimiláveis (Reação 58) e o hidrogênio produzido pode-se oxidar pela hidrogenase de assimilação (Reação 59) (Dasgupta et al., 2010). 


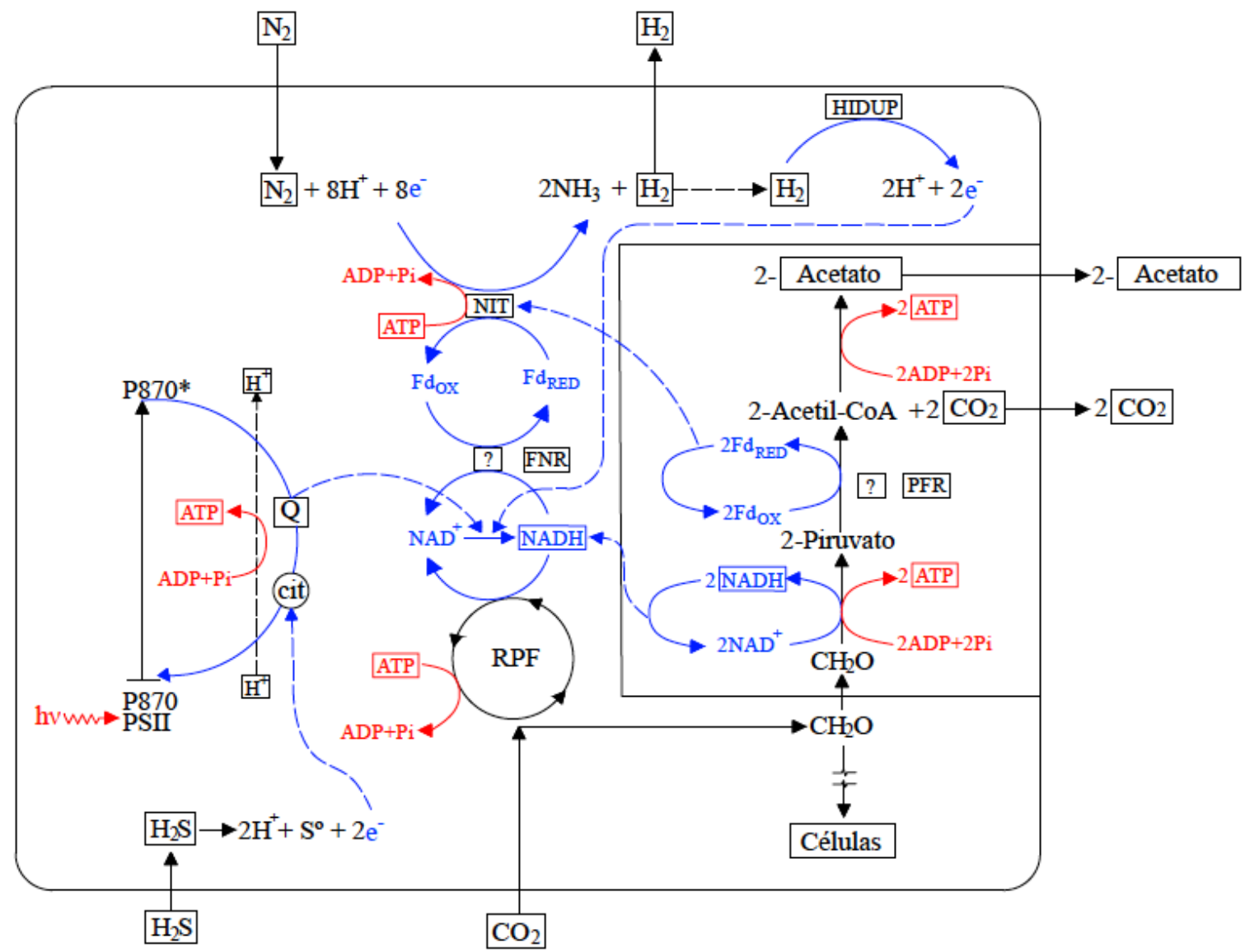

Figura 62. Fotossíntese anoxigênica em bactérias púrpuras sulfurosas.

Se a enzima PFR atua no processo, a transferência de elétrons pode ser direta à ferredoxina. Se essa transferência se realiza por meio do $\mathrm{NAD}(\mathrm{P}) \mathrm{H}$, a enzima FNR ou uma similar deve estar presente na transferência de elétrons do $\mathrm{NAD}(\mathrm{P}) \mathrm{H}$ à ferredoxina. A figura detalha o processo catabólico. No processo anabólico de, por exemplo, a formação de novas células, se produz um intermediário energético como acetil-CoA. PFR: Piruvato ferredoxina oxidorredutase. FNR: Ferredoxina NAD $(\mathrm{P})^{+}$ redutase. NIT: Nitrogenase. HIDUP: Hidrogenase de assimilação. Q: Quinona. cit: Citocromo. RPF: Ciclo redutivo das pentoses-fosfato.

\subsubsection{Bioquímica do metabolismo das bactérias verdes não sulfurosas}

As bactérias verdes não sulfurosas (Chloroflexaceae) são microorganismos fototróficos e quimiotróficos (Sirevåg, 1995), não estreitamente relacionadas com as bactérias verdes sulfurosas (Verméglio, Joliot \& Joliot I., 1995), e que usualmente habitam fontes termais com baixas concentrações de compostos orgânicos nas quais coexistem com cianobactérias, as quais são o produtor primário para seu metabolismo fotoorganotrófico (Madigan et al., 2015; Zannoni, 1995). Os microorganismos fototróficos são fotossintéticos anoxigênicos com um único fotossistema similar a PSII (Madigan et al., 2015; Sirevåg, 1995). 
Uma variedade de compostos orgânicos (acetato, piruvato, lactato, butirato, ácidos dicarboxílicos, alguns álcoois, açúcares e aminoácidos) se usam como doadores de elétrons para metabolismo fotoorganotrófico anoxigênico e, na escuridão, quimioorganotrófico aeróbio (Madigan et al., 2015; Sirevåg, 1995). Finalmente, estas bactérias também podem exibir metabolismo fotolitotrófico usando sulfeto $\left(\mathrm{H}_{2} \mathrm{~S}, \mathrm{HS}^{-}\right)$ou hidrogênio $\left(\mathrm{H}_{2}\right)$, mas o metabolismo é muito lento (Madigan et al., 2015; Sirevåg, 1995).

Em metabolismo fotoorganotrófico, as bactérias verdes não sulfurosas geram o poder redutor $(\mathrm{NADH})$ e a energia química (ATP) por processos similares aos descritos para bactérias púrpuras sulfurosas (Seção 6.1.2), mas usando a bacterioclorofila P840 das bactérias verdes sulfurosas (Seção 6.1.1) (Madigan et al., 2015). O poder redutor e a energia química se usam para assimilar substratos orgânicos e produzir material celular e glicogênio ou poli- $\beta$ hidroxibutirato como compostos de armazenamento (Sirevåg, 1995); estes últimos podem-se fermentar na escuridão para manutenção (metabolismo endógeno) mediante uma fermentação como apresentado na Seção 4.1.1 (Figura 4) e discutido para bactérias verdes sulfurosas (Seção 6.1.1). Estes processos se apresentam na Figura 63.

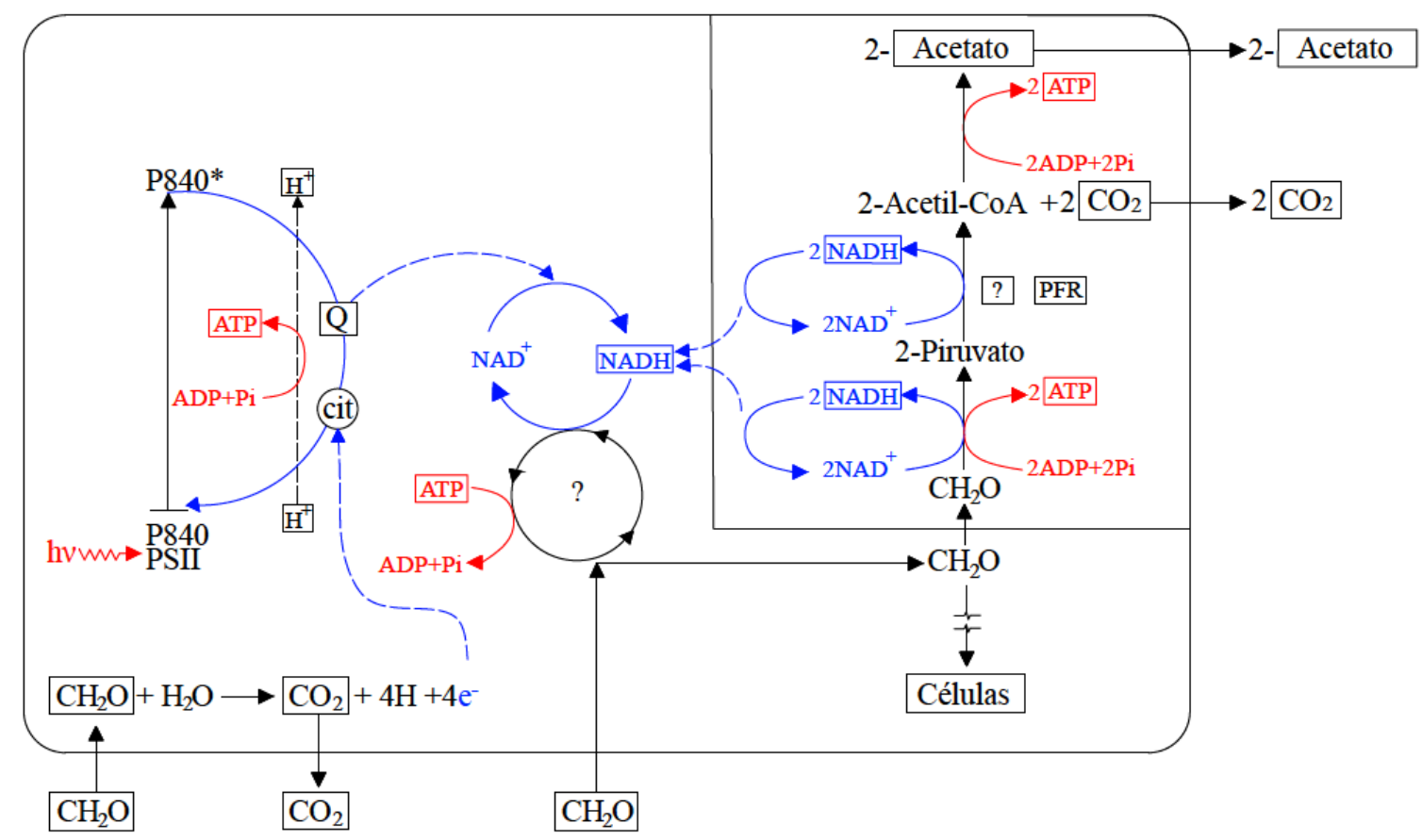

Figura 63. Fotossíntese anoxigênica em bactérias verdes não sulfurosas.

A figura detalha o processo catabólico. No processo anabólico de, por exemplo, a formação de novas células, se produz um intermediário energético como acetil-CoA. PFR: Piruvato ferredoxina oxidorredutase. Q: Quinona. cit: Citocromo. 
No metabolismo fotolitotrófico, a fotoassimilação da fonte de carbono $\left(\mathrm{CO}_{2}, \mathrm{HCO}_{3}{ }^{-}\right.$, $\mathrm{CO}_{3}{ }^{2-}$ ) se realiza pelo ciclo do 3-hidroxipropionato (Madigan et al., 2015; Sirevåg, 1995), enquanto no metabolismo quimioorganotrófico a assimilação de, por exemplo, acetato se realiza pelo ciclo do glioxilato (Sirevåg, 1995).

Respeito à fixação de nitrogênio, é possível que estas bactérias possuam esta característica metabólica, mas até o momento não tem sido cultivadas (Madigan, 1995).

\subsubsection{Bioquímica do metabolismo das bactérias púrpuras não sulfurosas}

As bactérias púrpuras não sulfurosas (Alphaproteobactéria e Betaproteobactéria) são o mais diverso grupo dos microorganismos fototróficos anoxigênicos (Imhoff, 1995) e possuem notável diversidade metabólica (Madigan, 1995; Madigan et al., 2015); tanta que são provavelmente os organismos metabolicamente mais diversos da natureza (Tabita, 1995). São microorganismos com metabolismo fototrófico e quimiotrófico, que usam preferencialmente um amplo intervalo de compostos orgânicos (ácidos orgânicos, álcoois primários e secundários, carboidratos, proteínas e compostos aromáticos) como doadores de elétrons, e sulfeto $\left(\mathrm{H}_{2} \mathrm{~S}, \mathrm{HS}^{-}\right)$, íon tiossulfato $\left(\mathrm{S}_{2} \mathrm{O}_{3}{ }^{2-}\right)$, ferro (II), hidrogênio $\left(\mathrm{H}_{2}\right)$ como doadores alternativos (Imhoff, Hiraishi \& Süling, 2015; Madigan et al., 2015). Bastante característico é o metabolismo fotossintético anoxigênico dos microorganismos fototróficos (fotoorganotrófico e fotolitotrófico) (Imhoff, Hiraishi \& Süling, 2015); microorganismos com um único fotossistema similar a PSII (Madigan et al., 2015). Nos gêneros destas bactérias a capacidade de fixar nitrogênio é quase universal e pode-se realizar na luz e na escuridão (Imhoff, 2015; Madigan, 1995; Madigan et al., 2015) em anaerobiose estrita e sob limitação de formas assimiláveis.

No metabolismo fotoorganotrófico, o aparato fotossintético fornece suficiente energia química (ATP) e poder redutor (elétrons); assim, os compostos orgânicos exógenos assimilados podem-se transformar diretamente em material celular produzindo um incremento na taxa de crescimento e um alto rendimento de biomassa celular (Sirevåg, 1995). A assimilação dos substratos orgânicos ocorre pelo ciclo redutivo dos ácidos tricarboxílicos (Boichenko, Greenbaum \& Seibert, 2004; Koku et al., 2002) e produz material celular e compostos de armazenamento. O poder redutor (NADH) e a energia química (ATP) necessários para esta assimilação se geram por processos fotossintéticos similares aos descritos para bactérias púrpuras sulfurosas (Seção 6.1.2). Os compostos de armazenamento podem-se fermentar na escuridão para manutenção (metabolismo endógeno) mediante 
fermentação como apresentado na Seção 4.1.1 (Figura 4) e discutido para bactérias verdes sulfurosas (Seção 6.1.1). Para fixar nitrogênio, em anaerobiose estrita e sob limitação de formas assimiláveis (Reação 58), o poder redutor e a energia química se fornecem à nitrogenase pelo metabolismo fotossintético e fermentativo. $\mathrm{O}$ hidrogênio produzido irreversivelmente como subproduto da fixação de nitrogênio pode-se oxidar pela hidrogenase de assimilação (Reação 59) (Dasgupta et al., 2010). Estes processos se apresentam na Figura 64.

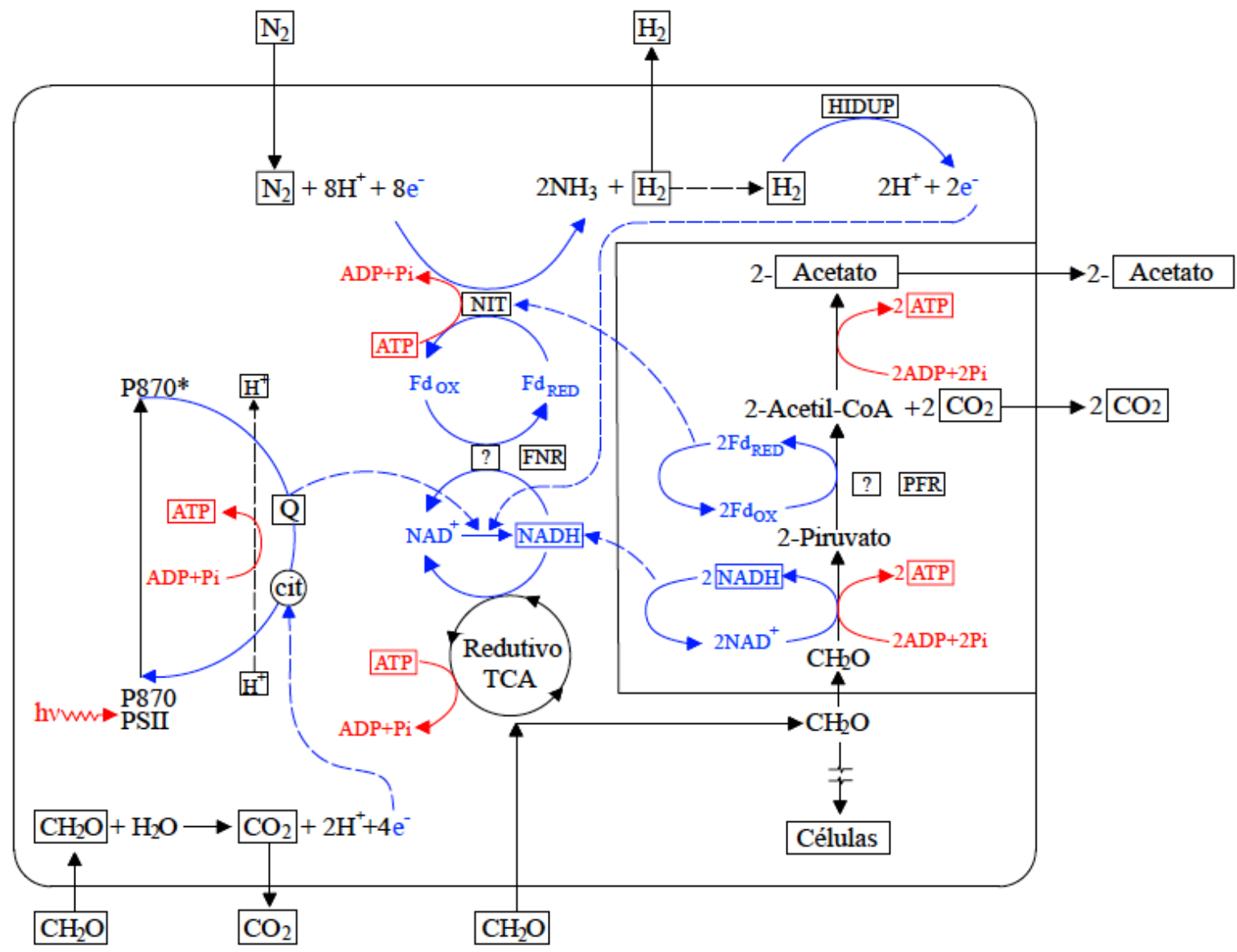

Figura 64. Fotossíntese anoxigênica em bactérias púrpuras não sulfurosas.

Se a enzima PFR atua no processo, a transferência de elétrons pode ser direta à ferredoxina. Se essa transferência se realiza por meio do $\mathrm{NAD}(\mathrm{P}) \mathrm{H}$, a enzima FNR ou uma similar deve estar presente na transferência de elétrons do $\mathrm{NAD}(\mathrm{P}) \mathrm{H}$ à ferredoxina. A figura detalha o processo catabólico. No processo anabólico de, por exemplo, a formação de novas células, se produz um intermediário energético como acetil-CoA. PFR: Piruvato ferredoxina oxidorredutase. FNR: Ferredoxina NAD(P) ${ }^{+}$ redutase. NIT: Nitrogenase. HIDUP: Hidrogenase de assimilação. Q: Quinona. cit: Citocromo. Redutivo TCA: Ciclo redutivo dos ácidos tricarboxílicos.

Para o metabolismo fotolitotrófico, a fotoassimilação da fonte de carbono inorgânico 
$\left(\mathrm{CO}_{2}, \mathrm{HCO}_{3}{ }^{-}, \mathrm{CO}_{3}{ }^{2-}\right)$ se realiza pelo ciclo redutivo das pentoses fosfato (ciclo de Calvin) (Imhoff, Hiraishi \& Süling, 2015; Madigan et al., 2015; Tabita, 1995). Esta fotoassimilação parece ser uma parte do metabolismo celular global ainda quando o metabolismo seja organotrófico (Koku et al., 2002).

$\mathrm{Na}$ escuridão, a maioria das espécies exibem metabolismo quimiotrófico (quimiolitotrófico e quimioorganotrófico) sob condições micro-óxicas até óxicas e, em condições anóxicas, exibem metabolismo fermentativo ou metabolismo oxidativo com açúcares como doadores elétrons e íons nitrato como aceptores (respiração anaeróbia, desnitrificação) (Imhoff, 1995; Imhoff, Hiraishi \& Süling, 2015; Madigan, 1995; Madigan et al., 2015).

Enquanto bactérias da classe Alphaproteobactéria em metabolismo fotolitotrófico podem usar sulfeto como doador de elétrons, oxidando-o só até enxofre elementar $\left(\mathrm{S}^{0}\right)$ (Imhoff, 1995). Bactérias da classe Betaproteobactéria não usam compostos de enxofre reduzidos como doadores fotossintéticos de elétrons e, ainda, o sulfeto em baixas concentrações inibe o metabolismo (Imhoff, Hiraishi \& Süling, 2015).

\subsection{Aplicação do modelo-resultados e discussão}

O modo de metabolismo preferencial das bactérias verdes e púrpuras sulfurosas é o fotolitotrófico anoxigênico, enquanto o metabolismo fotoorganotrófico anoxigênico sob diferentes substratos é preferencial nas bactérias verdes e púrpuras não sulfurosas (Imhoff, 1995, Madigan, 1995). Entre os processos metabólicos especializados das bactérias fototróficas anoxigênicas (bactérias verdes sulfurosas e púrpuras sulfurosas e não sulfurosas), um dos mais importantes é a fixação de nitrogênio catalisada pela enzima nitrogenase (Madigan, 1995) na qual se produz simultaneamente hidrogênio (Reação 58). Além da nitrogenase, essas bactérias podem conter hidrogenases; porém a produção de hidrogênio nesses microorganismos se atribui à nitrogenase (Boichenko, Greenbaum \& Seibert, 2004; Dasgupta et al., 2010; Koku et al., 2002). Não obstante, o processo de fixação de nitrogênio ainda não foi descrito em bactérias verdes não sulfurosas (Madigan, 1995), pelo que esses microorganismos ficam fora das análises posteriores desta pesquisa.

Ao aplicar o modelo biotermodinâmico aos metabolismos dos processos fotossintéticos anoxigênicos discutidos, para condições diferentes da padrão, se obtêm as biorreações apresentados nas Seções 6.2.1 e 6.2.2, baseadas nas semi-reações da Tabela 3. Cabe lembrar que, para todas as figuras apresentadas nessas seções, o quadro representa o 
intervalo biológico típico de $\mathrm{pH}$ no qual são realizados os processos e, portanto, onde os resultados do modelo fazem maior sentido.

Finalmente, como na fotossíntese oxigênica com cianobactérias, nesta análise se desconsidera o efeito da hidrogenase de assimilação (Reação 59) na produção de hidrogênio pela nitrogenase, com o escopo de estimar as produções máximas de hidrogênio.

\subsubsection{Comportamento da fotossíntese anoxigênica com bactérias sulfurosas}

Os resultados da aplicação do modelo biotermodinâmico aos metabolismos das bactérias verdes sulfurosas discutidos na Seção 6.1.1, para um comprimento de onda de 840 $\mathrm{nm}$, e das bactérias púrpuras sulfurosas discutidos na Seção 6.1.2, para um comprimento de onda de $870 \mathrm{~nm}$, se apresentam nas Tabelas 26 a 31 (Reações 70 a 75), nas quais se inclui a estequiometria da reação para diferentes $\mathrm{pH}$ (temperatura de $25^{\circ} \mathrm{C}$ ), e nas Figuras 65 a 70 , com o comportamento da energia livre dissipada como função do $\mathrm{pH}$ e pressão parcial de hidrogênio (temperatura constante de $25{ }^{\circ} \mathrm{C}$ ) e do $\mathrm{pH}$ e temperatura (pressão parcial de hidrogênio constante de $\left.1,00 \times 10^{-3} \mathrm{~atm}\right)$.

Os comportamentos da energia livre na produção de bactérias verdes sulfurosas (Figura 65) e púrpuras sulfurosas (Figura 68) são muito parecidos; a única diferença é a quantidade dissipada. Nas bactérias verdes é dissipada mais energia livre que nas bactérias púrpuras porquanto os fótons que participam no primer processo $(\lambda=840 \mathrm{~nm})$ têm maior energia que os fótons do segundo $(\lambda=870 \mathrm{~nm})$. Por outro lado, o efeito do $\mathrm{pH}$ sobre a energia livre dissipada é pequeno, mostrando leves incrementos para $\mathrm{pH}$ superiores a 6,0. A pressão parcial de hidrogênio não influi na energia livre dissipada devido a que não é consumido nem produzido (Figuras 65a e 68a) enquanto o aumento da temperatura a diminui desfavorecendo a conversão (Figuras 65b e 68b), mas em uma pequena percentagem. Nestes processos de crescimento celular, a grande energia livre dissipada é gerada pela captação da energia dos fótons, garantindo altas conversões.

Os resultados de energia livre dissipada e entalpia das Tabelas 26 e 29 para as reações de crescimento celular (Reações 70 e 73) evidenciam que o metabolismo fotossintético anoxigênico diminui a entropia do sistema pela transformação de reagentes de entropia alta em produtos de entropia baixa e, como na fotossíntese oxigênica, o aumento da entropia do universo se produz pela transferência de calor (entalpia) dos microorganismos aos redores. 
Tabela 26. Biorreação do modelo biotermodinâmico e estequiometria $\left(\mathrm{T}=25^{\circ} \mathrm{C}\right)$ da produção de glicose com bactérias verdes sulfurosas.

\begin{tabular}{|c|c|c|c|}
\hline \multicolumn{2}{|c|}{ Reação 70} & $f_{s}^{\circ}$ & $\begin{array}{c}\Delta_{r} G^{\circ} \\
\Delta_{r} H^{\circ} \\
\left(\mathrm{kJ} \mathrm{e}^{-} \mathrm{eq}^{-1}\right) \\
\end{array}$ \\
\hline 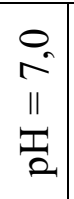 & $\begin{array}{l}4,53 \times 10^{-2} \mathrm{CO}_{2}+2,04 \times 10^{-1} \mathrm{HCO}_{3}^{-}+3,10 \times 10^{-2} \mathrm{NH}_{4}^{+}+3,13 \times 10^{-4} \mathrm{NH}_{3}+ \\
1,25 \times 10^{-3} \mathrm{H}_{2} \mathrm{PO}_{4}^{-}+6,27 \times 10^{-4} \mathrm{HPO}_{4}{ }^{2-}+2,67 \times 10^{-1} \mathrm{H}_{2} \mathrm{~S}+2,37 \times 10^{-1} \mathrm{HS}^{-}+ \\
4,12 \times 10^{-1} \mathrm{H}^{+}+2,00 \mathrm{~h} v \rightleftharpoons 3,13 \times 10^{-2} \mathrm{C}_{5} \mathrm{H}_{7} \mathrm{O}_{2} \mathrm{NP}_{0,06} \mathrm{~S}_{0,1}+1,54 \times 10^{-2} \mathrm{C}_{6} \mathrm{H}_{12} \mathrm{O}_{6} \\
+5,00 \times 10^{-1} \mathrm{~S}+3,20 \times 10^{-1} \mathrm{H}_{2} \mathrm{O}\end{array}$ & 0,63 & $\begin{array}{l}-240,5 \\
-291,9\end{array}$ \\
\hline $\begin{array}{l}n \\
2 \\
11 \\
x_{2} \\
2\end{array}$ & $\begin{array}{l}1,63 \times 10^{-2} \mathrm{CO}_{2}+2,32 \times 10^{-1} \mathrm{HCO}_{3}^{-}+4,67 \times 10^{-4} \mathrm{CO}_{3}{ }^{2-}+3,06 \times 10^{-2} \mathrm{NH}_{4}^{+}+ \\
6,25 \times 10^{-4} \mathrm{NH}_{3}+6,25 \times 10^{-4} \mathrm{H}_{2} \mathrm{PO}_{4}^{-}+1,25 \times 10^{-3} \mathrm{HPO}_{4}{ }^{2-}+1,31 \times 10^{-1} \mathrm{H}_{2} \mathrm{~S}+ \\
3,72 \times 10^{-1} \mathrm{HS}^{-}+5,78 \times 10^{-1} \mathrm{H}^{+}+2,00 \mathrm{~h} v \rightleftharpoons 3,13 \times 10^{-2} \mathrm{C}_{5} \mathrm{H}_{7} \mathrm{O}_{2} \mathrm{NP}_{0,06} \mathrm{~S}_{0,1}+ \\
1,54 \times 10^{-2} \mathrm{C}_{6} \mathrm{H}_{12} \mathrm{O}_{6}+5,00 \times 10^{-1} \mathrm{~S}+2,14 \times 10^{-1} \mathrm{H}_{2} \mathrm{O}\end{array}$ & 0,63 & $\begin{array}{l}-240,3 \\
-295,1\end{array}$ \\
\hline $\begin{array}{l}0 \\
\infty \\
11 \\
1 \\
\mathbb{2}_{2}\end{array}$ & $\begin{array}{l}5,45 \times 10^{-3} \mathrm{CO}_{2}+2,43 \times 10^{-1} \mathrm{HCO}_{3}^{-}+1,09 \times 10^{-3} \mathrm{CO}_{3}^{2-}+2,97 \times 10^{-2} \mathrm{NH}_{4}^{+}+ \\
1,57 \times 10^{-3} \mathrm{NH}_{3}+3,13 \times 10^{-4} \mathrm{H}_{2} \mathrm{PO}_{4}^{-}+1,57 \times 10^{-3} \mathrm{HPO}_{4}^{2-}+5,03 \times 10^{-2} \mathrm{H}_{2} \mathrm{~S}+ \\
4,53 \times 10^{-1} \mathrm{HS}^{-}+6,71 \times 10^{-1} \mathrm{H}^{+}+2,00 \mathrm{~h} v \rightleftharpoons 3,13 \times 10^{-2} \mathrm{C}_{5} \mathrm{H}_{7} \mathrm{O}_{2} \mathrm{NP}_{0,06} \mathrm{~S}_{0,1}+ \\
1,54 \times 10^{-2} \mathrm{C}_{6} \mathrm{H}_{12} \mathrm{O}_{6}+5,00 \times 10^{-1} \mathrm{~S}+1,44 \times 10^{-1} \mathrm{H}_{2} \mathrm{O}\end{array}$ & 0,63 & $\begin{array}{l}-240,2 \\
-297,0\end{array}$ \\
\hline
\end{tabular}
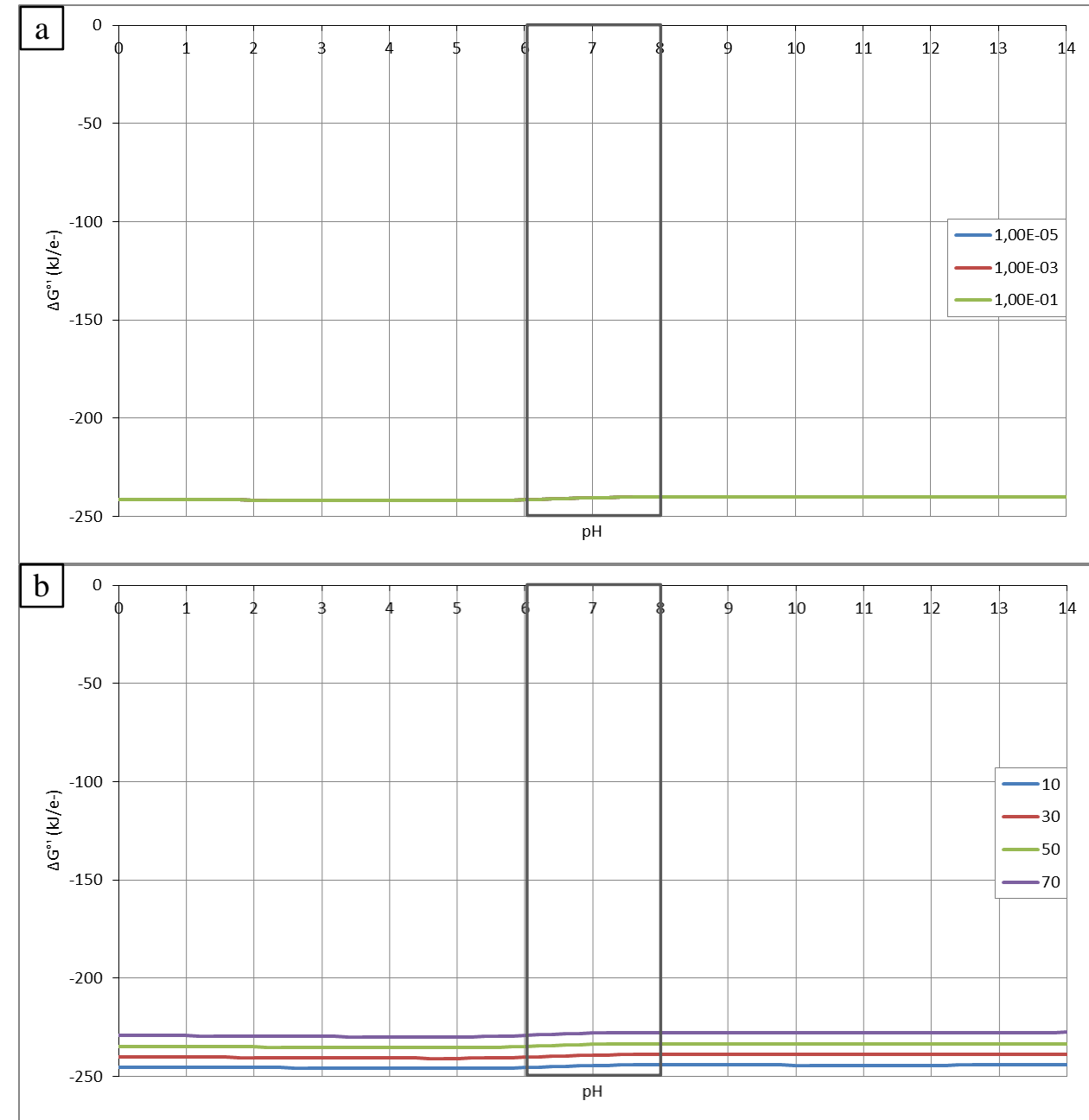

Figura 65. Energia livre da produção de glicose com bactérias verdes sulfurosas como função a) do $\mathrm{pH}$ e pressão parcial de hidrogênio (atm) e b) do $\mathrm{pH}$ e temperatura $\left({ }^{\circ} \mathrm{C}\right)$. 
Tabela 27. Biorreação do modelo biotermodinâmico e estequiometria $\left(\mathrm{T}=25^{\circ} \mathrm{C}\right)$ da fixação de nitrogênio com bactérias verdes sulfurosas.

\begin{tabular}{|c|c|c|c|}
\hline \multicolumn{2}{|c|}{ Reação 71} & $f_{s}^{\circ}$ & $\begin{array}{c}\Delta_{r} G^{\circ}, \\
\Delta_{r} H^{\circ} \\
\left(\mathrm{kJ} \mathrm{e}^{-} \mathrm{eq}^{-1}\right)\end{array}$ \\
\hline $\begin{array}{l}0 \\
\text { N } \\
\text { II } \\
\frac{T}{2}\end{array}$ & $\begin{array}{l}2,65 \times 10^{-1} \mathrm{H}_{2} \mathrm{~S}+2,35 \times 10^{-1} \mathrm{HS}^{-}+1,25 \times 10^{-1} \mathrm{~N}_{2}+4,84 \times 10^{-1} \mathrm{H}^{+}+2,00 \mathrm{~h} v \rightleftharpoons \\
2,49 \times 10^{-1} \mathrm{NH}_{4}^{+}+1,25 \times 10^{-3} \mathrm{NH}_{3}+5,00 \times 10^{-1} \mathrm{~S}+1,25 \times 10^{-1} \mathrm{H}_{2}\end{array}$ & - & $\begin{array}{l}-264,6 \\
-302,4\end{array}$ \\
\hline $\begin{array}{l}n \\
n \\
11 \\
\frac{\pi}{2}\end{array}$ & $\begin{array}{l}1,30 \times 10^{-1} \mathrm{H}_{2} \mathrm{~S}+3,70 \times 10^{-1} \mathrm{HS}^{-}+1,25 \times 10^{-1} \mathrm{~N}_{2}+6,16 \times 10^{-1} \mathrm{H}^{+}+2,00 \mathrm{~h} v \rightleftharpoons \\
2,46 \times 10^{-1} \mathrm{NH}_{4}^{+}+3,75 \times 10^{-3} \mathrm{NH}_{3}+5,00 \times 10^{-1} \mathrm{~S}+1,25 \times 10^{-1} \mathrm{H}_{2}\end{array}$ & - & $\begin{array}{l}-263,8 \\
-305,2\end{array}$ \\
\hline $\begin{array}{l}0 \\
\infty \\
\| \\
\frac{\pi}{2}\end{array}$ & $\begin{array}{l}5,00 \times 10^{-2} \mathrm{H}_{2} \mathrm{~S}+4,50 \times 10^{-1} \mathrm{HS}^{-}+1,25 \times 10^{-1} \mathrm{~N}_{2}+6,86 \times 10^{-1} \mathrm{H}^{+}+2,00 \mathrm{~h} v \rightleftharpoons \\
2,36 \times 10^{-1} \mathrm{NH}_{4}^{+}+1,38 \times 10^{-2} \mathrm{NH}_{3}+5,00 \times 10^{-1} \mathrm{~S}+1,25 \times 10^{-1} \mathrm{H}_{2}\end{array}$ & - & $\begin{array}{l}-263,1 \\
-306,4\end{array}$ \\
\hline
\end{tabular}
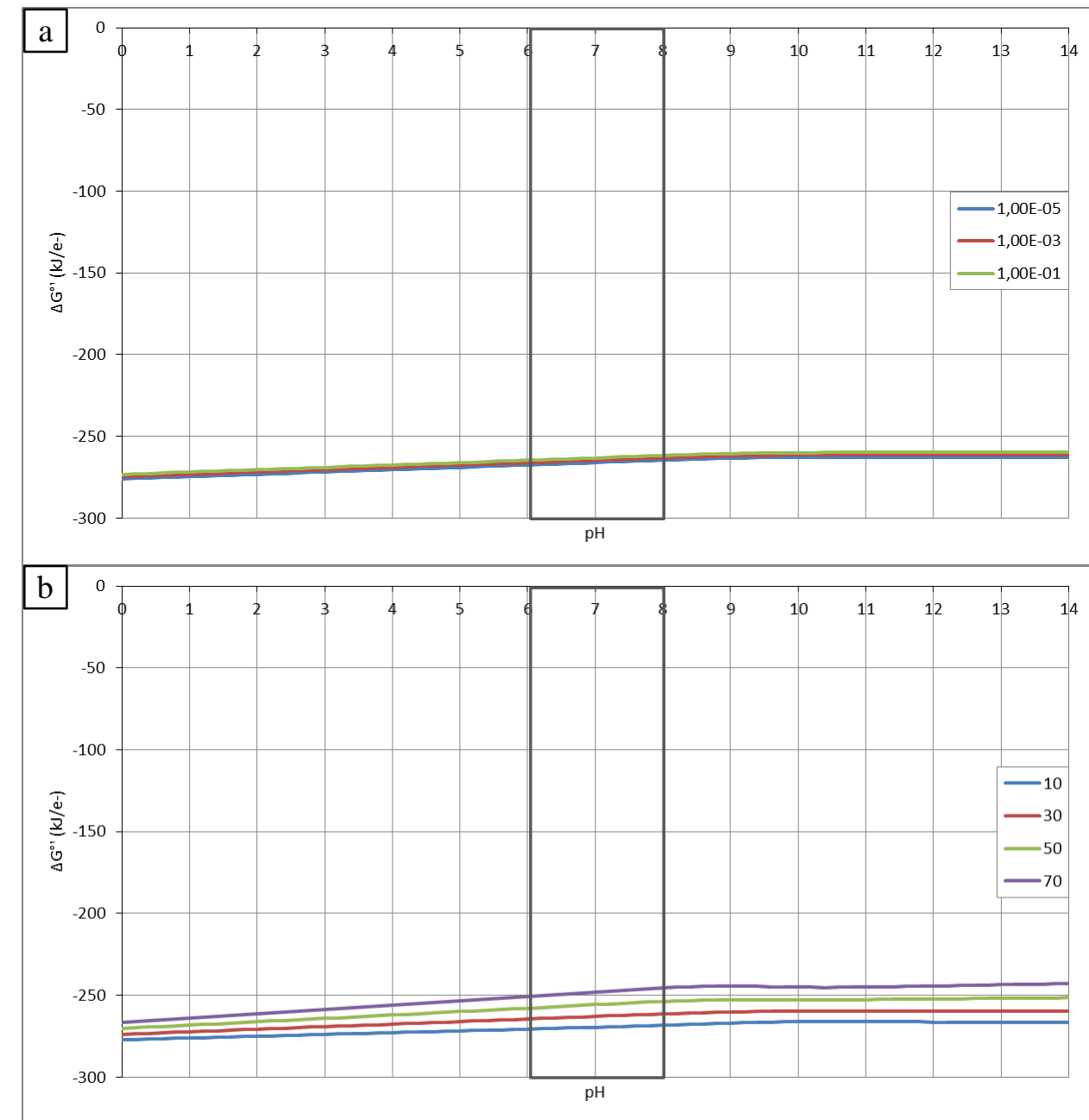

Figura 66. Energia livre da fixação de nitrogênio com bactérias verdes sulfurosas como função a) do pH e pressão parcial de hidrogênio (atm) e b) do $\mathrm{pH}$ e temperatura $\left({ }^{\circ} \mathrm{C}\right)$. 
Tabela 28. Biorreação do modelo biotermodinâmico e estequiometria $\left(\mathrm{T}=25^{\circ} \mathrm{C}\right)$ da fixação em ausência de nitrogênio assimilável com bactérias verdes sulfurosas.

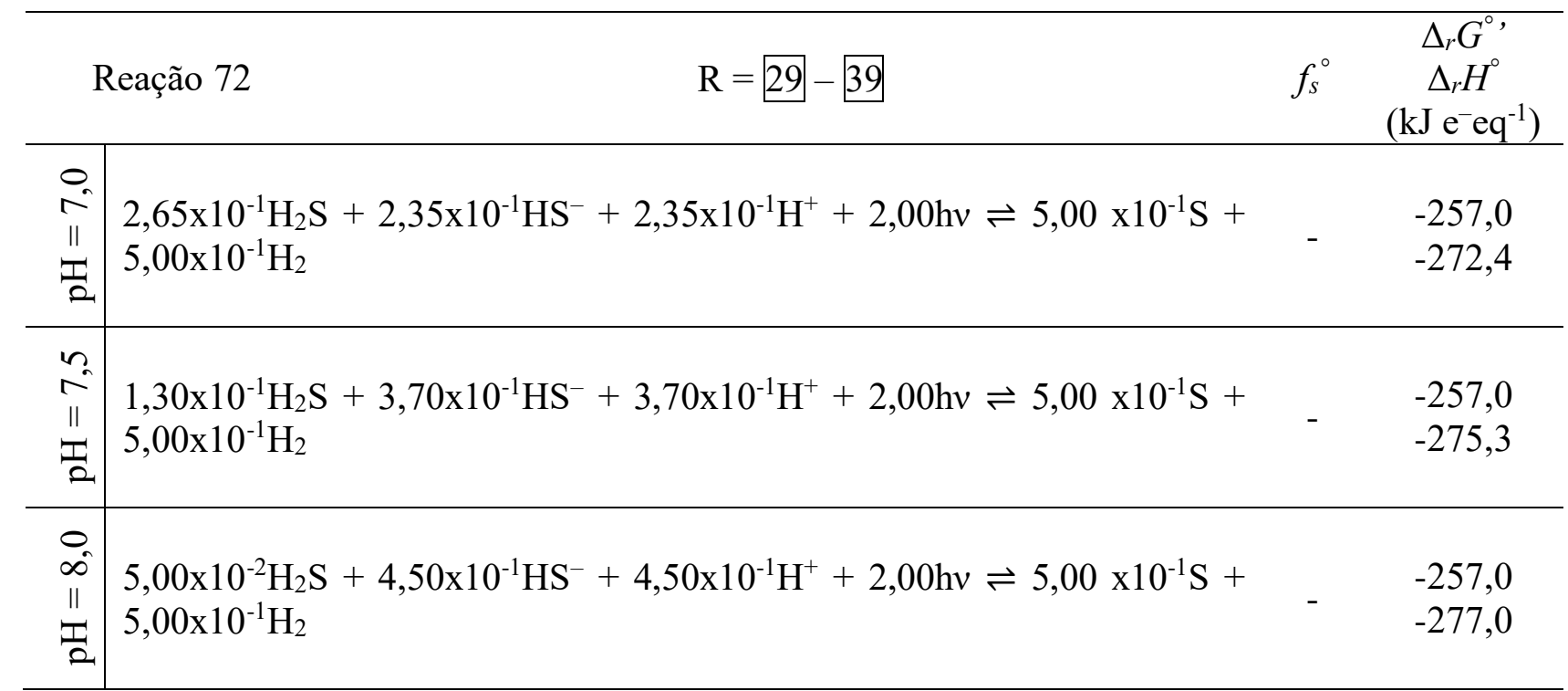
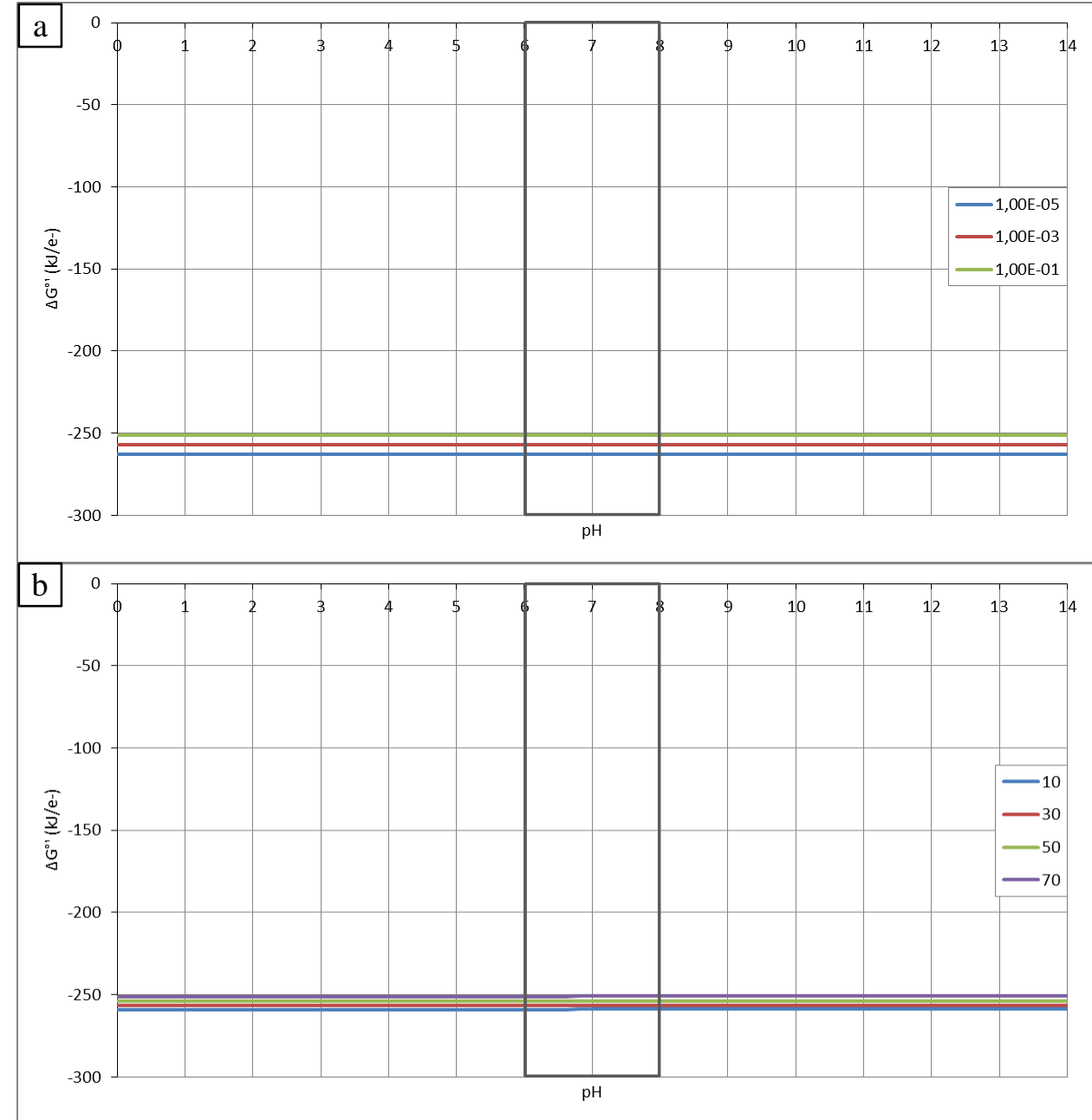

Figura 67. Energia livre da fixação em ausência de nitrogênio assimilável com bactérias verdes sulfurosas como função a) do $\mathrm{pH}$ e pressão parcial de hidrogênio (atm) e b) do $\mathrm{pH}$ e temperatura $\left({ }^{\circ} \mathrm{C}\right)$. 
Tabela 29. Biorreação do modelo biotermodinâmico e estequiometria $\left(\mathrm{T}=25^{\circ} \mathrm{C}\right)$ da produção de glicose com bactérias púrpuras sulfurosas.

\begin{tabular}{|c|c|c|c|}
\hline \multicolumn{2}{|c|}{ Reação 73} & $f_{s}^{\circ}$ & $\begin{array}{c}\Delta_{r} G^{\circ} \\
\Delta_{r} H^{\circ} \\
\left(\mathrm{kJ} \mathrm{e}^{-} \mathrm{eq}^{-1}\right)\end{array}$ \\
\hline 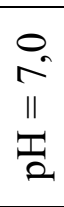 & $\begin{array}{l}4,53 \times 10^{-2} \mathrm{CO}_{2}+2,04 \times 10^{-1} \mathrm{HCO}_{3}^{-}+3,06 \times 10^{-2} \mathrm{NH}_{4}^{+}+3,09 \times 10^{-4} \mathrm{NH}_{3}+ \\
1,23 \times 10^{-3} \mathrm{H}_{2} \mathrm{PO}_{4}^{-}+6,17 \times 10^{-4} \mathrm{HPO}_{4}{ }^{2-}+2,67 \times 10^{-1} \mathrm{H}_{2} \mathrm{~S}+2,37 \times 10^{-1} \mathrm{HS}^{-}+ \\
4,12 \times 10^{-1} \mathrm{H}^{+}+2,00 \mathrm{~h} v \rightleftharpoons 3,09 \times 10^{-2} \mathrm{C}_{5} \mathrm{H}_{7} \mathrm{O}_{2} \mathrm{NP}_{0,06} \mathrm{~S}_{0,1}+1,58 \times 10^{-2} \mathrm{C}_{6} \mathrm{H}_{12} \mathrm{O}_{6} \\
+5,00 \times 10^{-1} \mathrm{~S}+3,18 \times 10^{-1} \mathrm{H}_{2} \mathrm{O}\end{array}$ & 0,62 & $\begin{array}{l}-231,3 \\
-282,1\end{array}$ \\
\hline 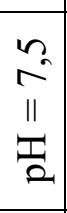 & $\begin{array}{l}1,63 \times 10^{-2} \mathrm{CO}_{2}+2,32 \times 10^{-1} \mathrm{HCO}_{3}^{-}+4,66 \times 10^{-4} \mathrm{CO}_{3}{ }^{2-}+3,02 \times 10^{-2} \mathrm{NH}_{4}^{+}+ \\
6,16 \times 10^{-4} \mathrm{NH}_{3}+6,16 \times 10^{-4} \mathrm{H}_{2} \mathrm{PO}_{4}^{-}+1,23 \times 10^{-3} \mathrm{HPO}_{4}{ }^{2-}+1,31 \times 10^{-1} \mathrm{H}_{2} \mathrm{~S}+ \\
3,72 \times 10^{-1} \mathrm{HS}^{-}+5,78 \times 10^{-1} \mathrm{H}^{+}+2,00 \mathrm{~h} v \rightleftharpoons 3,08 \times 10^{-2} \mathrm{C}_{5} \mathrm{H}_{7} \mathrm{O}_{2} \mathrm{NP}_{0,06} \mathrm{~S}_{0,1}+ \\
1,58 \times 10^{-2} \mathrm{C}_{6} \mathrm{H}_{12} \mathrm{O}_{6}+5,00 \times 10^{-1} \mathrm{~S}+2,12 \times 10^{-1} \mathrm{H}_{2} \mathrm{O}\end{array}$ & 0,62 & $\begin{array}{l}-231,1 \\
-285,3\end{array}$ \\
\hline 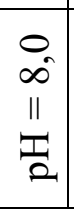 & $\begin{array}{l}5,45 \times 10^{-3} \mathrm{CO}_{2}+2,43 \times 10^{-1} \mathrm{HCO}_{3}^{-}+1,09 \times 10^{-3} \mathrm{CO}_{3}^{2-}+2,93 \times 10^{-2} \mathrm{NH}_{4}^{+}+ \\
1,54 \times 10^{-3} \mathrm{NH}_{3}+3,09 \times 10^{-4} \mathrm{H}_{2} \mathrm{PO}_{4}^{-}+1,54 \times 10^{-3} \mathrm{HPO}_{4}^{2-}+5,03 \times 10^{-2} \mathrm{H}_{2} \mathrm{~S}+ \\
4,53 \times 10^{-1} \mathrm{HS}^{-}+6,72 \times 10^{-1} \mathrm{H}^{+}+2,00 \mathrm{~h} v \rightleftharpoons 3,09 \times 10^{-2} \mathrm{C}_{5} \mathrm{H}_{7} \mathrm{O}_{2} \mathrm{NP}_{0,06} \mathrm{~S}_{0,1}+ \\
1,58 \times 10^{-2} \mathrm{C}_{6} \mathrm{H}_{12} \mathrm{O}_{6}+5,00 \times 10^{-1} \mathrm{~S}+1,43 \times 10^{-1} \mathrm{H}_{2} \mathrm{O}\end{array}$ & 0,62 & $\begin{array}{l}-231,1 \\
-287,2\end{array}$ \\
\hline
\end{tabular}
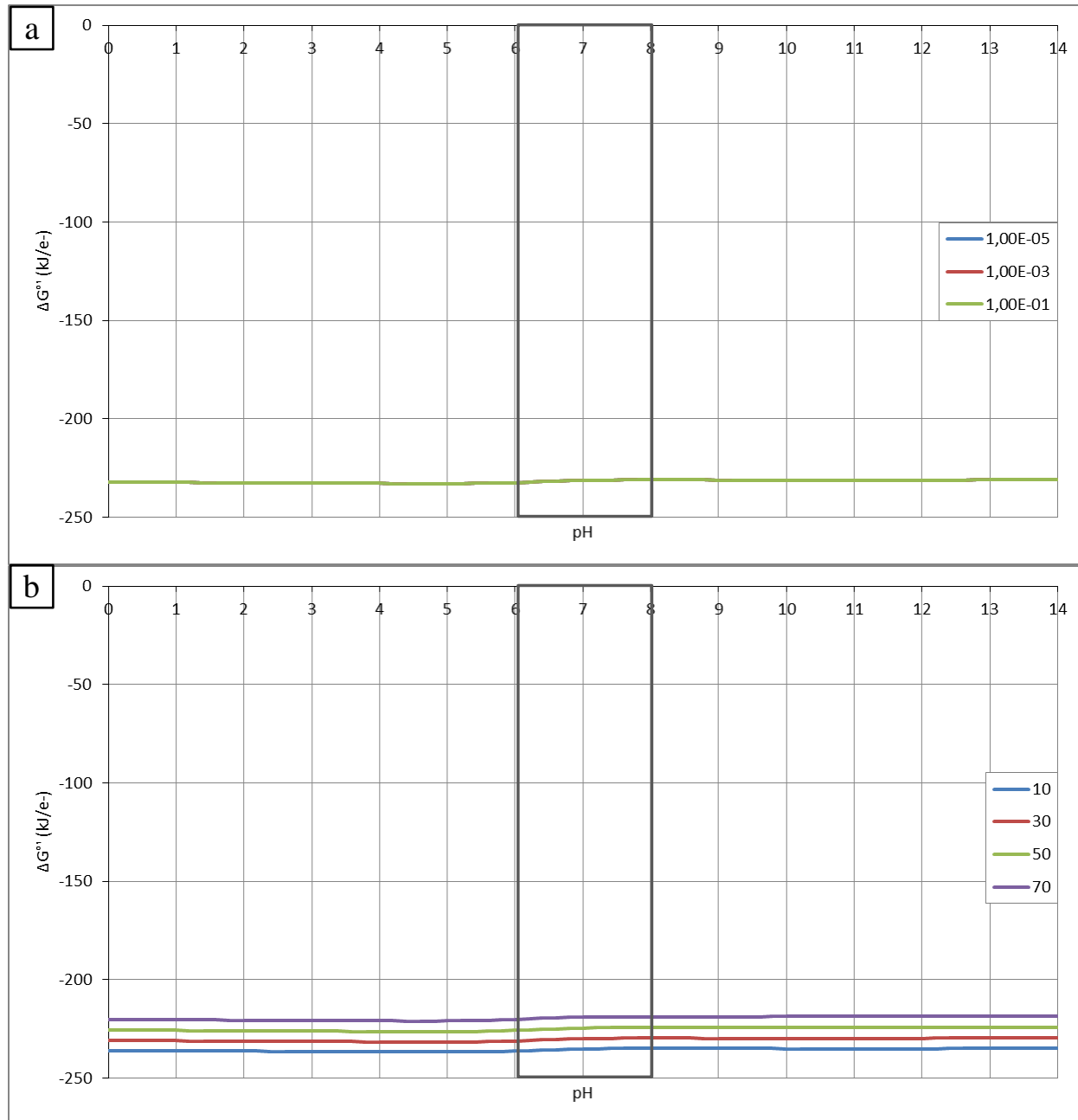

Figura 68. Energia livre da produção de glicose com bactérias púrpuras sulfurosas como função a) do pH e pressão parcial de hidrogênio (atm) e b) do $\mathrm{pH}$ e temperatura $\left({ }^{\circ} \mathrm{C}\right)$. 
Tabela 30. Biorreação do modelo biotermodinâmico e estequiometria $\left(\mathrm{T}=25^{\circ} \mathrm{C}\right)$ da fixação de nitrogênio com bactérias púrpuras sulfurosas.

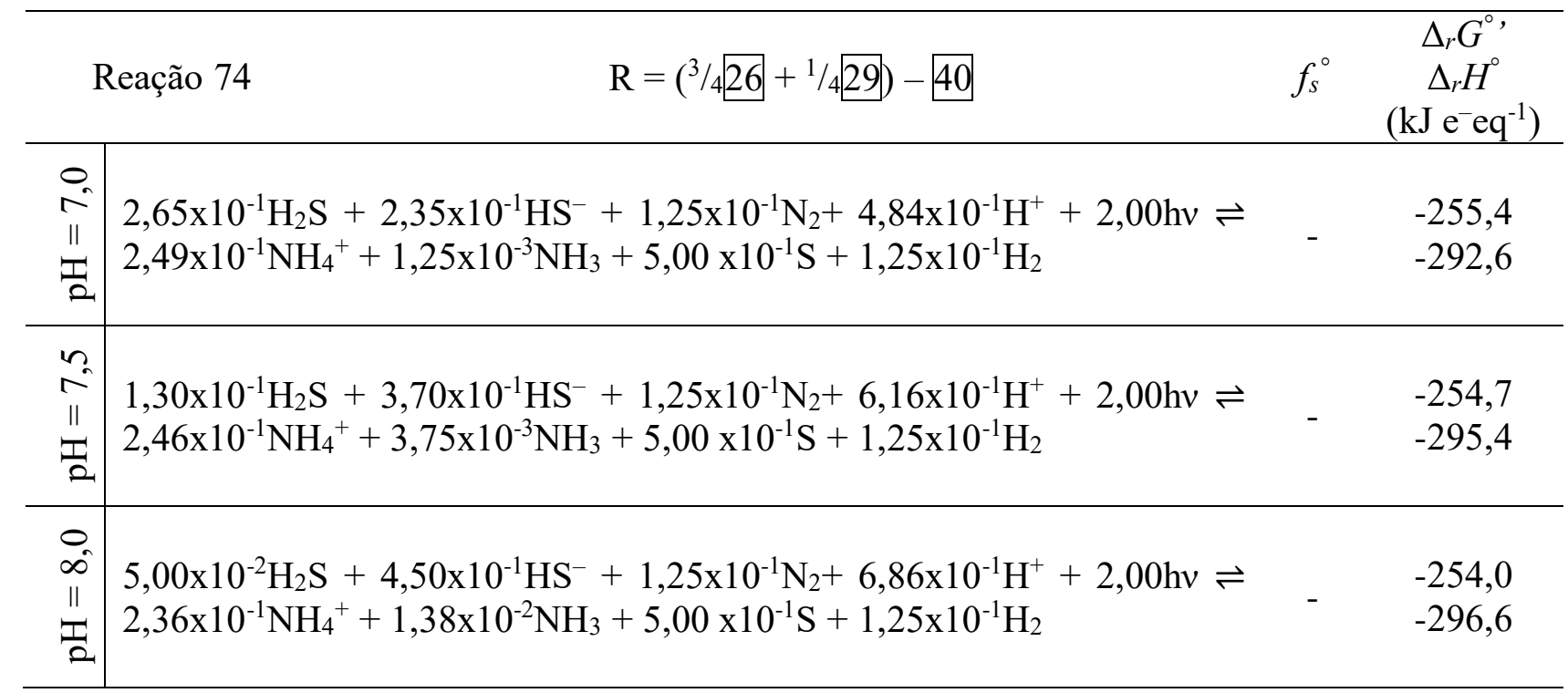
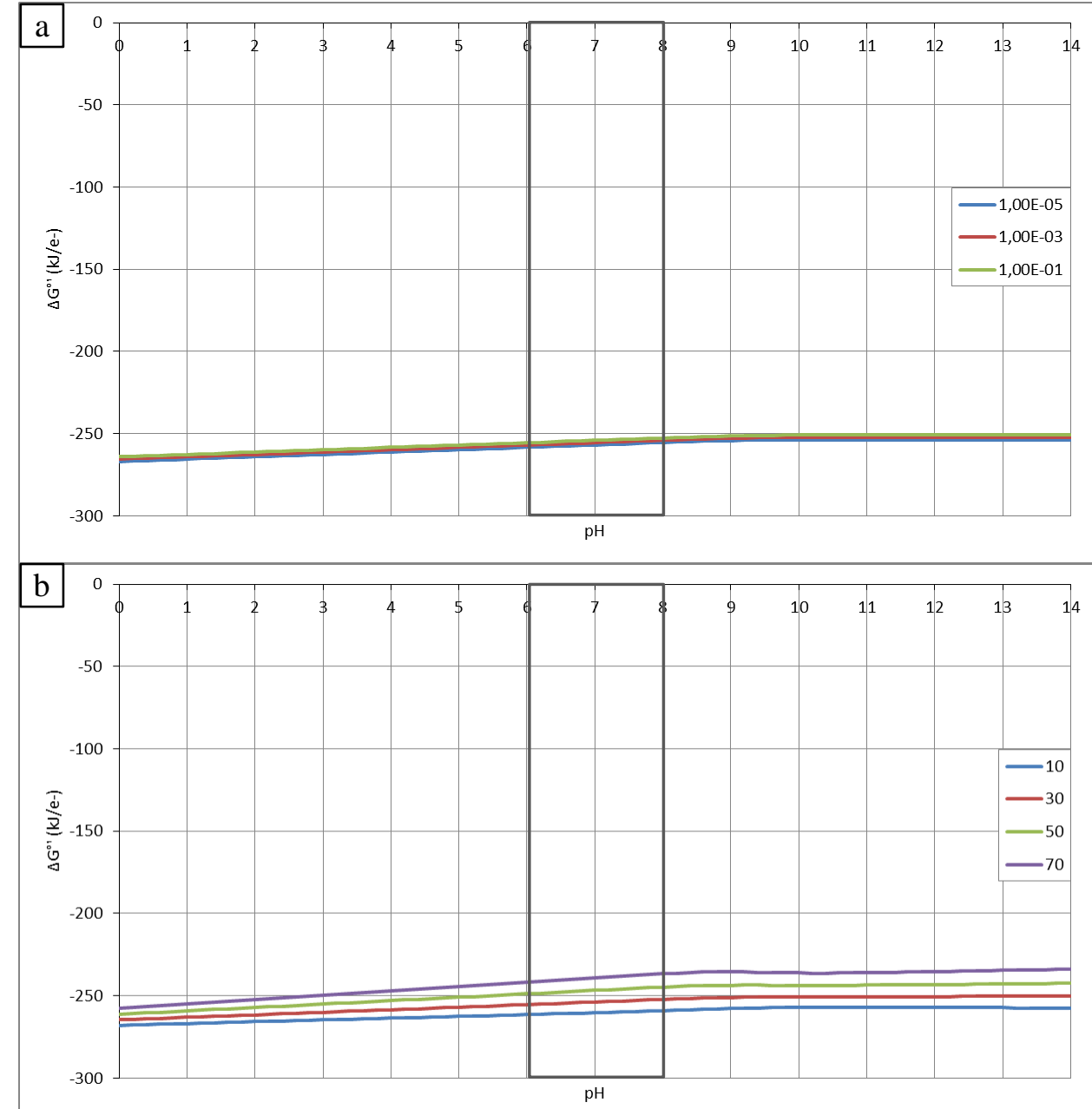

Figura 69. Energia livre da fixação de nitrogênio com bactérias púrpuras sulfurosas como função a) do $\mathrm{pH}$ e pressão parcial de hidrogênio (atm) e b) do $\mathrm{pH}$ e temperatura $\left({ }^{\circ} \mathrm{C}\right)$. 
Tabela 31. Biorreação do modelo biotermodinâmico e estequiometria $\left(\mathrm{T}=25^{\circ} \mathrm{C}\right)$ da fixação em ausência de nitrogênio assimilável com bactérias púrpuras sulfurosas.

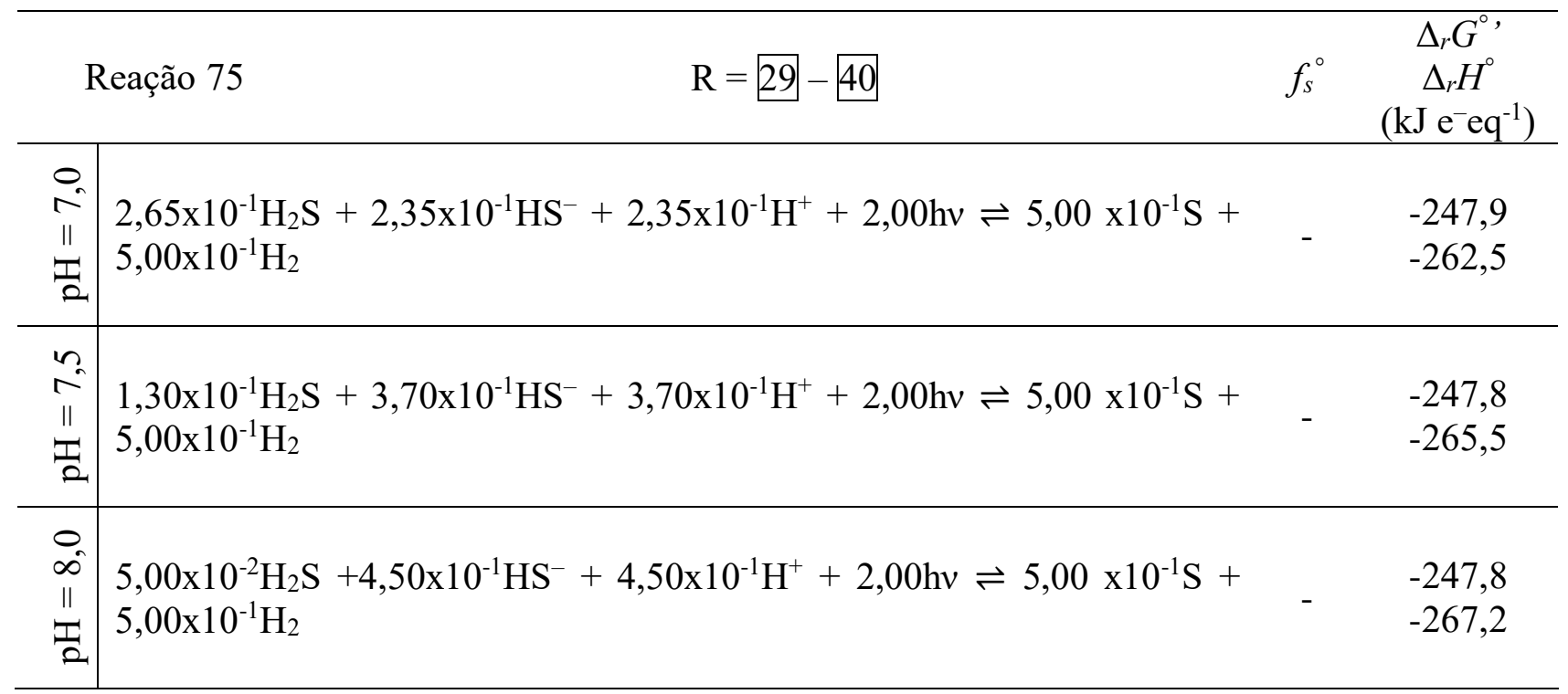
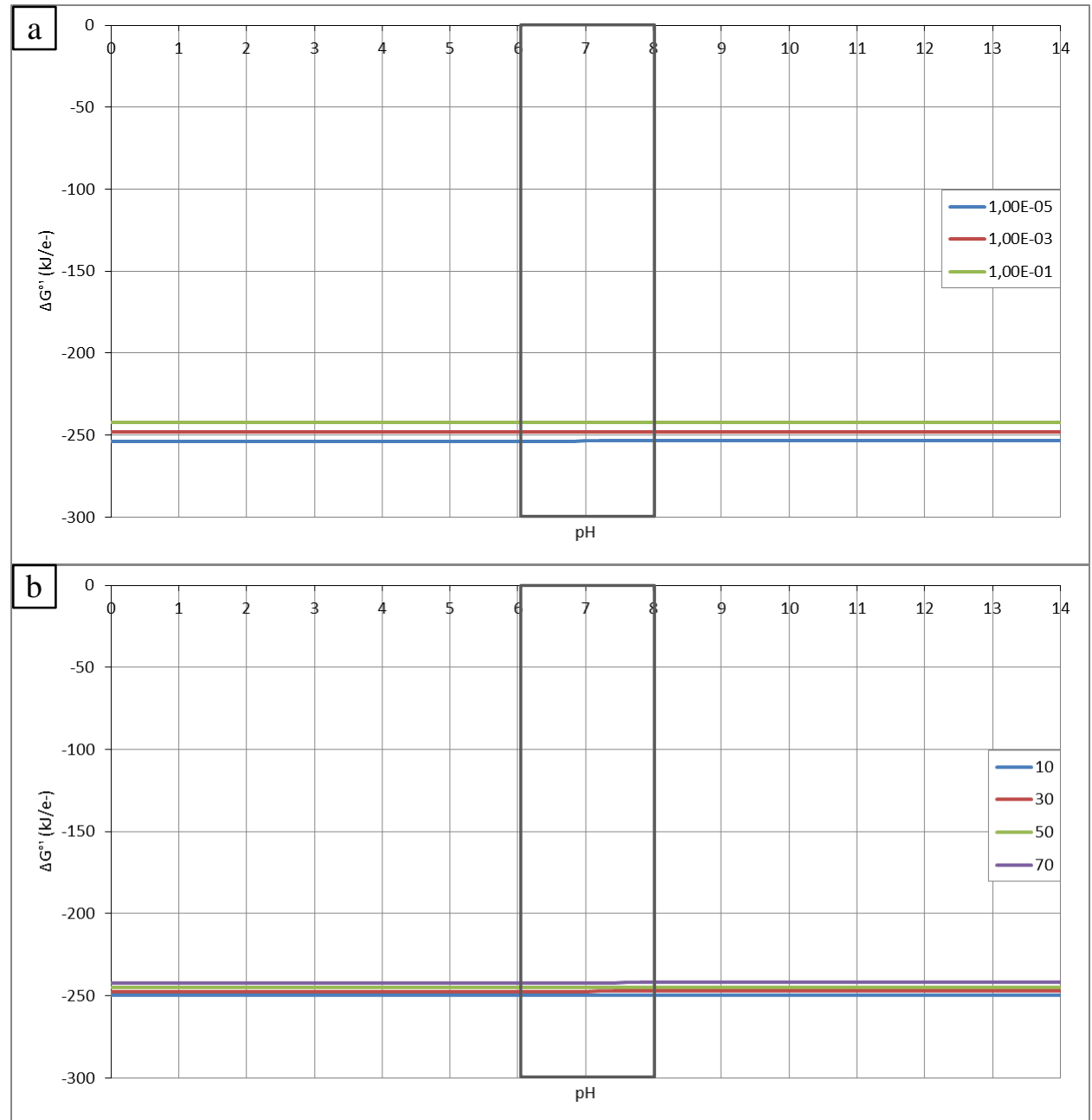

Figura 70. Energia livre da fixação em ausência de nitrogênio assimilável com bactérias púrpuras sulfurosas como função a) do $\mathrm{pH}$ e pressão parcial de hidrogênio (atm) e b) do pH e temperatura $\left({ }^{\circ} \mathrm{C}\right)$. 
Também são muito parecidos os comportamentos da energia livre na biofotólise indireta para a produção de hidrogênio pela nitrogenase em bactérias verdes sulfurosas e púrpuras sulfurosas, tanto quando o nitrogênio gasoso está presente (Figuras 66 e 69) quanto ausente (Figuras 67 e 70). Quando o nitrogênio gasoso está disponível, a energia livre dissipada aumenta com a diminuição do $\mathrm{pH}$ favorecendo levemente a conversão, e permanecem praticamente constantes para $\mathrm{pH}$ superiores a 8,0. Por outro lado, a pressão parcial de hidrogênio não influi significativamente na energia livre dissipada (Figuras 66a e 69a), enquanto o aumento da temperatura a diminui desfavorecendo a conversão (Figuras 66be 69b). Quando o nitrogênio gasoso não está disponível, o comportamento da energia livre é estável em todo o intervalo de $\mathrm{pH}$. Por outro lado, a diminuição da pressão parcial de hidrogênio (Figuras 67a e 70a), produto da reação, e a diminuição da temperatura (Figuras $67 \mathrm{~b}$ e $70 \mathrm{~b}$ ) favorecem o incremento da energia livre dissipada, mas o efeito da temperatura é apenas marginal.

Finalmente, todas as fixações de nitrogênio pela nitrogenase nas bactérias anoxigênicas são espontâneas nos intervalos de pH (0 a 14), pressões parciais de hidrogênio $\left(1,00 \times 10^{-5}\right.$ a $\left.1,00 \mathrm{~atm}\right)$ e temperatura $\left(10\right.$ a $\left.70{ }^{\circ} \mathrm{C}\right)$ avaliados; portanto, acontecem naturalmente sob condições químicas adequadas.

\subsubsection{Comportamento da fotossíntese anoxigênica com bactérias não sulfurosas}

Os resultados da aplicação do modelo biotermodinâmico aos metabolismos das bactérias púrpuras não sulfurosas discutidos na Seção 6.1.4, para um comprimento de onda de $870 \mathrm{~nm}$, se apresentam nas Tabelas 32 a 37 (Reações 76 a 81), nas quais se inclui a estequiometria da reação para diferentes $\mathrm{pH}$ (temperatura de $25^{\circ} \mathrm{C}$ ), e nas Figuras 71 a 76, com o comportamento da energia livre dissipada como função do $\mathrm{pH}$ e pressão parcial de hidrogênio (temperatura constante de $25{ }^{\circ} \mathrm{C}$ ) e do $\mathrm{pH}$ e temperatura (pressão parcial de hidrogênio constante de $\left.1,00 \times 10^{-3} \mathrm{~atm}\right)$.

As bactérias púrpuras não sulfurosas usam preferencialmente um metabolismo fotoorganotrófico no qual assimilam pequenos ácidos orgânicos (Antal et al., 2012; Boichenko, Greenbaum \& Seibert, 2004; Koku et al., 2002). Por tanto, nesta pesquisa se analisa o comportamento destas bactérias com crescimento sobre acetato e lactato como fontes de carbono. 
Tabela 32. Biorreação do modelo biotermodinâmico e estequiometria $\left(\mathrm{T}=25^{\circ} \mathrm{C}\right)$ da produção de glicose por fotofermentação de acetato com bactérias púrpuras não sulfurosas.

\begin{tabular}{|c|c|c|c|}
\hline \multicolumn{2}{|c|}{ Reação 76} & $f_{s}^{\circ}$ & $\begin{array}{c}\Delta_{r} G^{\circ} \\
\Delta_{r} H^{\circ} \\
\left(\mathrm{kJ} \mathrm{e}^{-} \mathrm{eq}^{-1}\right)\end{array}$ \\
\hline $\begin{array}{l}0 \\
\text { N } \\
I 1 \\
\frac{T}{2}\end{array}$ & $\begin{array}{l}1,24 \times 10^{-1} \mathrm{C}_{2} \mathrm{H}_{3} \mathrm{O}_{2}^{-}+1,25 \times 10^{-3} \mathrm{C}_{2} \mathrm{H}_{4} \mathrm{O}_{2}+3,18 \times 10^{-4} \mathrm{CO}_{2}+3,39 \times 10^{-2} \mathrm{NH}_{4}^{+} \\
+3,42 \times 10^{-4} \mathrm{NH}_{3}+1,37 \times 10^{-3} \mathrm{H}_{2} \mathrm{PO}_{4}^{-}+6,85 \times 10^{-4} \mathrm{HPO}_{4}{ }^{2-}+1,71 \times 10^{-3} \mathrm{H}_{2} \mathrm{~S}+ \\
1,71 \times 10^{-3} \mathrm{HS}^{-}+8,81 \times 10^{-2} \mathrm{H}^{+}+2,00 \mathrm{~h} v \rightleftharpoons 3,42 \times 10^{-2} \mathrm{C}_{5} \mathrm{H}_{7} \mathrm{O}_{2} \mathrm{NP}_{0,06} \mathrm{~S}_{0,1}+ \\
1,30 \times 10^{-2} \mathrm{C}_{6} \mathrm{H}_{12} \mathrm{O}_{6}+1,17 \times 10^{-3} \mathrm{HCO}_{3}+1,06 \times 10^{-1} \mathrm{H}_{2} \mathrm{O}\end{array}$ & 0,69 & $\begin{array}{l}-242,8 \\
-265,5\end{array}$ \\
\hline 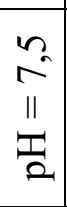 & $\begin{array}{l}1,25 \times 10^{-1} \mathrm{C}_{2} \mathrm{H}_{3} \mathrm{O}_{2}^{-}+9,32 \times 10^{-5} \mathrm{CO}_{2}+4,72 \times 10^{-4} \mathrm{CO}_{3}{ }^{2-}+3,35 \times 10^{-2} \mathrm{NH}_{4}^{+}+ \\
6,84 \times 10^{-4} \mathrm{NH}_{3}+6,84 \times 10^{-4} \mathrm{H}_{2} \mathrm{PO}_{4}^{-}+1,37 \times 10^{-3} \mathrm{HPO}_{4}{ }^{2-}+1,03 \times 10^{-3} \mathrm{H}_{2} \mathrm{~S}+ \\
2,39 \times 10^{-3} \mathrm{HS}^{-}+9,68 \times 10^{-2} \mathrm{H}^{+}+2,00 \mathrm{~h} v \rightleftharpoons 3,42 \times 10^{-2} \mathrm{C}_{5} \mathrm{H}_{7} \mathrm{O}_{2} \mathrm{NP}_{0,06} \mathrm{~S}_{0,1}+ \\
1,30 \times 10^{-2} \mathrm{C}_{6} \mathrm{H}_{12} \mathrm{O}_{6}+1,42 \times 10^{-3} \mathrm{HCO}_{3}^{-}+1,09 \times 10^{-1} \mathrm{H}_{2} \mathrm{O}\end{array}$ & 0,69 & $\begin{array}{l}-242,9 \\
-266,3\end{array}$ \\
\hline 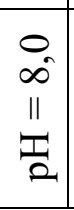 & $\begin{array}{l}1,25 \times 10^{-1} \mathrm{C}_{2} \mathrm{H}_{3} \mathrm{O}_{2}^{-}+4,55 \times 10^{-4} \mathrm{CO}_{2}+3,25 \times 10^{-2} \mathrm{NH}_{4}^{+}+1,71 \times 10^{-3} \mathrm{NH}_{3}+ \\
3,42 \times 10^{-4} \mathrm{H}_{2} \mathrm{PO}_{4}^{-}+1,71 \times 10^{-3} \mathrm{HPO}_{4}^{2-}+3,42 \times 10^{-4} \mathrm{H}_{2} \mathrm{~S}+3,08 \times 10^{-3} \mathrm{HS}^{-}+ \\
9,78 \times 10^{-2} \mathrm{H}^{+}+2,00 \mathrm{~h} v \rightleftharpoons 3,42 \times 10^{-2} \mathrm{C}_{5} \mathrm{H}_{7} \mathrm{O}_{2} \mathrm{NP}_{0,06} \mathrm{~S}_{0,1}+1,30 \times 10^{-2} \mathrm{C}_{6} \mathrm{H}_{12} \mathrm{O}_{6} \\
+1,14 \times 10^{-3} \mathrm{HCO}_{3}^{-}+1,75 \times 10^{-4} \mathrm{CO}_{3}^{2-}+1,09 \times 10^{-1} \mathrm{H}_{2} \mathrm{O}\end{array}$ & 0,69 & $\begin{array}{l}-242,6 \\
-266,4\end{array}$ \\
\hline
\end{tabular}
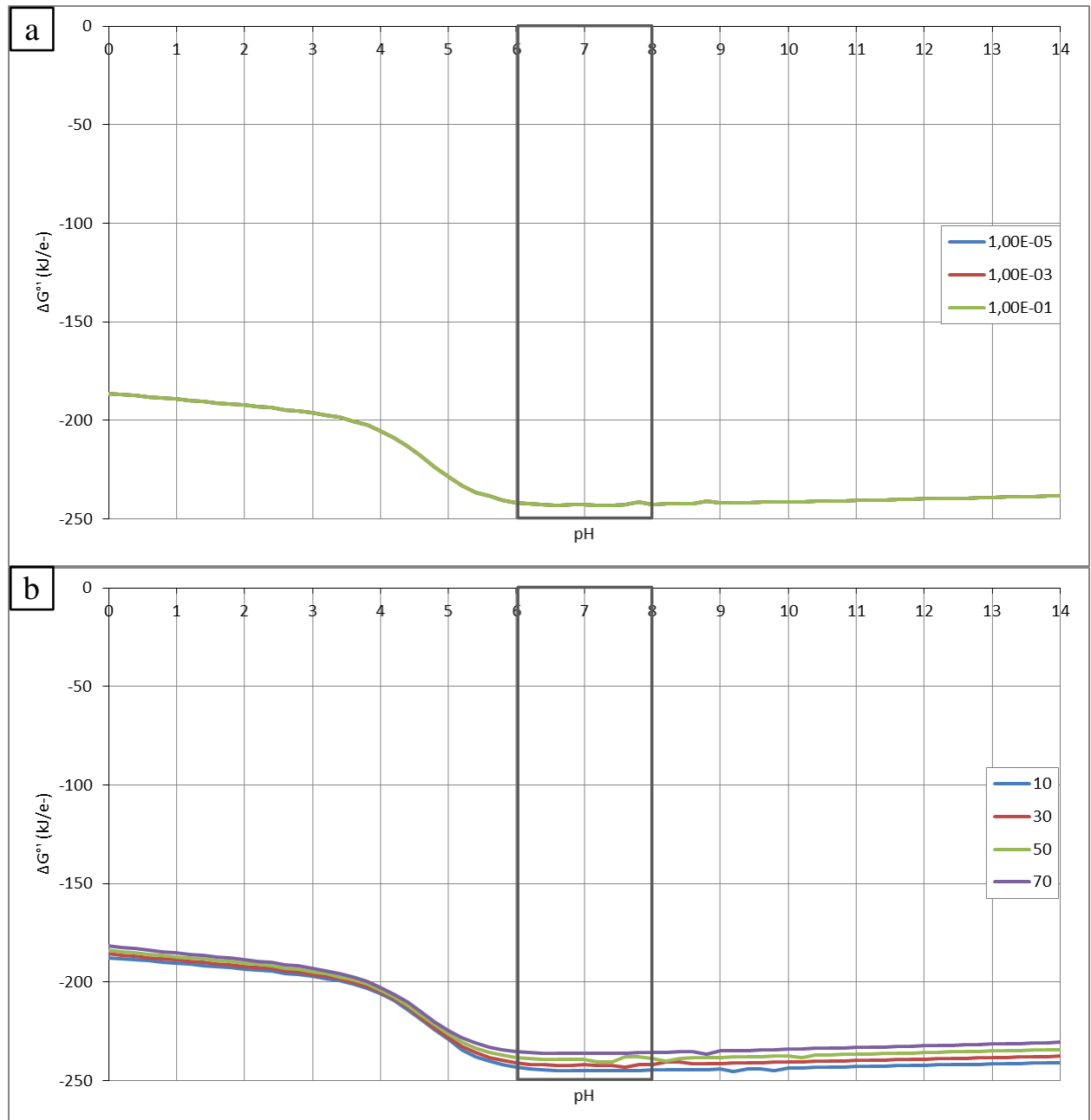

Figura 71. Energia livre da produção de glicose por fotofermentação de acetato com bactérias púrpuras não sulfurosas como função a) do $\mathrm{pH}$ e pressão parcial de hidrogênio (atm) e b) do $\mathrm{pH}$ e temperatura $\left({ }^{\circ} \mathrm{C}\right)$. 
Tabela 33. Biorreação do modelo biotermodinâmico e estequiometria $\left(\mathrm{T}=25^{\circ} \mathrm{C}\right)$ da fixação de nitrogênio por fotofermentação de acetato com bactérias púrpuras não sulfurosas.

Reação 77

$$
\mathrm{R}=(\sqrt[3]{4} \sqrt{26}+1 / 429)-41
$$

ㅇ. $1,24 \times 10^{-1} \mathrm{C}_{2} \mathrm{H}_{3} \mathrm{O}_{2}^{-}+1,25 \times 10^{-3} \mathrm{C}_{2} \mathrm{H}_{4} \mathrm{O}_{2}+2,49 \times 10^{-1} \mathrm{NH}_{4}^{+}+1,25 \times 10^{-3} \mathrm{NH}_{3}$

$\|+1,25 \times 10^{-1} \mathrm{~N}_{2}+4,58 \times 10^{-1} \mathrm{H}_{2} \mathrm{O}+1,63 \times 10^{-1} \mathrm{H}^{+}+2,00 \mathrm{hv} \rightleftharpoons 4,50 \times 10^{-2} \mathrm{CO}_{2}$

胥 $+2,05 \times 10^{-1} \mathrm{HCO}_{3}^{-}+1,25 \times 10^{-1} \mathrm{H}_{2}$

乞 $1,25 \times 10^{-1} \mathrm{C}_{2} \mathrm{H}_{3} \mathrm{O}_{2}^{-}+2,46 \times 10^{-1} \mathrm{NH}_{4}^{+}+3,75 \times 10^{-3} \mathrm{NH}_{3}+1,25 \times 10^{-1} \mathrm{~N}_{2}+$

\| $4,84 \times 10^{-1} \mathrm{H}_{2} \mathrm{O}+1,38 \times 10^{-1} \mathrm{H}^{+}+2,00 \mathrm{~h} v \rightleftharpoons 1,63 \times 10^{-2} \mathrm{CO}_{2}+2,34 \times 10^{-}-\quad-293,6$

贾 ${ }^{1} \mathrm{HCO}_{3}^{-}+1,25 \times 10^{-1} \mathrm{H}_{2}$

ㅇ. $1,25 \times 10^{-1} \mathrm{C}_{2} \mathrm{H}_{3} \mathrm{O}_{2}^{-}+2,36 \times 10^{-1} \mathrm{NH}_{4}^{+}+1,38 \times 10^{-2} \mathrm{NH}_{3}+1,25 \times 10^{-1} \mathrm{~N}_{2}+$

॥ $4,95 \times 10^{-1} \mathrm{H}_{2} \mathrm{O}+1,15 \times 10^{-1} \mathrm{H}^{+}+2,00 \mathrm{hv} \rightleftharpoons 5,00 \times 10^{-3} \mathrm{CO}_{2}+2,44 \times 10$

焉 ${ }^{1} \mathrm{HCO}_{3}{ }^{-}+1,25 \times 10^{-3} \mathrm{CO}_{3}{ }^{2-}+1,25 \times 10^{-1} \mathrm{H}_{2}$
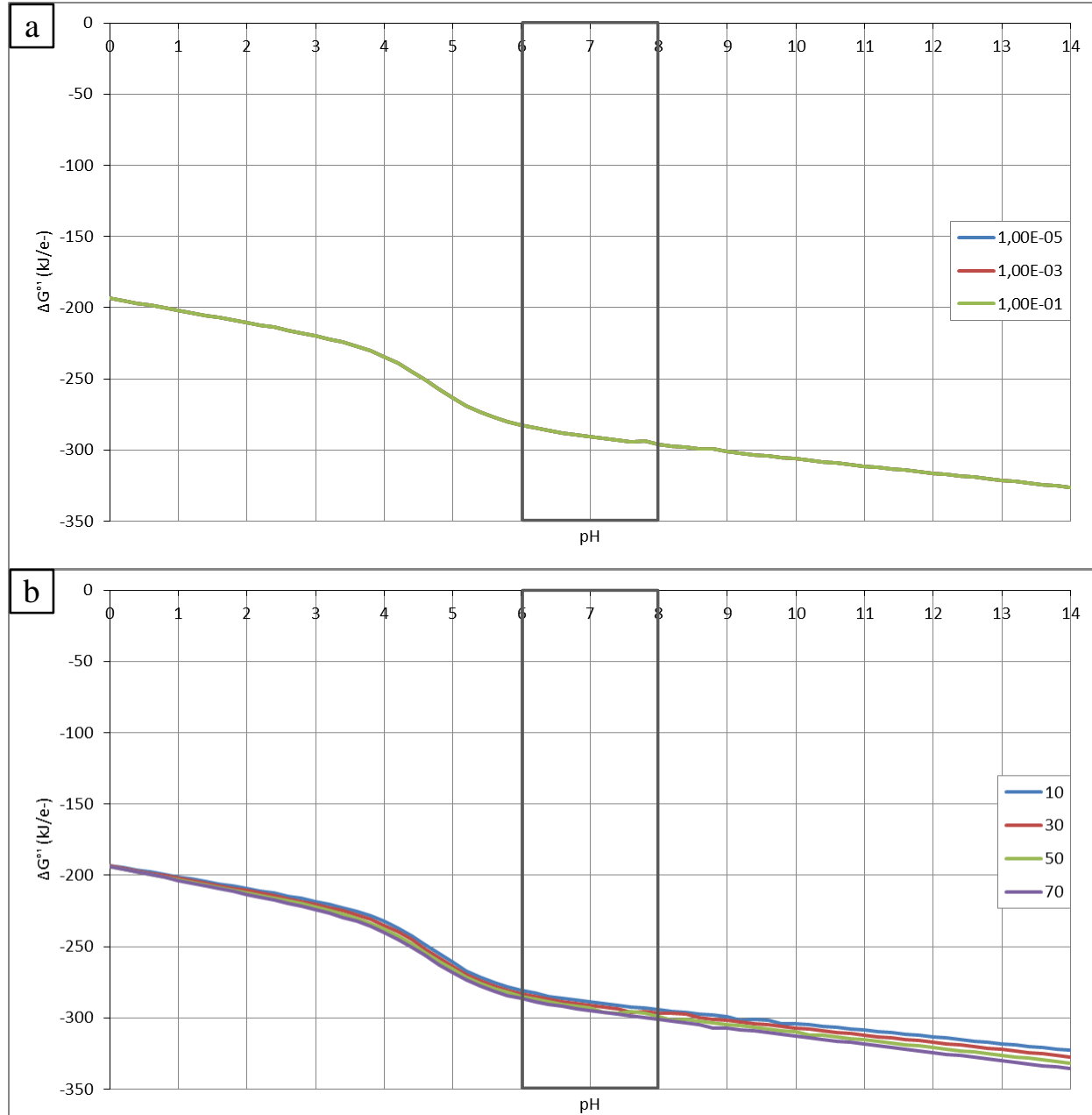

Figura 72. Energia livre da fixação de nitrogênio por fotofermentação de acetato com bactérias púrpuras não sulfurosas como função a) do $\mathrm{pH}$ e pressão parcial de hidrogênio (atm) e b) do $\mathrm{pH}$ e temperatura $\left({ }^{\circ} \mathrm{C}\right)$. 
Tabela 34. Biorreação do modelo biotermodinâmico e estequiometria $\left(\mathrm{T}=25^{\circ} \mathrm{C}\right)$ da fixação em ausência de nitrogênio assimilável por fotofermentação de acetato com bactérias púrpuras não sulfurosas.

\begin{tabular}{|c|c|c|c|}
\hline \multicolumn{2}{|c|}{ Reação 78} & $f_{s}^{\circ}$ & $\begin{array}{c}\Delta_{r} G^{\circ} \\
\Delta_{r} H^{\circ} \\
\left(\mathrm{kJ} \mathrm{e}^{-} \mathrm{eq}^{-1}\right)\end{array}$ \\
\hline 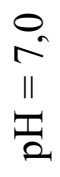 & $\begin{array}{l}1,24 \times 10^{-1} \mathrm{C}_{2} \mathrm{H}_{3} \mathrm{O}_{2}^{-}+1,25 \times 10^{-3} \mathrm{C}_{2} \mathrm{H}_{4} \mathrm{O}_{2}+4,58 \times 10^{-1} \mathrm{H}_{2} \mathrm{O}+2,00 \mathrm{~h} v \rightleftharpoons \\
4,50 \times 10^{-2} \mathrm{CO}_{2}+2,05 \times 10^{-1} \mathrm{HCO}_{3}^{-}+5,00 \times 10^{-1} \mathrm{H}_{2}+8,62 \times 10^{-2} \mathrm{H}^{+}\end{array}$ & - & $\begin{array}{l}-259,2 \\
-246,0\end{array}$ \\
\hline $\begin{array}{r}n \\
n \\
\frac{n}{2}\end{array}$ & $\begin{array}{l}1,25 \times 10^{-1} \mathrm{C}_{2} \mathrm{H}_{3} \mathrm{O}_{2}^{-}+4,84 \times 10^{-1} \mathrm{H}_{2} \mathrm{O}+2,00 \mathrm{~h} v \rightleftharpoons 1,63 \times 10^{-2} \mathrm{CO}_{2}+2,34 \times 10^{-} \\
{ }^{-} \mathrm{HCO}_{3}{ }^{-}+5,00 \times 10^{-1} \mathrm{H}_{2}+1,09 \times 10^{-1} \mathrm{H}^{+}\end{array}$ & - & $\begin{array}{l}-259,5 \\
-246,5\end{array}$ \\
\hline $\begin{array}{l}0 \\
\infty \\
11 \\
\frac{1}{2}\end{array}$ & $\begin{array}{l}1,25 \times 10^{-1} \mathrm{C}_{2} \mathrm{H}_{3} \mathrm{O}_{2}^{-}+4,95 \times 10^{-1} \mathrm{H}_{2} \mathrm{O}+2,00 \mathrm{~h} v \rightleftharpoons 5,00 \times 10^{-3} \mathrm{CO}_{2}+2,44 \times 10^{-} \\
{ }^{1} \mathrm{HCO}_{3}^{-}+1,25 \times 10^{-3} \mathrm{CO}_{3}{ }^{2-}+5,00 \times 10^{-1} \mathrm{H}_{2}+1,21 \times 10^{-1} \mathrm{H}^{+}\end{array}$ & - & $\begin{array}{l}-259,2 \\
-246,5\end{array}$ \\
\hline
\end{tabular}
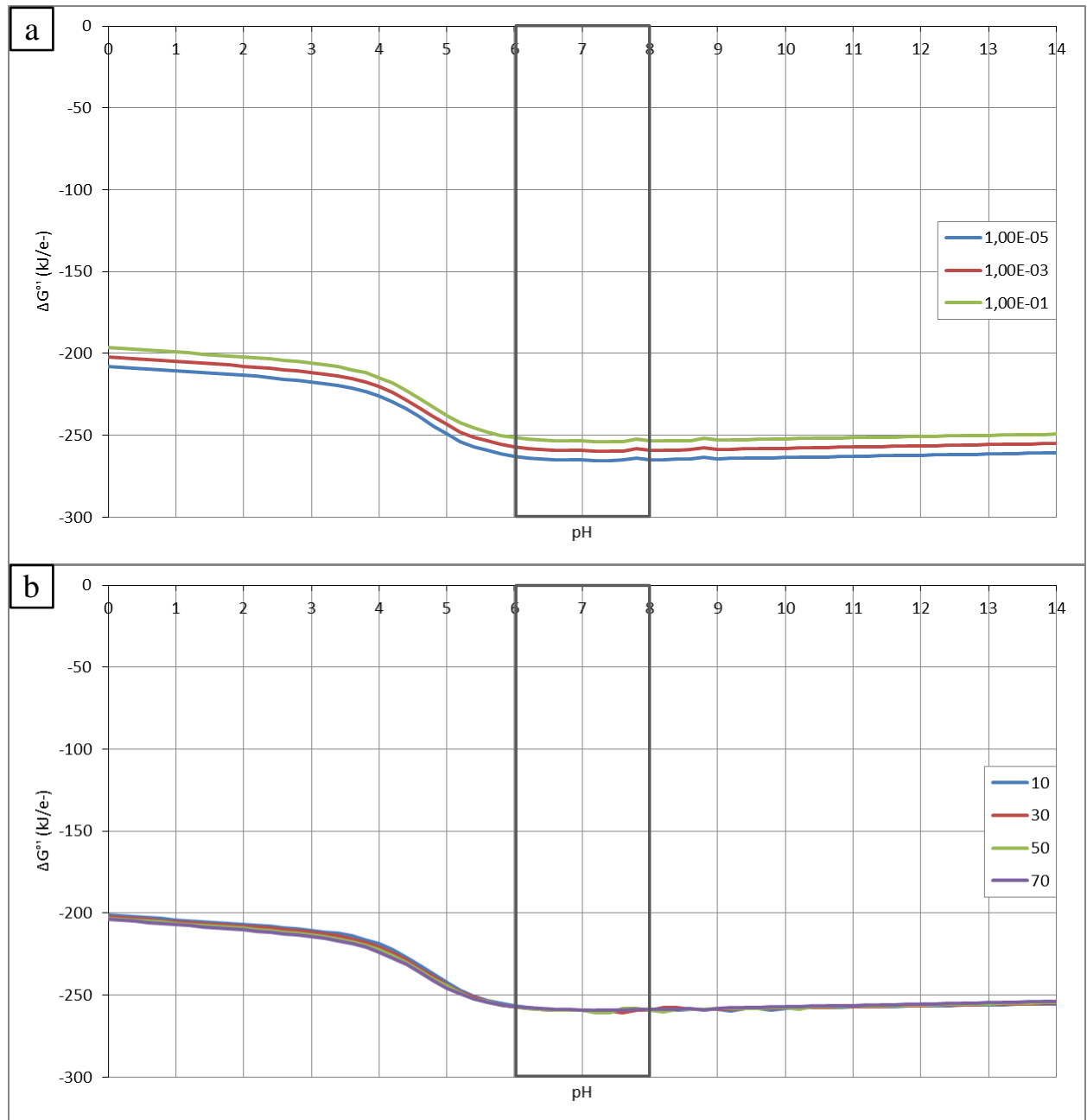

Figura 73. Energia livre da fixação em ausência de nitrogênio assimilável por fotofermentação de acetato com bactérias púrpuras não sulfurosas como função a) do pH e pressão parcial de hidrogênio (atm) e b) do $\mathrm{pH}$ e temperatura $\left({ }^{\circ} \mathrm{C}\right)$. 
Tabela 35. Biorreação do modelo biotermodinâmico e estequiometria $\left(\mathrm{T}=25^{\circ} \mathrm{C}\right)$ da produção de glicose por fotofermentação de lactato com bactérias púrpuras não sulfurosas.

Reação 79

$$
\mathrm{R}=f s^{\circ} 22+f e \sqrt{30}-42
$$

$f_{s}^{\circ} \quad \Delta_{r} H^{\circ}$

$\left(\mathrm{kJ} \mathrm{e}^{-} \mathrm{eq}^{-1}\right)$

. $8,33 \times 10^{-2} \mathrm{C}_{3} \mathrm{H}_{5} \mathrm{O}_{3}^{-}+3,58 \times 10^{-2} \mathrm{NH}_{4}^{+}+3,61 \times 10^{-4} \mathrm{NH}_{3}+1,45 \times 10^{-3} \mathrm{H}_{2} \mathrm{PO}_{4}^{-}$

$+7,23 \times 10^{-4} \mathrm{HPO}_{4}^{2-}+1,81 \times 10^{-3} \mathrm{H}_{2} \mathrm{~S}+1,81 \times 10^{-3} \mathrm{HS}^{-}+5,19 \times 10^{-2} \mathrm{H}^{+}+$

$\stackrel{ }{\|} 2,00 \mathrm{hv} \rightleftharpoons 3,61 \times 10^{-2} \mathrm{C}_{5} \mathrm{H}_{7} \mathrm{O}_{2} \mathrm{NP}_{0,06} \mathrm{~S}_{0,1}+1,14 \times 10^{-2} \mathrm{C}_{6} \mathrm{H}_{12} \mathrm{O}_{6}+5,21 \times 10^{-}$

$0,73-248,7$

2. ${ }^{4} \mathrm{CO}_{2}+3,83 \times 10^{-4} \mathrm{HCO}_{3}^{-}+1,16 \times 10^{-1} \mathrm{H}_{2} \mathrm{O}$

n $8,33 \times 10^{-2} \mathrm{C}_{3} \mathrm{H}_{5} \mathrm{O}_{3}^{-}+4,75 \times 10^{-4} \mathrm{CO}_{3}{ }^{2-}+3,53 \times 10^{-2} \mathrm{NH}_{4}^{+}+7,21 \times 10^{-4} \mathrm{NH}_{3}+$

- $7,21 \times 10^{-4} \mathrm{H}_{2} \mathrm{PO}_{4}^{-}+1,44 \times 10^{-3} \mathrm{HPO}_{4}{ }^{2-}+1,08 \times 10^{-3} \mathrm{H}_{2} \mathrm{~S}+2,52 \times 10^{-3} \mathrm{HS}^{-}+$

$\stackrel{ \pm}{\|} 5,40 \times 10^{-2} \mathrm{H}^{+}+2,00 \mathrm{~h} v \rightleftharpoons 3,61 \times 10^{-2} \mathrm{C}_{5} \mathrm{H}_{7} \mathrm{O}_{2} \mathrm{NP}_{0,06} \mathrm{~S}_{0,1}+1,14 \times 10^{-2} \mathrm{C}_{6} \mathrm{H}_{12} \mathrm{O}_{6}$

2. $+3,18 \times 10^{-4} \mathrm{CO}_{2}+1,06 \times 10^{-3} \mathrm{HCO}_{3}^{-}+1,16 \times 10^{-1} \mathrm{H}_{2} \mathrm{O}$

ㅇ. $8,36 \times 10^{-2} \mathrm{C}_{3} \mathrm{H}_{5} \mathrm{O}_{3}^{-}+4,41 \times 10^{-4} \mathrm{CO}_{2}+2,29 \times 10^{-4} \mathrm{CO}_{3}{ }^{2-}+3,43 \times 10^{-2} \mathrm{NH}_{4}^{+}+$

$\infty \quad 1,81 \times 10^{-3} \mathrm{NH}_{3}+3,62 \times 10^{-4} \mathrm{H}_{2} \mathrm{PO}_{4}^{-}+1,81 \times 10^{-3} \mathrm{HPO}_{4}{ }^{2-}+3,62 \times 10^{-4} \mathrm{H}_{2} \mathrm{~S}+$

$3,25 \times 10^{-3} \mathrm{HS}^{-}+5,54 \times 10^{-2} \mathrm{H}^{+}+2,01 \mathrm{hv} \rightleftharpoons 3,62 \times 10^{-2} \mathrm{C}_{5} \mathrm{H}_{7} \mathrm{O}_{2} \mathrm{NP}_{0,06} \mathrm{~S}_{0,1}+$ $0,73-249,3$

2. $1,14 \times 10^{-2} \mathrm{C}_{6} \mathrm{H}_{12} \mathrm{O}_{6}+1,57 \times 10^{-3} \mathrm{HCO}_{3}^{-}+1,16 \times 10^{-1} \mathrm{H}_{2} \mathrm{O}$
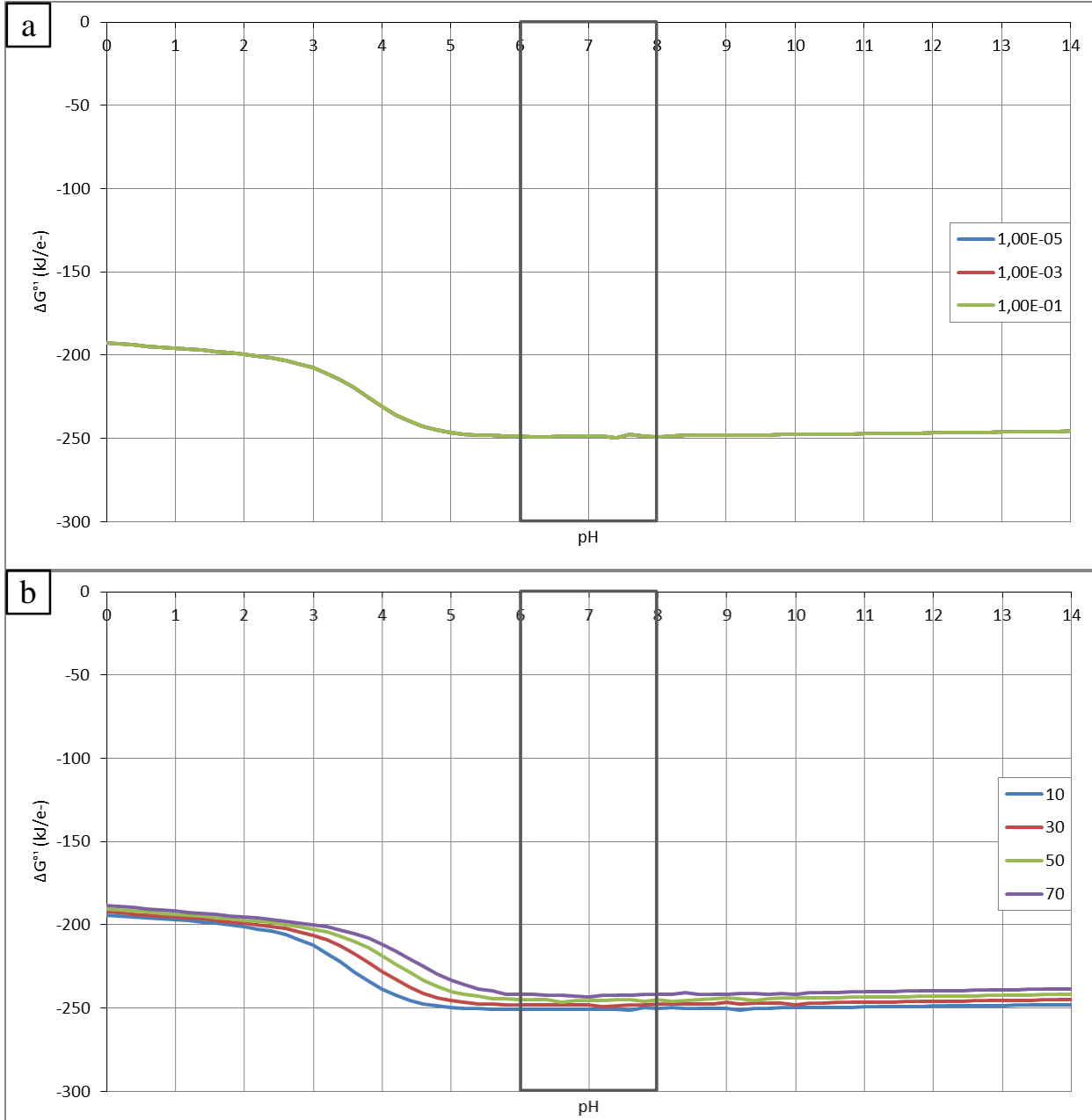

Figura 74. Energia livre da produção de glicose por fotofermentação de lactato com bactérias púrpuras não sulfurosas como função a) do $\mathrm{pH}$ e pressão parcial de hidrogênio (atm) e b) do $\mathrm{pH}$ e temperatura $\left({ }^{\circ} \mathrm{C}\right)$. 
Tabela 36. Biorreação do modelo biotermodinâmico e estequiometria $\left(\mathrm{T}=25^{\circ} \mathrm{C}\right)$ da fixação de nitrogênio por fotofermentação de lactato com bactérias púrpuras não sulfurosas.

\begin{tabular}{|c|c|c|c|}
\hline \multicolumn{2}{|c|}{ Reação 80} & $f_{s}^{\circ}$ & $\begin{array}{c}\Delta_{r} G^{\circ} \\
\Delta_{r} H^{\circ} \\
\left(\mathrm{kJ} \mathrm{e}^{-} \mathrm{eq}^{-1}\right)\end{array}$ \\
\hline $\begin{array}{l}\stackrel{0}{\sim} \\
\text { II } \\
\frac{\pi}{2}\end{array}$ & $\begin{array}{l}8,33 \times 10^{-2} \mathrm{C}_{3} \mathrm{H}_{5} \mathrm{O}_{3}^{-}+2,49 \times 10^{-1} \mathrm{NH}_{4}^{+}+1,25 \times 10^{-3} \mathrm{NH}_{3}+1,25 \times 10^{-1} \mathrm{~N}_{2}+ \\
4,54 \times 10^{-1} \mathrm{H}_{2} \mathrm{O}+1,28 \times 10^{-1} \mathrm{H}^{+}+2,00 \mathrm{~h} v \rightleftharpoons 4,58 \times 10^{-2} \mathrm{CO}_{2}+2,04 \times 10^{-} \\
{ }^{1} \mathrm{HCO}_{3}{ }^{-}+1,25 \times 10^{-1} \mathrm{H}_{2}\end{array}$ & - & $\begin{array}{l}-296,3 \\
-280,3\end{array}$ \\
\hline 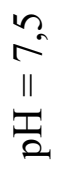 & $\begin{array}{l}8,33 \times 10^{-2} \mathrm{C}_{3} \mathrm{H}_{5} \mathrm{O}_{3}^{-}+2,46 \times 10^{-1} \mathrm{NH}_{4}^{+}+3,75 \times 10^{-3} \mathrm{NH}_{3}+1,25 \times 10^{-1} \mathrm{~N}_{2}+ \\
4,83 \times 10^{-1} \mathrm{H}_{2} \mathrm{O}+9,63 \times 10^{-2} \mathrm{H}^{+}+2,00 \mathrm{~h} v \rightleftharpoons 1,67 \times 10^{-2} \mathrm{CO}_{2}+2,33 \times 10^{-} \\
{ }^{1} \mathrm{HCO}_{3}{ }^{-}+1,25 \times 10^{-1} \mathrm{H}_{2}\end{array}$ & - & $\begin{array}{l}-299,2 \\
-280,0\end{array}$ \\
\hline $\begin{array}{l}\infty \\
\infty \\
\| \\
\stackrel{2}{2}\end{array}$ & $\begin{array}{l}8,36 \times 10^{-2} \mathrm{C}_{3} \mathrm{H}_{5} \mathrm{O}_{3}^{-}+2,36 \times 10^{-1} \mathrm{NH}_{4}^{+}+1,38 \times 10^{-2} \mathrm{NH}_{3}+1,25 \times 10^{-1} \mathrm{~N}_{2}+ \\
4,94 \times 10^{-1} \mathrm{H}_{2} \mathrm{O}+7,40 \times 10^{-2} \mathrm{H}^{+}+2,01 \mathrm{~h} v \rightleftharpoons 5,02 \times 10^{-3} \mathrm{CO}_{2}+2,44 \times 10^{-} \\
{ }^{1} \mathrm{HCO}_{3}{ }^{-}+8,36 \times 10^{-4} \mathrm{CO}_{2}+1,25 \times 10^{-1} \mathrm{H}_{2}\end{array}$ & - & $\begin{array}{l}-302,8 \\
-280,3\end{array}$ \\
\hline
\end{tabular}
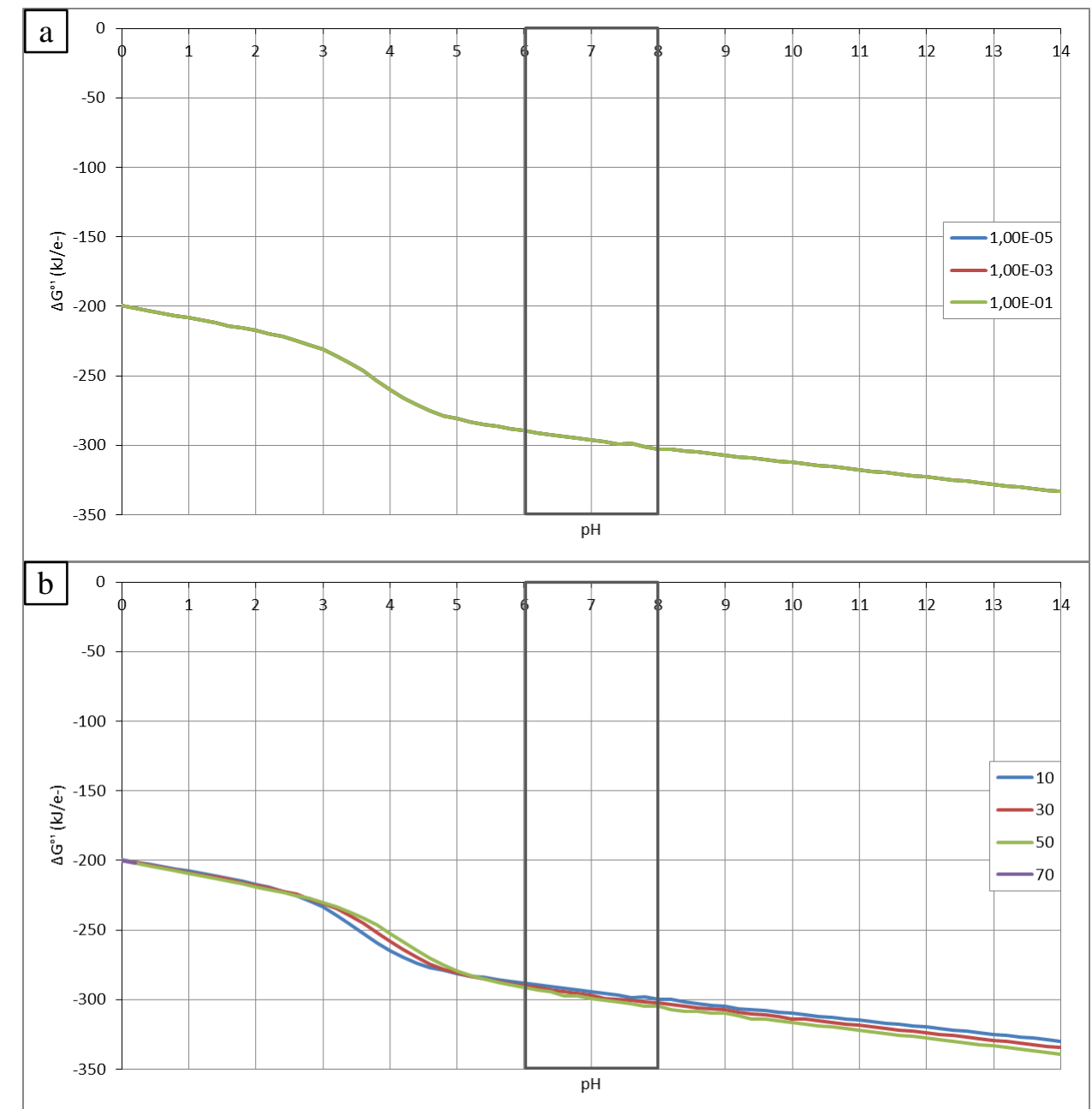

Figura 75. Energia livre da fixação de nitrogênio por fotofermentação de lactato com bactérias púrpuras não sulfurosas como função a) do $\mathrm{pH}$ e pressão parcial de hidrogênio (atm) e b) do $\mathrm{pH}$ e temperatura $\left({ }^{\circ} \mathrm{C}\right)$. 
Tabela 36. Biorreação do modelo biotermodinâmico e estequiometria $\left(\mathrm{T}=25^{\circ} \mathrm{C}\right)$ da fixação em ausência de nitrogênio assimilável por fotofermentação de lactato com bactérias púrpuras não sulfurosas.

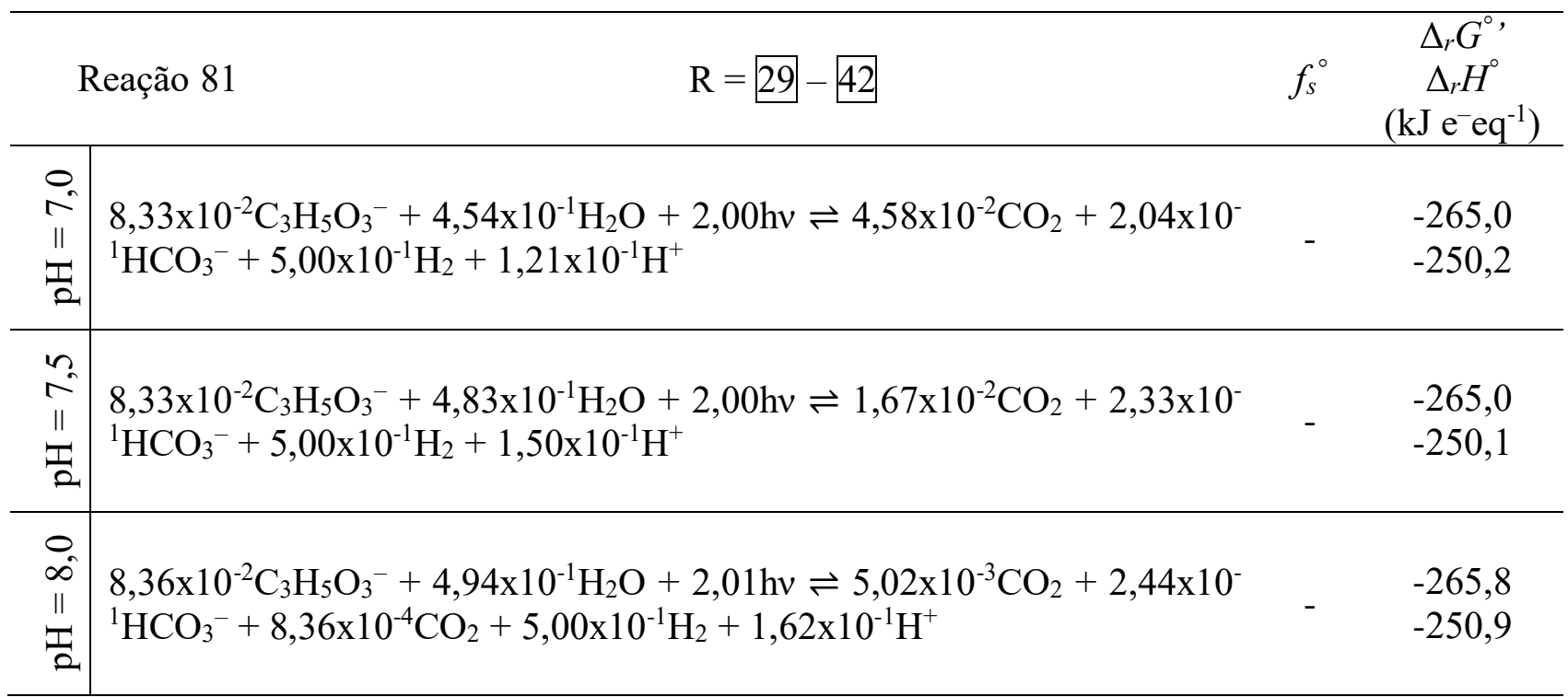
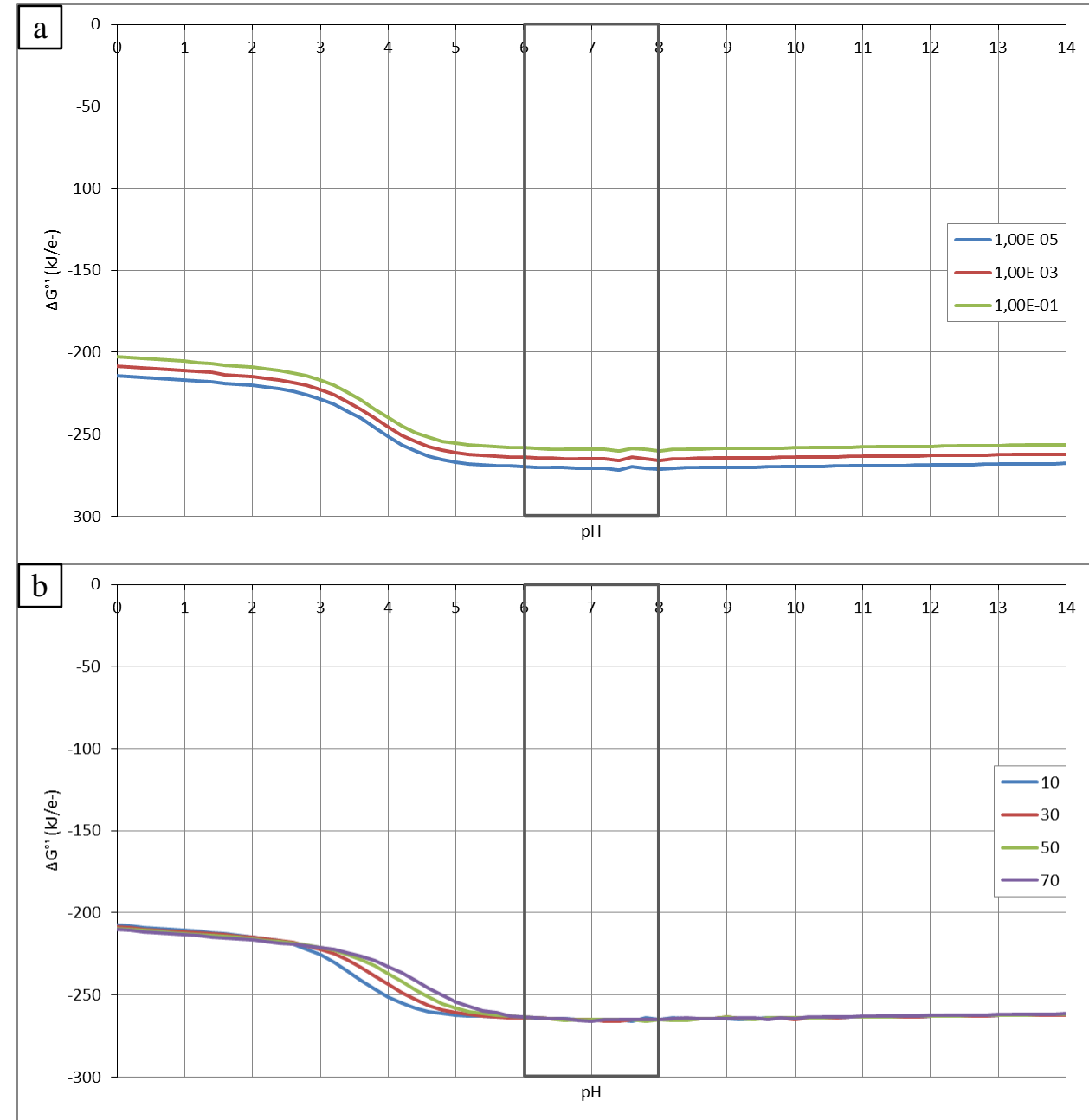

Figura 76. Energia livre da fixação em ausência de nitrogênio assimilável por fotofermentação de lactato com bactérias púrpuras não sulfurosas como função a) do pH e pressão parcial de hidrogênio (atm) e b) do $\mathrm{pH}$ e temperatura $\left({ }^{\circ} \mathrm{C}\right)$. 
Os comportamentos da energia livre na produção de bactérias púrpuras não sulfurosas com crescimento sobre acetato (Figura 71) e lactato (Figura 74) são muito parecidos. As diferenças presentes são consequência do uso de uma ou outra fonte de carbono; assim, quando o crescimento é sobre lactato, se dissipa uma energia livre levemente superior em todo o intervalo de $\mathrm{pH}$ que quando o crescimento é sobre acetato. Para os dois processos, a energia livre dissipada se incrementa significativamente para $\mathrm{pH}$ superiores a 3,0 favorecendo as conversões, e se estabiliza em pH superiores a 6,0. A pressão parcial de hidrogênio não influi devido a que não é consumido nem produzido (Figuras 71a e 74a), enquanto o aumento da temperatura diminui a energia livre dissipada em uma pequena percentagem, desfavorecendo levemente a conversão (Figuras $71 b$ e 74b). Não obstante, para crescimento sobre lactato (Reação 79), o efeito da temperatura é significativo no intervalo de $\mathrm{pH}$ entre 3,0 e 5,0. Nestes processos de crescimento celular, como com bactérias sulfurosas, a grande energia livre dissipada é gerada pela captação da energia dos fótons, garantindo altas conversões.

Os resultados de energia livre dissipada e entalpia das Tabelas 32 e 35 para as reações de crescimento celular (Reações 76 e 79) evidenciam que o metabolismo fotossintético anoxigênico diminui a entropia do sistema pela transformação de reagentes de entropia alta em produtos de entropia baixa e, como na fotossíntese oxigênica, o aumento da entropia do universo se produz pela transferência de calor (entalpia) dos microorganismos aos redores.

Também são muito parecidos os comportamentos da energia livre na biofotólise indireta para a produção de hidrogênio pela nitrogenase quando o nitrogênio gasoso está presente (Figuras 72 e 75) ou ausente (Figuras 73 e 76). Quando o nitrogênio gasoso está disponível, a energia livre dissipada aumenta significativamente com o aumento do $\mathrm{pH}$ favorecendo a conversão. Por outro lado, a pressão parcial de hidrogênio não influi na energia livre dissipada (Figuras 72a e 75a), enquanto a temperatura tem um efeito marginal (Figuras 72 b e 75b). Quando o nitrogênio gasoso não está disponível, a energia livre dissipada aumenta significativamente para $\mathrm{pH}$ superiores a 3,0 favorecendo as conversões, e se estabiliza em $\mathrm{pH}$ superiores a 6,0. Por outro lado, a diminuição da pressão parcial de hidrogênio (Figuras 73a e 76a), produto da reação, favorece o incremento da energia livre dissipada, enquanto a temperatura tem um efeito marginal (Figuras $73 b$ e 76b) com exceção do intervalo de $\mathrm{pH}$ entre 3,0 e 5,0 para o crescimento sobre lactato, no qual o efeito é perceptível.

Finalmente, todas as fixações de nitrogênio pela nitrogenase nas bactérias anoxigênicas são espontâneas nos intervalos de $\mathrm{pH}$ (0 a 14), pressões parciais de hidrogênio $\left(1,00 \times 10^{-5}\right.$ a $\left.1,00 \mathrm{~atm}\right)$ e temperatura $\left(10\right.$ a $\left.70{ }^{\circ} \mathrm{C}\right)$ avaliados; portanto, acontecem naturalmente sob condições químicas adequadas. 


\subsection{Rendimentos molares da fotossíntese anoxigênica}

A partir da estequiometria estabelecida pelo modelo biotermodinâmico se obtêm os rendimentos dos produtos da fotossíntese anoxigênica. A Figura 77 apresenta os rendimentos com bactérias verdes sulfurosas (Reação 70), púrpuras sulfurosas (Reação 73) e púrpuras não sulfurosas com crescimento sobre acetato (Reação 76) e lactato (Reação 79), em mols produzidas por $8 \mathrm{~mol}$ de fótons em função do $\mathrm{pH}$ para $25^{\circ} \mathrm{C}$.

A Figura 78 apresenta os mesmos rendimentos com bactérias verdes e púrpuras sulfurosas e púrpuras não sulfurosas, mas em função da temperatura para um pH 7,00.

Os resultados mostram que os rendimentos dos produtos para bactérias com metabolismo fotolitotrófico (verdes e púrpuras sulfurosas) praticamente não são influídos pelo pH (Figuras 77a e 77b) e são debilmente influídos pela temperatura (Figuras 78a e 78b); seu aumento desfavorece debilmente o rendimento das células. Além disso, embora os resultados sejam muito parecidos, os fótons de maior energia que participam na fotossíntese das bactérias verdes sulfurosas $(\lambda=840 \mathrm{~nm})$, favorecem levemente o rendimento das células quando comparado com o rendimento obtido com bactérias púrpuras sulfurosas $(\lambda=870 \mathrm{~nm})$ e, em consequência, desfavorecem o rendimento da glicose. Para as bactérias com metabolismo fotoorganotrófico (púrpuras não sulfurosas) o aumento do $\mathrm{pH}$ por acima do valor de $\mathrm{pK}_{\mathrm{A}}(4,8$ para acetato e 3,9 para lactato) favorece o rendimento das células (Figuras $77 \mathrm{c}$ e $77 \mathrm{~d}$ ), enquanto a temperatura não influi significativamente (Figuras $78 \mathrm{c}$ e $78 \mathrm{~d}$ ). Finalmente, os rendimentos de glicose são levemente superiores quando o crescimento é sobre acetato que sobre lactato.

A Figura 79 apresenta a distribuição dos elétrons transferidos do doador (sulfeto para os metabolismos fotolitotróficos e acetato ou lactato para os metabolismos fotoorganotróficos) aos produtos reduzidos produzidos na fotossíntese anoxigênica com bactérias verdes sulfurosas (Reação 70), púrpuras sulfurosas (Reação 73) e púrpuras não sulfurosas com crescimento sobre acetato (Reação 76) e lactato (Reação 79), em função do $\mathrm{pH}$ para $25^{\circ} \mathrm{C}$.

Os resultados evidenciam que a fração de elétrons destinada aos produtos do metabolismo da fotossíntese anoxigênica fotolitotrófica (bactérias verdes e púrpuras sulfurosas) é quase a mesma, mas levemente superior para bactérias verdes sulfurosas, enquanto para a fotossíntese anoxigênica fotoorganotrófica (bactérias púrpuras sulfurosas) a fração de elétrons para o crescimento sobre acetato favorece a produção de glicose quando comparada com a fração para crescimento sobe lactato. 

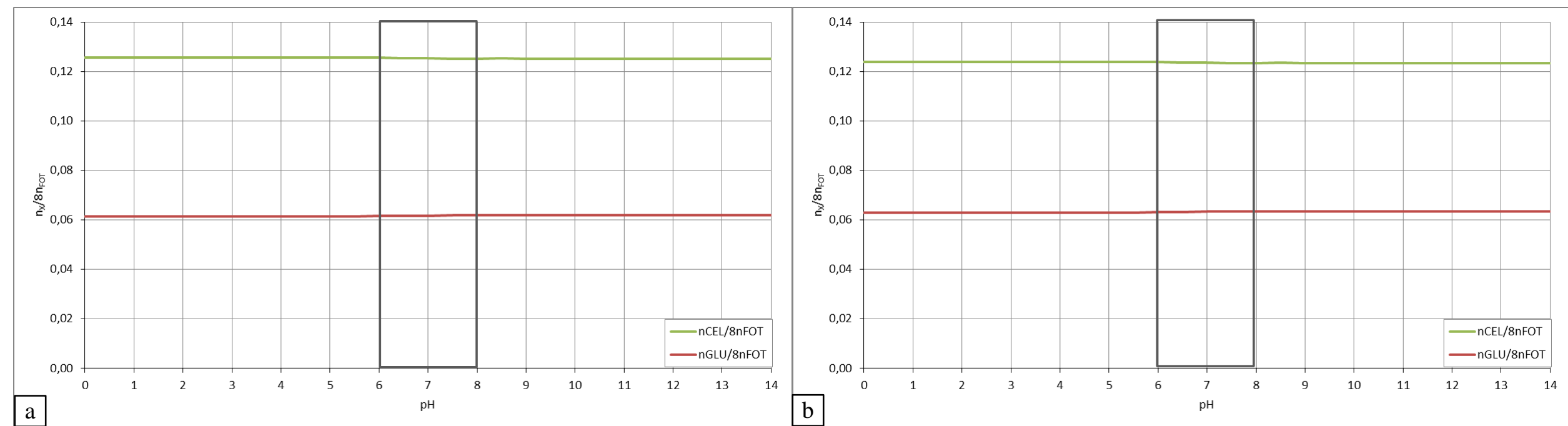

$\mathrm{a}$
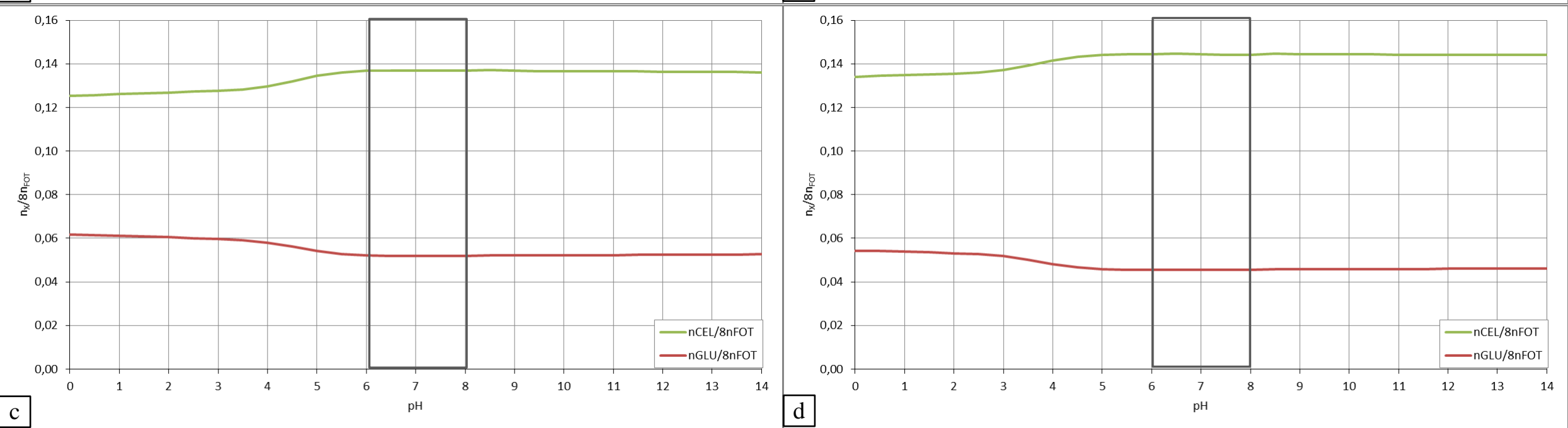

Figura 77. Rendimento dos produtos da fotossíntese anoxigênica com bactérias a) verdes sulfurosas, b) púrpuras sulfurosas, c) púrpuras não sulfurosas com crescimento sobre acetato e d) púrpuras não sulfurosas com crescimento sobre lactato, em mols produzidas por 8 mols de fótons em função do $\mathrm{pH}\left(\mathrm{T}=25^{\circ} \mathrm{C}, \mathrm{p}_{\mathrm{H} 2}=1,00 \times 10^{-3} \mathrm{~atm}\right)$. 

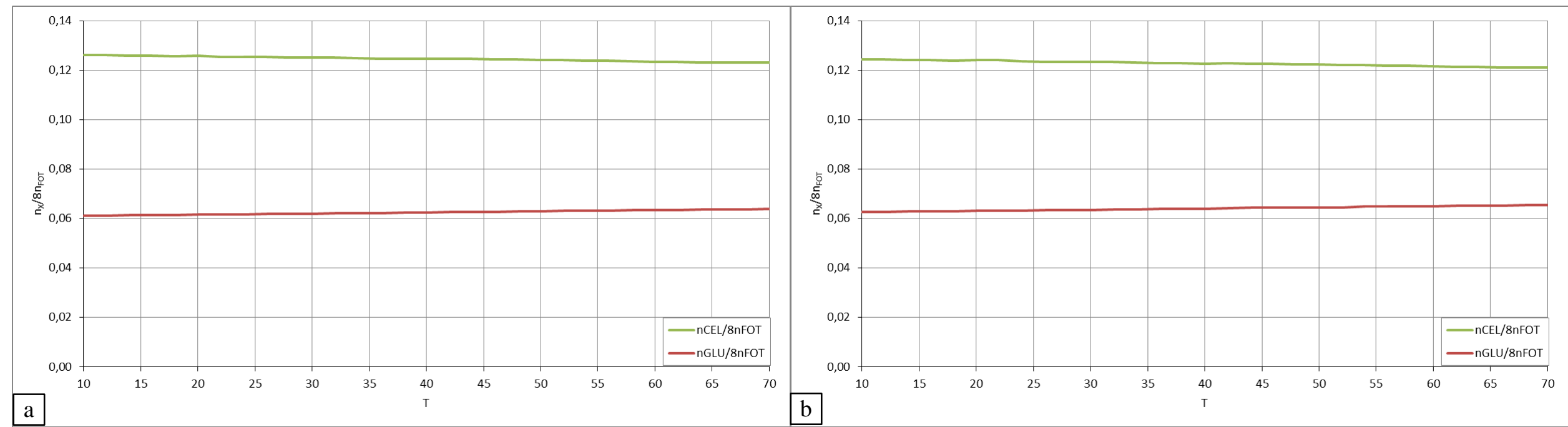

$\mathrm{a}$
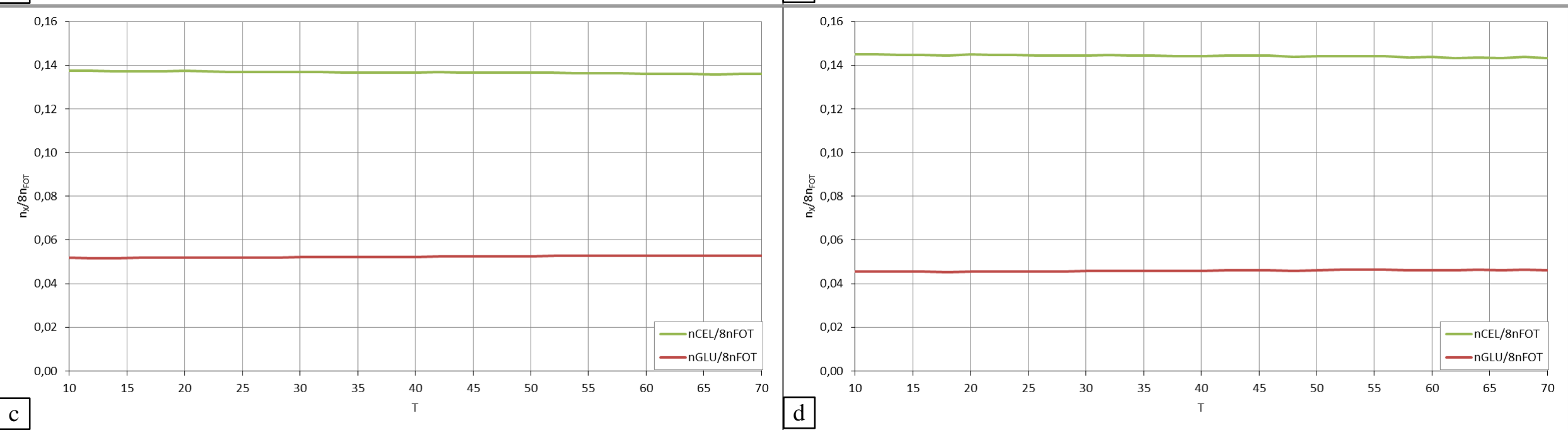

Figura 78. Rendimento dos produtos da fotossíntese anoxigênica com bactérias a) verdes sulfurosas, b) púrpuras sulfurosas, c) púrpuras não sulfurosas com crescimento sobre acetato e d) púrpuras não sulfurosas com crescimento sobre lactato, em mols produzidas por 8 mols de fótons em função da temperatura ( $\left.\mathrm{pH}=7,00, \mathrm{p}_{\mathrm{H} 2}=1,00 \times 10^{-3} \mathrm{~atm}\right)$. 

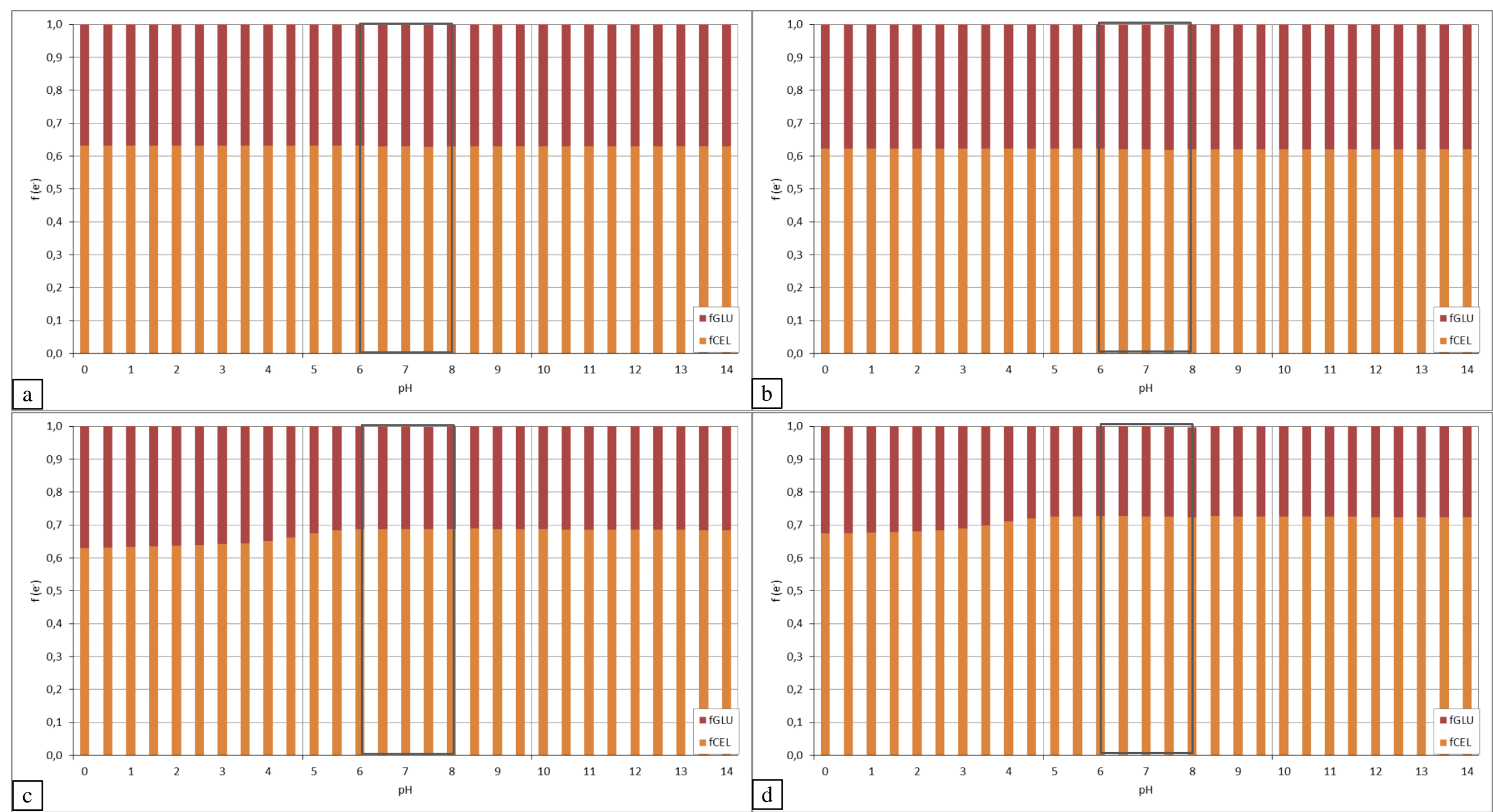

Figura 79. Fração de elétrons transferidos do doador a cada produto reduzido na fotossíntese anoxigênica com bactérias a) verdes sulfurosas, b) púrpuras sulfurosas, c) púrpuras não sulfurosas com crescimento sobre acetato e d) púrpuras não sulfurosas com crescimento sobre lactato, em função do $\mathrm{pH}\left(\mathrm{T}=25^{\circ} \mathrm{C}, \mathrm{p}_{\mathrm{H} 2}=1,00 \times 10^{-3} \mathrm{~atm}\right)$. 
$\mathrm{Na}$ fotossíntese anoxigênica, devido a que o oxigênio não está presente, os elétrons do doador podem-se usar diretamente para a fixação de nitrogênio gasoso pela nitrogenase produzindo amoníaco e hidrogênio (Reação 58) ou unicamente hidrogênio na ausência de nitrogênio gasoso (Reação 60). Esta é uma diferença fundamente respeito à fixação de nitrogênio na fotossíntese oxigênica com cianobactérias (Seção 5.1.2), na qual os elétrons são obtidos dos produtos de armazenamento.

Para as fixações da fotossíntese anoxigênica, a Figura 80 apresenta os rendimentos dos produtos da biofotólise indireta pela atividade da nitrogenase, na presença de nitrogênio gasoso, com bactérias verdes sulfurosas (Reação 71), púrpuras sulfurosas (Reação 74) e púrpuras não sulfurosas com crescimento sobre acetato (Reação 77) e lactato (Reação 80), em mols produzidas por $8 \mathrm{~mol}$ de fótons em função do $\mathrm{pH}$ para $25^{\circ} \mathrm{C}$.

A Figura 81 apresenta os mesmos rendimentos, mas em função da temperatura para um $\mathrm{pH} 7,00$.

Os resultados mostram que todos os rendimentos são iguais independentemente das bactérias e dos metabolismos e não são influídos pelo pH (Figura 80) ou pela temperatura (Figura 81). A lógica destes resultados é que os elétrons passam à nitrogenase diretamente do doador no sistema fotossintético e não por meio de intermediários de armazenamento como a glicose, como ocorre nas cianobactérias.

A Figura 82 apresenta a distribuição dos elétrons transferidos do doador (sulfeto para os metabolismos fotolitotróficos e acetato ou lactato para os metabolismos fotoorganotróficos) aos produtos reduzidos produzidos na biofotólise indireta pela atividade da nitrogenase, na presença de nitrogênio gasoso, com bactérias verdes sulfurosas (Reação 71), púrpuras sulfurosas (Reação 74) e púrpuras não sulfurosas com crescimento sobre acetato (Reação 77) e lactato (Reação 80), em função do $\mathrm{pH}$ para $25^{\circ} \mathrm{C}$.

Os resultados das frações de elétrons na presença de nitrogênio gasoso também são iguais independentemente das bactérias e dos metabolismos e não são influídos pelo pH. A fração de elétrons destinada à produção de hidrogênio é de 0,25 , enquanto o 0,75 restante destina-se à fixação de nitrogênio gasoso em amoníaco.

Quando o nitrogênio gasoso está ausente, todos os elétrons do doador se usam pela nitrogenase para a produção de hidrogênio atingindo o máximo rendimento (Reação 60). Para as fixações da fotossíntese anoxigênica, a Figura 83 apresenta os rendimentos dos produtos da biofotólise indireta pela atividade da nitrogenase, na ausência de nitrogênio gasoso, com bactérias verdes sulfurosas (Reação 72), púrpuras sulfurosas (Reação 75) e púrpuras não 

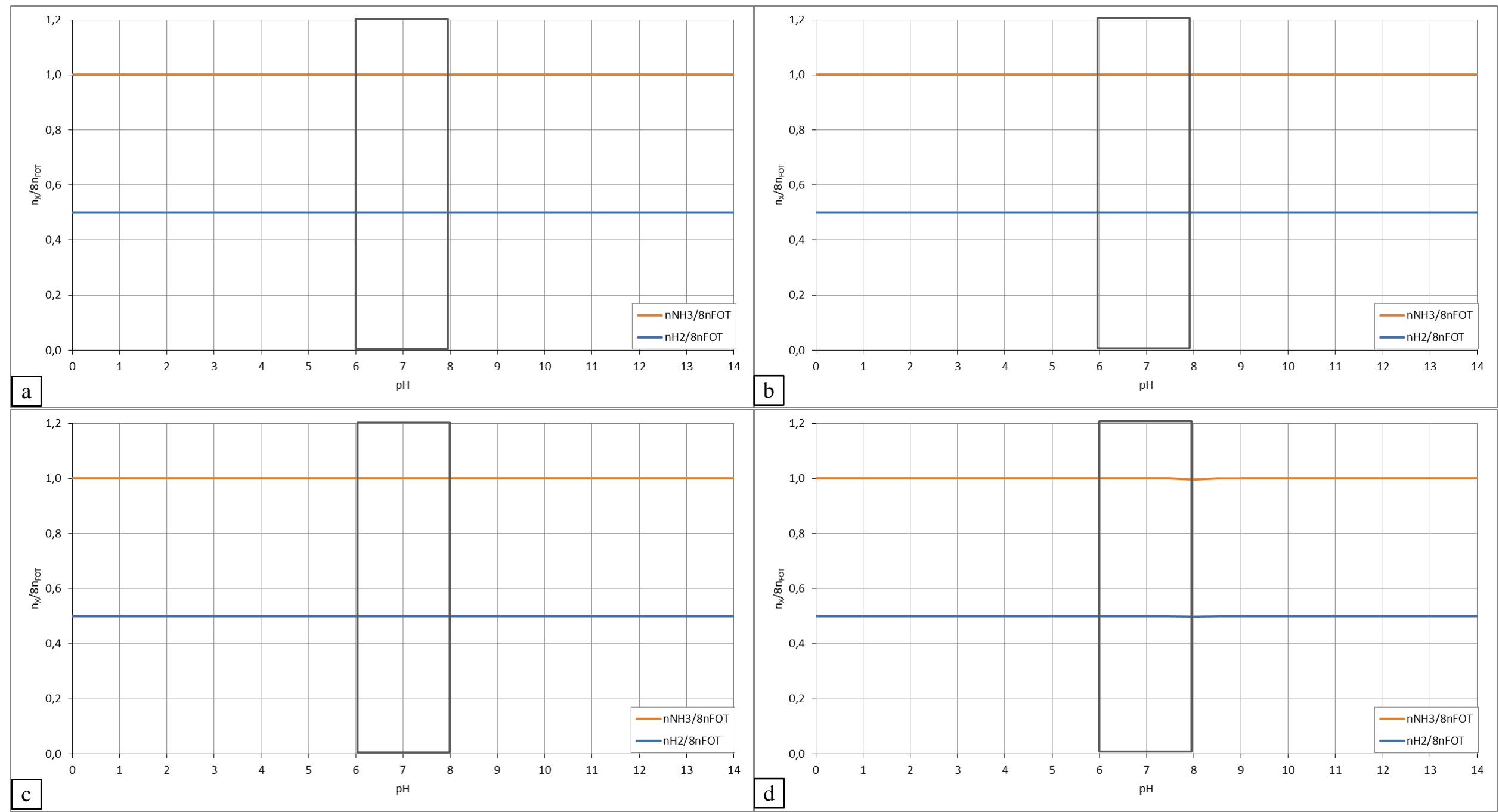

Figura 80. Rendimento dos produtos da biofotólise indireta pela atividade da nitrogenase, na presença de nitrogênio gasoso, com bactérias a)

verdes sulfurosas, b) púrpuras sulfurosas, c) púrpuras não sulfurosas com crescimento sobre acetato e d) púrpuras não sulfurosas com crescimento sobre lactato, em mols produzidas por 8 mols de fótons em função do $\mathrm{pH}\left(\mathrm{T}=25^{\circ} \mathrm{C}, \mathrm{p}_{\mathrm{H} 2}=1,00 \times 10^{-3} \mathrm{~atm}\right)$. 

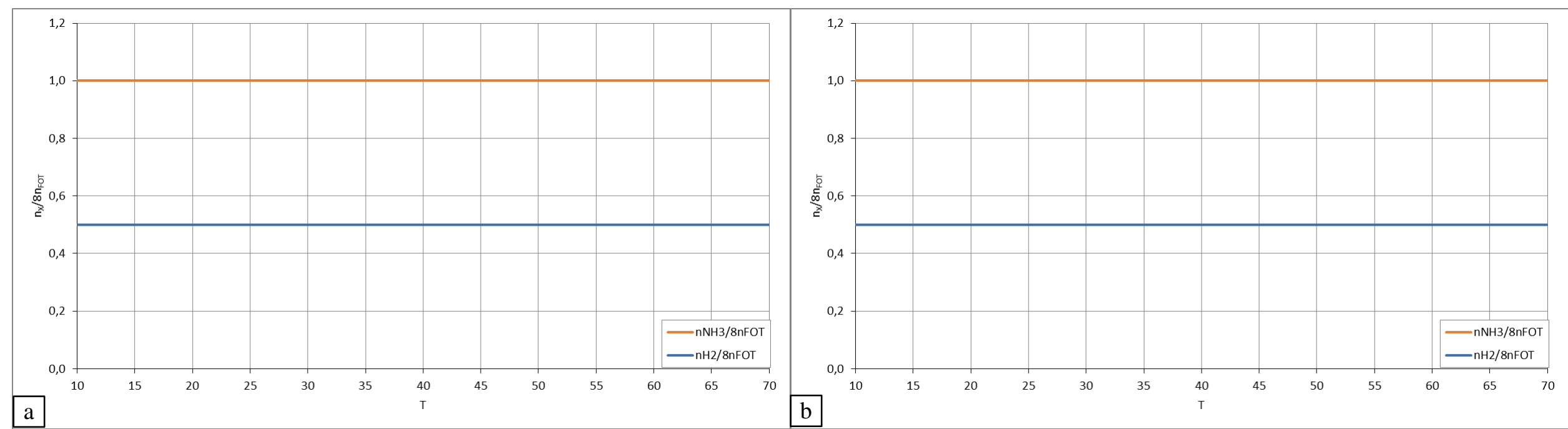
$\mathrm{b}$
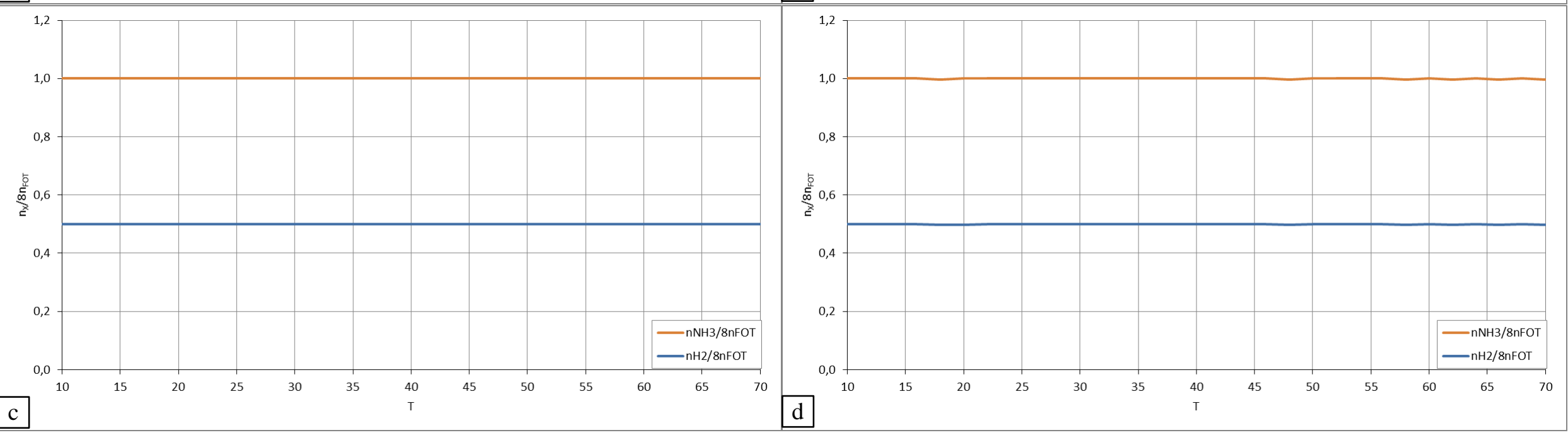

Figura 81. Rendimento dos produtos da biofotólise indireta pela atividade da nitrogenase, na presença de nitrogênio gasoso, com bactérias a)

verdes sulfurosas, b) púrpuras sulfurosas, c) púrpuras não sulfurosas com crescimento sobre acetato e d) púrpuras não sulfurosas com crescimento sobre lactato, em mols produzidas por 8 mols de fótons em função da temperatura $\left(\mathrm{pH}=7,00, \mathrm{p}_{\mathrm{H} 2}=1,00 \times 10^{-3} \mathrm{~atm}\right)$. 

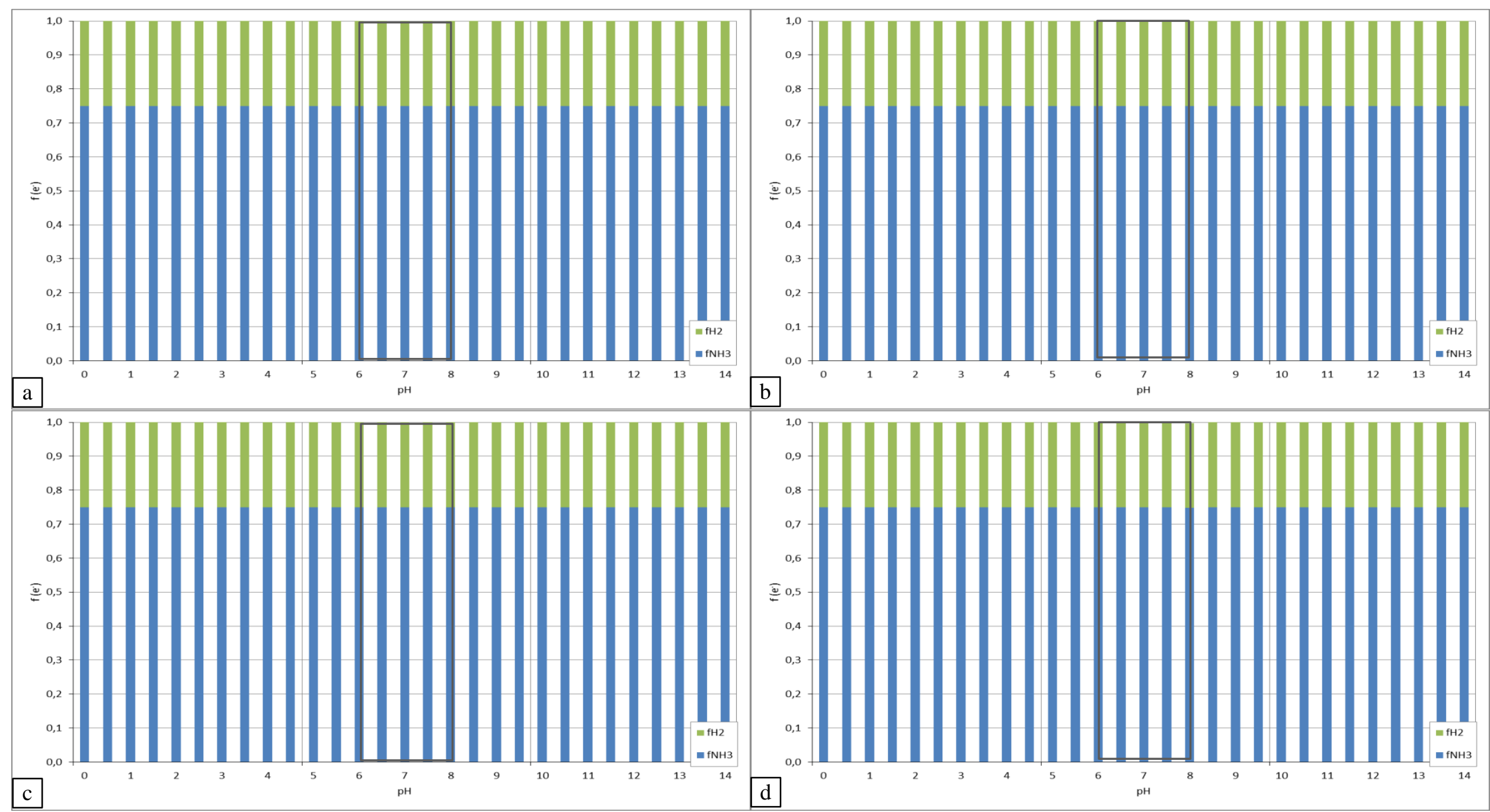

Figura 82. Fração de elétrons transferidos do doador a cada produto reduzido na biofotólise indireta pela atividade da nitrogenase, na presença de nitrogênio gasoso, com bactérias a) verdes sulfurosas, b) púrpuras sulfurosas, c) púrpuras não sulfurosas com crescimento sobre acetato e d) púrpuras não sulfurosas com crescimento sobre lactato, em função do $\mathrm{pH}\left(\mathrm{T}=25^{\circ} \mathrm{C}, \mathrm{p}_{\mathrm{H} 2}=1,00 \times 10^{-3} \mathrm{~atm}\right)$. 
sulfurosas com crescimento sobre acetato (Reação 78) e lactato (Reação 81), em mols produzidas por $8 \mathrm{~mol}$ de fótons em função do $\mathrm{pH}$ para $25^{\circ} \mathrm{C}$.

A Figura 84 apresenta os mesmos rendimentos, mas em função da temperatura para um pH 7,00.

Novamente, os rendimentos são iguais independentemente das bactérias e dos metabolismos e não são influídos pelo pH (Figura 83) ou pela temperatura (Figura 84). Quando o nitrogênio gasoso está ausente, todos os elétrons produzidos pela oxidação da glicose se usam para a produção de hidrogênio; como consequência, o rendimento de hidrogênio quando o nitrogênio está ausente é 4 vezes o rendimento quando está presente.

A Figura 85 apresenta a distribuição dos elétrons transferidos do doador (sulfeto para os metabolismos fotolitotróficos e acetato ou lactato para os metabolismos fotoorganotróficos) aos produtos reduzidos produzidos na biofotólise indireta pela atividade da nitrogenase, na ausência de nitrogênio gasoso, com bactérias verdes sulfurosas (Reação 72), púrpuras sulfurosas (Reação 75) e púrpuras não sulfurosas com crescimento sobre acetato (Reação 78) e lactato (Reação 81), em função do pH para $25^{\circ} \mathrm{C}$.

Os resultados das frações de elétrons mostram que na ausência de nitrogênio gasoso o $100 \%$ dos elétrons se destina para a produção de hidrogênio.

\subsection{Eficiências energéticas da fotossíntese anoxigênica}

A partir dos rendimentos dos produtos de armazenamento da fotossíntese anoxigênica (Figuras 77 e 78) se determinam as eficiências na conversão de energia solar em energia química atingidas pelas bactérias usando a Equação 92.

$$
\eta=\frac{\left(n_{G L U} / 8 n_{F O T} \times \Delta_{C} H_{G L U}^{\circ}\right)}{\left(8 E_{f}(\lambda)+n_{i} / 8 n_{F O T} \times \Delta_{C} H_{i}^{\circ}\right)} \times 100
$$

$\mathrm{Na}$ qual $\eta$ é a eficiência da fotossíntese anoxigênica, $n_{i}$ é o número de mols do componente $i$ e $\Delta_{C} H_{i}^{\circ}$ é a entalpia padrão de combustão do componente $i\left(-2801,4 \mathrm{~kJ}\right.$ mol $_{\mathrm{GLU}}{ }^{-1}$ para glicose, $-874,3 \mathrm{~kJ} \operatorname{mol}_{\mathrm{ACE}}{ }^{-1}$ para acetato e $-1380,0 \mathrm{~kJ}$ mol $_{\mathrm{LAC}}{ }^{-1}$ para lactato). No denominador, $n_{i}$ é o número de mols de acetato ou lactato (unicamente para bactérias púrpuras não sulfurosas). Cabe salientar que nestas estimativas não se considera a fração da energia solar que se converte em energia química representada pelas células dos microorganismos. 

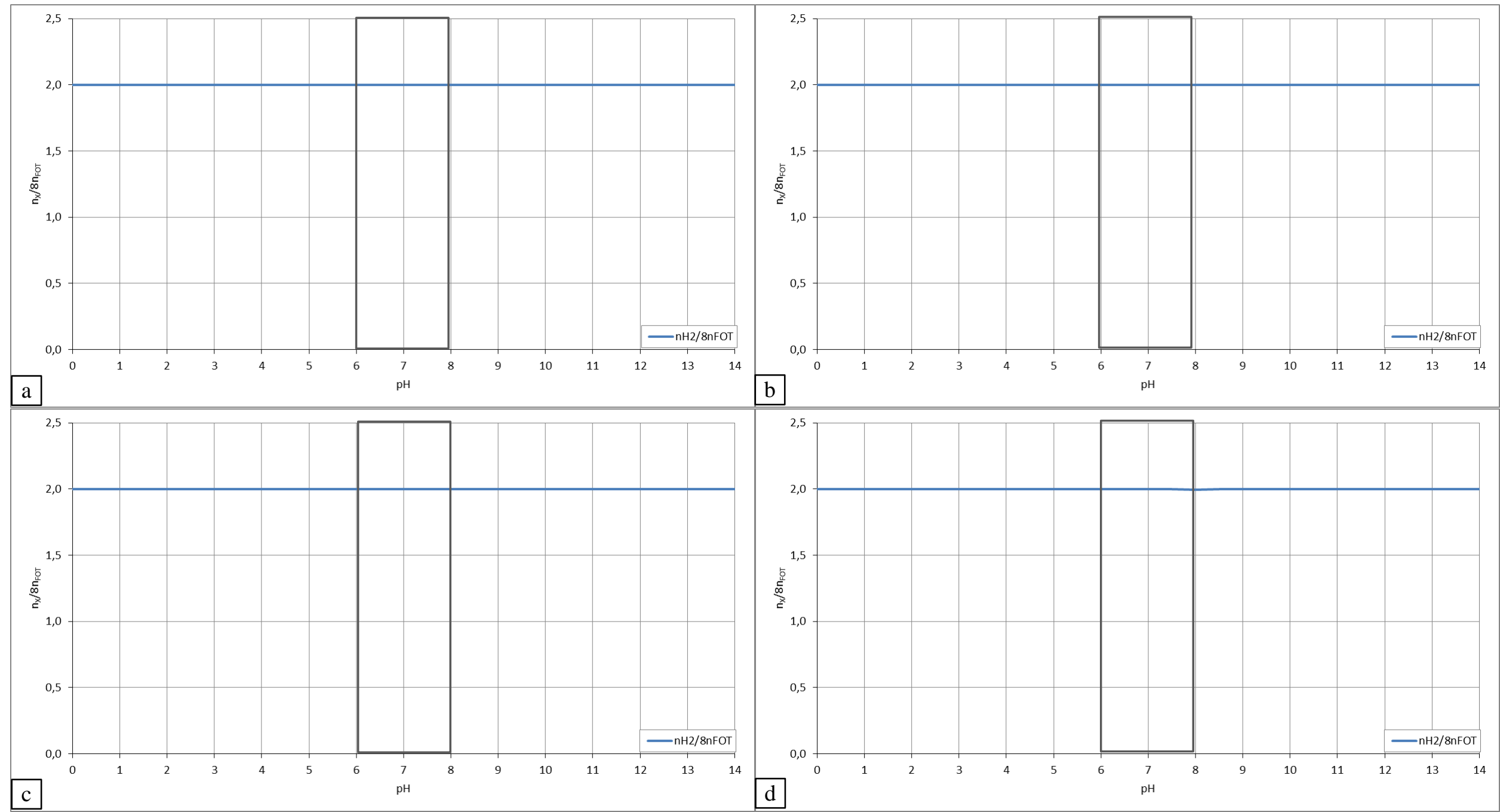

Figura 83. Rendimento dos produtos da biofotólise indireta pela atividade da nitrogenase, na ausência de nitrogênio gasoso, com bactérias a) verdes sulfurosas, b) púrpuras sulfurosas, c) púrpuras não sulfurosas com crescimento sobre acetato e d) púrpuras não sulfurosas com crescimento sobre lactato, em mols produzidas por 8 mols de fótons em função do $\mathrm{pH}\left(\mathrm{T}=25{ }^{\circ} \mathrm{C}, \mathrm{p}_{\mathrm{H} 2}=1,00 \times 10^{-3} \mathrm{~atm}\right)$. 

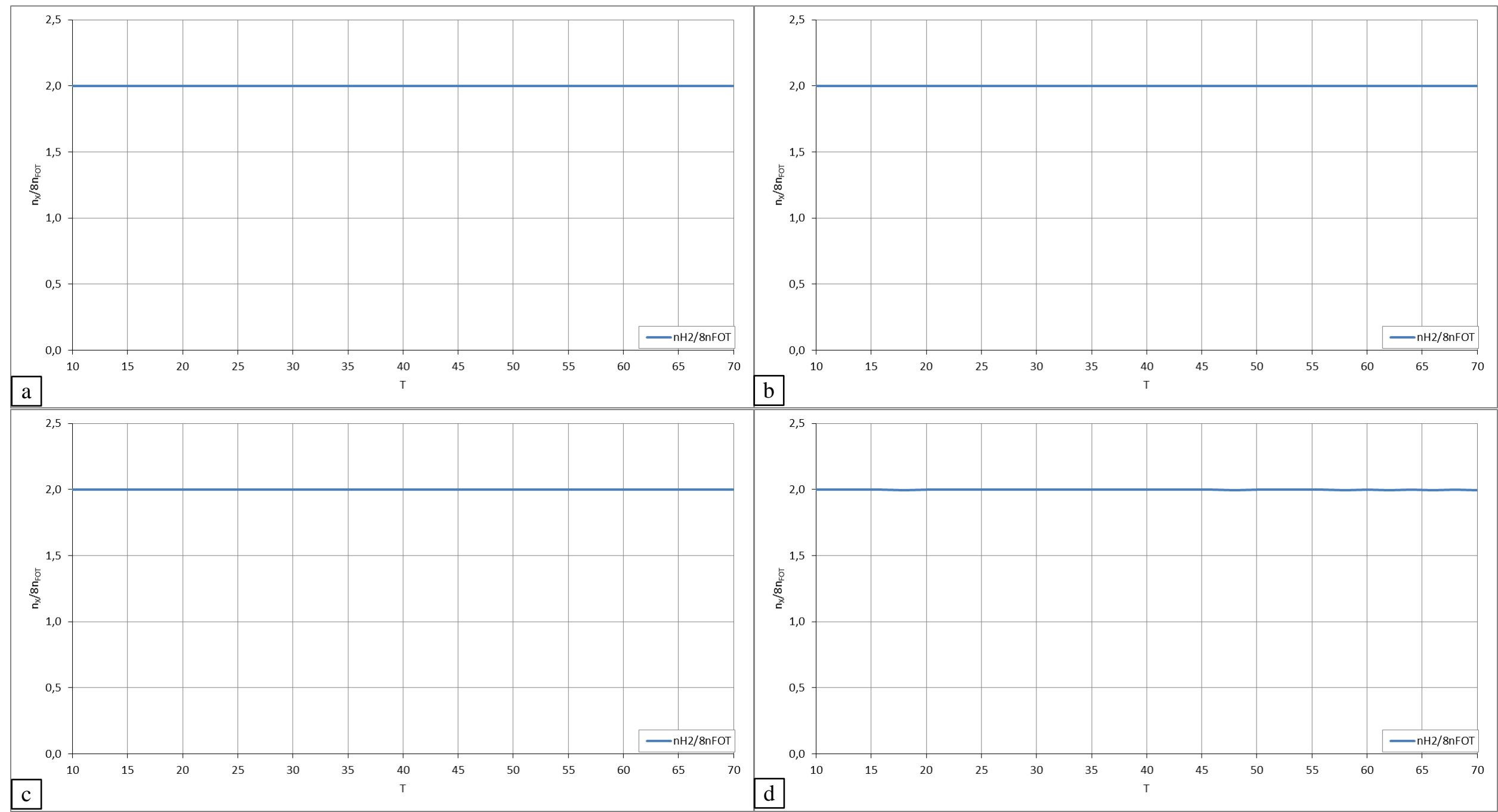

Figura 84. Rendimento dos produtos da biofotólise indireta pela atividade da nitrogenase, na ausência de nitrogênio gasoso, com bactérias a) verdes sulfurosas, b) púrpuras sulfurosas, c) púrpuras não sulfurosas com crescimento sobre acetato e d) púrpuras não sulfurosas com crescimento sobre lactato, em mols produzidas por 8 mols de fótons em função da temperatura $\left(\mathrm{pH}=7,00, \mathrm{p}_{\mathrm{H} 2}=1,00 \times 10^{-3} \mathrm{~atm}\right)$. 


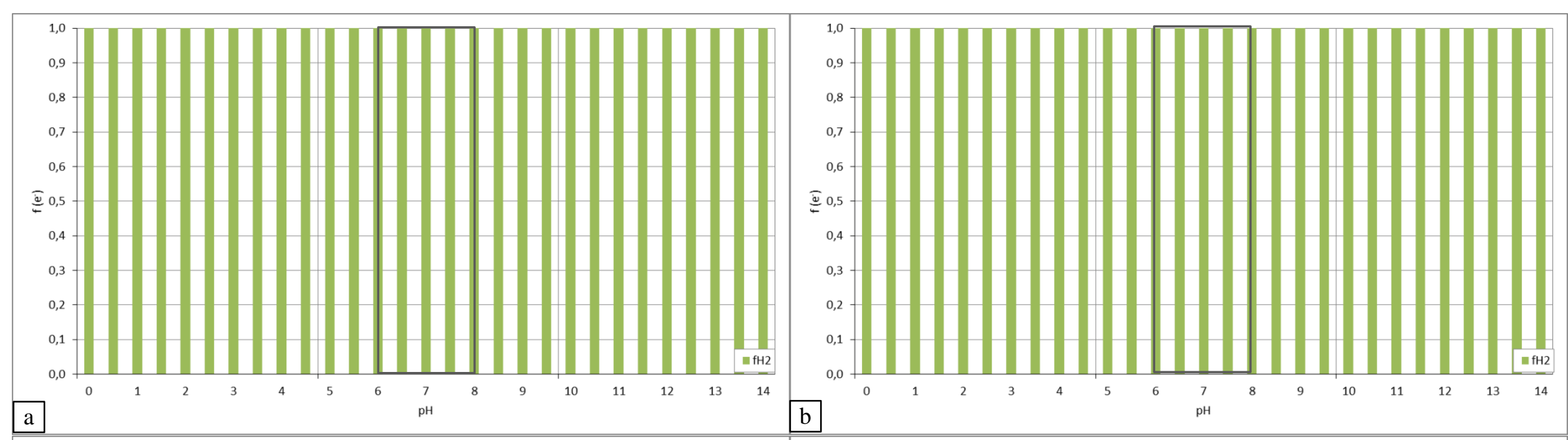

$\mathrm{a}$
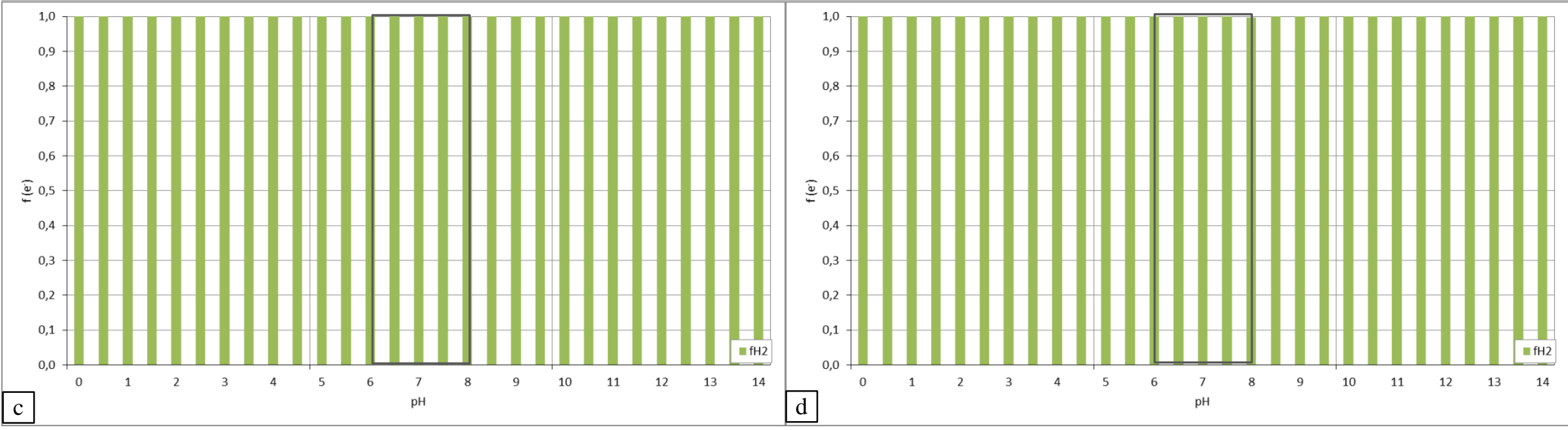

Figura 85. Fração de elétrons transferidos do doador a cada produto reduzido na biofotólise indireta pela atividade da nitrogenase, na ausência de nitrogênio gasoso, com bactérias a) verdes sulfurosas, b) púrpuras sulfurosas, c) púrpuras não sulfurosas com crescimento sobre acetato e d) púrpuras não sulfurosas com crescimento sobre lactato, em função do $\mathrm{pH}\left(\mathrm{T}=25^{\circ} \mathrm{C}, \mathrm{p}_{\mathrm{H} 2}=1,00 \times 10^{-3} \mathrm{~atm}\right)$. 
Os resultados da eficiência da fotossíntese anoxigênica para produção de glicose com bactérias verdes sulfurosas (Reação 70), púrpuras sulfurosas (Reação 73) e púrpuras não sulfurosas com crescimento sobre acetato (Reação 76) e lactato (Reação 79) são apresentados na Figura 86, em função do pH e da temperatura.

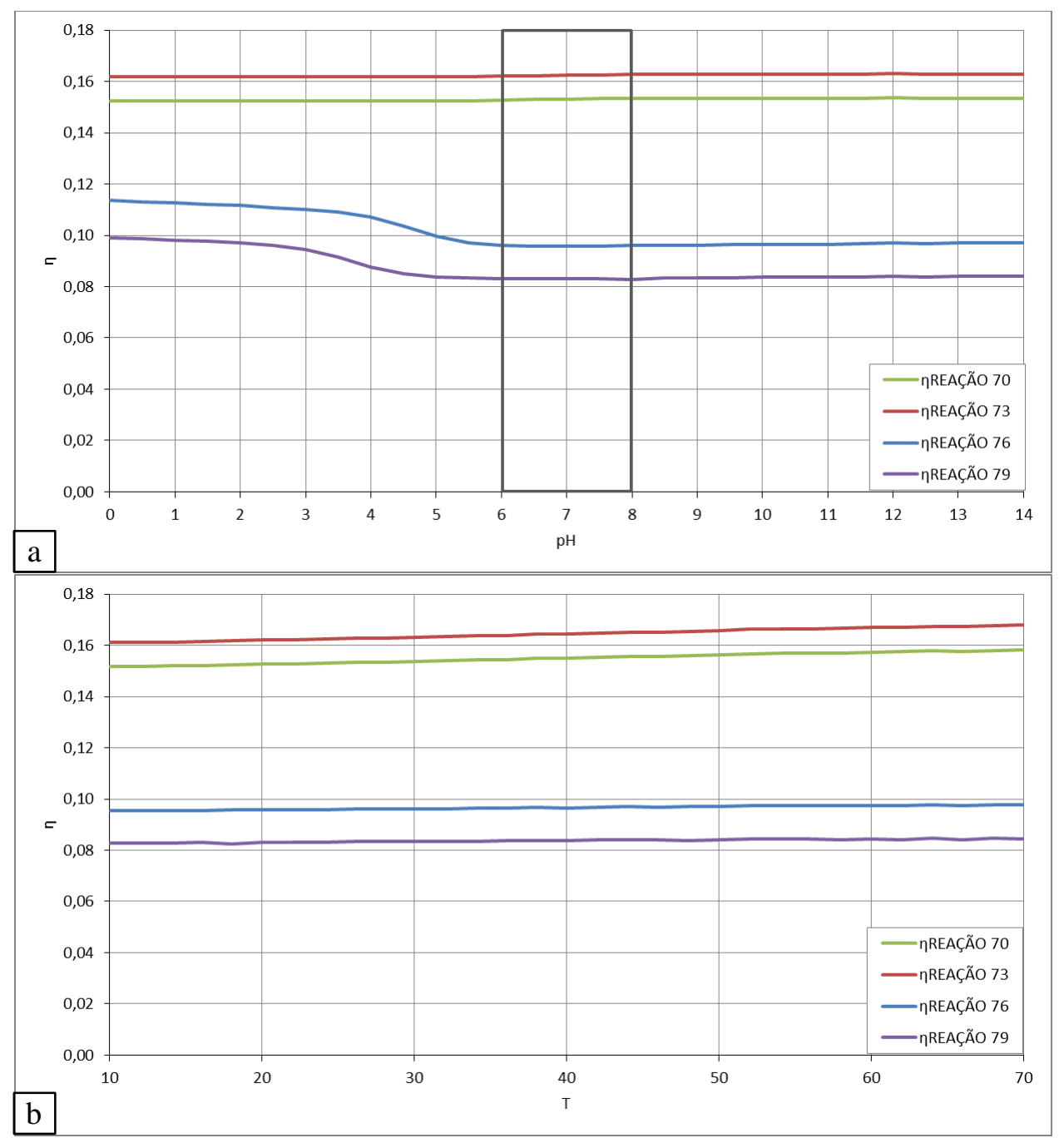

Figura 86. Eficiência da fotossíntese anoxigênica para produção de glicose com bactérias verdes sulfurosas, púrpuras sulfurosas e púrpuras não sulfurosas com crescimento sobre acetato e lactato, em função a) do $\mathrm{pH}\left(\mathrm{T}=25^{\circ} \mathrm{C}, \mathrm{p}_{\mathrm{H} 2}=1,00 \times 10^{-3} \mathrm{~atm}\right)$ e b) da temperatura

$$
\left(\mathrm{pH}=7,00, \mathrm{p}_{\mathrm{H} 2}=1,00 \times 10^{-3} \mathrm{~atm}\right) \text {. }
$$

Os resultados mostram que as eficiências da fotossíntese anoxigênica na conversão de energia solar em energia química em bactérias com metabolismo fotolitotrófico (verdes e púrpuras sulfurosas) praticamente não são influídos pelo $\mathrm{pH}$ enquanto o aumento da temperatura aumenta levemente as eficiências. A eficiência fotossintética das bactérias 
púrpuras sulfurosas e superior à eficiência das bactérias verdes sulfurosas em todo o intervalo de $\mathrm{pH}$ porquanto a maior energia dos fótons $(\lambda=840 \mathrm{~nm})$ nas últimas favorece a síntese celular e não de produtos de armazenamento. Para as bactérias com metabolismo fotoorganotrófico (púrpuras não sulfurosas), a eficiência fotossintética diminui com o aumento do $\mathrm{pH}$ por acima do valor de $\mathrm{pK}_{\mathrm{A}}$ (4,8 para acetato e 3,9 para lactato) porquanto esse aumento favorece o rendimento das células, enquanto a temperatura não influi significativamente nos resultados. Em todo o intervalo de $\mathrm{pH}$, a eficiência é superior quando o crescimento se realiza sobre acetato que quando se realiza sobre lactato.

Comparando os resultados das eficiências, os valores mais altos se obtêm para bactérias com metabolismo fotolitotrófico (verdes e púrpuras sulfurosas) devido a que nos cálculos da eficiência para bactérias fotoorganotróficas (púrpuras não sulfurosas) se leva em conta a entalpia de combustão do substrato orgânico (acetato ou lactato). Porém, em casos nos quais essa entalpia do substrato pode-se desconsiderar (e.g. quando são obtidos de águas residuárias), as eficiências desses processos aumentam aproximadamente 40\%, atingindo valores comparativamente muito parecidos aos das bactérias fotolitotróficas e até superiores para $\mathrm{pH}$ menores do $\mathrm{pK}_{\mathrm{A}}$.

Aqui, como na fotossíntese oxigênica, a energia solar contida nos fótons que efetivamente participam nas reações fotossintéticas e que não é usada para a síntese celular e de produtos de armazenamento se transfere como calor (entalpia) aos redores (universo).

Por outro lado, a partir dos rendimentos da biofotólise indireta para a produção de hidrogênio pela atividade da nitrogenase na fixação de nitrogênio gasoso (Figuras 80 e 81) se determinam as eficiências na conversão de energia solar em energia química usando a Equação 92, mas com o número de mols de hidrogênio e a entalpia padrão de combustão de hidrogênio $\left(-285,8 \mathrm{~kJ} \mathrm{~mol}_{\mathrm{H} 2}{ }^{-1}\right)$ no lugar dos dados da glicose. Nestes processos, os elétrons para a atividade da nitrogenase são obtidos diretamente do doador (sulfeto para os metabolismos fotolitotróficos e acetato ou lactato para os metabolismos fotoorganotróficos) e não a partir da glicose (produto de armazenamento). Cabe salientar também que nestas estimativas da eficiência, parte da energia solar fica contida nas células dos microorganismos e não se considera nos cálculos.

Os resultados da eficiência da biofotólise indireta pela atividade da nitrogenase, na presença de nitrogênio gasoso, com bactérias verdes sulfurosas (Reação 71), púrpuras sulfurosas (Reação 74) e púrpuras não sulfurosas com crescimento sobre acetato (Reação 77) e lactato (Reação 80) são apresentados na Figura 87, em função do pH e da temperatura. 


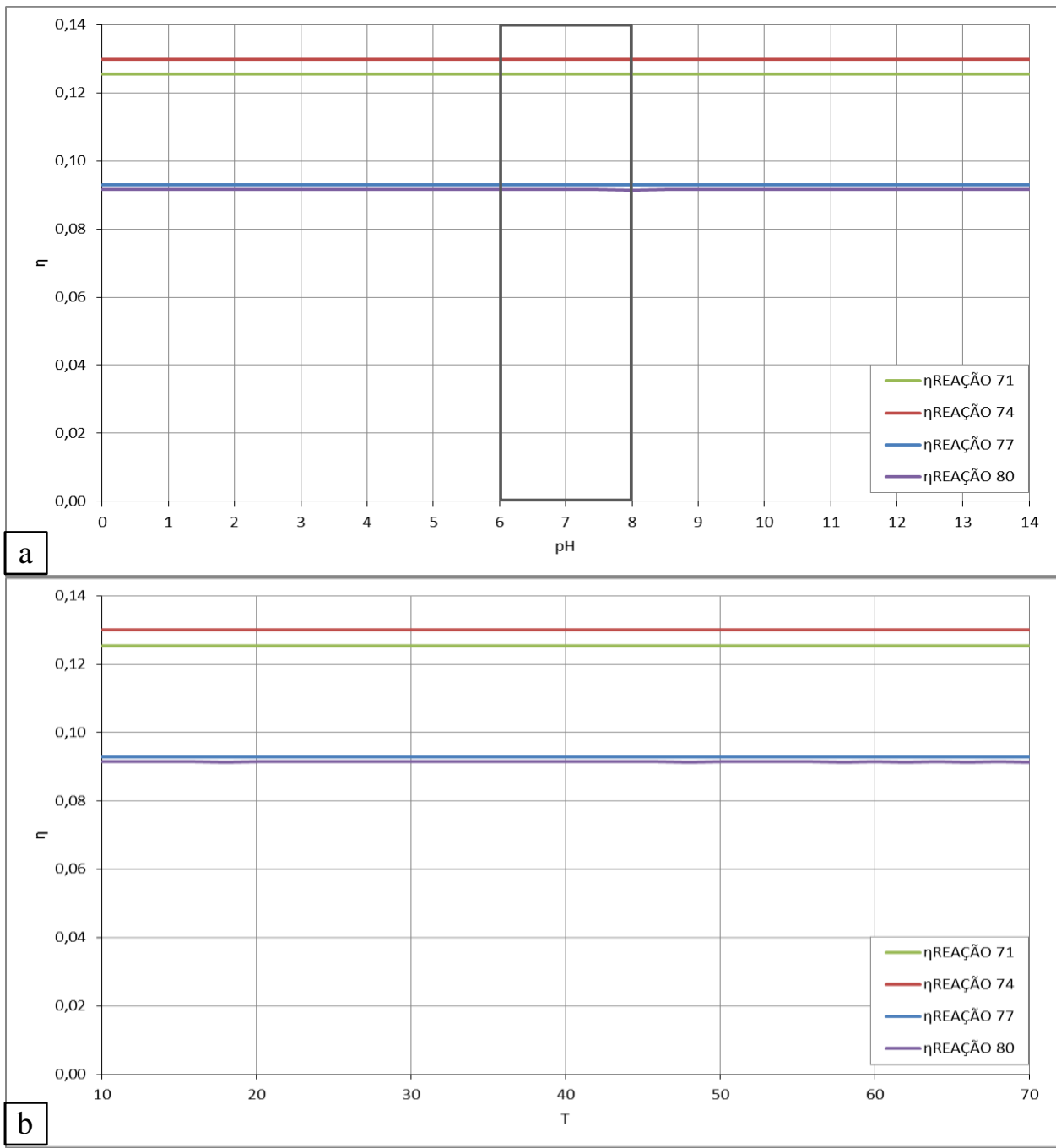

Figura 87. Eficiência da biofotólise indireta pela atividade da nitrogenase, na presença de nitrogênio gasoso, com bactérias verdes sulfurosas, púrpuras sulfurosas e púrpuras não sulfurosas com crescimento sobre acetato e lactato, em função a) do $\mathrm{pH}\left(\mathrm{T}=25^{\circ} \mathrm{C}, \mathrm{p}_{\mathrm{H} 2}=\right.$ $\left.1,00 \times 10^{-3} \mathrm{~atm}\right)$ e b) da temperatura $\left(\mathrm{pH}=7,00, \mathrm{p}_{\mathrm{H} 2}=1,00 \times 10^{-3} \mathrm{~atm}\right)$.

Neste caso, os resultados mostram que as eficiências da biofotólise indireta na conversão de energia solar em energia química não são influídos nem pelo $\mathrm{pH}$ nem pela temperatura e os resultados para as bactérias púrpuras sulfurosas são praticamente iguais independentemente do substrato de crescimento (acetato ou lactato). Comparando os resultados, as maiores eficiências se obtêm para bactérias com metabolismo fotolitotrófico (verdes e púrpuras sulfurosas) pela incorporação nos cálculos da entalpia de combustão do substrato orgânico para bactérias fotoorganotróficas (púrpuras não sulfurosas). Em caso de desconsiderar essa entalpia, as eficiências desses processos aumentam aproximadamente 40\%, atingindo valores comparativamente muito parecidos aos das bactérias fotolitotróficas. 
Por fim, os resultados da eficiência da biofotólise indireta pela atividade da nitrogenase, na ausência de nitrogênio gasoso, com bactérias verdes sulfurosas (Reação 72), púrpuras sulfurosas (Reação 75) e púrpuras não sulfurosas com crescimento sobre acetato (Reação 78) e lactato (Reação 81) são apresentados na Figura 88, em função do pH e da temperatura.

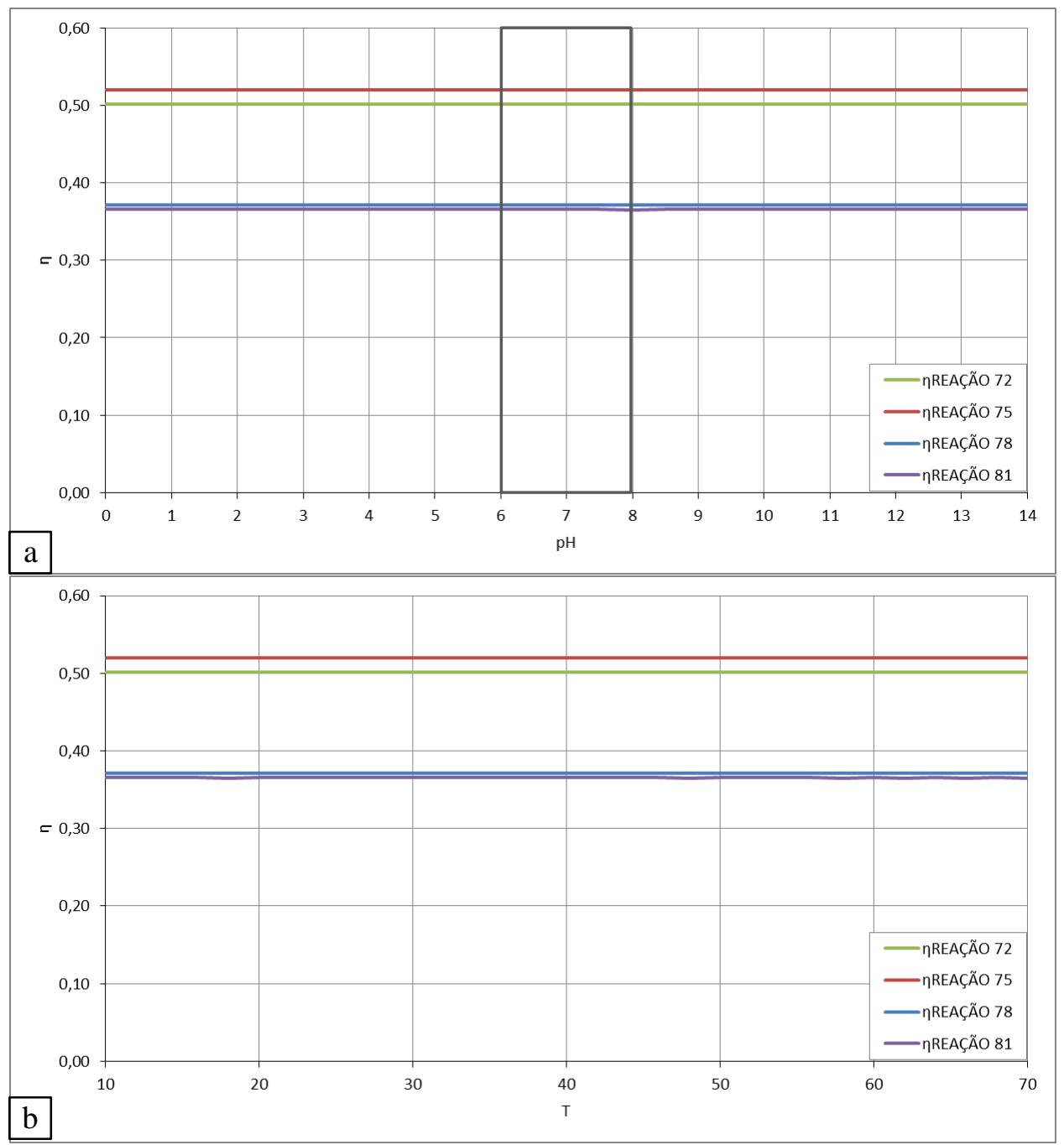

Figura 88. Eficiência da biofotólise indireta pela atividade da nitrogenase, na ausência de nitrogênio gasoso, com bactérias verdes sulfurosas, púrpuras sulfurosas e púrpuras não sulfurosas com crescimento sobre acetato e lactato, em função a) do $\mathrm{pH}\left(\mathrm{T}=25^{\circ} \mathrm{C}, \mathrm{p}_{\mathrm{H} 2}=\right.$ $\left.1,00 \times 10^{-3} \mathrm{~atm}\right)$ e b) da temperatura $\left(\mathrm{pH}=7,00, \mathrm{p}_{\mathrm{H} 2}=1,00 \times 10^{-3} \mathrm{~atm}\right)$.

O comportamento das eficiências da biofotólise indireta pela atividade da nitrogenase na ausência de nitrogênio gasoso é o mesmo que na presença do gás, mas multiplicada por 4 porquanto todos os elétrons produzidos pelo doador se usam para a produção de hidrogênio. 
Nos resultados da eficiência da fotossíntese anoxigênica da Figura 86, incertezas de \pm $5 \%$ em todas as energias livres e entalpias de reação geram variações entre $\pm 0,2 \%$ para as eficiências menores e $\pm 1,0 \%$ para as eficiências maiores, e nas Figuras 87 e 88, variações entre $\pm 0,2 \%$ para as eficiências menores e $\pm 0,6 \%$ para as eficiências maiores. Assim, como na digestão anaeróbia, é possível concluir que essas incertezas não afetam significativamente a distribuição das espécies no modelo biotermodinâmico.

\subsection{Conclusões}

Algumas conclusões acerca da fotossíntese oxigênica são iguais que para a fotossíntese anoxigênica:

- $\mathrm{Na}$ fotossíntese anoxigênica, a espontaneidade do crescimento celular é garantida pelos altos valores de energia livre gerada pela captação da energia solar dos fótons nos sistemas fotossintéticos.

- O modelo biotermodinâmico para a fotossíntese anoxigênica evidencia que a entropia do sistema diminui pela geração de produtos de menos entropia que os reagentes, e a exportação de entropia para o universo ocorre pela transferência de calor (entalpia).

- Independentemente de considerações cinéticas ou biológicas, o aumento da temperatura desfavorece levemente o rendimento das células na fotossíntese anoxigênica, do ponto de vista termodinâmico.

- Na produção de hidrogênio pela atividade da nitrogenase, os resultados mostram que o rendimento quando o nitrogênio gasoso está ausente é 4 vezes superior que quando está presente, o que concorda com a estequiometria da fixação.

Por outro lado:

- Todas as produções de hidrogênio por biofotólise indireta pela atividade da nitrogenase são processos espontâneos nos intervalos de $\mathrm{pH}$, pressões parciais de hidrogênio e temperaturas avaliados.

- Os rendimentos na produção de hidrogênio pela atividade da nitrogenase são iguais para todas as bactérias anoxigênicas porquanto os elétrons passam à nitrogenase diretamente do doador no sistema fotossintético.

- Desconsiderando a fração da energia solar que se converte em células e a energia do substrato nas bactérias púrpuras sulfurosas, a eficiência da produção de hidrogênio pela atividade da nitrogenase é muito similar em todas as bactérias anoxigênicas. 


\section{CONCLUSÕES GERAIS}

Do modelo:

- A aplicação do modelo biotermodinâmico permite avaliar as condições de espontaneidade das reações biológicas e estimar rendimentos molares e eficiências energéticas para a análise dos processos anaeróbios e fotossintéticos de recuperação de energia.

- O conhecimento do metabolismo dos processos biológicos e a seleção das reações bioquímicas são a base para a descrição de seu comportamento termodinâmico a partir da aplicação do modelo.

- O modelo permite separar as características termodinâmicas dos processos do comportamento biológico (e.g. inibições) ou químico (e.g. equilíbrio ou cinética) e oferece informação da influência das variáveis físico-químicas na espontaneidade dos processos.

Da aplicação:

- Da aplicação do modelo nos processos anaeróbios, a digestão anaeróbia separada (fermentação e metanogênese) atinge uma eficiência entre 10 e $12 \%$ maior na recuperação de energia que a digestão anaeróbia completa nos cenários avaliados.

- Da aplicação do modelo nos processos fotossintéticos, a produção de hidrogênio é mais eficiente com cianobactérias e bactérias anoxigênicas por meio da nitrogenase, que com microalgas por meio da hidrogenase. 


\section{RECOMENDAÇÕES}

- Aplicar o modelo desenvolvido na determinação de eficiências energéticas de diferentes configurações de processos combinados anaeróbios-fotossintéticos de recuperação de energia a partir de despejos.

- Adotar o desenvolvimento de modelos biotermodinâmicos como estratégia para a análise de processos biotecnológicos de interesse, tanto ambiental (e.g. tratamentos de despejos ou recuperação de materiais e energia) quanto industrial.

- Usar o modelo biotermodinâmico para melhorar o modelo cinético da digestão anaeróbia porquanto um dos resultados do modelo é a estequiometria das reações que é a base dos modelos cinéticos. 


\section{REFERÊNCIAS BIBLIOGRÁFICAS}

Albarrán-Zavala, E. \& Angulo-Brown, F. (2007). A simple thermodynamic analysis of photosynthesis. Entropy, 9: 152-168.

Anderson, K., Sallis, P. \& Uyanik, S. (2007). Anaerobic treatment processes. In: Mara, D. \& Horan, N. (Eds.). Handbook of water and wastewater microbiology. London-UK, Academic Press. 391-426.

Antal, T.K., Krendeleva, T.E., Pashchenko, V.Z., Rubin, A.B., Stensjo, K., Tyystjärvi, E., Ramakrishna, S., Los, D.A., Carpentier, R., Nishihara, H. \& Allakhverdiev, S.I. (2012). Photosynthetic hydrogen production: mechanisms and approaches. In: Azbar, N. \& Levin, D.B. (Eds). State of the art and progress in production of biohydrogen. Sharjah-U.A.E. Bentham Science Publishers. 25-53.

Archer, M.D. \& Barber, J. (2004). Photosynthesis and photoconversion. In: Archer, M.D. \& Barber, J. (Eds.). Molecular to global photosynthesis. London-UK, Imperial College Press. $1-41$.

Battley, E.H. (1960a). Enthalpy changes accompanying the growth of Saccharomyces cerevisiae (Hansen). Physiologia Plantarum, 13: 628-640.

Battley, E.H. (1960b). A Theoretical approach to the study of the thermodynamics of growth of Saccharomyces cerevisiae (Hansen). Physiologia Plantarum, 13: 674-686.

Battley, E.H. (2007). The sources of thermal energy exchange accompanying microbial anabolism. Journal of Thermal Analysis and Calorimetry, 87: 105-111.

Battley, E.H. (2013). A theoretical study of the thermodynamics of microbial growth using Saccharomyces cerevisiae and a different free energy equation. The Quarterly Review of Biology, 88: 69-96.

Beer, L.L., Boyd, E.S.; Peters, J.W. and Posewitz, M.C. (2009). Engineering algae for biohydrogen and biofuel production. Current Opinion in Biotechnology, 20: 264-271.

Bergman, B., Gallon, J.R., Rai, A.N. \& Stal, L.J. (1997). N2 fixation by non-heterocystous cyanobacteria. FEMS Microbiology Reviews, 19: 139-185.

Bitton, G. (2005). Wastewater microbiology. $3^{\text {th }}$ Edition. New Jersey-USA, John Wiley \& Sons.

Böhme, H. (1998). Regulation of nitrogen fixation in heterocyst-forming cyanobacteria. Trends in Plant Science, 3: 346-351.

Boichenko, V.A., Greenbaum, E. \& Seibert, M. (2004). Hydrogen production by photosynthetic microorganisms. In: Archer, M.D. \& Barber, J. (Eds.). Molecular to global photosynthesis. London-UK, Imperial College Press. 397-451.

Bolton, J.R. \& Hall, D.O. (1991). The maximum efficiency of photosynthesis. Photochemistry and Photobiology, 53: 545-548.

Brune, D.C. (1995). Sulfur compounds as photosynthetic electron donors. In: Blankenship, R.E., Madigan, M.T. \& Bauer, C.E. (Eds.). Anoxygenic photosynthetic bacteria. DordrechtNetherlands, Kluwer Academic Publishers. 847-870.

Castenholz, R.W. (2015). General characteristics of the cyanobacteria. In: Whitman, W.B. 
(Ed.). Bergey's manual of systematics of archaea and bacteria. John Wiley \& Sons in association with Bergey's Manual Trust. 1-23.

Catalanotti, C., Yang, W., Posewitz, M.C. \& Grossman, A.R. (2013). Fermentation metabolism and its evolution in algae. Frontiers in Plant Science, 4: 150.

Chen, C.Y., Yeh, K.L, Aisyah, R., Lee, D.J. \& Chang, J.S. (2011). Cultivation, photobioreactor design and harvesting of microalgae for biodiesel production: a critical review. Bioresource Technology, 102: 71-81.

Chernicharo, C.A. de L. (2007). Anaerobic reactors. In: Biological Wastewater Treatment Series. London-UK, IWA Publishing.

Chisti, Y. (2007). Biodiesel from microalgae. Biotechnology Advances, 25: 294-306.

Comeau, Y. (2008). Microbial metabolism. In: Henze, M., Loosdrecht, M.C.M. van, Ekama, G.A., \& Brdjanovic, D. (Eds.). Biological wastewater treatment: principles, modelling and design. London-UK, IWA Publishing. 9-32.

Cooney, M., Maynard, N., Cannizzaro, C. \& Benemann, J. (2007). Two-phase anaerobic digestion for production of hydrogen-methane mixtures. Bioresource Technology, 98: 2641-2651.

Dasgupta, C.N., Gilbert, J.J., Lindblad, P., Heidorn, T., Borgvang, S.A., Skjanes, K. \& Das, D. (2010). Recent trends on the development of photobiological processes and photobioreactors for the improvement of hydrogen production. International Journal of Hydrogen Energy, 35: 10218-10238.

Dębowski, M., Zieliński, M., Grala, A. \& Dudek, M. (2013). Algae biomass as an alternative substrate in biogas production technologies: review. Renewable and Sustainable Energy Reviews, 27: 596-604.

Degrenne, B., Pruvost, J. \& Legrand, J. (2011). Effect of prolonged hypoxia in autotrophic conditions in the hydrogen production by the green microalga Chlamydomonas reinhardtii in photobioreactor. Bioresource Technology, 102: 1035-1043.

Dubini, A. \& Gonzalez-Ballester, D. (2016). Biohydrogen from microalgae. In: Bux, F. \& Chisti, Y. (Eds). Algae biotechnology: products and processes. Switzerland, Springer. 165193.

Eroglu, E. \& Melis, A. (2011). Photobiological hydrogen production: recent advances and state of the art. In: Bioresource Technology, 102: 8403-8413.

Gfeller, R.P. \& Gibbs, M. (1984). Fermentative Metabolism of Chlamydomonas reinhardtii. I. Analysis of fermentative products from starch in dark and light. Plant Physiology, 75: 212-218.

Ghirardi, M.L., Zhang, J.P., Lee, J.W., Flynn, T., Seibert, M., Greenbaum, E. \& Melis, A. (2000). Microalgae: a green source of renewable $\mathrm{H}_{2}$. Trends in Biotechnology, 18: 506511.

Gimpel, J.A., Henríquez, V. \& Mayfield S.P. (2015). In metabolic engineering of eukaryotic microalgae: potential and challenges come with great diversity. Frontiers in Microbiology, 6: 1376.

Hallenbeck, P.C. \& Benemann, J.R. (2002). Biological hydrogen production; fundamentals and limiting processes. International Journal of Hydrogen Energy, 27: 1185-1193.

Haynes, W.M., Lide, D.R. \& Bruno, T.J. (2015). CRC Handbook of chemistry and physics: a 
ready-reference book of chemical and physical data. $96^{\text {th }}$ Edition. Boca Raton (FL)-USA, CRC Press.

Heijnen, J.J. \& van Dijken, J.P. (1992). In search of a thermodynamic description of biomass yields for the chemotrophic growth of microorganisms. Biotechnology and Bioengineering, 39: $833-858$.

Heijnen, J.J. (2013). A thermodynamic approach to predict black box model parameters for microbial growth. In: von Stockar, U. (Ed.). Biothermodynamics: the role of thermodynamics in biochemical engineering. Lausanne-Switzerland, EPFL Press. 443473.

Hoover \& Porges. (1952). Assimilation of dairy wastes by activated sludge. II. The equation of synthesis and rate of oxygen utilization. Sewage and Industrial Wastes, 24: 306-312.

Imhoff, J.F. (1995). Taxonomy and physiology of phototrophic purple bacteria and green sulfur bacteria. In: Blankenship, R.E., Madigan, M.T. \& Bauer, C.E. (Eds.). Anoxygenic photosynthetic bacteria. Dordrecht-Netherlands, Kluwer Academic Publishers. 1-15.

Imhoff, J.F. (2015). Chromatiales ord. nov. In: Whitman, W.B. (Ed.). Bergey's manual of systematics of archaea and bacteria. John Wiley \& Sons in association with Bergey's Manual Trust. 1-7.

Imhoff, J.F., Hiraishi, A. \& Süling, J. (2015). Anoxygenic phototrophic purple bacteria. In: Whitman, W.B. (Ed.). Bergey's manual of systematics of archaea and bacteria. John Wiley \& Sons in association with Bergey's Manual Trust. 1-23.

Jin, Q. (2012). Energy conservation of anaerobic respiration. American Journal of Science, 312: $573-628$.

Kapdan, I.K. \& Kargi, F. (2006). Bio-hydrogen production from waste materials. Enzyme and Microbial Technology, 38: 569-582.

Keller, J.U. (2013). Thermodynamic analysis of photosynthesis. In: von Stockar, U. (Ed.). Biothermodynamics: the role of thermodynamics in biochemical engineering. LausanneSwitzerland, EPFL Press. 535-543.

Khanal, S.K. (2008). Anaerobic Biotechnology for Bioenergy Production: Principles and Applications. Ames (IA)-USA, Wiley-Blackwell.

Kleerebezem R. \& van Loosdrecht M.C.M. (2010). A generalized method for thermodynamic state analysis of environmental systems. Critical Reviews in Environmental Science and Technology, 40: 1-54.

Kok, H.W. (2011) A thermodynamic analysis of photosynthesis: quantum requirement and theoretical biomass growth rates. Dissertation Master of Engineering, University of the Witwatersrand. Johannesburg-South Africa.

Koku, H., Eroglu, Í., Gündüz, U., Yücel, M. \& Türker, L. (2002). Aspects of the metabolism of hydrogen production by Rhodobacter sphaeroides. International Journal of Hydrogen Energy, 27: 1315-1329.

Kreuzberg, K. (1984). Starch fermentation via a formate producing pathway in Chlamydomonas reinhardii, Chhrogonium elongatum and Chlorella fusca. Physiologia Plantarum, 61: 87-94

Kyazze, G., Dinsdale, R., Guwy, A.J., Hawkes, F.R., Premier, G.C. \& Hawkes D.L. (2007). Performance characteristics of a two-stage dark fermentative system producing hydrogen and methane continuously. Biotechnology and Bioengineering, 97: 759-770. 
Liu, J.-S, Vojinovi, V., Patiño, R., Maskowc, Th. \& von Stockar, U. (2007). A comparison of various Gibbs energy dissipation correlations for predicting microbial growth yields. Thermochimica Acta, 458: 38-46.

Madigan, M.T. (1995). Microbiology of nitrogen fixation by anoxygenic photosynthetic bacteria. In: Blankenship, R.E., Madigan, M.T. \& Bauer, C.E. (Eds.). Anoxygenic photosynthetic bacteria. Dordrecht-Netherlands, Kluwer Academic Publishers. 915-928.

Madigan, M.T. (2015). Heliobacterium. In: Whitman, W.B. (Ed.). Bergey's manual of systematics of archaea and bacteria. John Wiley \& Sons in association with Bergey's Manual Trust. 1-4.

Madigan, M.T., Martinko, J.M., Bender, K.S., Buckley, D.H. \& Stahl, D.A. (2015). Brock biology of microorganisms. $14^{\text {th }}$ Edition. Boston (MA)-USA, Pearson.

Mara, D. (2003). Domestic wastewater treatment in developing countries. London-UK, Earthscan.

Mata, T.M., Martins, A.A. \& Caetano, N.S. (2010). Microalgae for biodiesel production and other applications: a review. Renewable and Sustainable Energy Reviews, 14: 217-232.

McCarty, P.L. (1972). Energetics of organic matter degradation. In: Mitchell, R. (Ed.). Water pollution microbiology. New York-USA, John Wiley \& Sons. 91-118.

McCarty, P.L. (2007). Thermodynamic electron equivalents model for bacterial yield prediction: modifications and comparative evaluations. Biotechnology and Bioengineering, 97: $377-388$.

Melis, A. \& Happe, T. (2001). Hydrogen production. Green algae as a source of energy. Plant Physiology, 127: 740-748.

Melis, A. (2007). Photosynthetic $\mathrm{H}_{2}$ metabolism in Chlamydomonas reinhardtii (unicellular green algae). Planta, 226: 1075-1086.

Melis, A., Zhang, L., Forestier, M., Ghirardi, M. \& Seibert, M. (2000). Sustained photobiological hydrogen gas production upon reversible inactivation of oxygen evolution in the green alga Chlamydomonas reinhardtii. Plant Physiology, 122: 127-135.

Melnicki, M.R., Eroglu, E. \& Melis, A. (2009). Changes in hydrogen production and polymer accumulation upon sulfur-deprivation in purple photosynthetic bacteria. International Journal of Hydrogen Energy, 34: 6157-6170.

Minkevich, I.G. \& Eroshin, V.K. (1973). Productivity and heat generation of fermentation under oxygen limitation. Folia Microbiologica, 18: 376-385.

Müller, V. (2003). Energy conservation in acetogenic bacteria. Applied and Environmental Microbiology, 69: 6345-6353.

Mus, F., Dubini, A., Seibert, M., Posewitz, M.C. \& Grossman, A.R. (2007). Anaerobic acclimation in Chlamydomonas reinhardtii: anoxic gene expression, hydrogenase induction, and metabolic pathways. The Journal of Biological Chemistry, 282: 2547525486.

Overmann, J. (2015). Green Sulfur Bacteria. In: Whitman, W.B. (Ed.). Bergey's manual of systematics of archaea and bacteria. John Wiley \& Sons in association with Bergey's Manual Trust. 1-8.

Perez-Garcia, O., Escalante, F.M.E., de-Bashan, L.E. \& Bashan, Y. (2011). Heterotrophic cultures of microalgae: metabolism and potential products. Water Research, 45: 11-36. 
Prince, R.C. \& Kheshgi H.S. (2005). The photobiological production of hydrogen: potential efficiency and effectiveness as a renewable fuel. Critical Reviews in Microbiology, 31: 1931 .

Radakovits, R., Jinkerson, R.E., Darzins, A. \& Posewitz, M.C. (2010). Genetic engineering of algae for enhanced biofuel production. Eukaryotic Cell, 9: 486-501.

Redfield, A.C., Ketchum, B.H. \& Richards, F.A. (1963). The influence of organisms on the composition of seawater. In: Hill, M.N. (Ed.). The composition of seawater: comparative and descriptive oceanography. The sea: ideas and observations on progress in the study of the seas, 2. New York-USA, John Wiley \& Sons. 26-77.

Rey, F.E., Heiniger, E.K. \& Harwood, C.S. (2007). Redirection of metabolism for biological hydrogen production. Applied and Environmental Microbiology, 73: 1665-1671.

Rittmann, B.E. \& McCarty, P.L. (2001). Environmental biotechnology: principals and applications. New York-USA, McGraw-Hill.

Roels, J.A. (1983). Energetics and kinetics in biotechnology. Amsterdam-Holland, Elsevier.

Sander, R. (1999). Compilation of Henry's law constants for inorganic and organic species of potential importance in environmental chemistry. Version 3. Mainz-Germany, Max-Planck Institute of Chemistry.

Sawyer, C.N., McCarty, P.L. \& Parkin, G.F. (2003). Chemistry for environmental engineering and science. $5^{\text {th }}$ Edition. New York-USA, McGraw-Hill.

Schnurer, A., Schink, B. \& Svensson, B.H. (1996). Clostridium ultunense sp nov, a mesophilic bacterium oxidizing acetate in syntrophic association with a hydrogenotrophic methanogenic bacterium. International Journal of Systematic Bacteriology, 46: 11451152 .

Schnurer, A., Svensson, B.H. \& Schink, B. (1997). Enzyme activities in and energetics of acetate metabolism by the mesophilic syntrophically acetate-oxidizing anaerobe Clostridium ultunense. FEMS Microbiology Letters, 154: 331-336.

Scott, S.A., Davey, M.P., Dennis, J.S., Horst, I., Howe, C.J., Lea-Smith, D.J. \& Smith, A.G. (2010). Biodiesel from algae: challenges and prospects. Current Opinion in Biotechnology, 21: $277-286$.

Sirevåg, R. (1995). Carbon metabolism in green bacteria. In: Blankenship, R.E., Madigan, M.T. \& Bauer, C.E. (Eds.). Anoxygenic photosynthetic bacteria. Dordrecht-Netherlands, Kluwer Academic Publishers. 871-883.

Speece, R.E. (1996). Anaerobic biotechnology for industrial wastewaters. Nashville (TN)USA, Archae Press.

Spilling, K. \& Seppälä, J. (2012). Photobiology and lipid metabolism in algae. In: Gordon, R. $\&$ Seckbach, J. (Eds). The science of algal fuels. phycology, geology, biophotonics, genomics and nanotechnology. Dordrecht-Netherlands, Springer. 385-398.

Srirangan, K., Pyne, M.E. \& Perry, C. (2011). Biochemical and genetic engineering strategies to enhance hydrogen production in photosynthetic algae and cyanobacteria. Bioresource Technology, 102: 8589-8604.

Stumm, W. \& Morgan, J.J. (1996). Aquatic chemistry: chemical equilibria and rates in natural waters. $3^{\text {th }}$ Edition. New York-USA, John Wiley \& Sons.

Subramanian, V., Dubini, A. \& Seibert, M. (2012). Metabolic pathways in green algae with 
potential value for biofuel production: algal fuel metabolism. In: Gordon, R. \& Seckbach, J. (Eds). The science of algal fuels. phycology, geology, biophotonics, genomics and nanotechnology. Dordrecht-Netherlands, Springer. 401-422.

Tabita, F.R. (1995). The biochemistry and metabolic regulation of carbon metabolism and $\mathrm{CO}_{2}$ fixation in purple bacteria. In: Blankenship, R.E., Madigan, M.T. \& Bauer, C.E. (Eds.). Anoxygenic photosynthetic bacteria. Dordrecht-Netherlands, Kluwer Academic Publishers. 885-914.

Tamagnini, P., Leitão, E., Oliveira, P., Ferreira, D., Pinto, F., Harris, D.J. Heidorn, T. \& Lindblad, P. (2007). Cyanobacterial hydrogenases: diversity, regulation and applications. FEMS Microbiology Reviews, 31: 692-720.

Thauer, R.K., Jungermann, K. \& Decker, K. (1977). Energy conservation in chemotrophic anaerobic bacteria. Bacteriological Reviews, 41: 100-180.

Topf, M., Tavassi, M., Kinel-Tahan, Y., Iluz, D., Dubinsky, Z. \& Yehoshua, Y. (2012). Algal oils: biosynthesis and uses. In: Gordon, R. \& Seckbach, J. (Eds). The science of algal fuels. phycology, geology, biophotonics, genomics and nanotechnology. Dordrecht-Netherlands, Springer. 197-214.

Valdez-Vazquez, I. \& Poggi-Varaldo, H.M. (2009). Hydrogen production by fermentative consortia. Renewable and Sustainable Energy Reviews, 13: 1000-1013.

VanBriesen, J.M. (2002). Evaluation of methods to predict bacterial yield using thermodynamics. Biodegradation, 13: 171-190.

Verméglio, A., Joliot, P. \& Joliot I, A. (1995). Organization of electron transfer components and supercomplexes. In: Blankenship, R.E., Madigan, M.T. \& Bauer, C.E. (Eds.). Anoxygenic photosynthetic bacteria. Dordrecht-Netherlands, Kluwer Academic Publishers. 279-295.

von Stockar, U. \& Liu J.S. (1999). Does microbial life always feed on negative entropy? Thermodynamic analysis of microbial growth. Biochimica et Biophysica Acta, 1412: 191211.

von Stockar, U., Gustafsson, L., Larsson, C., Marison, I., Tissot, P. \& Gnaiger, E. (1993). Thermodynamic considerations in constructing energy balances for cellular growth. Biochimica et Biophysica Acta, 1183: 221-240.

Wagman, W.H., Evans, V.B., Parker R.H., Schumm, R.H., Bailey S.M., Halow, I., Churney, K.L. \& Nuttall, R.L. (1982). The NBS tables of chemical thermodynamic properties. Journal of Physical Chemical Reference Data, 11 (Suppl. 2): 2-10-2-11.

Westerhoff, H.V. \& van Dam, K. (1987). Mosaic non-equilibrium thermodynamics and the control of biological free energy transduction. Amsterdam-Holland, Elsevier.

Whitton, B.A. \& Potts, M. (2012). Introduction to the cyanobacteria. In: Whitton, B.A. (Ed). Ecology of cyanobacteria II: their diversity in space and time. Dordrecht-Netherlands, Springer. 1-13.

Yeager, C.M., Milliken, C.E., Bagwell, C.E., Staples, L., Berseth, P.A. \& Sessions, H.T. (2011). Evaluation of experimental conditions that influence hydrogen production among heterocystous cyanobacteria. International Journal of Hydrogen Energy, 36: 7487-7499.

Yu, J. \& Takahashi, P. (2007). Biophotolysis-based hydrogen production by cyanobacteria and green microalgae. In: Méndez-Vilas, A. (Ed.). Communicating current research and educational topics and trends in applied microbiology. 79-89. 
Zannoni, D. (1995). Aerobic and anaerobic electron transport chains in anoxygenic phototrophic bacteria. In: Blankenship, R.E., Madigan, M.T. \& Bauer, C.E. (Eds.). Anoxygenic photosynthetic bacteria. Dordrecht-Netherlands, Kluwer Academic Publishers. 949-971.

Zinder, S.H. \& Koch, M. (1984). Non-aceticlastic methanogenesis from acetate: acetate oxidation by a thermophilic syntrophic coculture. Archives of Microbiology,138: 263-272.

Zinder, S. H. (1994). Syntrophic acetate oxidation and "reversible acetogenesis". In: Drake, H. L. (Ed.). Acetogenesis. New York-USA, Springer. 386-415. 